\title{
Advancement of High Temperature Black Liquor Gasification Technology
}

\author{
Final Technical Report
}

Under cooperative agreement DE-FC26-04NT42259 with the U.S. Department of Energy, Office of Biomass Programs and administered by the National Energy Technology Laboratory.

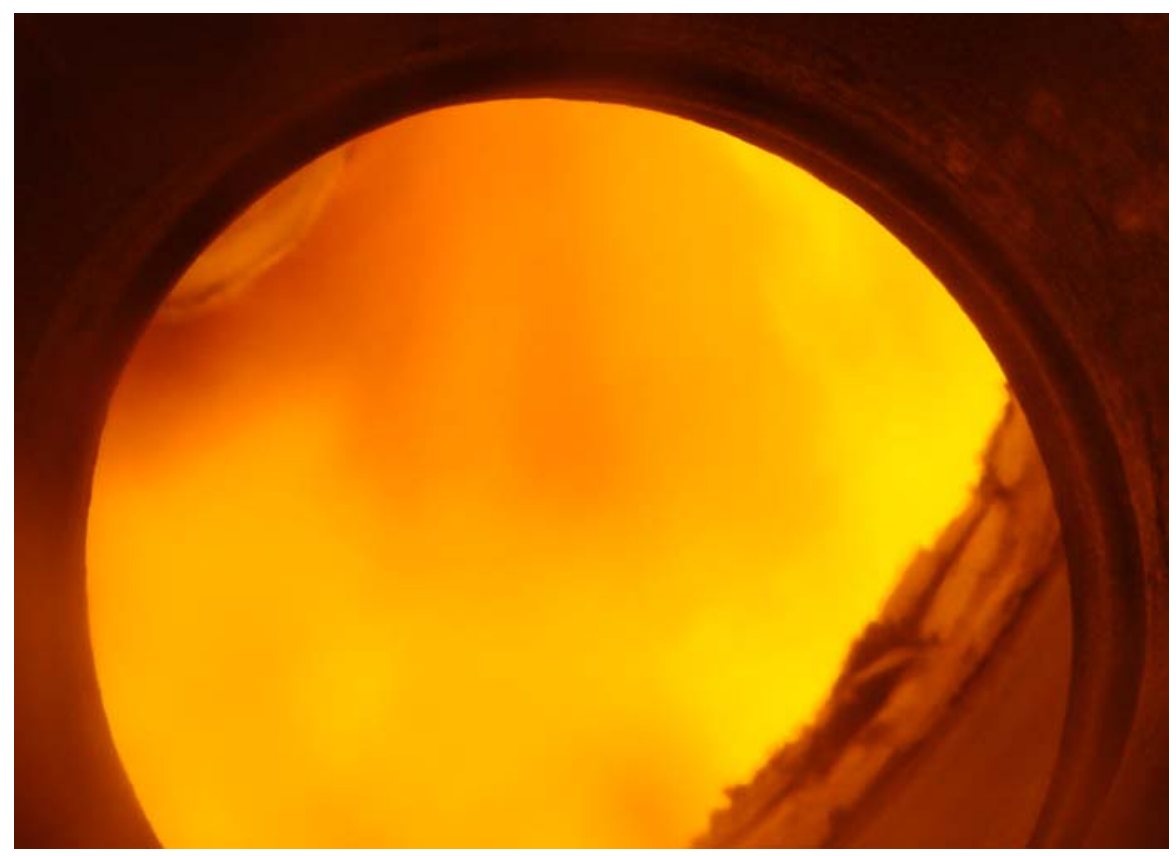

Project Director/Principal Principal Investigator: Craig Brown ${ }^{1}$

Contributing Authors: Ingvar Landälv ${ }^{2}$, Ragnar Stare ${ }^{3}$, Jerry Yuan $^{4}$, Nikolai DeMartini ${ }^{5}$, Nasser Ashgriz

DOE Project Officer: Larry Rath ${ }^{7}$

Reporting Period: October 1, 2004 through March 31, 2008

Reporting Date: December 31, 2008 (Revision 0)

Submitted by: Weyerhaeuser Company

32901 Weyerhaeuser Way South

Federal Way, WA 98063

\footnotetext{
${ }^{1}$ Weyerhaeuser Company, PO Box 1391, New Bern, NC 28563-1391, ph (253) 924-2643, cell (253) 709-3369

${ }^{2}$ Chemrec AB, Floragaten 10 B, Stockholm S-114 31, Sweden, ph +46 (8) 440 4057, cell +46 (70) 4832234

${ }^{3}$ Chemrec AB, Floragaten 10 B, Stockholm S-114 31, Sweden, ph +46 (8) 440 4069, cell +46 (73) 3580165

${ }^{4}$ Process Simulation Ltd., Vancouver, BC

${ }^{5}$ Institute of Paper Science and Technology, Georgia Institute of Technology, Atlanta, GA

${ }^{6}$ Simulent Inc., Toronto, ON

${ }^{7}$ National Energy Technology Laboratory, Pittsburgh, PA 


\section{Notice}

This report was prepared as an account of work sponsored by an agency of the United States Government. Neither the United States Government nor any agency thereof, nor any of their employees, makes any warranty, express or implied, or assumes any legal liability or responsibility for the accuracy, completeness, or usefulness of any information, apparatus, product, or process disclosed, or represents that its use would not infringe privately owned rights. Reference herein to any specific commercial product, process, or service by trade name, trademark, manufacturer, or otherwise does not necessarily constitute or imply its endorsement, recommendation, or favoring by the United States Government or any agency thereof. The views and opinions of authors expressed herein do not necessarily state or reflect those of the United States Government or any agency thereof.

Throughout this project, Weyerhaeuser Company has appreciated the opportunity to work on this new technology project and undertaking with all parties involved in an effort to promote the advancement of the science of biomass gasification. In no way should any statement of Weyerhaeuser be construed as any criticism of any company, contractor, researcher or governmental agency, as all parties have attempted in good faith to expand the scientific understanding in this area through trial and experimentation. Success and failure is part of the process of pursuing new science and technology. Our sole intent also is to promote good science through describing the facts in this project, and we hope that others will be able to carry on further experimentation in the scientific development of black liquor gasification. 
Final Technical Report Rev. 0

DE-FC26-04NT42259

\section{Executive Summary}

Weyerhaeuser operates the world's only commercial high-temperature black liquor gasifier at its pulp mill in New Bern, NC. The unit was started-up in December 1996 and currently processes about $15 \%$ of the mill's black liquor. Weyerhaeuser, Chemrec AB (the gasifier technology developer), and the U.S. Department of Energy recognized that the long-term, continuous operation of the New Bern gasifier offered a unique opportunity to advance the state of high temperature black liquor gasification toward the commercial-scale pressurized O2-blown gasification technology needed as a foundation for the Forest Products BioRefinery of the future.

Weyerhaeuser along with its subcontracting partners submitted a proposal in response to the 2004 joint USDOE and USDA solicitation - "Biomass Research and Development Initiative". The Weyerhaeuser project "Advancement of High Temperature Black Liquor Gasification" was awarded USDOE Cooperative Agreement DE-FC26-04NT42259 in November 2004. The overall goal of the DOE sponsored project was to utilize the Chemrec ${ }^{\mathrm{TM}}$ black liquor gasification facility at New Bern as a test bed for advancing the development status of molten phase black liquor gasification. In particular, project tasks were directed at improvements to process performance and reliability. The effort featured the development and validation of advanced CFD modeling tools and the application of these tools to direct burner technology modifications. The project also focused on gaining a fundamental understanding and developing practical solutions to address condensate and green liquor scaling issues, and process integration issues related to gasifier dregs and product gas scrubbing. The Project was conducted in two phases with a review point between the phases.

Weyerhaeuser pulled together a team of collaborators to undertake these tasks. Chemrec AB, the technology supplier, was intimately involved in most tasks, and focused primarily on the design, specification and procurement of facility upgrades. Chemrec $\mathrm{AB}$ is also operating a pressurized, O2-blown gasifier pilot facility in Piteå, Sweden. There was an exchange of knowledge with the pressurized projects including utilization of the experimental results from facilities in Piteå, Sweden. Resources at the Georgia Tech Research Corporation (GTRC, a.k.a., the Institute of Paper Science and Technology) were employed primarily to conduct the fundamental investigations on scaling and plugging mechanisms and characterization of green liquor dregs. The project also tapped GTRC expertise in the development of the critical underlying black liquor gasification rate subroutines employed in the CFD code. The actual CFD code development and application was undertaken by Process Simulation, Ltd (PSL) and Simulent, Ltd. PSL focused on the overall integrated gasifier CFD code, while Simulent focused on modeling the black liquor nozzle and description of the black liquor spray. For nozzle development and testing Chemrec collaborated with ETC (Energy Technology Centre) in Piteå utilizing their test facility for nozzle spray investigation. GTI (Gas Technology Institute), Des Plains, IL supported the team with advanced gas analysis equipment during the gasifier test period in June 2005. 
Final Technical Report Rev. 0

DE-FC26-04NT42259

\section{Phase I Work \& Results}

The development of CFD models for the overall gasifier reactor and gasifier sprays and the correlation of these models to existing gasifier operation and experimental data from Chemrec's spray test facility in Piteå was a key Phase I accomplishment..

Field testing of the black liquor gasifier at New Bern was done to establish a basis for comparison and development of CFD models of the gasifier. The field testing revealed large inconsistencies in the measured material and energy balances. Adjustments to inlet black liquor and air flows were made on the basis of elemental material balances and the condensate energy balance. These adjustments lead to much improved mass balance closures. Detailed balances were then calculated on the basis of the corrected flows and these served as a basis for comparison with equilibrium and CFD reactor models. These comparisons showed some differences but overall reasonable agreement.

Another key phase I activity was directed at establishing a fundamental understanding of fouling and plugging mechanisms in the green liquor and condensate circuits that impact process reliability. This knowledge was used to evaluate, and implement practical engineering solutions, to improve process reliability. The project also featured evaluation of means to mitigate the impact of gasifier operations on downstream pulp mill processes.

The detailed material and energy balance work also revealed that the gasifier was operating at higher air to fuel ratio and therefore higher reactor temperatures than previously understood. As demonstrated in the field testing, reducing air to fuel ratio is limited by negative impact on green liquor quality, specifically dregs quantity and settling characteristics. More detailed analysis revealed the carbon content of the green liquor dregs increased dramatically as air to fuel ratio was dropped, resulting in less dense and therefore less easily settled dregs.

\section{Phase II Work \& Results}

DOE funding cutbacks significantly diminished the original Phase II project scope. As a result, the Phase II effort was focused primarily on relatively simple modifications to the existing burner design. These were directed at reducing air to fuel ratio $(\mathrm{A} / \mathrm{F})$ while maintaining green liquor quality. Reducing $\mathrm{A} / \mathrm{F}$ reduces reactor temperature and improved overall process efficiency. Reducing reactor temperature should also have a significant impact on refractory life and therefore process reliability.

The New Bern mill has made significant progress over the past ten years improving the performance and reliability of the gasifier operation. In particular, improvements in refractory materials and design have lead to extended run time between replacements $[1,2,3,4,5]$. The phase I results suggested there was an opportunity to reduce gasifier operating temperature and thereby improve process thermal efficiency and reliability. Due to the Arrhenius nature of the refractory chemical reactions, reducing the reactor operating temperature should significantly extend refractory life or enable the use of less costly materials. For this reason, a new air to fuel control algorithm was implemented in the mill's DCS. This has elevated the importance of this parameter to operators and given them a more direct means to reduce 
Final Technical Report Rev. 0

DE-FC26-04NT42259

operating temperature and increase efficiency. As a result of this attention to air to fuel ratio, reactor temperatures are typically $100^{\circ} \mathrm{C}$ or more cooler than previously.

The burner improvements implemented in Phase II included four new black liquor nozzle designs and a simple modification to the air distributor. The new liquor nozzle designs were directed a providing a narrower size distribution and eliminating a "tail" of larger drop sizes observed in both the CFD modeling and experimental work in Phase I. Two of the new nozzles were based on modifications of the existing T-type nozzle. The other two nozzles were new concepts based on a Y-type nozzle. Unfortunately none of the tested burner improvements provided a significant benefit versus the status quo. There is reason to believe that further refinement of some of these concepts could provide a benefit. Chemrec intend to continue work with Weyerhaeuser to implement these improvements.

It is essential to have reliable thermocouples to measure gasifier operating temperature. The current air purged type thermocouples typically last about six months and are quite expensive to maintain. A number of different concepts were investigated in detail. Only one was brought forward to field testing. This new design was supplied by a manufacturer who provides similar units to slagging type coal gasifiers. Testing to date on this new type has shown it to be at least as reliable as the current type. It is also more sensitive to temperature swings and typically indicates reactor temperature 10 to $50^{\circ} \mathrm{C}$ hotter than the standard type.

\section{$\underline{\text { Recommendations }}$}

The overall goal of the project was to "demonstrate the commercial applicability of a technology that advances the goals of Agenda 2020" and specifically that related to advancing the state of black liquor gasification development. During the performance period of this contract, October 2004 through March 2008, the reliability and performance of the New Bern gasifier has improved. However, in addition to the work effort associated with this project, the New Bern plant has received increased attention in a number of areas. Since the results of this project are intermingled with the total effort, it is hard to break-out the contributions of specific task to the overall success, but taken as a whole the project has met the stated objective.

Further work should focus on areas which have the potential to significantly:

- Decrease maintenance cost

- Increase energy efficiency

- Increase reliability

- Increased capacity

Since these areas are so intimately interrelated, successes in one area will almost surely result in improvements in the others. The following is a list of specific recommendations for further work to be performed at the New Bern unit. It is expected that this work will continue with collaboration between mill and Chemrec resources: 
Final Technical Report Rev. 0

DE-FC26-04NT42259

- Work with field instruments to increase understanding of plant performance combined with follow-up and feed back to mill operations.

- Lower steam consumption for atomization of black liquor

- Further work with nozzle concepts initiated during this project.

- Further work with nozzle spray angle to increase throughput capacity and green liquor quality

- Air distribution device may be reinstalled if suitable time slot can be identified together with the mill

- Further work on thermocouples and alternate temperature measurement solutions.

Besides directly benefiting the New Bern plant, the intent of this work was to advance the overall state of molten phase (slagging) black liquor gasification. Much of the work undertaken has been relevant to Chemrec's ongoing pressurized, oxygen-blown development work. For example, although funding did not permit further work on short time contactors or an indirect quench at New Bern, both of these developments have been implemented at Chemrec's 30 bar pilot plant in Piteå, Sweden. The short time contactors have been installed since start-up and the plant has operated with an indirectly cooled quench tube since February 2008. The contactors have so far only been in operations under shorter periods but have shown very promising results (high sulfur capture per unit and very high selectivity towards $\mathrm{H}_{2} \mathrm{~S}$ ). So far, no operational problems have been observed with the indirectly cooled quench tube in the Piteå pilot after about 3000 hours of operations. Since product gas from the pressurized unit is only partly cooled by injection of condensate, the indirect quench tube at Piteå operates at considerably higher temperature than expected in the New Bern case. 


\section{Table of Contents}

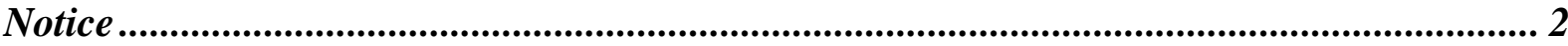

Executive Summary ................................................................................................................................... 3

List of Figures ................................................................................................................................ 10

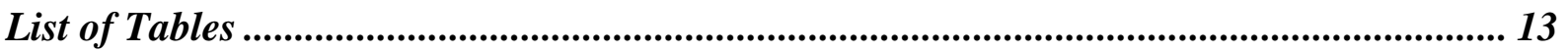

Abbreviations and Acronyms ....................................................................................................... 14

1 Introduction ......................................................................................................................... 16

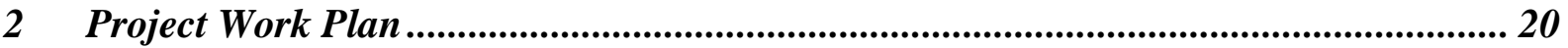

$2.1 \quad$ Brief Task descriptions ............................................................................................................... 21

2.1.1 Task 1 - The development of and correlation of CFD modeling tools to the New Bern

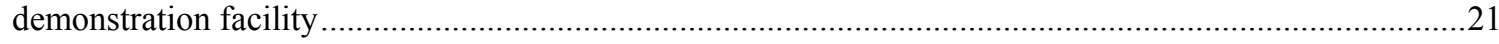

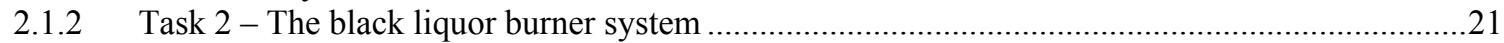

2.1.3 Task 3 - Process Reliability - Green liquor \& condensate scaling .............................................21

2.1.4 Task 4 - Process Integration in mill - Dregs characterization \& sulfur capture ............................22

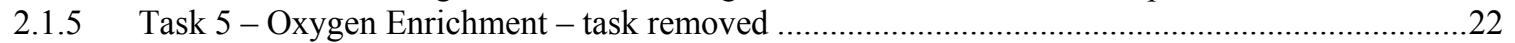

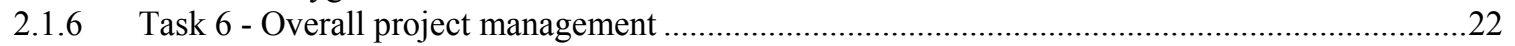

$2.2 \quad$ Project Work Phasing …................................................................................................................ 23

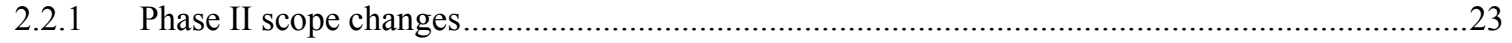

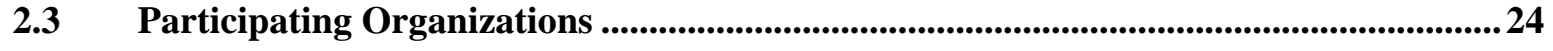

3 Task 1 - The development of and correlation of CFD modeling tools to the New Bern demonstration facility....................................................................................................................... 26

3.1 Summarized Task 1 accomplishments \& conclusions......................................................... 26

3.2 Establishing a baseline field test matrix .................................................................................2 27

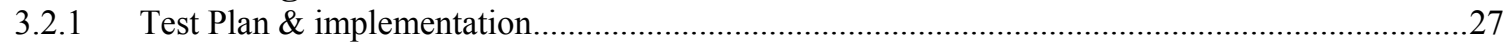

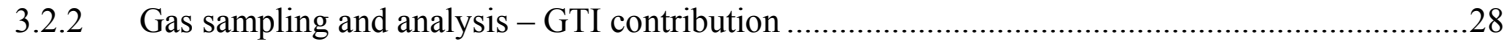

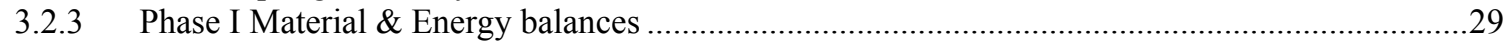

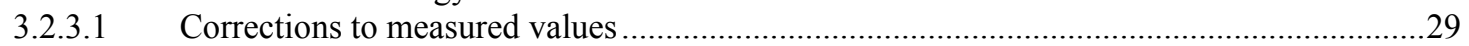

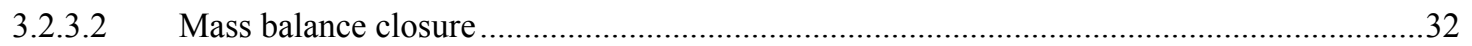

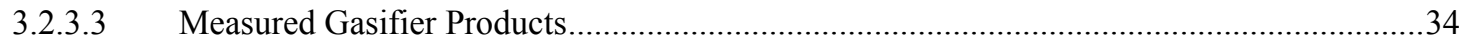

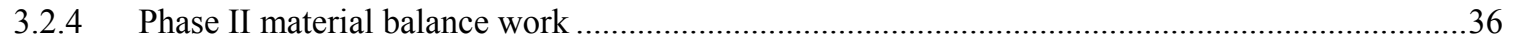

3.2.4.1 Overall material balance - from Nozzle test period February/March 2007 ..........................37

3.2.4.2 Overall material balance - from Nozzle test period February/March 2008..........................39

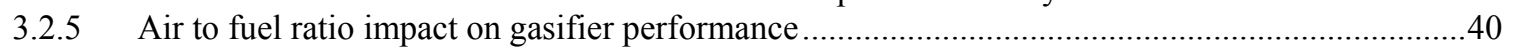

3.3 New Bern gasifier CFD model development ....................................................................4 42

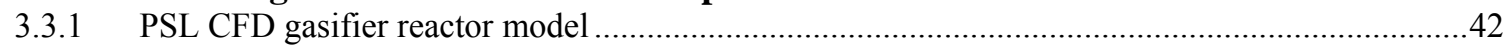

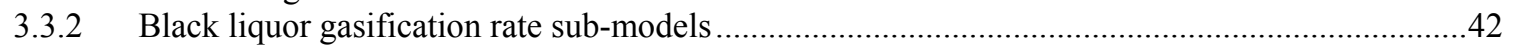

3.4 Black liquor spray model development .................................................................................... 43

3.4.1 Development of a CFD black liquor spray model (Simulent) .....................................................43

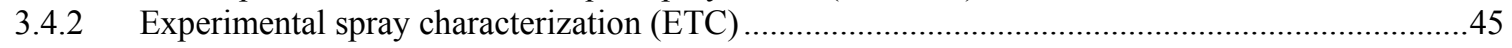

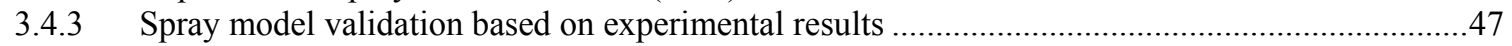

3.4.4 Spray model prediction for test matrix conditions ....................................................................

3.4.5 Transferring Simulent spray results into PSL gasifier model........................................................52 
Correlation CFD and equilibrium models to field test matrix ......................................53

3.5.1 Comparison of measured and predicted mass and energy balances for baseline test condition.....53

3.5.2 Comparison of measured and model predicted values for selected variables ...............................58

3.5.3 CFD Model predictions for reactor temperature and velocity distribution ....................................64

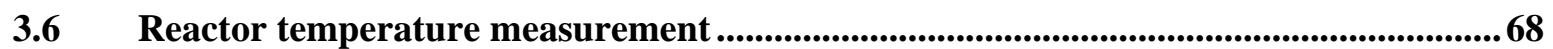

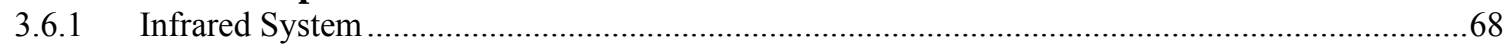

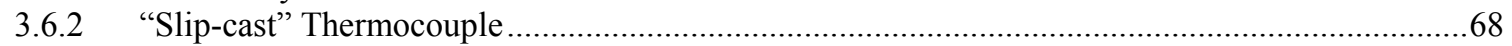

3.6.3 Commercial solution from entrained flow coal gasifiers ..............................................................69

4 Task 2 - Improvements to the black liquor burner system ............................................ 71

4.1 Black Liquor Nozzle Design and Testing ................................................................... 72

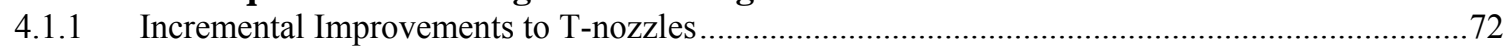

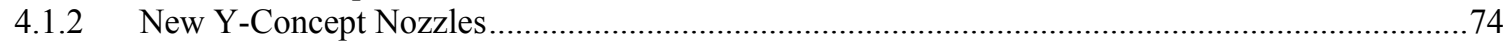

4.1.3 Nozzle Field Test Results: February - March 2007 ……..........................................................8

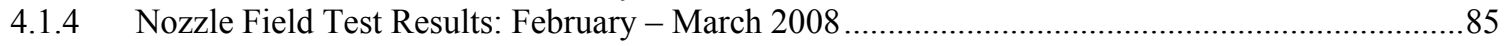

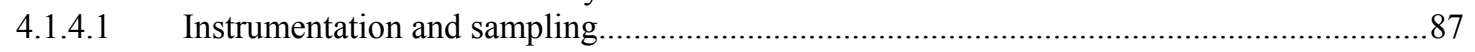

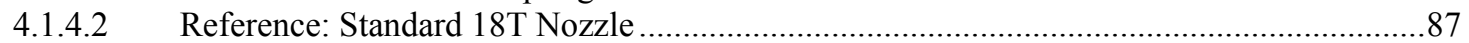

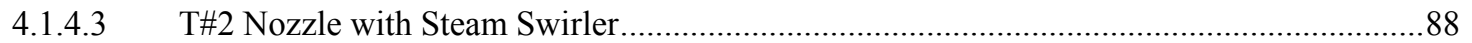

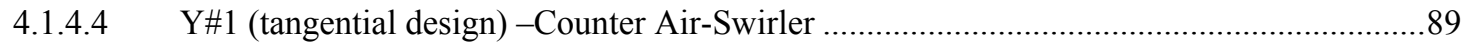

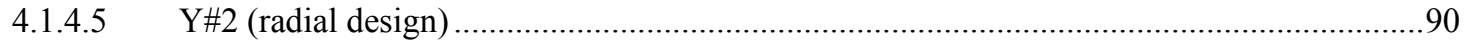

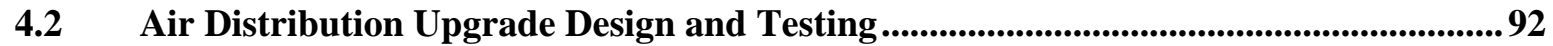

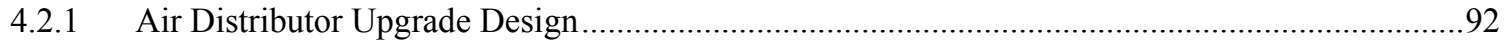

4.2.2 Improved Air Distribution Field Test Results ..........................................................................

4.3 Improved Air to Fuel Ratio Control.........................................................................................95

5 Task 3 - Process reliability - green liquor and condensate scaling................................. 96

5.1 Condensate plugging \& scaling investigation and measures ..........................................96

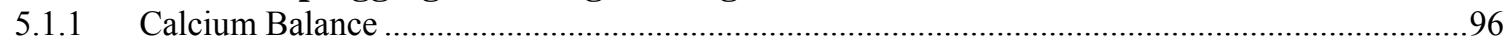

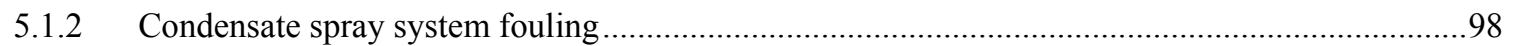

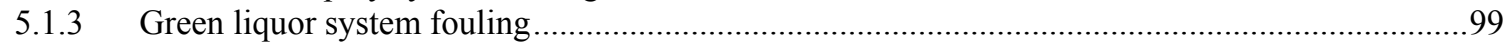

5.1.4 Evaluation of practical solutions to green liquor and condensate scaling/plugging problems ......100

5.2 Indirect cooled quench tube ................................................................................................... 101

5.3 Cooled Support Ring (ORNL MPLUS Projects)............................................................... 102

$5.4 \quad$ Reliability development ......................................................................................................... 105

6 Task 4 - Process Integration in the Pulp Mill .............................................................. 106

6.1 Green Liquor Dregs Characterization ................................................................................... 106

6.2 Dregs Morphology .................................................................................................................. 109

6.3 Evaluate alternatives for dregs treatment............................................................................ 111

6.4 Green Liquor Filter Cloth Testing........................................................................................... 113

6.5 Short Time Contactors...................................................................................................................... 116

$7 \quad$ Summary of Task Results ................................................................................................ 119

7.1 Task 1 - The development of and correlation of CFD modeling tools to the New Bern

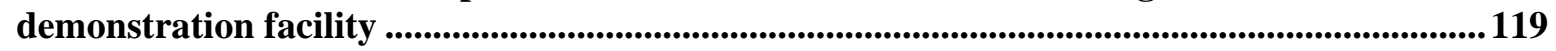

7.2 Task 2 - The black liquor burner system............................................................................. 120 
7.3 Task 3 - Process Reliability - Green liquor \& condensate scaling.............................. 121

7.4 Task 4 - Process Integration in mill - Dregs characterization ....................................... 121

$8 \quad$ Conclusions and Recommendations............................................................................. 123

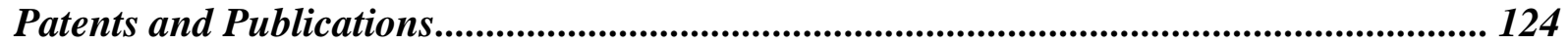

Acknowledgements .......................................................................................................... 124

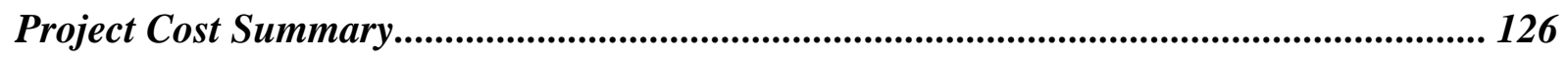

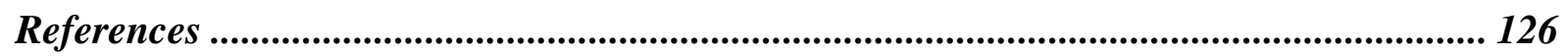

Appendix 1 - GTI Quarterly Report 7 (DE-FC36-03G013175)

Appendix 2 - IPST Quarterly Report 12

Appendix 3 - PSL Report on Task 1

Appendix 4 - Simulent Report on Comparison with ETC 80cp Syrup Test 


\section{List of Figures}

Figure 1-1 Process schematic of New Bern Chemrec gasifier facility .................................... 18

Figure 3-1 Black liquor flows, calculated based on sodium balance vs. measured values...... 30

Figure 3-2 Theoretical flame temperature vs. air:fuel ratio ................................................. 31

Figure 3-3 Calculation for secondary air based on energy balance around the gasifier and cooling section of the scrubber ........................................................................... 32

Figure 3-4 New Bern gasifier process schematic showing calcium balance for baseline test

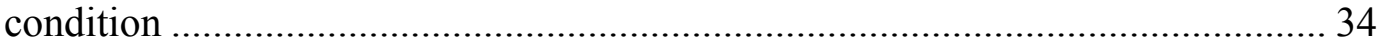

Figure 3-5 $\mathrm{CO}_{2} / \mathrm{CO}(\mathrm{vol} \% / \mathrm{vol} \%)$ in gasifier product vs. $\mathrm{H}_{2} \mathrm{O} / \mathrm{Corg}(\mathrm{lb} / \mathrm{lb})$ in gasifer feed,

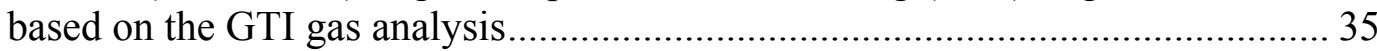

Figure 3-6 Molar flows $(\mathrm{lb} / \mathrm{h})$ of $\mathrm{H}_{2}, \mathrm{CO}$ and $\mathrm{CH}_{4}$ for the various conditions.......................... 36

Figure 3-7 Unburned $\mathrm{C}$ as a percentage of organic carbon fed to the gasifier.......................... 36

Figure 3-8 Carbon and N2 mass balance for Feb. 20, 2007 trial run at 9:00 am .................... 38

Figure 3-9 Overall mass balance based on mill instrument - week of Feb 17, 2008 ............... 40

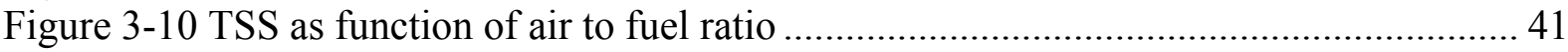

Figure 3-11 Carbon loss as function of air to fuel ratio ...................................................... 42

Figure 3-12 Example of Simulent 2-D spray simulation ..................................................... 44

Figure 3-13 Example of Simulent's 3-D simulation.............................................................. 45

Figure 3-14 ETC Nozzle test facility schematic \& photo …………………............................ 46

Figure 3-15 Photo of ETC spray measurement.................................................................. 47

Figure 3-16 Axial velocity profiles for repeated $80 \mathrm{cp}$ syrup runs and a water run. Not all data

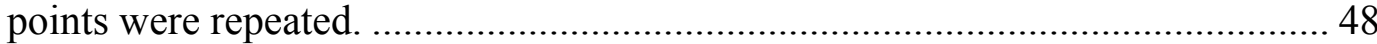

Figure 3-17 D10 and D32 (SMD) profiles for repeated $80 \mathrm{cp}$ syrup runs and a water run. Not

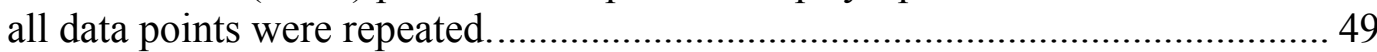

Figure 3-18 Spray dispersion as function of firing rate …………………………................. 51

Figure 3-19 Sampling locations for particle distribution and dispersion................................ 53

Figure 3-20 Comparison of the thermodynamic model predicted $\mathrm{CO}_{2} / \mathrm{CO}$ ratio in gasifier product vs. $\mathrm{H}_{2} \mathrm{O} /$ Corg in gasifier feed with linear fit to GTI gas analysis given in

Figure 35.

Figure 3-21 Comparison of CFD model predicted $\mathrm{CO}_{2} / \mathrm{CO}$ ratio in gasifier product vs. $\mathrm{H}_{2} \mathrm{O} /$ Corg in gasifer feed with linear fit to GTI gas analysis given in Figure 35. 61

Figure 3-22 CFD predicted gas temperature in the gasifier at different air/fuel ratio ............. 65

Figure 3-23 CFD predicted gas temperature at three firing rates with $\mathrm{A} / \mathrm{F}=2.83$................... 66

Figure 3-24 CFD predicted gas temperature at three firing rates with $\mathrm{A} / \mathrm{F}=2.42$................... 66

Figure 3-25 CFD predicted velocity distribution at three firing rate with $\mathrm{A} / \mathrm{F}=2.83 \ldots \ldots \ldots \ldots \ldots . .67$

Figure 3-26 CFD predicted gas temperature distribution at three swirl levels ....................... 67

Figure 3-27 Alternative Thermocouple Design .............................................................. 70

Figure 3-28 Comparison of outputs from original (OD) and alternate (AD) design

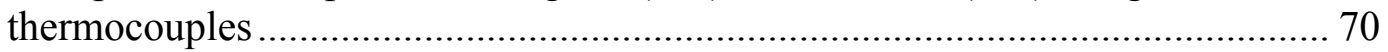

Figure 4-1 ETC CFD modeling results show distribution of flow at nozzle entrance for original and six alternative designs................................................................... 73

Figure 4-2 CFD comparison of baseline and uniform droplet distributions ............................ 75

Figure 4-3 Comparison of Simulent's concept nozzle with existing nozzle............................. 76 
Final Technical Report Rev. 0

DE-FC26-04NT42259

Figure 4-4 CFD comparison of reactor temperatures for the existing and new Simulent nozzles.

Figure 4-5 CFD comparison of droplet trajectories for the existing and new Simulent nozzles.

Figure 4-6 CFD simulation area for one hole of a Y-type black liquor nozzle ....................... 79

Figure 4-7 CFD simulation for black liquor flow at level A-A according to Figure 4-6........ 80

Figure 4-8 Total Suspended Solids versus A/F ratio for the standard and modified 18T (T\#1) nozzle

Figure 4-9 TSS vs steam addition at constant (A/F ratio) for the standard and modified 18T (T\#1) nozzle

Figure 4-10 The dregs organic carbon content given as a function of $\mathrm{A} / \mathrm{F}$ ratio for the standard and the modified T\#1 nozzle 84

Figure 4-11 Fraction of black liquor carbon remaining as organic carbon in the green liquor 85

Figure 4-12 Imhoff cone settling results and black liquor flows during Feb/Mar 2008 nozzle trials.

Figure 4-13 The flame picture is taken approx 15.00 2008-mar-06. The flow rate is $50 \mathrm{gpm}$ black liquor and the nozzle pressure in the 25-30 psig range. Typical Imhoff cone after $2 \mathrm{~h}$ in the New Bern Mill, the picture is from 21-Feb-2008

Figure 4-14 Flame picture for the radial Y-jet below was taken at $31 \mathrm{gpm}$. The green liquor Imhoff cone from the same test, note the very fine particles in the clear phase... 90

Figure 4-15 Radial Y-jet 45 gpm, the dark streaks from the nozzle are interpreted as jets of black liquor coming out. Maximised steam flow to the left.

Figure 4-16 CFD results demonstrate poor air distribution entering reactor and potential

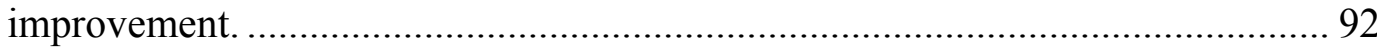

Figure 4-17 Illustration of diverter plates added to existing air plenum............................. 93

Figure 4-18 Pressure drop over air inlet with and without perforated diffuser plate.............. 94

Figure 5-1 Example calcium balance results based on trial flow data and stream composition analysis; stream values are given in $1 \mathrm{~b} / \mathrm{s}$; stream temperatures are indicated in bold.

Figure 5-2 Predicted $\mathrm{CaCO}_{3}$ solubility as a function of temperature for condensate to quench sprays based on June 20, 2005 baseline data. Dashed line indicates average $\mathrm{Ca}^{2+}$ level for stream and range of temperatures in quench spray system.

Figure 5-3 Predicted $\mathrm{CaCO}_{3}$ and pirssonite solubility as a function of temperature for circulating green liquor based on average composition data. Filled square indicates average sodium concentration and minimum temperature of raw green liquor.

Figure 5-4 Daily average green liquor recirculation pump speed showing typical rising trends caused by $\mathrm{CaCO}_{3}$ scale deposition. Period of time sine anti-scale additive has been applied does not show this characteristic trend.

Figure 5-5 Cooled support ring critical heat flux (CHF) ............................................. 103

Figure 5-6 New Bern gasifier reliability, May 2007 through April 2008 ........................... 105

Figure 6-1 Measured bulk density of dregs vs. unburned carbon content with data grouped by acceptable dregs settling criteria (TSS $<750 \mathrm{mg} / \mathrm{L}$ ).

Figure 6-2 Selected SEM photomicrographs of individual particles isolated from composite dregs samples from indicated mill test conditions. 
Figure 6-3 Calculated unburned carbon leaving gasifier boundary vs. corrected air/fuel ratio and operating load.

Figure 6-4 Calculated unburned carbon leaving gasifier boundary vs. corrected air/fuel ratio and atomizing nozzle steam pressure

Figure 6-5 Schematic showing location of green liquor filter cloth test stand ..................... 114

Figure 6-6 Photo comparing filtrate from exposed (left) and unexposed filter cloths........... 115

Figure 6-7 Short time contactor design from LAPCO ..................................................... 117

Figure 6-8 Schematic of Chemrec's DP-1 pilot facility in Piteå Sweden .............................. 118 
Final Technical Report Rev. 0

DE-FC26-04NT42259

\section{List of Tables}

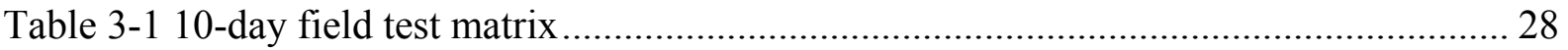

Table 3-2 Average black liquor composition for 10-day trial period ...................................... 28

Table 3-3 Gasifier balances (Out/In) for C, Na, S, Ca, V; vanadium was analyzed only on

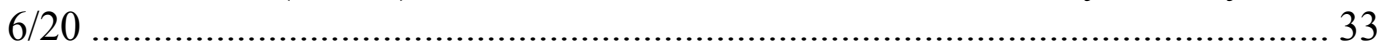

Table 3-4 Black liquor composition for Feb/Mar 2007 test period ....................................... 37

Table 3-5 Nitrogen flows with the inlet air (uncorrected) and outlet gas based on outlet gas

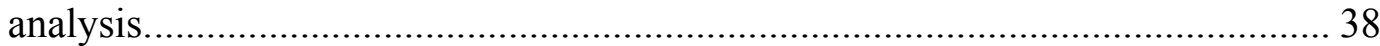

Table 3-6 Carbon balance around the gasifier and scrubber................................................... 39

Table 3-7 Diameter statistics for three measurement positions. One $80 \mathrm{cp}$ syrup and one water run shown. DvXX is the diameter below which $\mathrm{XX} \%$ of the total volume is

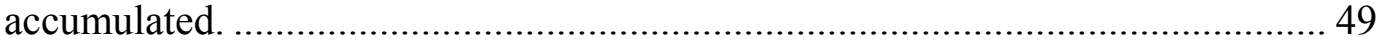

Table 3-8 Measured and predicted mass balances for June 20 baseline test ........................... 55

Table 3-9 Measured \& predicted energy balance for June 20 baseline test.............................. 55

Table 3-10 Comparison of measured and predicted product gas compositions........................ 57

Table 3-11 Comparison of measured temperature with that obtained by energy balance, thermodynamic calculation and CFD modeling. .................................................. 59

Table 3-12 Measured vs. calculated $\mathrm{CO}_{2}$ values in the product gas from the gasifier. The measured $\mathrm{CO}_{2}$ values are those measured at the scrubber exit..............................6 60

Table 3-13 Measured vs. calculated $\mathrm{CO}$ values in the product gas from the gasifier. The measured $\mathrm{CO}$ values are those measured at the scrubber exit. ............................... 60

Table 3-14 Measured vs. calculated $\mathrm{H}_{2}$ values in the product gas from the gasifier. The measured $\mathrm{H}_{2}$ values are those measured at the scrubber exit.

Table 3-15 Measured vs. calculated $\mathrm{CH}_{4}$ values in the product gas from the gasifier. The measured $\mathrm{CH}_{4}$ values are those measured at the scrubber exit.

Table 3-16 Measured, thermodynamically and CFD calculated $\mathrm{H}_{2} \mathrm{~S}$ values in the product gas from the gasifier. The measured $\mathrm{H}_{2} \mathrm{~S}$ values are those measured at the venturi exit.

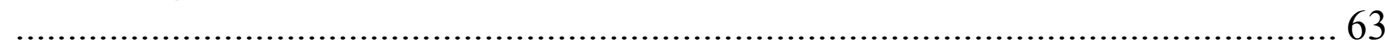

Table 3-17 Measured vs. CFD predicted unburned carbon in smelt (mass fraction). .............. 64

Table 4-1 Test Conditions for Feb/Mar 2007 nozzle testing .................................................. 81

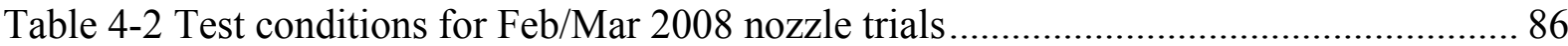

Table 6-1 Comparison of dregs characteristics for June 2005 test conditions........................ 107 
Final Technical Report Rev. 0

DE-FC26-04NT42259

\section{Abbreviations and Acronyms}

A/F Air to fuel ratio, mass air/mass black liquor solids

$\mathrm{AD}$ Alternate design used in reference to reactor thermocouples

AF\&PA American Forest and Paper Association

Agenda 2020 Joint technology alliance between DOE and the AF\&PA

BL Black liquor - refers to the spent pulping liquor recovered in a pulp mill

BLS or bls Black liquor solids - refers to the solids portion of the black liquor

BLGCC Black liquor gasification combined cycle

CFD Computational Fluid Dynamics

Chemrec Chemrec AB. Stockholm Sweden also used to refer to Chemrec AB's proprietary black liquor gasification technology

cp Centipoise (viscosity)

CSR Cooled support ring - a critical subcomponent in the New Bern gasifier

DME DiMethyl Ether, $\mathrm{CH}_{3} \mathrm{OCH}_{3}$

DOE or United States Department of Energy - in this case the Energy Efficiency

USDOE or and Renewable Energy Office of Biomass Programs

DOE-EERE

DP-1 Chemrec's pressurized, $\mathrm{O}_{2}$-blown, black liquor gasification

demonstration plant in Piteå, Sweden

ETC Swedish Energy Technology Centre, Piteå Sweden

FEM Finite Element Model

GC Gas Chromatography

GIT Georgia Institute of Technology, Atlanta, Georgia

GL Green liquor - combined $\mathrm{Na}_{2} \mathrm{CO}_{3}+\mathrm{Na}_{2} \mathrm{~S}$ stream in a pulp mill

GTI The Institute of Gas Technology, Des Plaines, Illinois

GTRC Georgia Tech Research Corporation - the contracting branch of GIT

HAZOP or Hazard and Operability Study - a method for identifying and evaluating

Hazop the risks associated with a process

HHV Higher heating value

ICP-AES Optical emission spectrometry with inductively coupled plasma

ICQP Indirectly cooled quench pipe - an internal gasifier component

IPST The Institute of Paper Science and Technology at GIT 


\author{
kpph 1000 pounds per hour \\ LHV Lower heating value \\ MPLUS Metal Processing Laboratory Users Facility at ORNL \\ NAELS Non-ideal aqueous electrolyte system modeling software \\ OD Original design used in reference to reactor thermocouples \\ ORNL Oak Ridge National Laboratory, Oak Ridge, Tennessee \\ P\&ID Process and instrument diagram \\ PDA Phase doppler anemometry \\ PSL Process Simulations Ltd., Vancouver, British Columbia \\ SEM Scanning Electron Microscope \\ Simulent Simulent, Ltd., Toronto Canada \\ SMD Sauter mean diameter \\ TSS Total suspended solids \\ TTA Total Titratable Alkali \\ USDA United States Department of Agriculture
}


Final Technical Report Rev. 0

DE-FC26-04NT42259

\section{Introduction}

One of the largest sources of indigenous, renewable and sustainable raw material in the United States is represented by the 278 million dry tons of wood processed each year by U.S. Pulp and Wood Products facilities[6], coupled with an estimated 100 million dry tons or more of residuals within the vicinity of these mills. Pulp and paper mills have existing infrastructure to receive, store, and handle woody biomass residuals. It is logical and desirable to utilize the existing infrastructure at pulp and paper mills to explore innovative ways to integrate gasification of wood residuals and black liquor with recovery of pulping chemicals. The forest products industry gasification initiative would more than double the ability to generate electric power from renewable, sustainable forest residuals and spent pulping liquors - or alternatively, produce significant amounts of liquid fuels, hydrogen, and/or bio-based chemicals. Black liquor generation in the US pulp mills could be used for automotive fuel generation. If all mills were converted the energy in that new product stream would correspond to 9-13 million tons of diesel equivalents per year depending on selected product.

Agenda 2020 is the joint federal-industry program executed by DOE and the AF\&PA (American Forest and Paper Association) on November 22, 1994. A key objective of Agenda 2020 is to demonstrate the commercial applicability of technologies that advance the goals delineated in the Forest Products Industry Technology Roadmap[7]. The efficient and successful demonstration of gasification of black liquor from wood pulping processes is a key Agenda 2020 objective. In 2000, the U.S. DOE and the forest and paper industry recommitted to a partnership targeted at bringing wood residual and spent pulping liquor gasification to the point where these technologies are a viable commercial choice for pulp and paper mills.

Once gasification technology is implemented, pulp and paper mills will have choices of how best to utilize and convert their spent pulping liquors and residual materials. Among those choices will be the production of clean, renewable and sustainable electric power. Black liquor gasification in an integrated combined cycle (BLGCC) has the potential of producing more than twice the current output of electricity per ton of pulp. Alternatively clean, renewable and sustainable liquid fuels, hydrogen, and/or chemicals can be produced. When gasified with oxygen, black liquor converts to a high quality synthesis gas. It is similar to syngas produced from fossil residual oil. Conventional processes can then be used to convert the gas to liquid fuels, hydrogen and/or chemicals. Preliminary studies have shown that the economics of this choice may be equal to, or in some cases even better, than using the gas to generate electric power.

Development of the Chemrec ${ }^{\mathrm{TM}}$ high temperature technology began in the late 1980s. The original parent company of this technology, SKF Steel, began the development of plasma- 
Final Technical Report Rev. 0 DE-FC26-04NT42259

based gasifiers for black liquor, but excessive carryover of alkali materials and high electrical power consumption caused them to abandon this approach. They built a lower temperature pilot plant in 1987 that established the feasibility of black liquor gasification without plasma energy support. Kværner purchased the technology in 1990 and continued development of both low-pressure air-blown and a high-pressure oxygen-blown technologies. This effort culminated in the first semi-commercial demonstration of the technology at the Frövi Kraftliner mill in Frövifors Sweden. The Frövifors unit started-up in 1991 with a design capacity of 165,000 lb of kraft black liquor solids per day.

The Weyerhaeuser pulp mill at New Bern, NC installed and began operating the world's first commercial black liquor gasification system in December 1996. The atmospheric Chemrec ${ }^{\mathrm{TM}}$ "booster" gasifier was installed as part of a pulp mill optimization project to de-bottleneck the black liquor processing limit of the mill's recovery boiler. The gasifier was designed to process $734,000 \mathrm{lb}$ of black liquor solids per day; equivalent to about $15 \%$ incremental pulp capacity.

A process schematic is shown in Figure 1-1. The process consists of two main vessels, the gasifier reactor with a quench vessel underneath and the fuel gas cooling column. The gasifier is fed with pressurized black liquor, steam for atomization and preheated air for partial combustion (gasification). The hot product consisting of smelt droplets and fuel gas leaves the reactor in the bottom and is cooled to saturation temperature at the outlet of the reactor via direct contact with process condensate being rerouted from the gas cooler downstream. Green liquor is formed in the bottom of the quench vessel via dissolving of the smelt droplets from the gasifier in weak wash and condensate. The saturated fuel gas is cooled in a cooling column using external indirect cooling of the condensate and after final sulfur removal the cooled gas is fed to the mill's power boiler. Detail descriptions of the New Bern gasifier system and its operating history have been reported elsewhere $[8,9,10,11,12,13,14]$.

With support from the Swedish government Chemrec has built a pressurized, oxygen blown pilot unit in Piteå, Sweden. To achieve all the benefits of the technology, pressurized operation using oxygen as oxidant is necessary. This $44,000 \mathrm{lb}$ black liquor solids per day pilot has been in operation since 2005 and accumulated almost $6000 \mathrm{~h}$ of operation as per June 2008.The plant will be equipped with a synthesis unit producing DME (Di-Methyl-Ether) through a grant received from the European Community and the Swedish Energy Agency. It will be part of a larger effort including the construction of 14 DME fueled VOLVO trucks, field tests etc. The plant is planned to be on stream early 2010. Chemrec is currently involved in the planning of two demonstration projects, one planned to be located at the New Page Mill in Escanaba, MI, USA and one at the Smurfit-Kappa mill in Piteå, Sweden. Investment decision for the first plant is planned for second half, 2009. 
Final Technical Report Rev. 0

DE-FC26-04NT42259

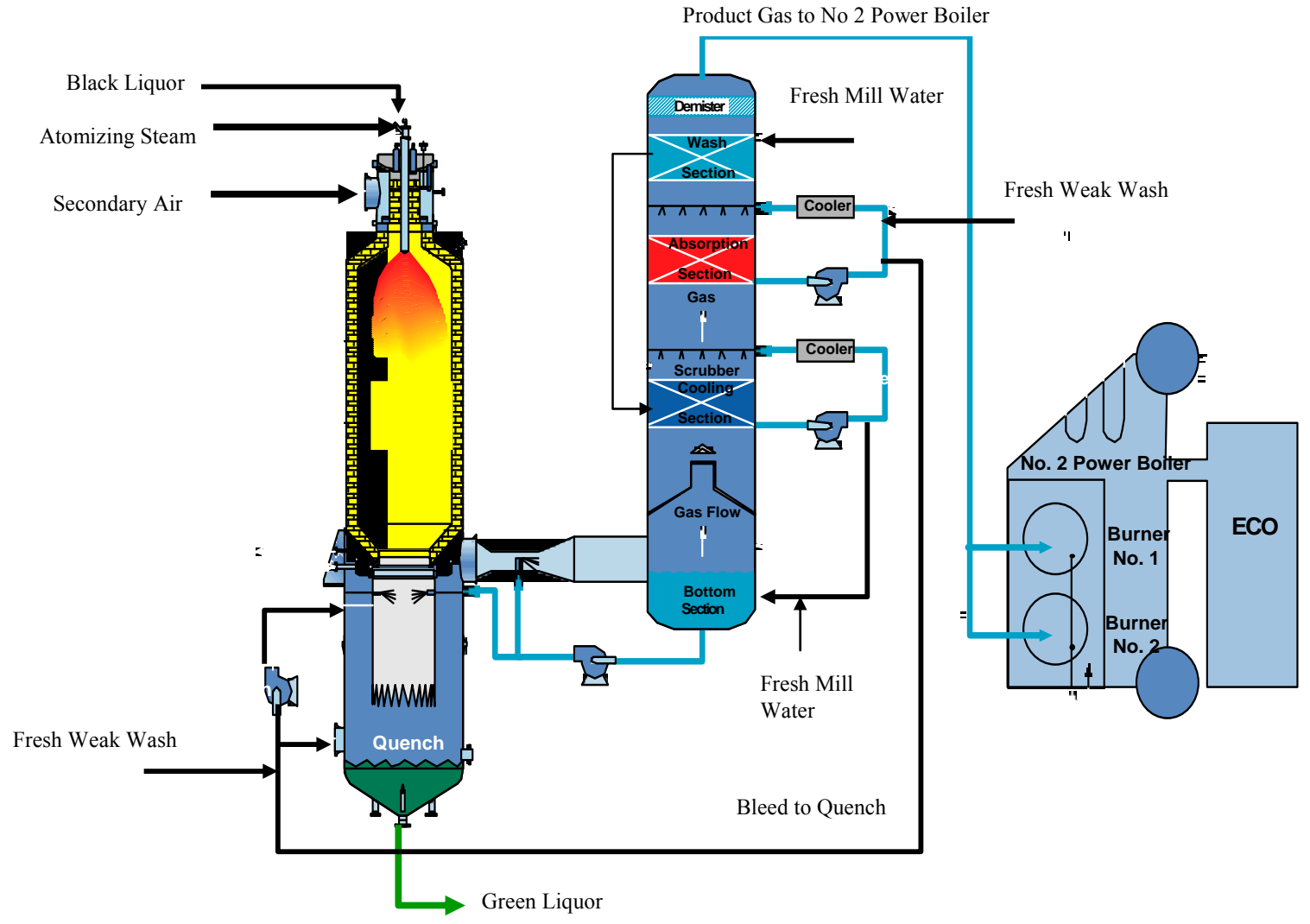

Figure 1-1 Process schematic of New Bern Chemrec gasifier facility

Weyerhaeuser and Chemrec have long recognized that combining learning's from commercial operation of the atmospheric unit at New Bern with those of the pressurized pilot unit in Sweden provides an unusual opportunity to advance the state of high temperature black liquor gasification technology development and reduce commercialization risk for future full scale pressurized plants.. With this in mind, Weyerhaeuser submitted a proposal to the DOE in response to the joint USDOE and USDA solicitation - "Biomass Research and Development Initiative" (DE-PS36-04GO94002). The underlying theme for the proposal was to use the long-term, continuous operation of the New Bern facility as a test-bed for black liquor gasification technology development. Specifically, Weyerhaeuser along with Chemrec and a team of collaborators, proposed to:

- Develop and validate the CFD modeling tools based on the New Bern plant operation,

- utilize the validated CFD models to enhance the gasifier performance through improvements to the black liquor burner design, and

- utilize the commercial operation of the facility to evaluate solutions to long term process issues (e.g. scaling and other process integration issues work by implementing and demonstrating solutions at New Bern)" 
Final Technical Report Rev. 0 DE-FC26-04NT42259

The USDOE recognized the opportunity and awarded Cooperative Agreement DE-FC2604NT42259 to Weyerhaeuser. The following report documents the results of work completed under this contract. 
Final Technical Report Rev. 0

DE-FC26-04NT42259

\section{Project Work Plan}

Weyerhaeuser along with its subcontracting partners submitted a proposal in response to the 2004 joint USDOE and USDA solicitation - "Biomass Research and Development Initiative". The Weyerhaeuser project "Advancement of High Temperature Black Liquor Gasification" was awarded USDOE Cooperative Agreement DE-FC26-04NT42259 in November 2004. The overall goal of the DOE sponsored project was to utilize the Chemrec ${ }^{\mathrm{TM}}$ black liquor gasification facility at New Bern as a test bed for advancing the development status of molten phase gasification. In particular, project tasks were directed at improvements to process performance and reliability. The effort featured the development and validation of advanced CFD modeling tools and the application of these tools to direct burner technology modifications. The project also focused on gaining a fundamental understanding and developing practical solutions to address condensate and green liquor scaling issues, and process integration issues related to gasifier dregs and product gas scrubbing.

The overall project goal is aligned with the broader goals of Agenda 2020, a joint federalindustry program executed by DOE and the American Forest \& Paper Association in 1994. Specifically, the development and demonstration of black liquor gasification is a key Agenda 2020 focus area and a cornerstone technology for the envisioned Forest Products Biorefinery. Improvements demonstrated at the New Bern gasifier are a logical step in providing an improved technology database that along with results from Chemrec's pressurized pilot plant facility in Sweden will enable the pulp and paper industry to achieve several important improvements for high temperature black liquor gasification, namely to:

- Build technology leadership to advance global competitiveness

- Build energy self-sufficiency by taking advantage of biomass

- Meet demanding new environmental standards and requirements without incurring the predicted increases in cost for additional capital equipment, operations and energy consumption

- Protect the industry's most valuable resource (the forest) through sustainable management

- Continue providing high quality product

- Improve safety (an overarching goal of both industry and government)

The important development efforts described below have been conducted by Weyerhaeuser at its commercial black liquor gasifier facility in New Bern together with the gasifier technology developer (Chemrec AB), the Institute of Paper Science and Technology at Georgia Tech, Process Simulation Ltd., Simulent Ltd., and DOE EERE through its Office of Biomass Programs. 
Final Technical Report Rev. 0

DE-FC26-04NT42259

\subsection{Brief Task descriptions}

\subsubsection{Task 1 - The development of and correlation of CFD modeling tools to the New Bern demonstration facility}

Task 1 focused on the development of CFD modeling tools and the utilization of the New Bern facility as a platform for validation/correlation of black liquor gasification models versus actual operation. PSL had responsibility for the overall development of an integrated CFD model of the overall gasifier reactor which served as the cornerstone for this task. New fundamental rate subroutines describing black liquor gasification were developed by IPST and incorporated into the reactor model by PSL. In addition, a detailed CFD model describing the black liquor atomizer was developed by Simulent. PSL and Simulent worked closely to develop a technique to transfer representative spray data from the Simulent spray model into PSL's overall reactor model. Experimental spray data was generated at Chemrec's nozzle development facility located at the Swedish Energy Technology Centre (ETC) in Piteå, Sweden. This data was used by PSL to validate the CFD spray model. A two week field test program was conducted at the New Bern plant to provide a common basis for modeling the gasifier; i.e., a matrix of test results to be used as the basis for validation and correlation of the modeling work. The development and implementation of a reliable process temperature measurement technique was included in task 1.

\subsubsection{Task 2 - The black liquor burner system}

Task 2 focused on the development of burner system improvements based on the results and application of the CFD models developed in Task 1. Four new black liquor nozzles were designed, fabricated and tested under this task. Two of these were improvements to the existing "T-type" nozzle, and two were for a new concept nozzle based on a "Y-type." A means to improve air distribution was also taken from concept through to implementation under this task. Chemrec completed detailed design and fabrication of the above improvement. These were tested during two separate field trials at the New Bern plant.

\subsubsection{Task 3 - Process Reliability - Green liquor \& condensate scaling}

Task 3 addressed reliability as a significant barrier to commercial operation of the fully integrated full-scale black liquor process system. Scaling and plugging problems in the condensate and green liquor circulation loops had been a key cause for lost availability requiring shutdowns about every 8-12 weeks at New Bern. IPST lead a fundamental study to understand the root causes of these scaling and plugging problems. This involved both field and laboratory investigations. Based on this study practical solutions were proposed. The task originally involved the design, procurement, installation, and evaluation of an indirect cooled quench tube as one means of eliminating the green liquor recirculation loop altogether. During phase I a preliminary design for the indirect quench was developed and a budgetary 
Final Technical Report Rev. 0

DE-FC26-04NT42259

installed cost estimate developed. Unfortunately, DOE budget cuts in phase II precluded implementation.

\subsubsection{Task 4 - Process Integration in mill - Dregs characterization \& sulfur capture}

The Task 4 effort addressed a key process integration issue related to the gasifier dregs in the pulp mill lime cycle. IPST lead a detailed characterization of green liquor dregs and their impact on downstream processes. This involved both field and laboratory investigations with the aim to define/evaluate practical alternatives for treatment of the dregs.

In addition, Chemrec lead an effort to look at green liquor filtration as an alternate means of dealing with gasifier dregs. Currently, green liquor from the gasification unit is continuously blended with green liquor from the mill's recovery boiler. The combined green liquor stream is taken to a green liquor clarifier where dregs are settled and removed. The gasifier dregs are markedly different than the recovery boiler dregs and at times have caused problems in the clarifier and downstream processes. Green liquor filtration is practiced at many mills throughout the world on recovery boiler green liquor. As a first step to understanding the filtration option for gasifier dregs, Chemrec lead an effort directed at understanding the dregs filterability. A slip stream test station was installed to look at the impact of the gasifier dregs on filter cloth performance.

A second Task 4 effort was directed at evaluating a new "short contact time" scrubber as a means of improving poor $\mathrm{H}_{2} \mathrm{~S}$ scrubber performance. The concept for the short contact time scrubber is to increase the absorption selectivity of $\mathrm{H}_{2} \mathrm{~S}$ over $\mathrm{CO}_{2}$ through the use of reduced contact times between product gas and the absorbing liquid. Chemrec lead the design and preparation of procurement documents for a short contact time scrubber pilot slipstream facility. However, procurement and installation was never realized due to DOE budget reductions in phase II.

\subsubsection{Task 5 - Oxygen Enrichment - task removed}

Task 5 was targeted to demonstrate the benefits of oxygen enrichment on the New Bern gasifier utilizing the CFD model derived from Task 1 to help establish a test program. The task 5 was removed completely after budget reductions in phase II.

\subsubsection{Task 6 - Overall project management}

Task 6 involved the overall project management, coordination with participants and reporting of progress/timely preparation of DOE reports. This task was lead by Weyerhaeuser as the project's prime contractor and Principal Investigator. 
Final Technical Report Rev. 0

DE-FC26-04NT42259

\subsection{Project Work Phasing}

The project was divided into two phases with a key go/no-go review point between the phases. The overall principles and key task for each phase are summarized below:

PHASE I - Develop fundamental understanding of issues and develop technology improvement concepts. This phase included: black liquor gasifier CFD model development, black liquor spray CFD model development, field testing at New Bern to establish modeling basis for validation and correlation, generation and evaluation of experimental spray data as a basis for validation of the spray model, field and laboratory investigations of green liquor and condensate scaling issues, field and laboratory characterization of gasifier green liquor dregs, conceptual and preliminary designs of improved hardware and instrumentation, select hardware for procurement, installation and process investigation in Phase II.

PHASE II - Implementation and evaluation of process improvements. This phase involves the final engineering, procurement, installation, and evaluation of equipment, materials and services required by the overall project. This phase includes installation of equipment and materials to perform field test programs on additional temperature measurement devices, gasifier burner nozzles and devices for optimized air distribution at burner inlet. Evaluation of alternative dregs treatment will be completed in the form of green liquor filtration tests. Data obtained will be summarized in a report to the DOE.

The reporting of the performed work is divided per task and sub-grouped further to give the best presentation of the work with all planning, information gathering, design/development, implementation/installation and evaluation in a sequence. The division into phase I and II is only mentioned when it adds understanding to the report.

\subsubsection{Phase II scope changes}

Due to internal budget constraints, DOE significantly reduced the budget for phase II of the project. As a result, the phase II scope was reduced and the work statement was up-dated. Based on the remaining budget and the outcomes of phase I work, the project team decided to focus the remaining effort on implementing low cost burner system improvements and limited green liquor dregs filtration trials.

Key scope eliminations of the phase II budget cuts were: fabrication and implementation of the indirect quench design, fabrication and installation of pilot short time contractor, and oxygen enrichment trials. Besides implementation cost and risk, elimination of the indirect 


\section{Final Technical Report Rev. 0 \\ DE-FC26-04NT42259}

quench was justified by the fact that the green liquor scaling problem had been mitigated during phase I by addition of a chemical additive (see later discussion).

\subsection{Participating Organizations}

In order to undertake the above tasks, Weyerhaeuser pulled together a team of key collaborators:

Weyerhaeuser New Bern Cellulose Fiber mill is the location the world's only commercial black liquor gasifier. The overall theme of the project was to use the Chemrec ${ }^{\mathrm{TM}}$ gasifier at New Bern as a test bed to advance the state of molten phase black liquor gasification. Weyerhaeuser's corporate R\&D resources provide overall project management and New Bern mill operations and maintenance personnel provided key support during field testing.

Chemrec AB (Stockholm, Sweden) is the developer and supplier of the gasifier technology used at New Bern. Besides the atmospheric pressure "booster" technology used at New Bern, Chemrec is also developing a pressurized, oxygen-blown version of the technology. The pressurized version of the technology offers improved efficiency and safety over traditional recovery boilers and provides a pathway to production of transportation grade fuels from black liquor. Chemrec currently have a 20 tonne/day (black liquor solids), 30 bar, oxygenblown pilot plant located at the Smurfit-Kappa mill in Piteå, Sweden. Given their keen interest in the project results, Chemrec were intimately involved in all project tasks. In particular, as the technology supplier, Chemrec were responsible for the design and implementation of Phase II improvements.

The Institute of Paper Science and Technology at Georgia Tech (Atlanta, GA) provided expertise in the development of the underlying black liquor gasification rate subroutines employed in the CFD code. IPST researchers also conducted fundamental investigations on scaling and plugging mechanisms and characterization of green liquor dregs and evaluated mass and energy balance closures in the field tests.

Process Simulation, Ltd (Vancouver, BC) has a background in developing and applying CFD models for black liquor recovery boilers. PSL had previously developed a first-pass CFD model of the New Bern gasifier. They were responsible for the overall development of an integrated gasifier CFD code. This included incorporating IPST developed gasification rate subroutines and black liquor spray model results from Simulent, as well as validation and correlation of the model to the field test results.

Simulent, Ltd. (Toronto, ON) has experience developing and applying CFD models for spray atomizers. Simulent's work focused on the development CFD modeling the black liquor nozzle and description of the black liquor spray. Simulent utilized experimental spray results 
Final Technical Report Rev. 0

DE-FC26-04NT42259

provided by ETC to validate the spray model and worked closely with PSL on a technique to pass spray modeling results into PSL's integrated gasifier model.

The Gas Technology Institute (GTI, Des Plaines, IL) filled a critical need in the gasifier field testing by providing a detail analysis of the product gas composition exiting the gasifier. GTI work was sponsored under a separate DOE funded project (DE-FC36-03GO13175).

The Swedish Energy Technology Centre (ETC, Piteå, Sweden) participated as subcontractor to Chemrec AB. Chemrec's black liquor spray facility is located at and operated by ETC. Experimental spray data generated at ETC were used to validate Simulent's CFD spray model. ETC also developed CFD models for flows inside the existing black liquor nozzles and were responsible for two of the nozzle concepts fabricated and tested during phase II of the project. 
Final Technical Report Rev. 0

DE-FC26-04NT42259

\section{Task 1 - The development of and correlation of CFD modeling tools to the New Bern demonstration facility}

The overall objective of Task 1 was develop CFD modeling tools to enable prediction of key gasifier performance parameters as a function of operating conditions and burner design. PSL developed an integrated CFD model of the gasifier reactor which included: the extraction and incorporation of relevant fundamental experimental data into the gasification rate subroutines developed by IPST, incorporation of a black liquor droplet generation sub-model, enhancements to the liquor-droplet tracking, and treatment of droplets impacting on the refractory lined wall. Simulent developed a CFD model of the black liquor sprays giving detail description of droplet size distributions and trajectories as a function of nozzle geometry and operating conditions. Experimental nozzle tests were conducted at Chemrec's spray facility at ETC to serve as a basis for validating Simulent's black liquor spray submodel. PSL and Simulent worked closely together on a technique to transfer data between Simulent's spray model and PSL's reactor model. A field test matrix, developed in collaboration with the modelers, was conducted on the New Bern gasifier. The test matrix was simulated in the CFD models thereby developing correlations between model predictions and the actual gasifier operation.

In addition to the above modeling work, new concepts for reactor temperature measurement were developed, procured, and field tested.

\subsection{Summarized Task 1 accomplishments \& conclusions}

The key achievement under Task 1 was the development and "validation" of CFD models of the gasifier reactor and black liquor sprays. These models incorporate sufficient complexity to reproduce the overall trends in the gasifier performance. The application of these tools lead to an increased understanding for the reactor flow patterns and how they are impacted by the burner spray and air supply. The models can and have been used to evaluate different burner design concepts that were fabricated and tested in Task 2.

In terms of correlating CFD model predictions to field test results and system material-energy balances, the project team encountered a number of significant challenges, both in measurement as well as in modeling activities. Field measurements of liquor and air flow rates had to be changed significantly to make material and energy balances work out. The requirement for these changes introduced some uncertainty in these parameters. Modeling of the field test matrix cases has shown how difficult it is to get a direct one to one agreement between the measurement results and the modeling predictions. The reasons for this include uncertainty in the measurements, as well as representation of the physics in the sub-models for the flow, liquor chemistry and sprays. 
Final Technical Report Rev. 0

DE-FC26-04NT42259

Nozzle spray modeling and validation share the same achievements and challenges as for the overall reactor modeling. Incorporating a detail spray model into the overall reactor model provided a key project benefit: i.e., by comparing model results for the "actual" nozzle to a theoretical "ideal" nozzle, a window of opportunity for improvement based on nozzle changes has been demonstrated. This provides a target toward which burner nozzle development can strive.

Three new temperature measurement systems were designed. Two of these were fabricated and one of these is undergoing field testing in the New Bern gasifier. It has seen about 8000 hrs of operation through October 2008. Reliability is comparable with the current air purged type thermocouple. Time will tell whether a significant improvement in reliability has been achieved. The new design is more responsive and indicates a somewhat higher temperature than the air purged type design.

\subsection{Establishing a baseline field test matrix}

\subsubsection{Test Plan \& implementation}

Two weeks of field trials were conducted during the summer of 2005 to serve as the foundation for validation and correlation of the CFD modeling tools. Additional goals were to eliminate "anecdotal" accounts of gasifier performance and to provide additional data on stream compositions and flows for Tasks 3 and 4.

Key controlled parameters during the trial period included:

- Black liquor firing rate (baseline target 620,000 black liquor solids rate)

- Air-to-fuel ratio (baseline target 1.95 based on measured values)

- Steam-to-fuel ratio (125 psig baseline pressure)

- Swirl register setting ( $100 \%$ damper position for baseline)

- Liquor firing temperature (baseline $246^{\circ} \mathrm{F}$ )

Key dependent variables for correlation with CFD models included:

- Unburned carbon (Total Suspended Solids, TSS, in GL as \% of carbon in BL)

- Gasification zone exit temperature (based on air-purged thermocouple measurements)

- Product gas analysis - Continuous monitoring of $\mathrm{CO}, \mathrm{CO}_{2}, \mathrm{H}_{2}, \mathrm{H}_{2} \mathrm{~S}, \mathrm{CH}_{4}$, higher hydrocarbons

Other beneficial data in support of Tasks 3 and 4 included:

- Black liquor elemental analysis 
Final Technical Report Rev. 0 DE-FC26-04NT42259

- Green liquor quality; i.e. Imhoff cone test (settled dregs), TTA (Total Titratable Alkali)

- Dregs samples for characterization; e.g., particle size distribution, chemical composition, SEM

- Condensate and green liquor samples for composition analysis; e.g. tars, $\mathrm{Ca}$

- Product gas analysis before and after scrubber; $\mathrm{H}_{2} \mathrm{~S}, \mathrm{CO}_{2}$, hydrocarbons

The basic test conditions are shown in Table 3-1. The values in the table are measured values based on mill instrumentation. The average black liquor composition over the test period is given in Table 3-2.

\begin{tabular}{|c|c|cc:c|}
\hline Date & Target Condition & $\begin{array}{c}\text { BL flow } \\
\text { BLS/d }\end{array}$ & $\begin{array}{c}\text { Air/Fuel } \\
\text { psig }\end{array}$ \\
\hline 13-Jun-05 & Baseline & 617000 & 1.95 & 125 \\
\hline 14-Jun-05 & Low A/F & 619000 & 1.80 & 125 \\
\hline 15-Jun-05 & Low firing rate & 373000 & 1.92 & 125 \\
\hline 16-Jun-05 & High firing rate + low A/F & 689000 & 1.86 & 125 \\
\hline 17-Jun-05 & High firing rate & 680000 & 1.96 & 125 \\
\hline 20-Jun-05 & Baseline repeat & 628000 & 1.93 & 125 \\
\hline 21-Jun-05 & Reduce Swirl position to 70\% & 629000 & 1.92 & 125 \\
\hline 22-Jun-05 & Reduce atomizing steam press. & 622000 & 1.95 & 110 \\
\hline 23-Jun-05 & Lowest A/F & 615000 & 1.66 & 125 \\
\hline 24-Jun-05 & Incr atm stm press @ low A/F & 623000 & 1.66 & 145 \\
\hline
\end{tabular}

Table 3-1 10-day field test matrix

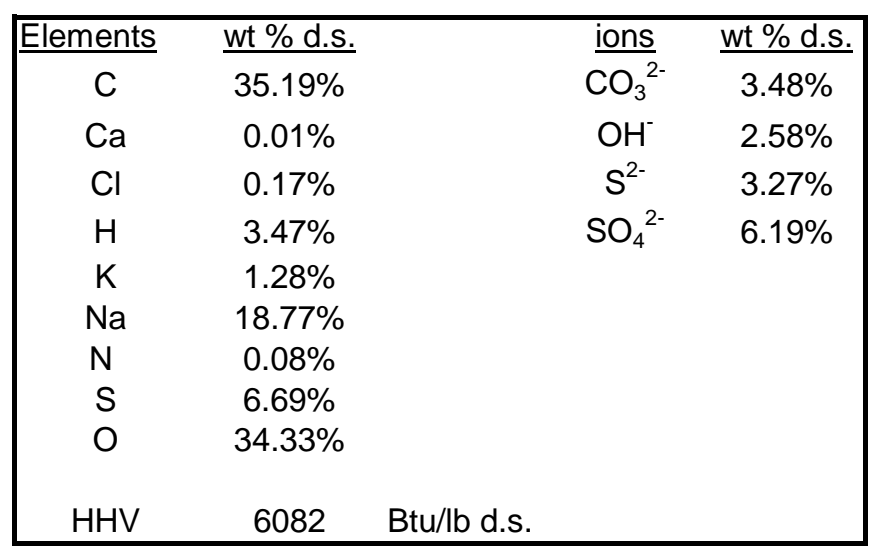

Table 3-2 Average black liquor composition for 10-day trial period

\subsubsection{Gas sampling and analysis - GTI contribution}

Gas Technology Institute, resources filled a critical need in implementation of the gasifier "test matrix" by providing detail analysis of the product gas. GTI's gas analysis data were 
Final Technical Report Rev. 0 DE-FC26-04NT42259

reported to Weyerhaeuser and IPST and were a key part of the material and energy balance calculations. GTI's work was supported under a separate DOE project DE-FC36-03GO13175.

GTI set-up a sophisticated product gas sampling system downstream of the venturi scrubber and upstream of the product gas scrubber column. This is a particularly challenging location because the product gas at this location contains between $60-70 \%$ moisture content (wet basis). A detail description of the GTI sampling system is attached in Appendix 1.

\subsubsection{Phase I Material \& Energy balances}

A significant effort was devoted to establishing mass and energy balances around the gasifier and quench to provide a basis for correcting measured black liquor and air flows and to reconcile differences between measured reactor temperature and exit gas compositions. This was needed to develop a self-consistent set of input parameters for the CFD modeling work and a meaningful data set for model comparison.

\subsubsection{Corrections to measured values}

Preliminary mass balances using the analytical data and mill measurements resulted in significant imbalances for calcium, carbon, sodium, and sulfur. For these four elements, the inlet flows were apparently $10-30 \%$ higher than the outlet flows. Because black liquor is the primary input source for these elements, it was concluded that the measured black liquor flow rate was too high.

Figure 3-1 shows the correlation between the measured black liquor flow rate and the black liquor flow rate calculated by sodium balance. This comparison suggested that the measured black liquor flow was about $10 \%$ too high. This was confirmed during a subsequent outage when the flow meter instrumentation indicated a positive flow when the black liquor supply was turned off. 
Final Technical Report Rev. 0

DE-FC26-04NT42259

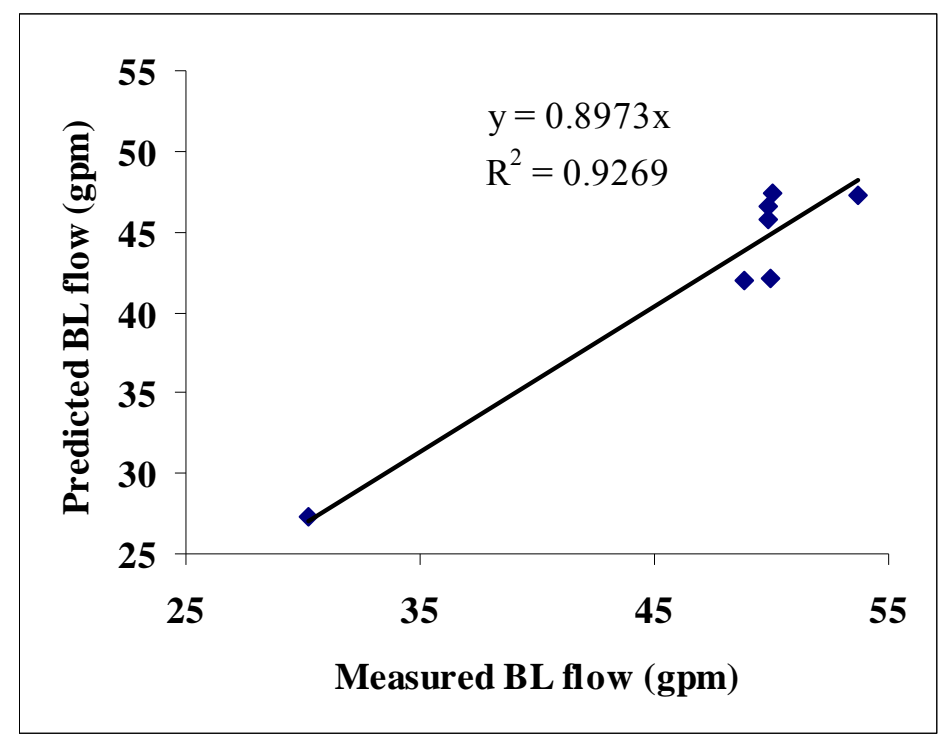

Figure 3-1 Black liquor flows, calculated based on sodium balance vs. measured values

Adjusting the black liquor flow to lower values based on the sodium balance did improve the carbon balance, but the flow of carbon out of the gasifier was still significantly less than the flow in. It was determined that the likely source of this error was a higher air flow into the gasifier than the measured value corrected by an established correlation. By working backwards from the measured product gas flow rate and using nitrogen as a tie-component, the calculated air flow rate into the gasifier was determined to be closer to the "raw" mass flow meter reading rather than the "corrected" air flow rate compensated for temperature and pressure.

These calculations suggested that the actual gasifier temperature was considerably higher than measured by the reactor thermocouple during the mill trials in June 2005. The reactor outlet temperature and inlet air flow rate were therefore determined by using an energy balance. The energy balance was based on the measured condensate flow from the cooling section of the scrubber, which is a direct measure of how much water is evaporated in the quench. Iterative calculations were made using the thermodynamic calculations to correlate air:fuel ratio to temperature, Figure 3-2. 
Final Technical Report Rev. 0 DE-FC26-04NT42259

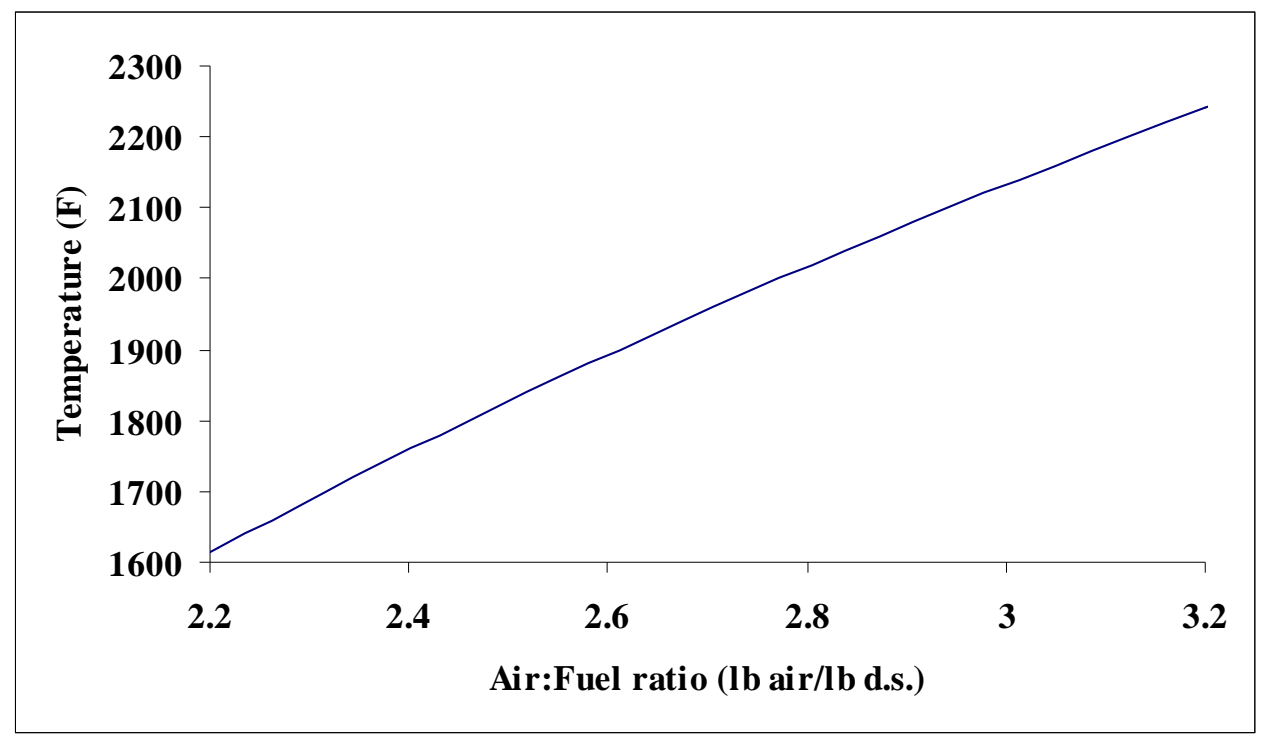

Figure 3-2 Theoretical flame temperature vs. air:fuel ratio

The average black liquor composition based on analysis of the black liquor composite samples from each of the 10 test days (Table 3-2) and an assumed heat loss from the reactor of $500 \mathrm{~kW}$ were used for the thermodynamic calculations. The relationship between the calculated air flow rate and the measured "corrected" air flow rate is given in Figure 3-3. Based on this correlation, the secondary airflow was about $30 \%$ higher than the "corrected" measured value. The validity of this correction seemed to be confirmed by experience during the June 17 high firing rate trial. During this trial the secondary blower was running at it's maximum capacity of $72 \mathrm{kpph}$ which is the value given by the correlation in Figure 3-3. 
Final Technical Report Rev. 0 DE-FC26-04NT42259

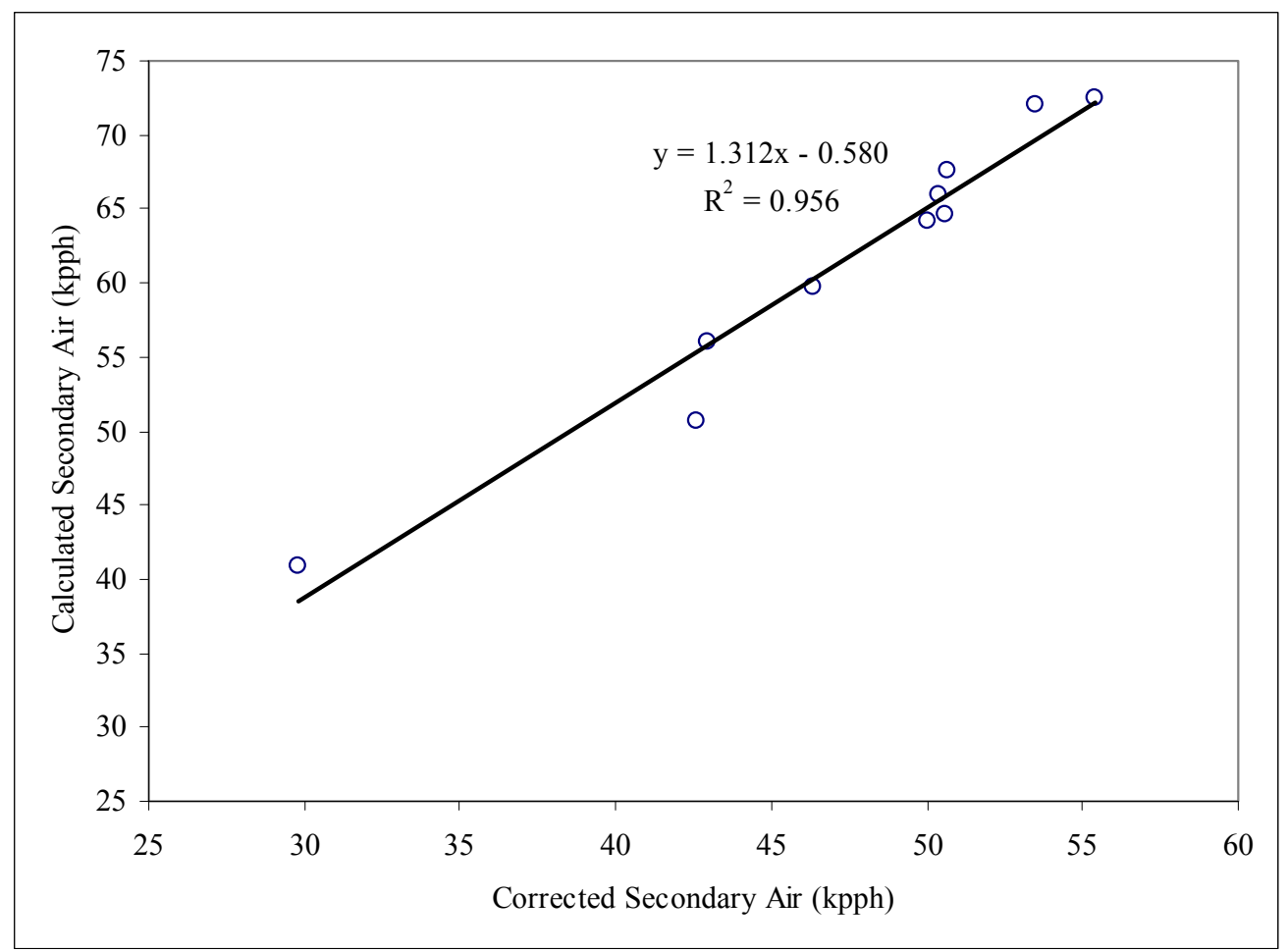

Figure 3-3 Calculation for secondary air based on energy balance around the gasifier and cooling section of the scrubber

\subsubsection{Mass balance closure}

The final mass balances closure for $\mathrm{Na}, \mathrm{C}, \mathrm{S}, \mathrm{Ca}$ and $\mathrm{V}$ are presented in Table 3-3. Samples were analyzed for vanadium only on $6 / 20$ and sulfur was not obtained in the gas phase analysis on 6/13, but analysis for the other species, $\mathrm{Na}, \mathrm{C}$ and $\mathrm{Ca}$ analyses were performed on all relevant samples from the ten trial days in the test matrix. These closure values are based on the average black liquor composition given earlier in Table 3-2, a corrected black liquor flow rate of $89.7 \%$ of the measured (see above), an air flow rate calculated using the equation in Figure 3-3, and the scrubber exit gas compositions (except for sulfur). The other flows around the gasifier were used as measured. Also, the other analytical data were not averaged across the trial days. The balances for $\mathrm{C}, \mathrm{Na}, \mathrm{S}$ and $\mathrm{V}$ were $\pm 7 \%$ or better except for $\mathrm{S}$ on $6 / 14$. The Ca balances were consistently low. 
Final Technical Report Rev. 0 DE-FC26-04NT42259

\begin{tabular}{|c|c|c|c|c|c|c|}
\hline \multirow[b]{2}{*}{ Date } & \multirow[b]{2}{*}{ Condition } & \multicolumn{5}{|c|}{ Gasifier Balance (Out/In) } \\
\hline & & C & $\mathrm{Na}$ & $\mathrm{S}$ & $\mathrm{Ca}$ & $\mathrm{V}$ \\
\hline 13-Jun & Baseline & 1.03 & 0.99 & & 0.81 & \\
\hline$\overline{14}-\overline{-J u n}-$ & Low A $\bar{A} \bar{F}$ & $1 . \overline{01}$ & $0.9 \overline{4}$ & $0 . \overline{8}$ & $\overline{0} . \overline{6} \overline{1}$ & \\
\hline$\overline{15}-\mathrm{Jun}$ & Low firing rate & $0 . \overline{95}$ & 1.00 & $0 . \overline{9}$ & $0 . \overline{7} \overline{5}$ & \\
\hline$\overline{16}-\overline{J u n}$ & High firing rate & 1.02 & $0.9 \overline{3}$ & $\overline{1} . \overline{0}$ & $\overline{0} . \overline{7} \overline{8}$ & \\
\hline$\overline{17}-\overline{-J u n}$ & High firing rate-higher $\bar{A} / \bar{F}$ & 1.05 & $0.9 \overline{4}$ & $\overline{1} . \overline{3}$ & $\overline{0} . \overline{8} \overline{2}$ & \\
\hline 20-Jun & Repeat Baseline (week 2) & 1.02 & 1.03 & 0.97 & 0.80 & 0.94 \\
\hline$\overline{21}-\overline{J u n}$ & Reduce swirl to $70 \%$ & $0 . \overline{99}$ & 1.04 & $0 . \overline{6}$ & $\overline{0} . \overline{8} \overline{2}$ & \\
\hline$\overline{22}-\overline{J u n}$ & Reduce atomizing steam press & 1.01 & $0 . \overline{3}$ & $0 . \overline{9}$ & $\overline{0} . \overline{4} \overline{5}$ & \\
\hline $23-J u n$ & Lowest $\mathrm{A} / \overline{\mathrm{F}}$ & 0.99 & 0.97 & 1.03 & $0.7 \overline{4}$ & \\
\hline$\overline{24}-\overline{J u n}{ }^{-}$ & Increase $\overline{a t m}$ stm to $\overline{14} 5 \overline{\mathrm{ps}}$ & $0 . \overline{98}$ & $0 . \overline{94}$ & $0 . \overline{9}$ & $\overline{0} \overline{\overline{7}} \overline{3}$ & \\
\hline
\end{tabular}

Table 3-3 Gasifier balances (Out/In) for C, Na, S, Ca, V; vanadium was analyzed only on $6 / 20$

Initially it was planned to use calcium as the tie-element to complete mass balances on the various streams, but the closures for $\mathrm{Ca}$ were low. The majority of the calcium out of the gasifier is found in the green liquor dregs as $\mathrm{Ca}_{2} \mathrm{CO}_{3}$ (see Figure 3-4). The calcium imbalance may be due to accumulation of calcium scale in the system or in variations in the determination of dregs (total suspended solids, TSS). Duplicate measurements of TSS were made at 1 and 3 hours after a stable operating condition was reached. The difference between the highest and lowest measurement was typically about $15 \%$. Averages of the measured TSS were used, but the noted variation in this measurement could be a significant source of error in the $\mathrm{Ca}$ balance because $\mathrm{Ca}$ is a major component of the dregs. For future mass balances, vanadium appears to be a better tie-element to use to balance flows, as it is mostly found in the filtered green liquor rather than the dregs. 
Final Technical Report Rev. 0

DE-FC26-04NT42259

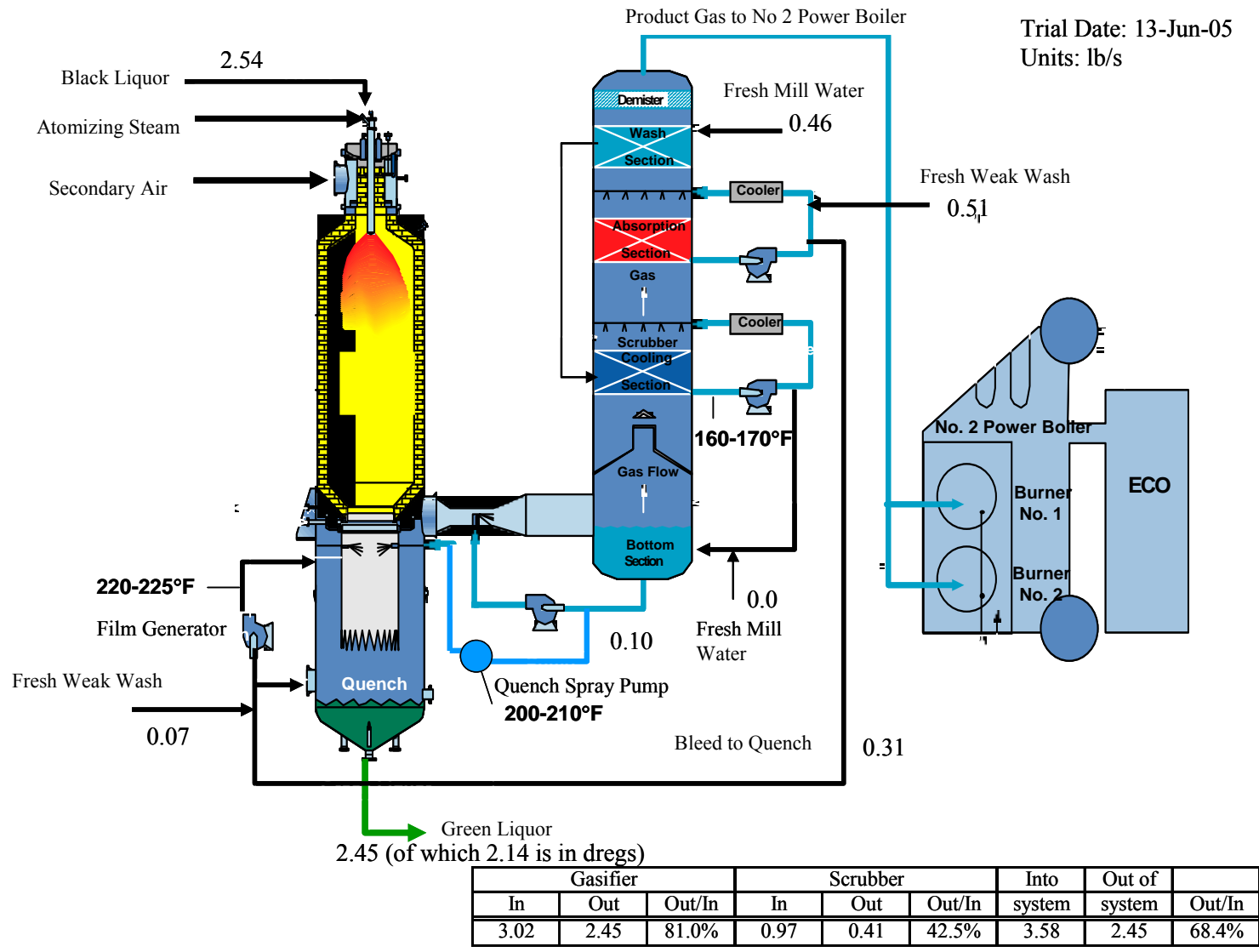

Figure 3-4 New Bern gasifier process schematic showing calcium balance for baseline test condition

\subsubsection{Measured Gasifier Products}

Variations in $\mathrm{CO}_{2} / \mathrm{CO}$ ratio and unburned carbon were noted during preliminary analysis of the trial data. This variation can largely be explained by the ratio of water to organic carbon fed to the gasifier, Figure 3-5. The $\mathrm{CO}_{2} / \mathrm{CO}$ ratio measured both at the venturi exit and scrubber exit are shown. The high concentration of fine spray in the venturi exit seems to have interfered with the gas analysis, resulted in more scatter of the data. The scrubber exit data follows a linear relationship much more closely. Since the scrubber removes relatively little $\mathrm{CO}_{2}$, the scrubber exit gas compositions are likely the more reliable estimate of $\mathrm{CO}_{2} / \mathrm{CO}$ ratio at the gasifier exit. Water enters the gasifier with the black liquor, air and atomizing steam. Steam was not adjusted as a function of firing rate so it had an impact on gas composition for the cases in which load was changed. For the baseline case on $6 / 20$, the steam represented $37 \%$ of the water entering the gasifier, while for the low firing rate case (6/15) it represented $48 \%$ and on the high firing rate cases it represented $36 \%$. 
Final Technical Report Rev. 0

DE-FC26-04NT42259

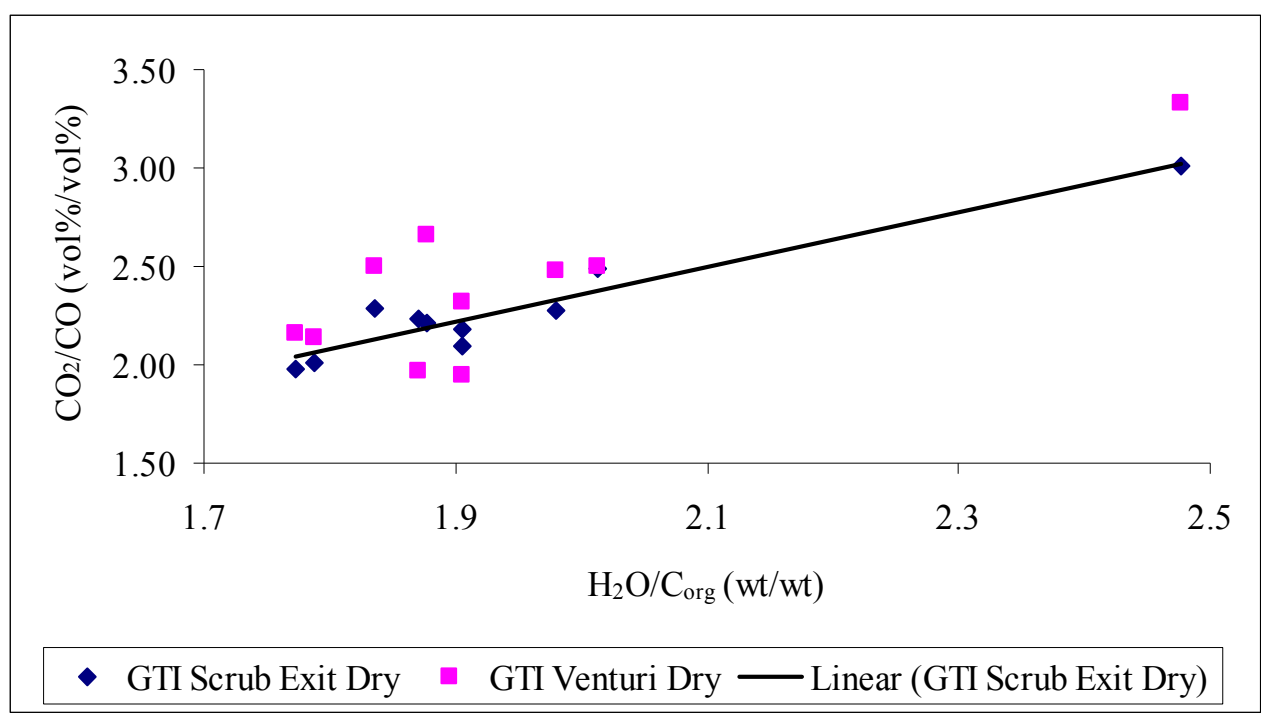

Figure 3-5 $\mathrm{CO}_{2} / \mathrm{CO}(\mathrm{vol} \% / v o l \%)$ in gasifier product vs. $\mathrm{H}_{2} \mathrm{O} / \mathrm{Corg}(\mathrm{lb} / \mathrm{lb})$ in gasifer feed, based on the GTI gas analysis

Figure 3-6 shows the molar flow rates for the product fuel gases $\mathrm{H}_{2}, \mathrm{CO}$ and $\mathrm{CH}_{4}$. On a mass basis, $\mathrm{CO}$ is the dominant constituent, but on a molar basis it is $\mathrm{H}_{2}$. As can be seen in Figure $3-6$, there is good agreement between the two baseline cases. Note that the data in Figure 3-6 are presented in a different sequence from the chronological trial order.

Calculations were made to compare the fraction of organic carbon fed to the gasifier that remains as unburned carbon in the green liquor dregs, Figure 3-7. As can be seen, the baseline conditions were repeatable and the amount of unburned carbon was less than $0.2 \%$. However, the amount of unburned carbon was significantly higher for the lowest air flows, high firing rate and reduced swirl cases. The firing rate of the gasifier is clearly limited by both the blower for the secondary air and the residence time in the gasifier which is insufficient to allow complete burnout of the carbon at high throughput. 
Final Technical Report Rev. 0

DE-FC26-04NT42259

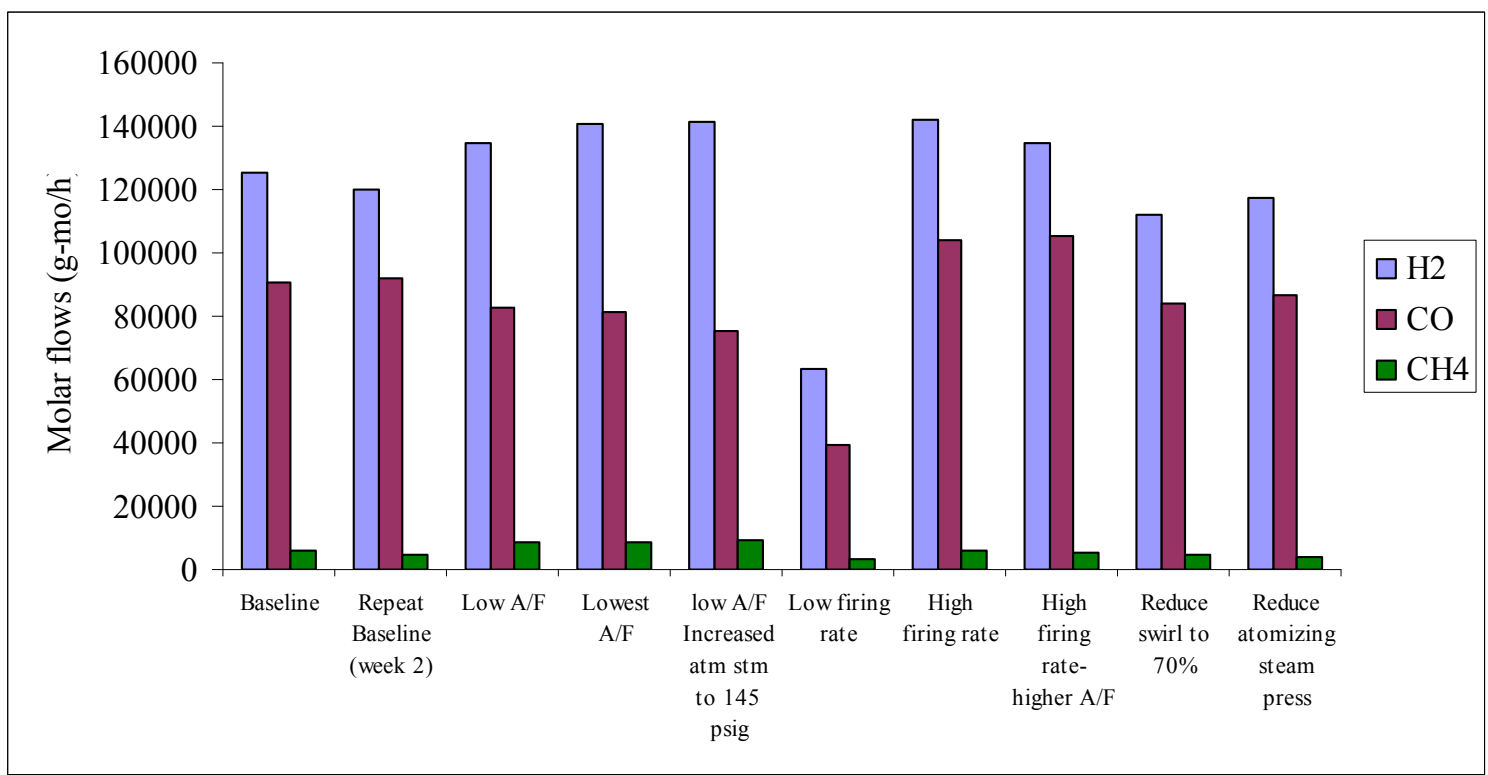

Figure 3-6 Molar flows (lb/h) of $\mathrm{H}_{2}, \mathrm{CO}$ and $\mathrm{CH}_{4}$ for the various conditions

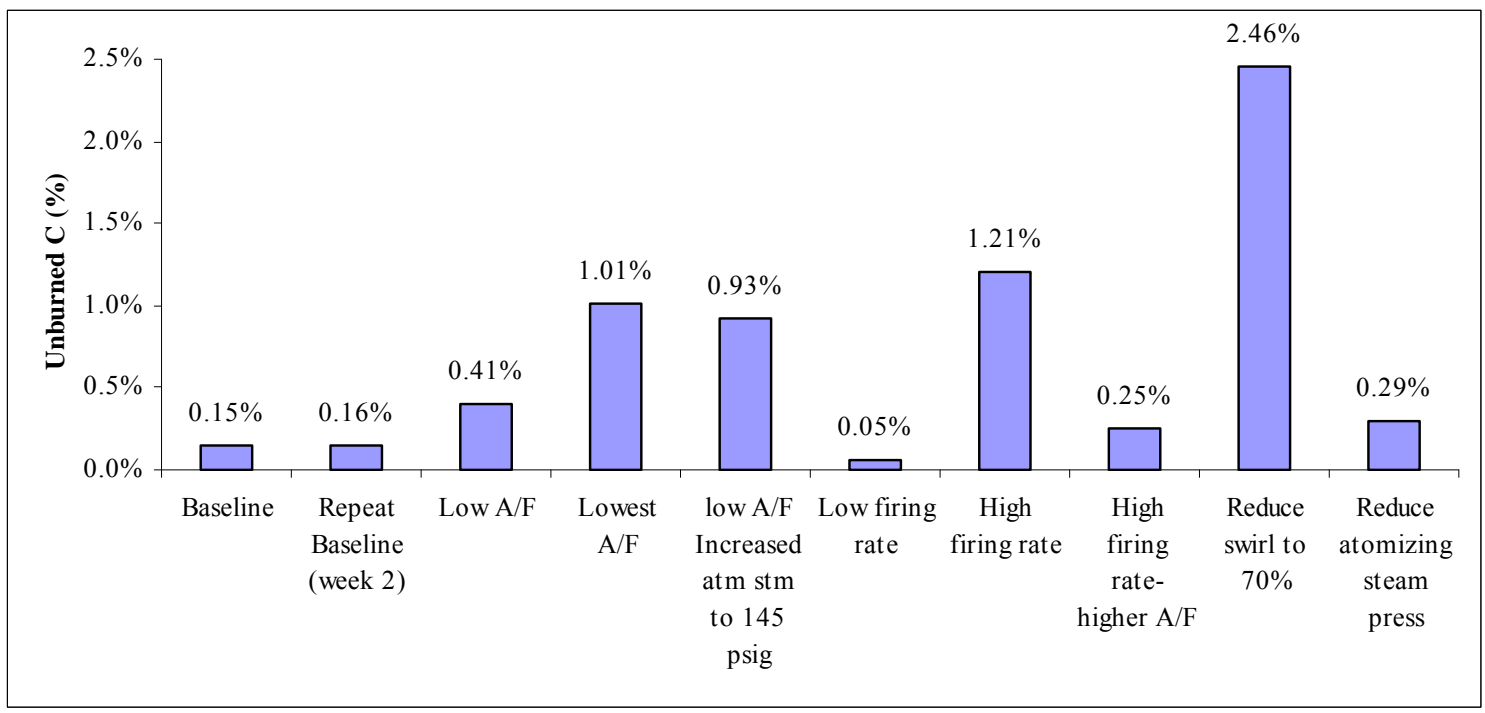

Figure 3-7 Unburned $C$ as a percentage of organic carbon fed to the gasifier.

\subsubsection{Phase II material balance work}

Additional material balances were completed as part of the phase II nozzle testing activities. The results are presented below. Note that the corrections to the black liquor and air flow measurements used in phase I were not applied in the phase II data reported below. 
Final Technical Report Rev. 0

DE-FC26-04NT42259

\subsubsection{Overall material balance - from Nozzle test period February/March 2007}

To be able to draw correct conclusions from experiment with different nozzles and to improve the overall operations of the plant mass balances calculations need to be accurate within certain limits. IPST carried out measurements during the February/March 2007 nozzle trials which gave increased insight into the matter and lead to calibration and maintenance work on some of the instruments.

The elementary composition of the fired black liquor during the test period is shown in Table 3-4.

\begin{tabular}{cc}
\hline Species & wt-\% DS \\
\hline $\mathrm{C}$ & 34.9 \\
$\mathrm{Ca}$ & 0.015 \\
$\mathrm{Cl}$ & 0.14 \\
$\mathrm{H}$ & 3.3 \\
$\mathrm{~K}$ & 1.48 \\
$\mathrm{Na}$ & 18.9 \\
$\mathrm{~N}$ & 0.18 \\
$\mathrm{~S}$ & 6.38 \\
$\mathrm{O}$ & 34.7 \\
$\mathrm{HHV}$ & 6,030 BTU/lb D.S. \\
\hline
\end{tabular}

\section{Table 3-4 Black liquor composition for Feb/Mar 2007 test period}

GTRC and Chemrec took samples of black liquor, green liquor, formed condensate and circulating weak wash. All samples are analyzed for carbonaceous compounds to estimate carbon conversion. For a smaller number of test points, gas samples were withdrawn in steel containers. Sampling set-up was arranged by URS and they were responsible for delivery and pick up of containers within a stated time period for the canisters. Bottles were filled by Chemrec staff. Gas analysis is made for the dominant species in the gas: $\mathrm{CO}, \mathrm{CO}_{2}, \mathrm{H}_{2}, \mathrm{~N}_{2}, \mathrm{O}_{2}$, $\mathrm{CH}_{4}$ and $\mathrm{H}_{2} \mathrm{~S}$.

Nitrogen and carbon balances were made. An illustration of the work is given in Figure 3-8 showing the material balance for measurements done Feb 20. These data are combined with three other data gathering occasions in Table 3-5 and 3-6. Table 3-5 shows the nitrogen balances and Table 3-6 the carbon balances. Nitrogen balances agrees reasonable well ( $0.5-$ $4 \%$ difference between in and out) while carbon balances show a larger deviation (about 4-8\% difference between 
Final Technical Report Rev. 0

DE-FC26-04NT42259

Trial Date: 20-Feb-07

Trial Time:9:00

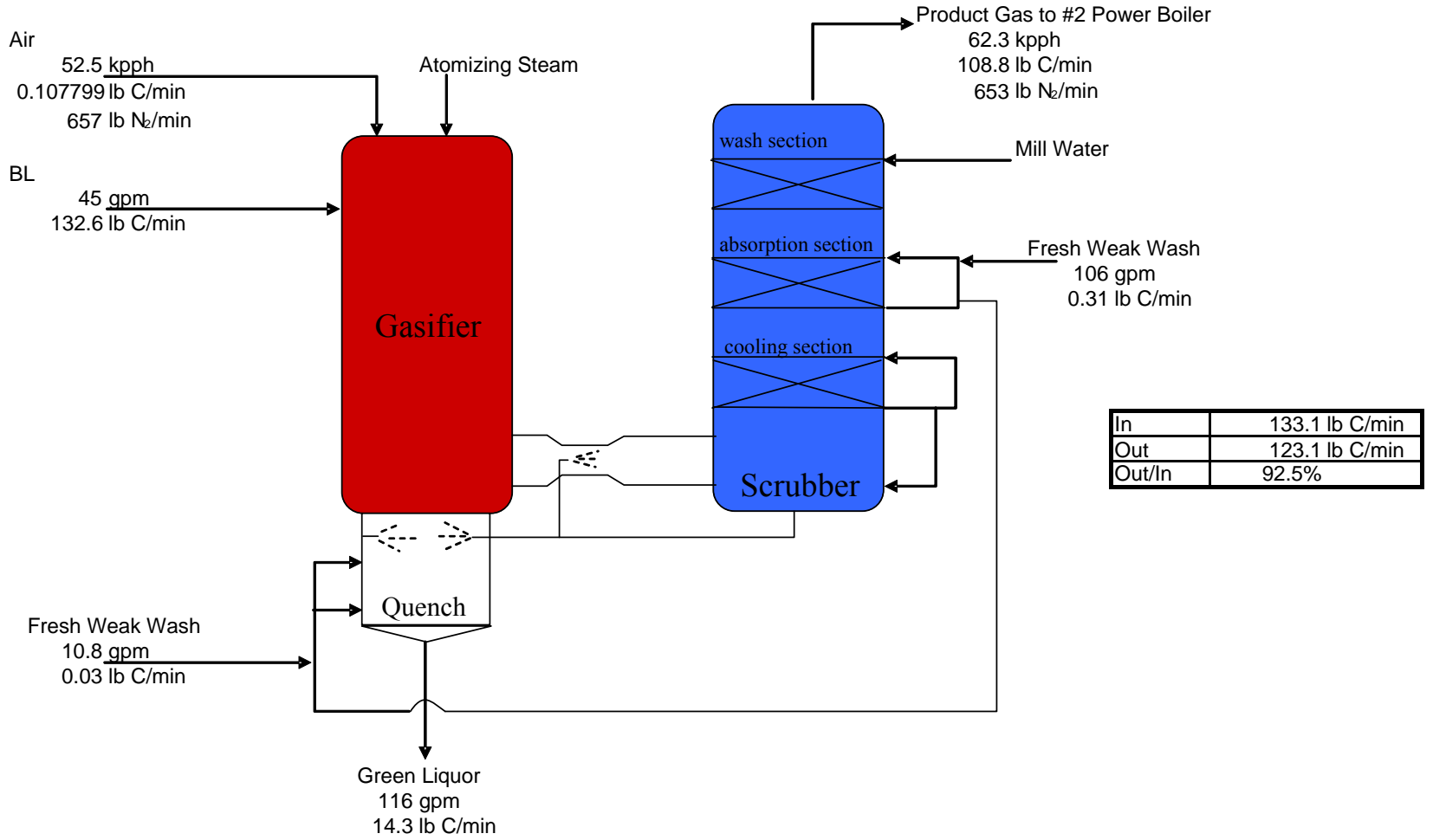

Figure 3-8 Carbon and N2 mass balance for Feb. 20, 2007 trial run at 9:00 am

\begin{tabular}{|c|c|c|c|c|}
\hline $\begin{array}{l}\text { Date } \\
\text { Time }\end{array}$ & $\begin{array}{c}\text { 19-Feb-07 } \\
8: 30\end{array}$ & $\begin{array}{c}\text { 20-Feb-07 } \\
9: 00\end{array}$ & $\begin{array}{c}\text { 21-Feb-07 } \\
12: 45\end{array}$ & $\begin{array}{c}\text { 27-Mar-07 } \\
13: 00\end{array}$ \\
\hline & Ib N $N_{2} / \mathrm{min}$ & lb $\mathrm{N}_{2} / \mathrm{min}$ & $\mathrm{Ib} \mathrm{N} / \mathrm{min}$ & $\mathrm{lb} \mathrm{N} / \mathrm{min}$ \\
\hline In & 630.7 & 657.0 & \begin{tabular}{|l|}
609.4 \\
\end{tabular} & 596 \\
\hline Oüt & 608.5 & 653.5 & 597.8 & 572 \\
\hline Out/In & $96.5 \%$ & $99.5 \%$ & $98.1 \%$ & $96.0 \%$ \\
\hline
\end{tabular}

Table 3-5 Nitrogen flows with the inlet air (uncorrected) and outlet gas based on outlet gas analysis. 
Final Technical Report Rev. 0

DE-FC26-04NT42259

\begin{tabular}{|c|c|c|c|c|}
\hline $\begin{array}{l}\text { Date } \\
\text { Time }\end{array}$ & $\begin{array}{c}19-F e b-07 \\
8: 30\end{array}$ & $\begin{array}{c}20-F e b-07 \\
9: 00\end{array}$ & $\begin{array}{c}21-F e b-07 \\
12: 45\end{array}$ & $\begin{array}{r}27-M a r-07 \\
13: 00\end{array}$ \\
\hline In & lb C/min & $\mathrm{lb} \mathrm{C} / \mathrm{min}$ & $\mathrm{lb} \mathrm{C} / \mathrm{min}$ & lb C/min \\
\hline Black Liquor & 126.7 & 132.6 & 132.2 & 129.6 \\
\hline Air & $0 . \overline{1}$ & $\overline{0} . \overline{1}^{-}$ & $0 . \overline{1}$ & $0 . \overline{1}$ \\
\hline Weak Wash & 0.4 & $\overline{0} \overline{3}$ & 0.4 & $0 . \overline{4}$ \\
\hline Total in & 127.2 & 133.1 & 132.7 & 130.1 \\
\hline Out & $\mathrm{Ib} \mathrm{C} / \mathrm{min}$ & $\mathrm{Ib} \mathrm{C} / \mathrm{min}$ & $\mathrm{Ib}$ C/min & $\mathrm{lb} \mathrm{C} / \mathrm{min}$ \\
\hline Green Liquor & 14.0 & 14.3 & 15.8 & 17.5 \\
\hline Product Gas & $10 \overline{1} \overline{1}$ & $1 \overline{0} . \overline{8}$ & $\overline{1} 0 \overline{7} . \overline{3}$ & $105 \overline{7}$ \\
\hline Total out & 122.1 & 123.1 & 123.0 & 123.2 \\
\hline Out/In & $\overline{96.0 \%}$ & $\overline{\overline{92.5 \%}}$ & $\overline{92.7 \%}$ & $\overline{94.7 \%}$ \\
\hline
\end{tabular}

Table 3-6 Carbon balance around the gasifier and scrubber.

The total carbon in the gas stayed fairly constant during the tests, also when data before and after the mill shut down are compared (this took place between the February 21 and March 27). The results indicate that the black liquor flow meter reads too high (same as previously indicated for the June 2005 tests). The presented data do not include any instrument data corrections as was the case in the June 2005 plant trials.

\subsubsection{Overall material balance - from Nozzle test period February/March 2008}

To draw correct conclusions from experiments with different nozzles and to improve the overall operations of the plant, mass balances calculations need to be accurate within certain limits. IPST carried out measurements during the February/March 2008 nozzle tests in New Bern. Results are included in the Appendix 2. A continuous material balance based on hourly data can also be made based on mill instruments. This method does not allow for various substance splits. Figure 3-9 shows the material balance based on the hourly averages from mill instruments during a period when the Std 18T and the ETC nozzle were tested. As demonstrated in the Figure 3-9, these basic mass balances demonstrate very good closure. 
Final Technical Report Rev. 0

DE-FC26-04NT42259

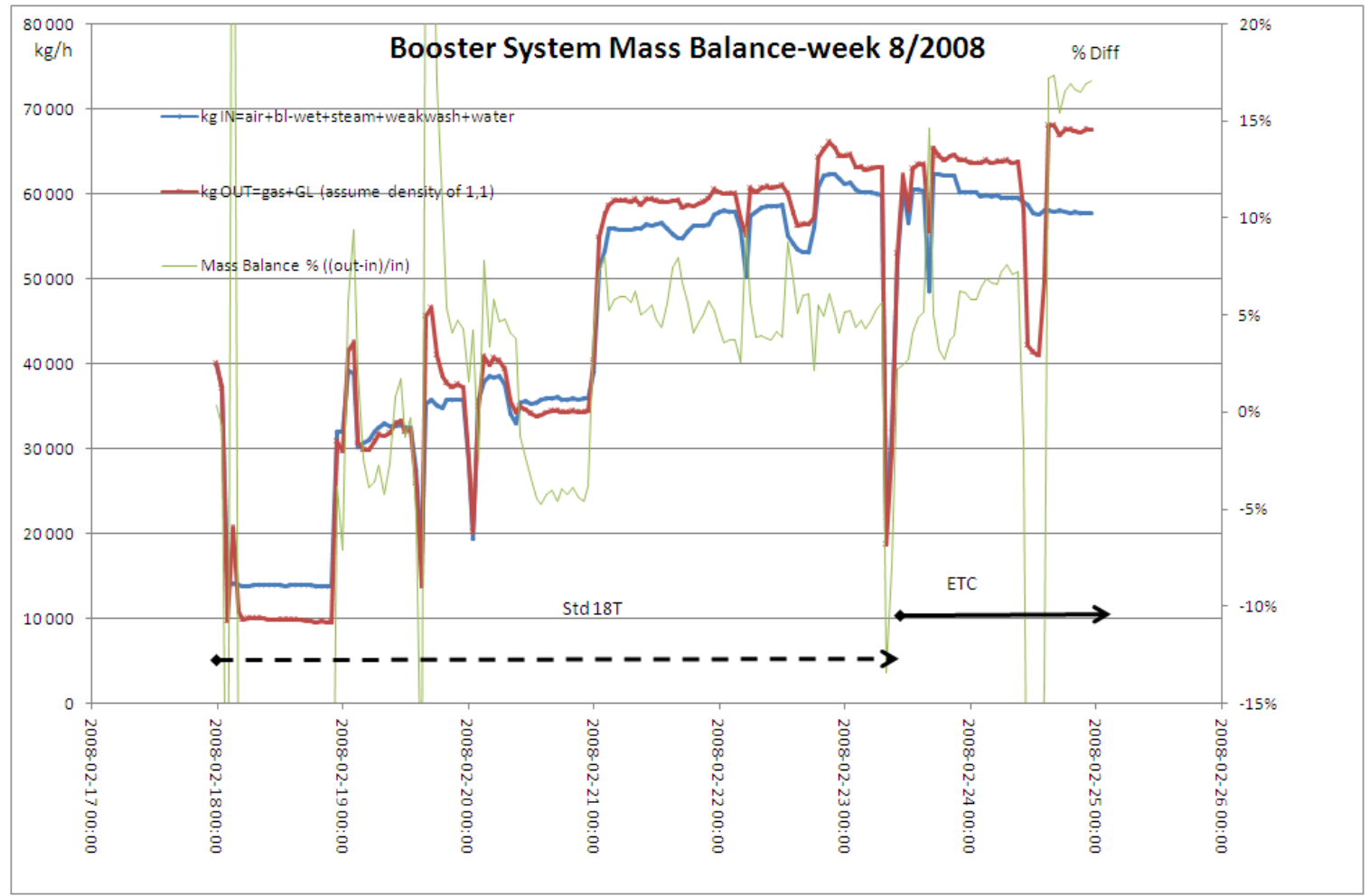

Figure 3-9 Overall mass balance based on mill instrument - week of Feb 17, 2008

Note that the sign on the closure is load sensitive. At the lower load more material is indicated to enter the system than what is encountered in the exit streams. As the load increases this situation reverses to encountering more in the exit than in the entering streams.

\subsubsection{Air to fuel ratio impact on gasifier performance}

One important result of the detailed mass and energy balance calculations is that the actual operating air:fuel ratio and thus the gasifier temperature are significantly higher than measured at the mill. This result has several implications. Running at a lower air:fuel ratio will improve process efficiency and should also help increase the life of the refractory lining by reducing the reactor temperature.

However, there are limitations on how low the air:fuel ratio can be dropped at a given black liquor firing rate without causing problems in downstream processes due to incomplete carbon conversion in gasifier. When air to fuel ratio was dropped during the mill trials in June 2005, two things occurred in the product green liquor: 1) the total suspended solids in the green liquor increased (Figure 3-10), and 2) the settling rate of these solids decreased. 
Final Technical Report Rev. 0

DE-FC26-04NT42259

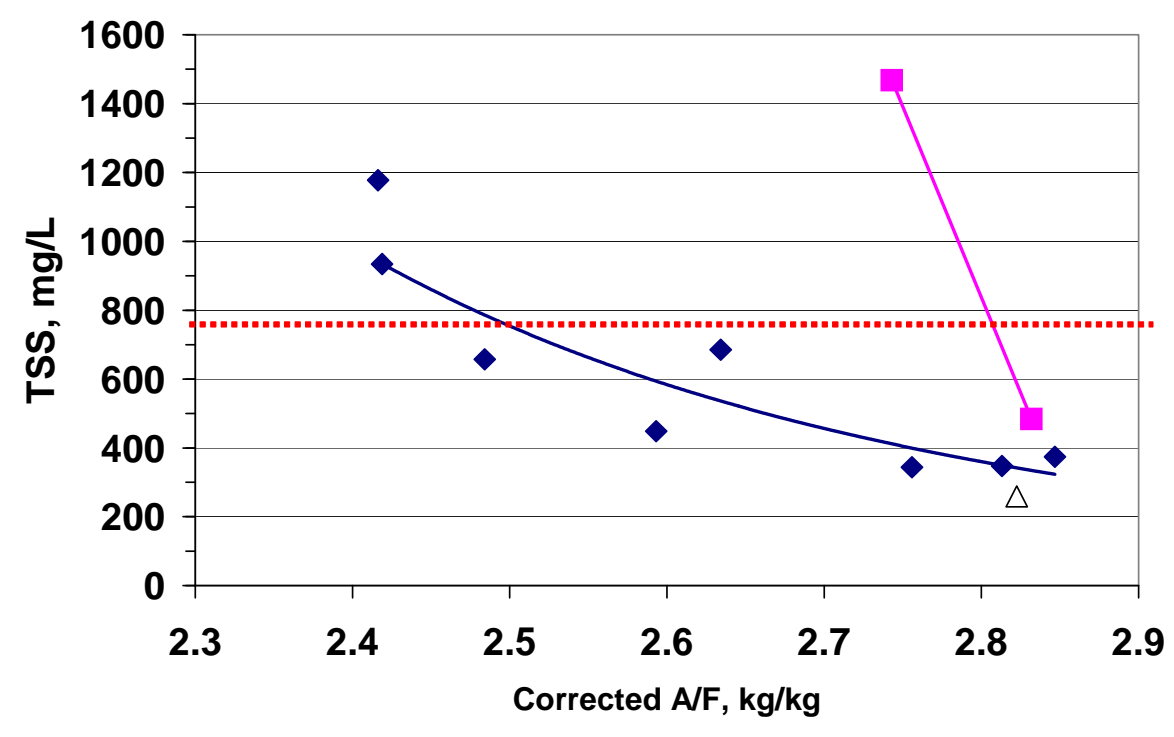

- Baseline Firing Rate $\square$ High Firing Rate $\triangle$ Low Firing Rate

Figure 3-10 TSS as function of air to fuel ratio

Total unburned carbon leaving the gasifier boundary was estimated from the average raw green liquor flow rate, the measured TSS values, and the unburned carbon content of the dregs samples. Figure 3-11 shows the unburned carbon loss with green liquor as a function of load and air/fuel ratio. Mill experience indicates that gravity settling in clarifier tanks is not effective at conditions forming high levels of low-density dregs (region above the dotted horizontal line in Figures 3-10 and 3-11). The practical implication for current operation is that the air/fuel ratio must be maintained at greater than 2.5 at base load conditions and greater than 2.8 at highest load. 
Final Technical Report Rev. 0

DE-FC26-04NT42259

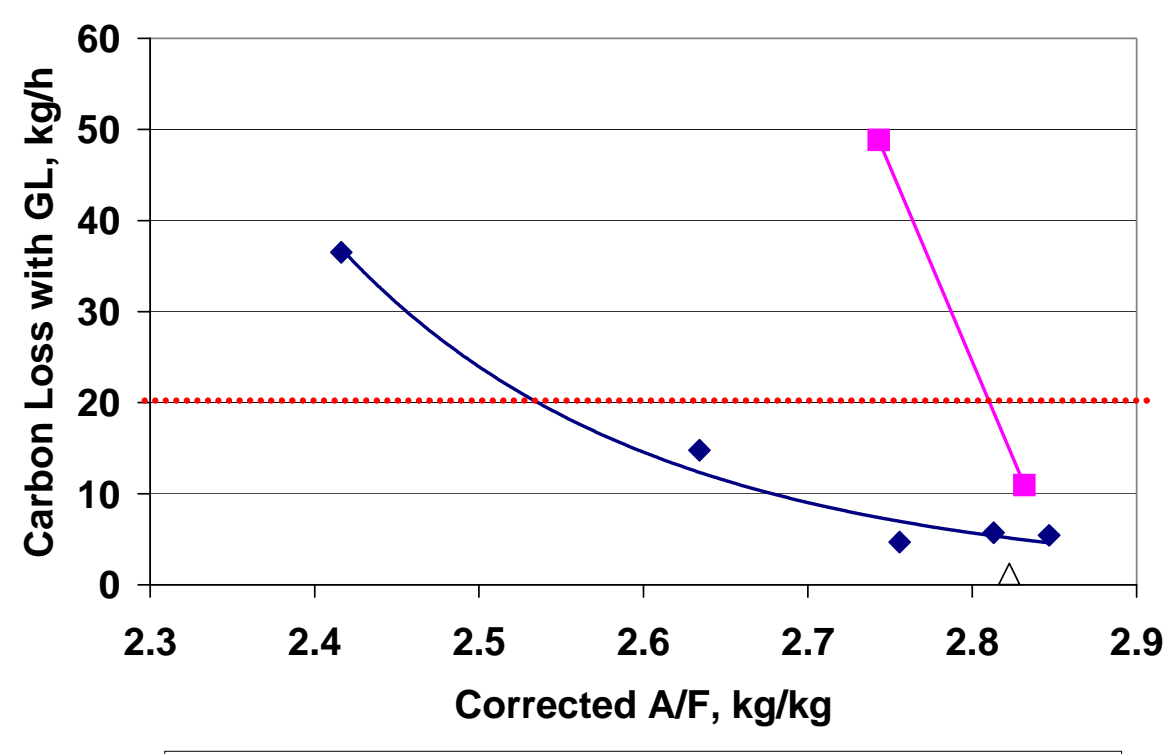

- Baseline Firing Rate $\quad$ High Firing Rate $\triangle$ Low Firing Rate

Figure 3-11 Carbon loss as function of air to fuel ratio

\subsection{New Bern gasifier CFD model development}

\subsubsection{PSL CFD gasifier reactor model}

Process Simulation, Ltd. had overall responsibility for development and application of a CFD model describing the New Bern gasifier. In order for PSL to be successful, Weyerhaeuser recognized it would be necessary bring together and coordinate inputs from a variety of sources. In particular, the Institute of Paper Science and Technology at Georgia Tech provided critical input on the underlying gasification rate equations, Simulent Ltd. provided detail descriptions of the black liquor spray, and Chemrec provided key reactor dimensional information and process descriptions. PSL incorporated this input into their CFD modeling code and then demonstrated reasonable correlation between the model predictions and gasifier performance as measured in the field test matrix. Once "validated," PSL's gasifier model was used to evaluate potential upgrades to the gasifier burner system.

\subsubsection{Black liquor gasification rate sub-models}

Incorporation of underlying rate equations for black liquor gasification was a critical task in development of PSL's model of the New Bern gasifier. Researchers at IPST have done extensive experimental and fundamental work on the development of black liquor gasification rate equations. PSL and IPST collaborated closely on the development and integration of 
Final Technical Report Rev. 0

DE-FC26-04NT42259

gasification rate subroutines into PSL's gasifier reactor model. A detail description of this activity is included in Appendix 3 and in publication [15]

\subsection{Black liquor spray model development}

Simulent Ltd. had responsibility for development and validation of a black liquor atomization CFD model. The black liquor spray model developed by Simulent is a three-dimensional algorithm that models transient, turbulent, and chemically reactive flows. The algorithm simultaneously solves the continuity equation for all the species, the continuity equation for the total fluid flow, the momentum equation for the total fluid flow and the energy equation. The algorithm also solves the equation of state and considers the chemical reactions. It accounts for evaporation, collision, and break-up of black liquor droplets.

\subsubsection{Development of a CFD black liquor spray model (Simulent)}

The numerical procedure developed by Simulent for modeling black liquor atomization is a three step process.

- The flow inside the nozzle is modeled and the initial breakups are simulated (2D model inside the nozzle),

- Using a statistical model, the initial droplet size is calculated at the nozzle exit (atomization model),

- Using the above initial droplet size and a 3D algorithm, spray is modeled outside the nozzle (3D model outside the nozzle).

An example of Simulent's 2D simulation of the standard T-type nozzle is shown in Figure 3-12. Black liquor enters the outlet nozzle hole through a horizontal slot. It meets a jet of steam at a (close to) 90 degree angle. The force from the steam acting on the black liquor makes the liquid break up to form a film on the wall of the outlet hole.

The model predicts how the steam flow and the black liquor interact to create a volume of droplets in and outside the outlet hole. The model also predicts different levels of coalescence to form new, larger droplets in the outlet region. One interesting observation for the current nozzle geometry and operating conditions was a pulsation in the black liquor film and droplet formation. The modeling work indicated this pulsation lead to undesirable characteristics in the droplet size distribution. As a result, minimizing this pulsation became a key design goal for Simulent in their phase II nozzle design work. 
Final Technical Report Rev. 0

DE-FC26-04NT42259

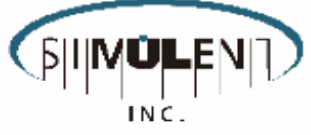

Effect of Black Liquor Mass Flow Rate

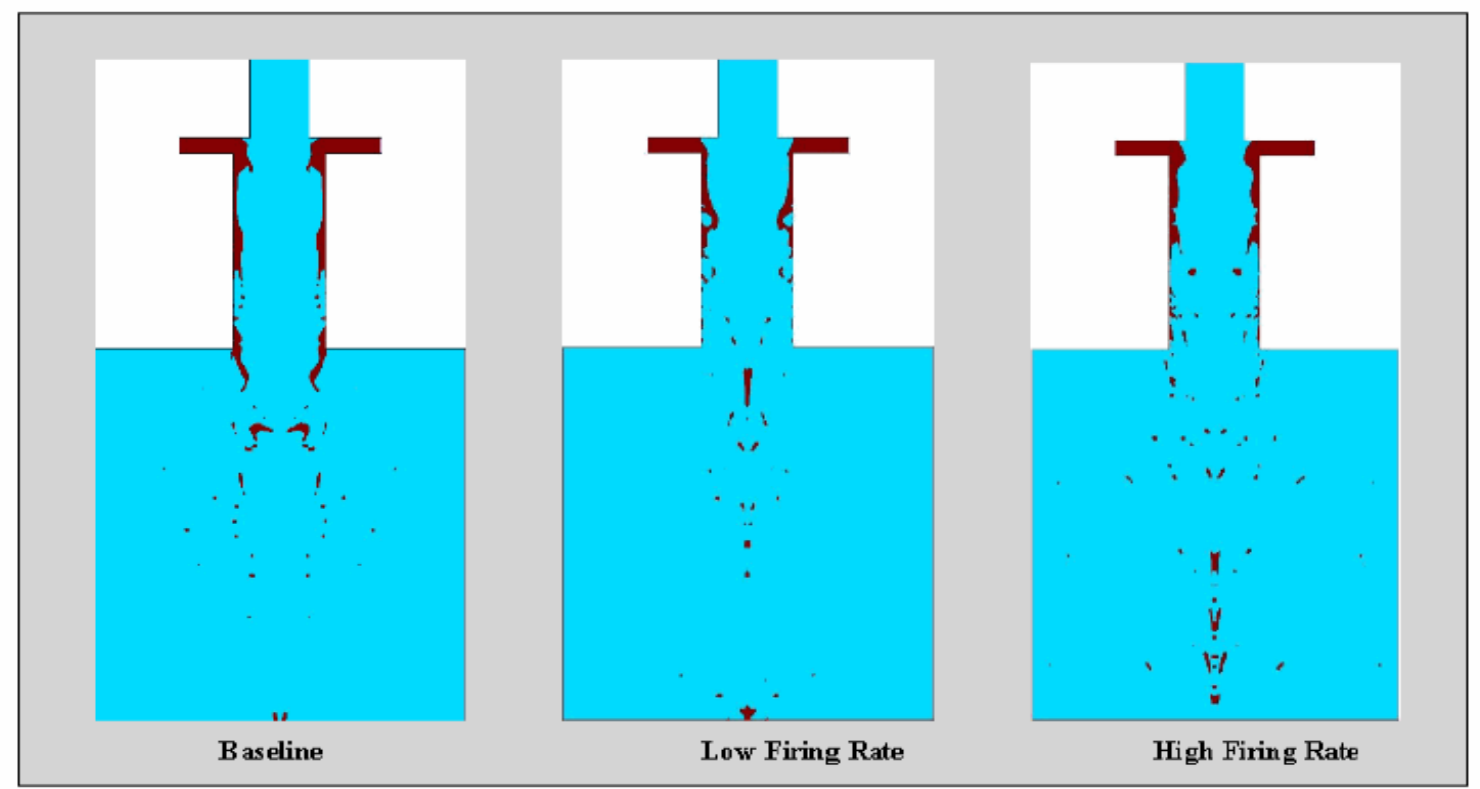

time $=1460 \times 10-5$

Figure 3-12 Example of Simulent 2-D spray simulation

An example of a Simulent's 3D simulation is show in the Figure 3-13 below. The spray is created from a model based on a single hole - not multiple holes in a circle as is the design of the real nozzle. The single-hole model was repeated around the nozzle periphery and the interaction between the individual sprays from each hole was studied. The effect of spray interaction including droplet coalescence was studied for 4, 12 and 18 multi-hole nozzles. As expected, the results showed that as the number of nozzles is increased, spray interaction increased. For the eighteen nozzle configuration a uniform dispersion pattern was observed. Another observation is the annular dispersion of black liquor particles does not fill the center region; i.e. a hollow region remained at the center for all conditions studied. 
Final Technical Report Rev. 0 DE-FC26-04NT42259

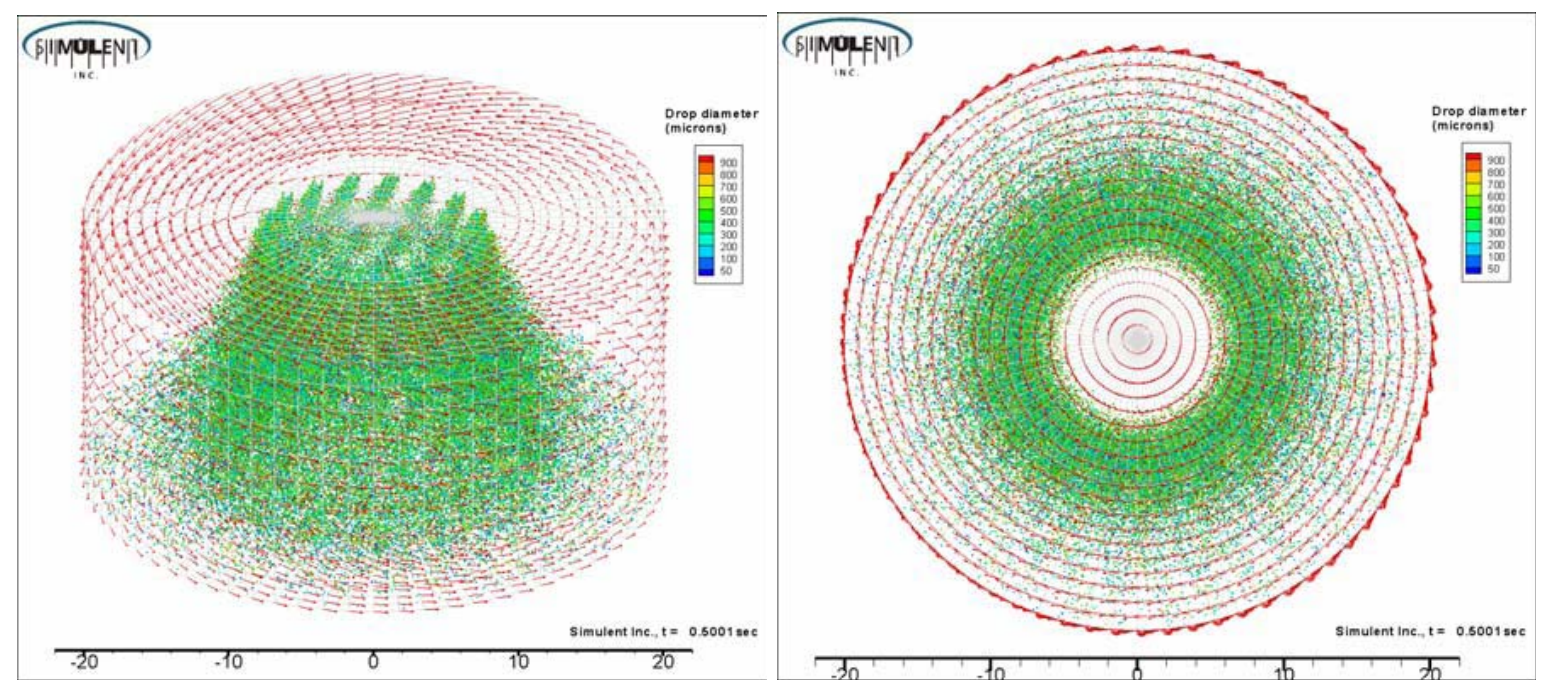

Figure 3-13 Example of Simulent's 3-D simulation

\subsubsection{Experimental spray characterization (ETC)}

In order to validate Simulent's CFD model, a series of experiments were conducted at Chemrec's nozzle test facility. The facility is located at the Swedish Energy Technology Centre (ETC) in Piteå, Sweden. Chemrec produced an experimental nozzle having the same geometry and size as the standard T nozzle used with the exception that the experimental nozzle was equipped with just one of the 18 holes used in the New Bern commercial nozzle.

The nozzle test facility is illustrated and shown in Figure 3-14 and Figure 3-15. In Figure 3-14 a process schematic shows how the test unit was built up. Gas and liquid flow rates in the onehole nozzle can be the same as in one hole of the real nozzle in New Bern. Both water and water/syrup mixtures were tested. The water/syrup mixture was used to simulate the higher viscosities associated with black liquor. The testing went well after typical start up problems; e.g. keeping the water/syrup mixture free of gas (air) bubbles when being pumped around and used several times. Bubbles within droplets disturbed the measurements.

The measurements were carried out using a Phase Doppler Anemometry (PDA) instrument. This equipment is a non-intrusive, scattering light interferometry technique that simultaneously measures size and velocity of spherical particles and requires no calibration. Measurements are performed on single particles (droplets), thus allowing detailed analysis of the atomization characteristics. The PDA technique is based on two focused laser beams that intersect with each other to form a measurement volume. Where the two laser beams intersect, they create an interference fringe pattern of bright and dark fringes thus the particle emits light with a frequency proportional to its velocity, since the fringes distance is known. The PDA system also measures particle diameter by processing the phase difference signal of the 
Final Technical Report Rev. 0 DE-FC26-04NT42259

scattered light between two receiving probes. An important property when measuring is the structure of the studied particles. PDA measurements assume both spherical and homogenous droplets. If the droplets are non spherical, the beams will reflect/refract and travel another way than predicted thus making PDA measurements impossible. Also the medium of the drops is important for the measurement procedure. The properties important to know are the refractive index and the transmittance of the medium. If the medium have a low rate of transmittance it is hard to measure in the refractive orders. The reflective order is then a more appropriate mode of measuring. With PDA, drop sizes between $0.5 \mu \mathrm{m}$ to several millimetres can be measured.
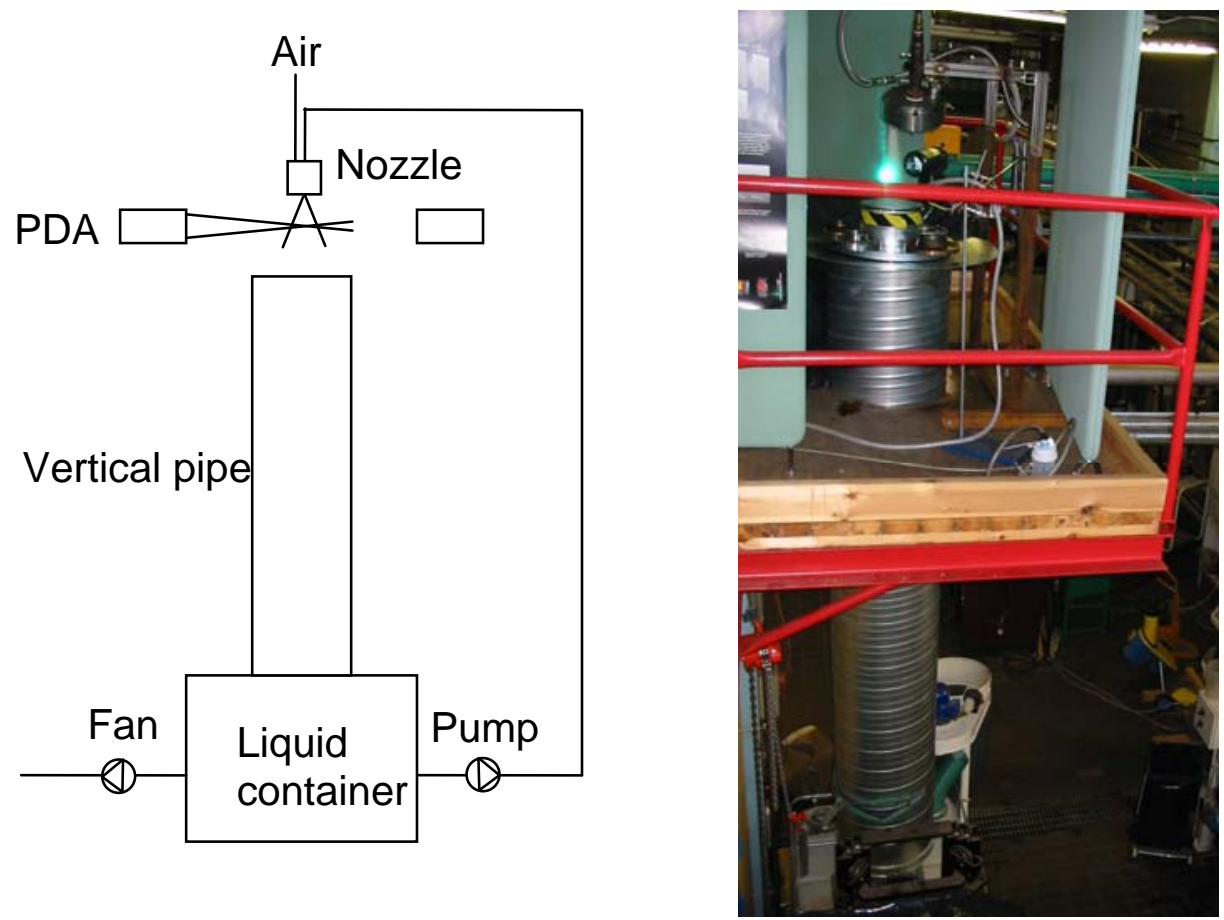

Figure 3-14 ETC Nozzle test facility schematic \& photo 
Final Technical Report Rev. 0

DE-FC26-04NT42259

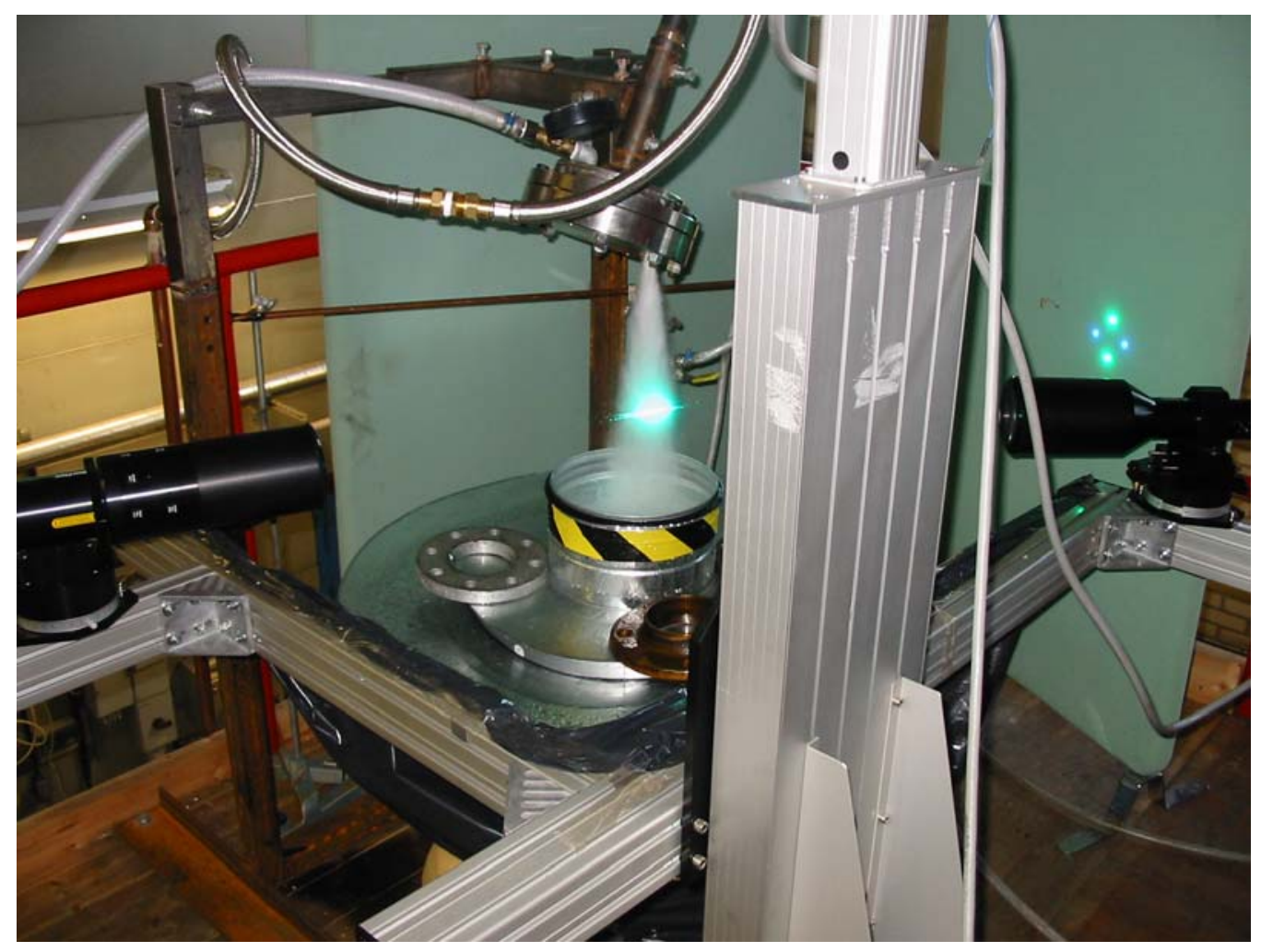

Figure 3-15 Photo of ETC spray measurement

\subsubsection{Spray model validation based on experimental results}

Validation of the Simulent atomization nozzle was done based upon ETC's experimental data for both water and $80 \mathrm{cp}$ syrup-water mixture. In the water case, parametric studies of the ETC single nozzle burner were conducted using Simulent's code. The effects of varying air velocity, exit droplet size, droplet velocity, and entrance angle were studied using water as the input fluid. After adjusting for differences in the location of measured versus calculated values, quite good agreement was observed between the predicted and experimental results for water.

In the second validation step, ETC performed a series of experiments on the single nozzle using a corn syrup and water solution. In these experiments black liquor is simulated with a corn syrup mixture at $80 \mathrm{cp}$ viscosity. Although originally intended to be a simulation of black liquor at New Bern operating conditions, $80 \mathrm{cp}$ viscosity turned out to be quite a bit less than the actual $200 \mathrm{cp}$ condition.

Figure 3-16 shows a comparison of the axial velocity profile one nozzle diameter downstream of outlet hole for both water and $80 \mathrm{cp}$ water-syrup mixture. As can be seen from the curves, 
Final Technical Report Rev. 0

DE-FC26-04NT42259

water and the $80 \mathrm{cp}$ water/syrup mixture behaved vary similar with respect to axial velocity across the hole.

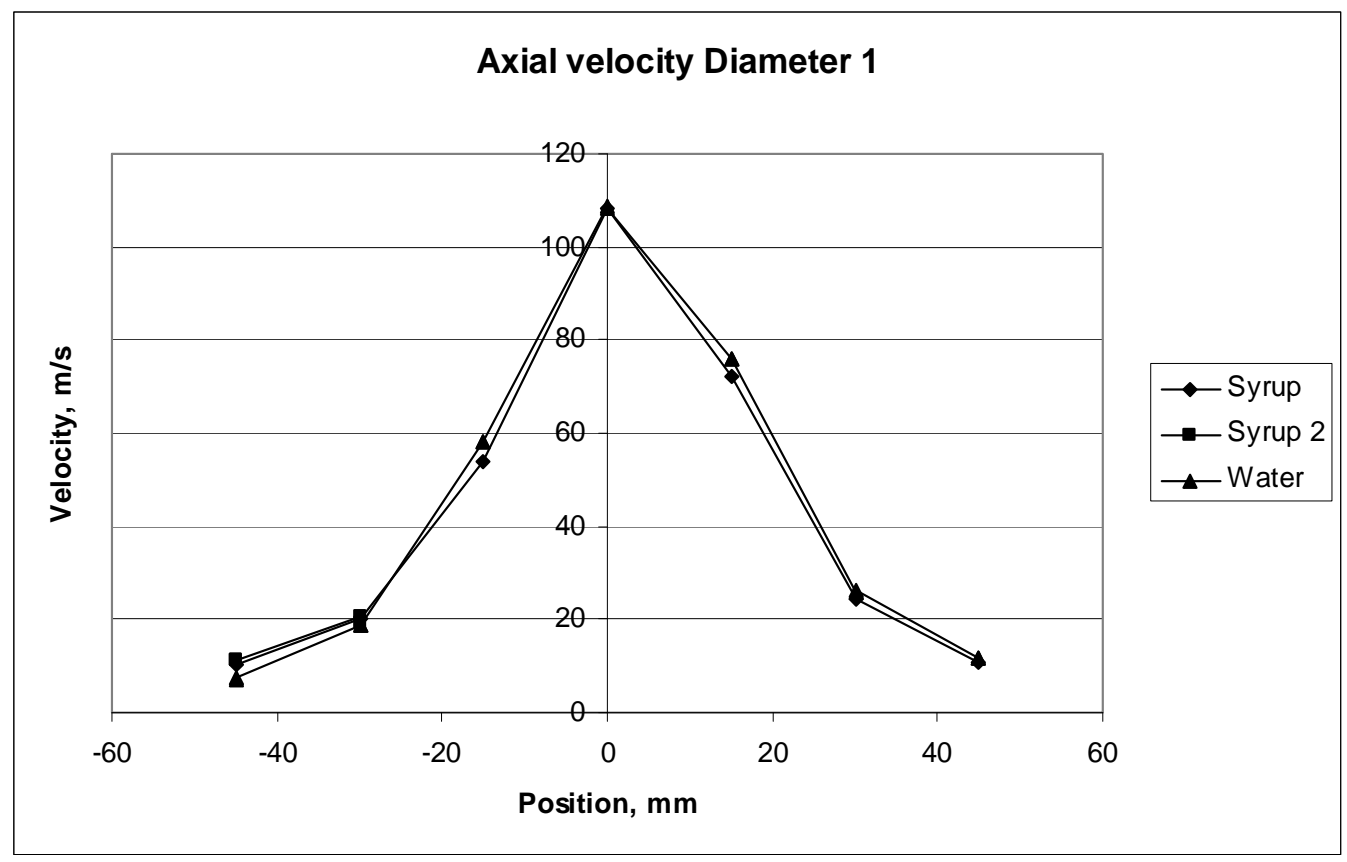

Figure 3-16 Axial velocity profiles for repeated $80 \mathrm{cp}$ syrup runs and a water run. Not all data points were repeated.

Mean diameter statistics are plotted in Figure 3-17 and listed in Table 3-7 for both the water and the $80 \mathrm{cp}$ syrup-water mixture tests. Note that DvXX is the diameter below which XX \% of the total volume is accumulated ${ }^{8}$. Surprisingly, the ETC results showed little or no difference in the droplet size between the $1 \mathrm{cp}$ water and $80 \mathrm{cp}$ corn syrup cases. In terms of the arithmetic average (D10) the sizes were even smaller for the $80 \mathrm{cp}$ corn syrup mixture. These results seemingly contradicted well established atomization theories and other published empirical models which suggest drop size should increase with increasing viscosity.

${ }^{8}$ The arithmetic mean diameter, D10, is defined as $\sum \mathrm{N}_{\mathrm{i}} \mathrm{D}_{\mathrm{i}} / \sum \mathrm{N}_{\mathrm{i}}$. The Sauter mean diameter, abbreviated as "D32" or "SMD", is expressed by the following formula: $\Sigma \mathrm{di}^{3} \bullet \mathrm{ni} / \Sigma \mathrm{di}^{2} \bullet$ ni (The ratio of the sum total of volume to that of surface area of the measured droplets). Therefore, the Sauter mean diameter is called "volume-surface mean diameter". 
Final Technical Report Rev. 0 DE-FC26-04NT42259

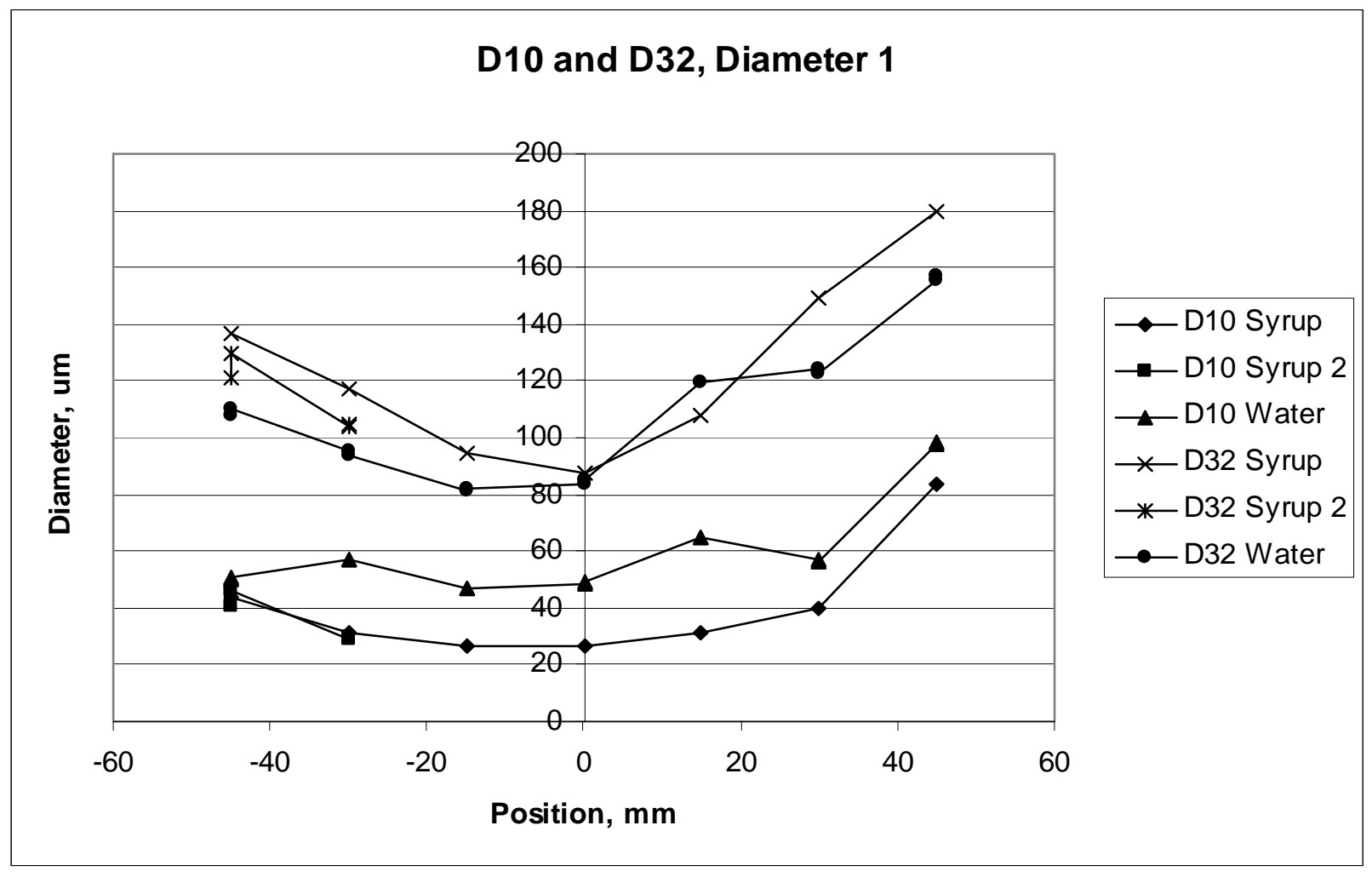

Figure 3-17 D10 and D32 (SMD) profiles for repeated $80 \mathrm{cp}$ syrup runs and a water run. Not all data points were repeated.

\begin{tabular}{|l|rr|rr|rr|}
\hline Position & $\mathbf{1}$ & & & & & \\
& Syrup & Water & Syrup & Water & Syrup & Water \\
\hline D10 & 26.4 & 48.8 & 26.5 & 47.0 & 39.8 & 56.9 \\
D20 & 33.5 & 55.2 & 34.6 & 53.6 & 57.8 & 70.8 \\
D30 & 46.2 & 63.5 & 48.3 & 61.8 & 79.2 & 85.5 \\
D32 & 87.7 & 83.9 & 94.4 & 82.1 & 148.9 & 124.6 \\
D43 & 168.8 & 121.2 & 175.3 & 115.1 & 203.8 & 159.0 \\
Dv10 & 33.5 & 44.3 & 36.7 & 44.2 & 78.3 & 70.3 \\
Dv50 & 170.6 & 90.3 & 177.3 & 90.1 & 209.2 & 153.5 \\
Dv90 & 301.4 & 255.4 & 305.0 & 212.6 & 305.0 & 251.0 \\
Span & 1.6 & 2.3 & 1.5 & 1.9 & 1.1 & 1.2 \\
\hline
\end{tabular}

Table 3-7 Diameter statistics for three measurement positions. One $80 \mathrm{cp}$ syrup and one water run shown. DvXX is the diameter below which $\mathrm{XX} \%$ of the total volume is accumulated. 
Final Technical Report Rev. 0

DE-FC26-04NT42259

The explanation for this surprising behavior was found by studying the droplet size distributions and the statistics used to describe them. To be able to compare different nozzles or different operating conditions for one nozzle, it is important to know the distribution shape. One statistic alone cannot characterize the distribution. At least two measures are needed together with the distribution function. This is rarely presented. The typical measure that is used to compare atomization performance of nozzles is a diameter statistic called D32 or Sauter mean diameter (SMD). SMD is one way to characterize the drop size distribution which normally covers a wide range of droplet sizes. Many other statistics are used as well.

From empirical correlations in the literature, it is known that increasing viscosity (the black liquor or syrup compared to water) should yield larger droplets and hence D32. As shown in Table 3-7, this was the result when the tests were run at ETC. However, the arithmetic average (D10) of the droplet sizes showed decreased diameters with increased viscosity. An extensive analysis of the $80 \mathrm{cp}$ syrup data showed a large number of large droplets for the syrup mixture compared to the water data, thus yielding a larger Sauter Mean Diameter (D32). However, the peak in the number distribution is at small droplet sizes and that peak shifted towards smaller droplets for the increased viscosity case; hence the smaller arithmetic diameter average. Therefore, the reason for the contradicting statistics is the changed shape of the distribution

It was theorized that the observed dual behavior with increased viscosity may be due to two different atomization mechanisms. The increased viscosity decreases the instabilities responsible for ligament or sheet break-up, but the increased viscosity may also allow the ligaments to stretch further before break-up, thus thinner ligaments could break up into smaller droplets. The latter effect is not present in the empirical formulations used by Simulent to predict droplet sizes from ligaments. Since the Simulent model yields a value for D32 with an assumed distribution function it was difficult to get a direct comparison of the ETC experimental results and Simulent model predictions. A detail description of this comparison for the $80 \mathrm{cp}$ syrup case is included in Appendix 4. The overall conclusions from that work were that:

- The overall average size for both simulation and experiment are reasonably close;

- Simulations can capture asymmetries seen in the experimental data exiting in the actual burner;

- Simulations can reasonably model the droplet size distribution and dispersion after two-times the nozzle radius (wings; in the droplet size distribution graphs);

- Droplet size distribution in the simulation were slightly larger than the experiment data due to the differences in the actual (experimental) and input (simulation) air velocities near the orifice axis.

As a result of this validation work, it was decided that: 
Final Technical Report Rev. 0

DE-FC26-04NT42259

1. Simulent's predictions for spray characteristics at $200 \mathrm{cp}$, based on the field test matrix conditions, would be incorporated into the PSL overall reactor model. A description of these results and how the data were transferred into PSL's CFD model is given below in sections 3.4.4 and 3.4.5.

2. The focus of the nozzle development effort was shifted to find solutions in nozzle geometry which would minimize the formation of large droplets observed in the experimental work. Both ETC and Simulent focused their efforts there and new nozzle designs were fabricated and tested during Phase II of the project. A description of that effort and results are given later in section 4, Task 2 Improvements to the black liquor burner system.

\subsubsection{Spray model prediction for test matrix conditions}

The principle for the buildup of the Simulent spray model was given earlier in section 3.4.1. The model was used to predict the spray pattern for the test matrix cases as defined in Table 3-1. The model predicted detailed droplet size distributions, velocities and trajectories for the selected cases. Average droplet size varied within $6 \%$ when going from low to high firing rate and average droplet viscosity varied with $13 \%$. The results were transferred to PSL's overall reactor model (section 3.4.5).

One interesting observation from the simulations was the impact of black liquor flow rate on droplet dispersion. As seen in Figure 3-18 the spray dispersion widens as the black liquor load increases.
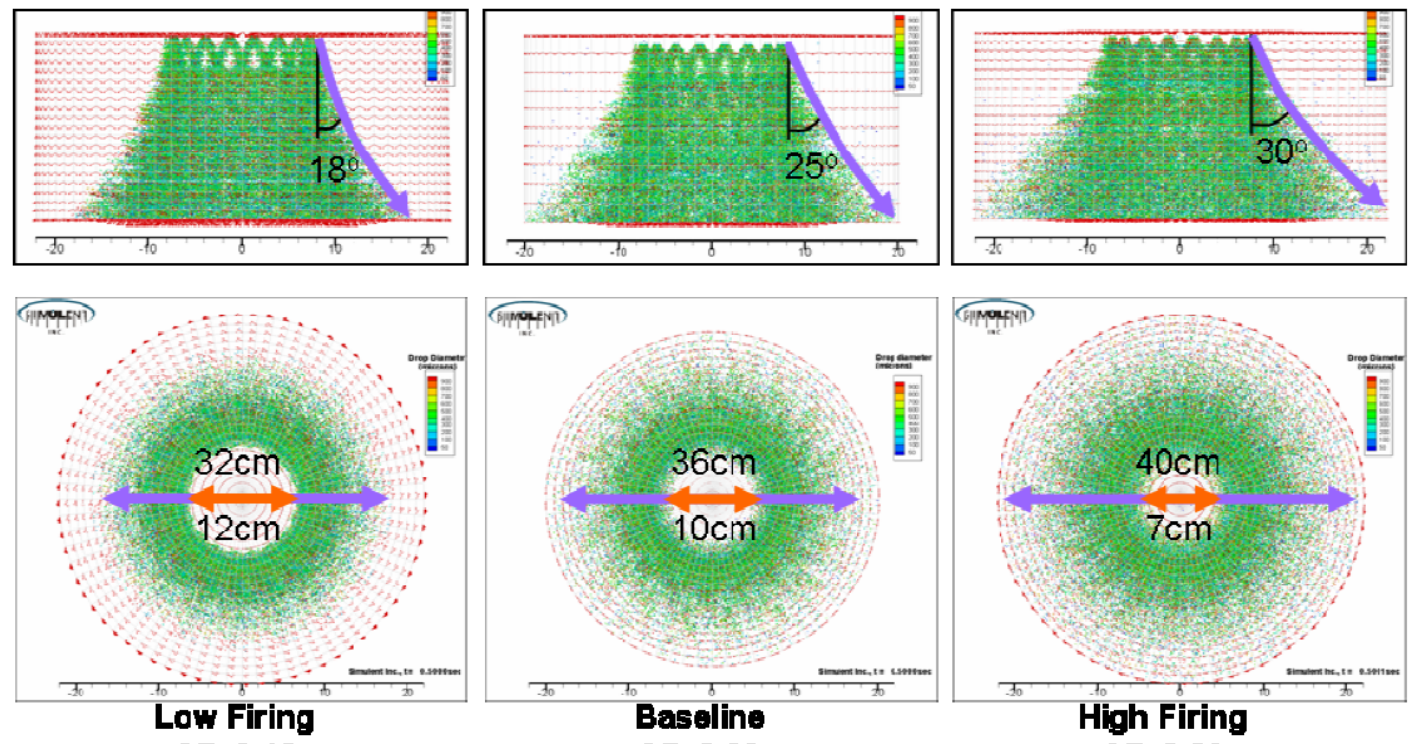

AF $=2.42$
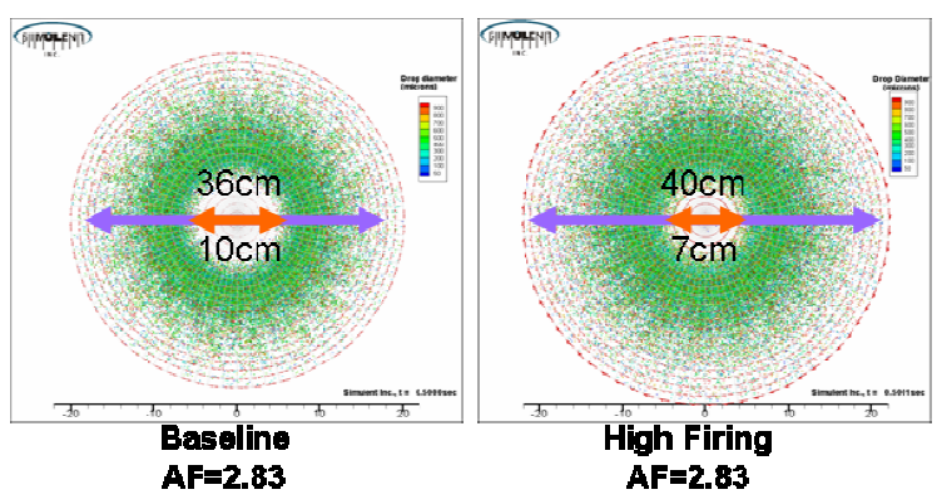

Figure 3-18 Spray dispersion as function of firing rate 
Final Technical Report Rev. 0

DE-FC26-04NT42259

\subsubsection{Transferring Simulent spray results into PSL gasifier model}

PSL's CFD model is focused on the gas flows, heat transfer and black liquor gasification rates in the gasifier. The liquor spray characteristics, including droplet size, velocity and location, are key inputs to the model. It is known that droplet size distribution and velocity are critical parameters for the black liquor gasification and have a significant impact on the gasifier performance.

Simulent is specialized in the development and application of CFD modeling techniques to atomization. Through detailed modeling of black liquor flow, atomization steam flow, and liquor droplet formation and dispersion, Simulent can predict liquor droplet size, location and initial velocity.

A key part of this project was to find an "optimal" means for data communication between Simulent's spray model and PSL's gasifier model. As Simulent was only modeling the spray in the vicinity of the nozzle exit, they were able to include many more droplets in their model (approximately 9 million) and resolve the domain with high accuracy $(80 \times 72 \times 40)$ cells for a cylinder with a radius of $40 \times 20 \mathrm{~cm}$ cylindrical domain. However, as PSL was modeling the whole reactor and considers chemical reactions they were limited to include up to 10,000 particles in their domain. Optimal data transfer would need to have the following minimum characteristics:

- Capture droplet distribution

- Capture droplet dispersion

- Contain all droplet properties (size, velocity)

For the above reasons, three sampling locations were chosen: a) $1 \mathrm{~cm}$, b) $10 \mathrm{~cm}$, and c) $20 \mathrm{~cm}$ below the nozzle exit (Figure 3-19). Our analysis showed that $20 \mathrm{~cm}$ below the nozzle exit is the "optimal" location to capture both droplet distribution and dispersion. 
Final Technical Report Rev. 0

DE-FC26-04NT42259

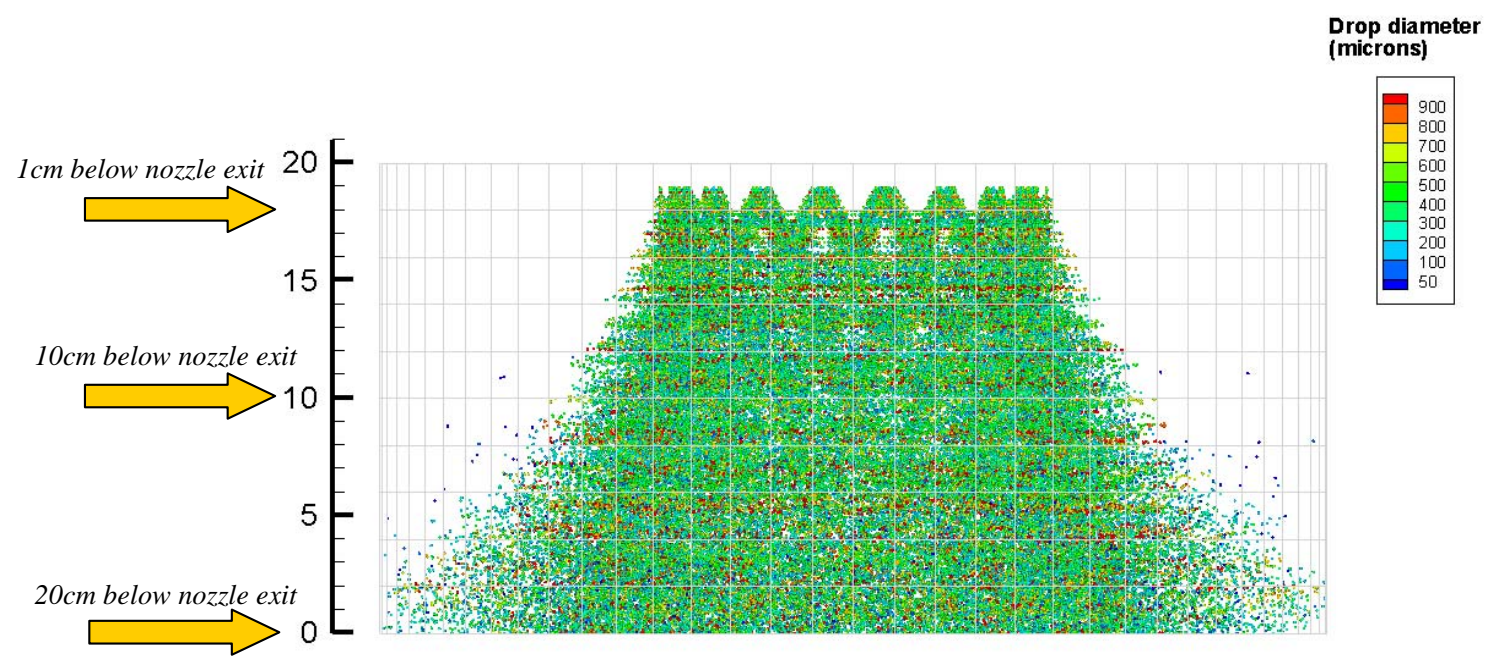

Figure 3-19 Sampling locations for particle distribution and dispersion

The next task was to "sample" particles at this location and find "10,000" particles which represent best droplet distribution and dispersion at this location. To do this, a "temporal sampling method" was used and by interpolating data at different times, 10000 particles representing droplet distribution and dispersion were chosen. These particles were then tabulated and data was transferred to PSL

\subsection{Correlation CFD and equilibrium models to field test matrix}

A tremendous effort was put forth to "validate" the CFD model based on the June 2005 field test matrix. Because it was not possible to make measurements within the gasifier reactor volume, this validation relied heavily upon comparisons of overall mass and energy balances based on measured values, predicted by equilibrium models, and PSL's CFD model. As noted earlier, this proved difficult due in part to apparent problems with measured values. Also an attempt was made to correlate the measured changes in reactor temperature and green liquor quality as a function of test matrix conditions (e.g. air to fuel ratio) with CFD predictions for the same conditions. A summary of that work follows below and was reviewed in publication $[15]$

\subsubsection{Comparison of measured and predicted mass and energy balances for baseline test condition}

Overall mass and energy balances were calculated for the June 2005 test matrix base case test condition with an air-to-fuel ratio of $2.83 \mathrm{~kg}$ air $/ \mathrm{kg}$ BLS for measured values and for three different modeling results. This air-to-fuel ratio corresponds to an air factor (actual air/stoichiometric air demand for complete combustion) of 0.63 . The three modeling cases 
Final Technical Report Rev. 0 DE-FC26-04NT42259

were the CFD model by Process Simulation, Ltd (PSL) and equilibrium models developed by IPST and Chemrec. The "measured values" refer to the values after the adjustments to liquor and air flows noted earlier in section 3.2.3.1. The IPST equilibrium calculations were made using the thermodynamic software FACTSage 5.3.1 and the Chemrec calculations with a program developed by Chemrec.

The equilibrium models were adjusted for compounds that are known to be affected by kinetics and not reach equilibrium and for estimated heat losses. In the IPST model, preset values were used for $\mathrm{CH}_{4}$ content in dry product gas, organic carbon content in smelt, and sulfide to total sulfur ratio in the smelt. The Chemrec model was adjusted for the $\mathrm{CH}_{4}$ and carbon contents. Without these adjustments, the equilibrium calculated gas $\mathrm{CH}_{4}$ content would be very low and there would be no unburned carbon and very little $\mathrm{Na}_{2} \mathrm{SO}_{4}$ remaining in the smelt. Consequently, the temperature predicted by the equilibrium models would not be representative of the actual temperature in the gasifier and that would affect all product gas concentrations. All other compounds were assumed to be at equilibrium. The smelt was assumed to be an ideal solution of $\mathrm{Na}_{2} \mathrm{~S}, \mathrm{Na}_{2} \mathrm{SO}_{4}, \mathrm{Na}_{2} \mathrm{CO}_{3}, \mathrm{NaCl}, \mathrm{NaOH}, \mathrm{K}_{2} \mathrm{CO}_{3}$, and $\mathrm{K}_{2} \mathrm{~S}$.

The outlet boundary used in these balances is the gasifier outlet, upstream of the quench. Since measurements are not possible at this location, the "measured" values for outlet flows and compositions are in fact back calculated based on the measured product gas flow and composition downstream of the venturi scrubber and the green liquor flow and composition (smelt). The "measured" outlet temperature was calculated based on the energy balance.

The total mass balance closures are shown in Table 3-8 for the June 20th baseline case. The overall measured mass balance closure was $96 \%$. Both the equilibrium and CFD models gave a higher product gas flow and a lower smelt flow than the measurements. 
Final Technical Report Rev. 0 DE-FC26-04NT42259

\begin{tabular}{|c|c|c|c|c|}
\hline & Measured & IPST & PSL & Chemrec \\
\hline & Flow & Flow & Flow & Flow \\
\hline Inputs & $\mathrm{kg} / \mathrm{s}$ & $\mathrm{kg} / \mathrm{s}$ & $\mathrm{Kg} / \mathrm{s}$ & $\mathrm{Kg} / \mathrm{s}$ \\
\hline Black Liquor Solids & 2.94 & 2.94 & 2.94 & 2.94 \\
\hline Black Liquor $\mathrm{H}_{2} \mathrm{O}$ & 1.11 & 1.11 & 1.11 & 1.11 \\
\hline Air & 8.32 & 8.32 & 8.32 & 8.32 \\
\hline Atomizing Steam & 0.72 & 0.72 & 0.72 & 0.72 \\
\hline Total Inputs & 13.10 & 13.10 & 13.10 & 13.10 \\
\hline \multicolumn{5}{|l|}{ Outputs } \\
\hline Product Gas & 11.33 & 12.02 & 11.95 & 11.96 \\
\hline Smelt & 1.21 & 1.08 & 1.15 & 1.14 \\
\hline Total Outputs & 12.54 & 13.10 & 13.10 & 13.10 \\
\hline Difference & $-4.3 \%$ & $0.0 \%$ & $0.0 \%$ & $0.0 \%$ \\
\hline
\end{tabular}

\section{Table 3-8 Measured and predicted mass balances for June 20 baseline test}

A detailed energy balance based on lower heating values showing where the energy is expended is given in Table 3-9. Of the incoming streams, black liquor lower heating value accounted for $91 \%$ of the energy input. The rest was attributed to sensible heats in black liquor solids, water in black liquor, air, and atomizing steam. The largest of these was sensible heat in air $(6 \%)$.

Inputs
BL Lower Heating Value (Solids)
Sensible heat in BLS
Sensible heat in liquor water
Sensible heat in air
Sensible heat in atomizing steam
Total Heat Input
Outputs
LHV of product gas
Sensible heat in product gas
Sensible heat in smelt
Carbon Loss with smelt
Sulfide formation
Reactor shell loss
BL water evaporation
Smelt melting
Other (S vaporization, NaOH formation)
Total Heat Output

\begin{tabular}{|c|c|c|c|c|c|c|c|}
\hline \multicolumn{2}{|c|}{ Measured } & \multicolumn{2}{|c|}{$\begin{array}{c}\text { IPST Equilibrium } \\
\text { Model }\end{array}$} & \multicolumn{2}{|c|}{$\begin{array}{c}\text { Chemrec } \\
\text { Equilibrium Model }\end{array}$} & \multicolumn{2}{|c|}{ CFD Model } \\
\hline KW & $\%$ heat in & KW & $\%$ heat in & KW & $\%$ heat in & $\mathrm{KW}$ & $\%$ heat in \\
\hline 39367 & $91 \%$ & 39367 & $91 \%$ & 39367 & $91 \%$ & 39367 & $91 \%$ \\
\hline 651 & $2 \%$ & 651 & $2 \%$ & 651 & $2 \%$ & 651 & $2 \%$ \\
\hline 427 & $1 \%$ & 427 & $1 \%$ & 427 & $1 \%$ & 427 & $1 \%$ \\
\hline 2529 & $6 \%$ & 2529 & $6 \%$ & 2529 & $6 \%$ & 2529 & $6 \%$ \\
\hline 233 & $1 \%$ & 233 & $1 \%$ & 233 & $1 \%$ & 233 & $1 \%$ \\
\hline 43206 & $100 \%$ & 43206 & $100 \%$ & 43206 & $100 \%$ & 43206 & $100 \%$ \\
\hline KW & $\%$ heat in & $\mathrm{kW}$ & $\%$ heat in & 0 & $\%$ heat in & $\mathrm{kW}$ & $\%$ heat in \\
\hline 16837 & $39 \%$ & 12714 & $29 \%$ & 12516 & $29 \%$ & 9969 & $23 \%$ \\
\hline 17047 & $39 \%$ & 19160 & $44 \%$ & 19711 & $46 \%$ & 19329 & $45 \%$ \\
\hline 1887 & $4 \%$ & 1756 & $4 \%$ & 1924 & $4 \%$ & 1914 & $4 \%$ \\
\hline 52 & $0 \%$ & 107 & $0 \%$ & 33 & $0 \%$ & 1859 & $5 \%$ \\
\hline 4264 & $10 \%$ & 5012 & $12 \%$ & 5176 & $12 \%$ & 5008 & $12 \%$ \\
\hline 187 & $0 \%$ & 187 & $0 \%$ & 500 & $1 \%$ & 187 & $0 \%$ \\
\hline 2711 & $6 \%$ & 2711 & $6 \%$ & 2711 & $6 \%$ & 2711 & $6 \%$ \\
\hline 440 & $1 \%$ & 408 & $1 \%$ & 422 & $1 \%$ & 388 & $1 \%$ \\
\hline 295 & $1 \%$ & 1108 & $3 \%$ & 542 & $1 \%$ & 1753 & $4 \%$ \\
\hline 43720 & $101 \%$ & 43164 & $100 \%$ & 42993 & $100 \%$ & 43120 & $100 \%$ \\
\hline
\end{tabular}

\section{Table 3-9 Measured \& predicted energy balance for June 20 baseline test}

On the basis of lower heating values, the energy balance closure for the measured case was $101 \%$. The fact that a higher energy balance closure than a mass balance closure was obtained 
Final Technical Report Rev. 0

DE-FC26-04NT42259

suggests that the measured energy content of some output stream may have been higher than it actually was.

Both the equilibrium predictions suggest that $29 \%$ of the total incoming energy was in the lower heating value of the product gas. The measured value showed a substantially higher fraction $(39 \%)$ of the incoming energy in the product gas lower heating value, while the CFD prediction had a smaller fraction $(23 \%)$. As discussed below, it was concluded that the measured product gas higher heating value was likely larger than the actual value. The CFD prediction for the amount of energy in the product gas lower heating value is believed to be low. Comparing the energy in product gas lower heating values to those in black liquor LHV gives $43 \%$ for the measured value, $32 \%$ for the equilibrium predictions, and $26 \%$ for the CFD model.

All three models show $44-45 \%$ of the incoming energy exiting in the sensible heat of the product gas. The measured value was 39\%. The lower measured value reflects both the lower measured temperature and lower measured product gas flow. The mass balance closure suggests that the product gas flow may have been higher than measured.

Sulfide formation is the next largest energy sink, and consumes $10-12 \%$ of the incoming energy. $6 \%$ of the incoming energy is expended on evaporating water in black liquor. $4 \%$ exits as sensible heat in smelt and $1 \%$ goes to melting the alkali salts. $0.1 \%$ exits as lost carbon according to the measurements whereas the CFD model predicts 5\% losses in both unburned carbon and unvolatilized material. For the measured values, the only other measured energy output in this analysis was volatilization of sulfur which accounted for $1 \%$. The IPST equilibrium case also included equilibrium alkali volatilization and $\mathrm{NaOH}$ formation, and these other sources accounted for $4 \%$ of the total input energy. The Chemrec model included both $\mathrm{NaOH}$ formation and sulfur volatilization. The other sources for the CFD model include $\mathrm{S}$ volatilization, unreleased volatiles and $\mathrm{Na}$ in smelt.

A comparison of the measured and predicted compositions of the different product streams, the product gas heating values and outlet temperatures is shown in Table 3-10. The measured product gas heating values were substantially greater than those predicted by any model. The two equilibrium models gave very similar predictions: approximately $1640 \mathrm{~kJ} / \mathrm{kg}$ for the higher heating value (HHV) and $1150 \mathrm{~kJ} / \mathrm{kg}$ for the lower heating value (LHV). The measured values were approximately $40 \%$ greater than the equilibrium values. The difference between the measured and predicted product gases indicates that either the equilibrium models fail to predict the gas composition or the measured values had substantial errors. 
Final Technical Report Rev. 0 DE-FC26-04NT42259

\begin{tabular}{|c|c|c|c|c|}
\hline Product gas & $\begin{array}{c}\text { Measured } \\
\text { vol } \%\end{array}$ & $\begin{array}{l}\text { IPST } \\
\text { vol \% }\end{array}$ & $\begin{array}{c}\text { Chemrec } \\
\text { vol } \%\end{array}$ & $\begin{array}{l}\text { CFD } \\
\text { vol \% }\end{array}$ \\
\hline $\mathrm{O}_{2}$ & & & & $0.02 \%$ \\
\hline $\mathrm{CH}_{4}$ & $0.3 \%$ & $0.3 \%$ & $0.3 \%$ & $0.3 \%$ \\
\hline $\mathrm{CO}_{2}$ & $12.2 \%$ & $12.4 \%$ & $12.3 \%$ & $14.7 \%$ \\
\hline $\mathrm{CO}$ & $5.8 \%$ & $4.7 \%$ & $4.5 \%$ & $3.0 \%$ \\
\hline $\mathrm{H}_{2} \mathrm{O}$ & $24.0 \%$ & $28.7 \%$ & $29.6 \%$ & $28.0 \%$ \\
\hline $\mathrm{H}_{2}$ & $7.6 \%$ & $4.7 \%$ & $4.4 \%$ & $5.1 \%$ \\
\hline $\mathrm{H}_{2} \mathrm{~S}$ & $0.2 \%$ & $0.1 \%$ & $0.2 \%$ & $0.2 \%$ \\
\hline $\mathrm{N}_{2}$ & $50.0 \%$ & $48.6 \%$ & $48.7 \%$ & $49.5 \%$ \\
\hline Other (alkali, $\mathrm{SO}_{2}$ ) & & $0.5 \%$ & & \\
\hline $\mathrm{LHV}, \mathrm{KJ} / \mathrm{kg}$ & 1487 & 1057 & 1047 & 839 \\
\hline $\mathrm{HHV}, \mathrm{KJ} / \mathrm{kg}$ & 2041 & 1634 & 1641 & 1404 \\
\hline Temperature, ${ }^{\circ} \mathrm{C}$ & 1101 & 1158 & 1188 & 1173 \\
\hline Smelt & & & & \\
\hline & & mass & & mass \\
\hline Inorganic & mass $\%$ & $\%$ & mass \% & $\%$ \\
\hline $\mathrm{Na}_{2} \mathrm{~S}(\mathrm{l})$ & $26.5 \%$ & $34.8 \%$ & $32.7 \%$ & $33.3 \%$ \\
\hline $\mathrm{Na}_{2} \mathrm{SO}_{4}(\mathrm{I})$ & $6.0 \%$ & $8.0 \%$ & $1.5 \%$ & $5.8 \%$ \\
\hline $\mathrm{Na}_{2} \mathrm{CO}_{3}(\mathrm{I})$ & $67.4 \%$ & $54.4 \%$ & $46.0 \%$ & $26.1 \%$ \\
\hline $\mathrm{K}_{2} \mathrm{CO}_{3}(\mathrm{I})$ & & $0.5 \%$ & $0.2 \%$ & $5.8 \%$ \\
\hline $\mathrm{NaCl}(\mathrm{I})$ & & $0.1 \%$ & $0.4 \%$ & $0.7 \%$ \\
\hline $\mathrm{NaOH}(\mathrm{I})$ & & $1.4 \%$ & $14.5 \%$ & $15.7 \%$ \\
\hline $\mathrm{K}_{2} \mathrm{~S}(\mathrm{I})$ & & $0.3 \%$ & $1.9 \%$ & $0.0 \%$ \\
\hline $\mathrm{Na}(\mathrm{l})$ & & $0.0 \%$ & $0.0 \%$ & $6.5 \%$ \\
\hline Unburned Carbon & $0.1 \%$ & $0.3 \%$ & $0.1 \%$ & $3.1 \%$ \\
\hline $\begin{array}{l}\text { Unreleased } \\
\text { Volatiles }\end{array}$ & & & & $2.9 \%$ \\
\hline
\end{tabular}

\section{Table 3-10 Comparison of measured and predicted product gas compositions}

The measured product gas composition corresponds to a water gas shift equilibrium at 970C, which is a substantially lower temperature than that calculated from the energy balance (1101C). The equilibrium for water gas shift reactions is typically obtained in product gases. The difference between the water gas shift equilibrium temperature and the calculated temperature suggests that the product gas composition may have errors.

Overall, the measured gas had less oxygen than the product gases from the equilibrium predictions. The oxygen balance closure for the measured case was $90 \%$, and this may explain the discrepancy. Either the input oxygen was overestimated or the output oxygen underestimated. If too high an air flow was used in the equilibrium calculations, the equilibrium predictions would underestimate the product gas heating value. In the latter case (output oxygen underestimated), the concentrations of oxygen containing gases may have been underestimated in the product gas, which would lead to a measured heating value that is higher than the actual heating value.

The product gas heating values predicted by the CFD model were lower than those either measured or predicted by the equilibrium model. They were approximately $60 \%$ lower than the measured values. One reason for the low heating values predicted by the CFD model compared to the equilibrium model may be that the CFD model predicted higher amounts of 


\section{Final Technical Report Rev. 0 \\ DE-FC26-04NT42259}

carbon remaining in the smelt. With lower amounts of combustible material released into the gas phase, there is higher oxygen to combustible ratio in the gas. Therefore, the carbon and hydrogen in the product gas become burnt to a higher degree, i.e., the predicted $\mathrm{CO}_{2}$-to- $\mathrm{CO}$ and $\mathrm{H}_{2} \mathrm{O}$-to- $\mathrm{H}_{2}$ ratios increase. Thus, the gas heating value predicted by the CFD model is low.

The CFD model showed a carbon content of 3.1\% in the smelt plus an additional $3 \%$ in unreleased volatiles. The unreleased volatiles corresponded to $1.2 \%$ carbon in smelt, which makes the overall unburned carbon in the smelt $4.4 \%$ for the CFD model. This corresponds to $4.7 \%$ of the total carbon input with black liquor. The measured carbon content in the smelt was only $0.1 \%$ for the base case runs. The presence of both high amounts of unburned carbon and unreleased volatiles imply that the rates for both carbon gasification and devolatilization that were used in the model were slower than the actual rates.

The reported measured smelt composition values included only $\mathrm{Na}_{2} \mathrm{~S}, \mathrm{Na}_{2} \mathrm{SO}_{4}$, and $\mathrm{Na}_{2} \mathrm{CO}_{3}$; these were back-calculated from measured green liquor compositions. The measured reduction efficiency was $89 \%$. This value was adjusted for the IPST equilibrium model. For the Chemrec model, in which no adjustment was made for the sulfate content, the reduction efficiency was 98\%. The CFD model, which includes kinetics for sulfate reduction, gave 91\% reduction efficiency which is quite close to the measured value. The kinetics of sulfate reduction may be slightly overestimated in the model.

The adjusted temperature for the measurements was $1101^{\circ} \mathrm{C}$. All models predicted higher temperatures: $1158-1188^{\circ} \mathrm{C}$. The CFD temperature prediction fell in between the two equilibrium predictions.

\subsubsection{Comparison of measured and model predicted values for selected variables}

For the purpose of the Thermodynamic model and CFD calculations, only one variable at a time was changed. The closest model cases based on mass and energy balances were chosen for comparison, however, the conditions were not exactly the same as all variables changed slightly from day to day. There was no trial data that corresponded to the low firing rate + lower A/F case, so no measured values are reported for that case. For the purpose of the thermodynamic calculations, the $\mathrm{SO}_{4} / \mathrm{S}_{\text {total }}$ in the smelt, the unburned carbon as a mass fraction of the smelt, and the $\mathrm{CH}_{4}$ concentration in the gas were all forced to the values determined by the mass/energy balances so the these values are compared only to the CFD calculated values.

Table 3-11 compares the measured temperature with that obtained by energy balance, thermodynamic calculation and CFD modeling. As can be seen, the calculations all give a higher temperature than measured except for the baseline + lowest $\mathrm{A} / \mathrm{F}$ case where the temperature based on energy balance is lower than that measured. The temperature in the 


\section{Final Technical Report Rev. 0 DE-FC26-04NT42259}

reactor was only measured by one thermocouple. It is not clear if the measurement is in error due to location, corrosion, or some other effect.

\begin{tabular}{|c|c|c|c|c|c|c|}
\hline $\begin{array}{c}\text { Date } \\
\text { of closest case }\end{array}$ & Condition & $\begin{array}{l}\text { Measured } \\
\text { Temp }\left({ }^{\circ} \mathrm{F}\right)\end{array}$ & $\begin{array}{c}\text { Energy Balance } \\
\text { Temp }\left({ }^{\circ} \mathrm{F}\right)\end{array}$ & $\begin{array}{c}\text { Thermodynamic } \\
\text { Temp }\left({ }^{\circ} \mathrm{F}\right)\end{array}$ & $\begin{array}{c}\text { CFD Max. Gas } \\
\text { Temp }\left({ }^{\circ} \mathrm{F}\right)\end{array}$ & $\begin{array}{l}\text { CFD Exit Gas } \\
\left.-T^{-}-{ }^{-}{ }^{\circ} \overline{(} \bar{F}\right)\end{array}$ \\
\hline 20-Jun & Baseline & 1781 & $\begin{array}{ll}2014 \\
\end{array}$ & $\begin{array}{ll}2140 \\
\end{array}$ & 242460 & 2143 \\
\hline $23-\overline{-J u n}$ & Baseline+lowering $\overline{\mathrm{A}} / \mathrm{F}$ & $-\overline{71} \overline{3}$ & & $20 \overline{3}$ & $24 \overline{2} 2$ & $20 \overline{1}$ \\
\hline $23-$ Jun & Baseline+lowest $\mathrm{A} / \mathrm{F}$ & 1638 & 1626 & $191 \overline{2}$ & $23 \overline{5} 2-$ & $186 \overline{4}$ \\
\hline$--\overline{17}-\overline{-} \overline{-}-\dot{2}$ & $5-5=-\overline{0}-1$ & -3 & & & & \\
\hline 16-Jun & High Firng Rate & $--1 / 21$ & 2036 & $\frac{2152}{21}-\frac{2}{7}$ & 2410 & 2152 \\
\hline-10 & IHIgn Firing Kate Low A/F & & & & & 2134 \\
\hline$--\overline{15}-\overline{J u n}^{-}$ & $\overline{\text { Low Firing }} \overline{\text { Rate }}-\overline{-}$ & $---\overline{177} \overline{7}$ & $---\overline{2036}$ & $\overline{2} 07 \overline{6}$ & $264 \overline{4}$ & $\overline{2} 1 \overline{7} \overline{2}$ \\
\hline & Low Firing Rate $+\mathrm{L}$ ow $\mathrm{A} / \mathrm{F}$ & & & & $2 \overline{45} \overline{1}$ & $190 \overline{6}$ \\
\hline$-\overline{21}-\overline{-J u n}$ & $\overline{\text { Low }} \overline{\text { Swirl }}-\overline{-}$ & $---\overline{1765}-$ & $-\overline{1975}-$ & $\overline{2} 15 \overline{6}$ & $-\overline{2469}-$ & $215 \overline{1}$ \\
\hline
\end{tabular}

Table 3-11 Comparison of measured temperature with that obtained by energy balance, thermodynamic calculation and CFD modeling.

A final point regarding the temperatures is that the CFD calculations give what appear to be reasonable trends, and the predicted product gas temperatures at the exit of the reactor are very close to those of thermodynamic calculations. The CFD modeling also indicates that some local areas in the reactor the temperature can be much higher than the product gas temperature.

The data presented in Table 3-12 and Table 3-13 indicates reasonable agreement between the measured and thermodynamically calculated values for $\mathrm{CO}_{2}$ and $\mathrm{CO}$. This suggests that the water gas shift reaction approaches equilibrium in the gasifier. On the other hand, the kinetic model used in the CFD model for the water gas shift reaction limits the approach to equilibrium in the calculated species distribution and does not obtain good agreement with the measured values. The measured $\mathrm{CO}_{2}$ and $\mathrm{CO}$ concentrations are from the scrubber exit for the reasons discussed earlier (see section 3.2.3.3 Measured Gasifier Products).

Comparisons of the $\mathrm{CO}_{2} / \mathrm{CO}$ ratio for the equilibrium and CFD models are presented as functions of input organic carbon to total water to the gasifier in Figure 3-20 and Figure 3-21. The model predictions are compared with a linear fit of the actual GTI measured gas composition data shown previously in Figure 3-5. These figures clearly show that the actual gas composition closely matches the equilibrium modeled condition for water gas shift, while the CFD model predicts considerably higher $\mathrm{CO}_{2} / \mathrm{CO}$ ratios due to the assumed kineticallylimited water gas shift reaction. 
Final Technical Report Rev. 0 DE-FC26-04NT42259

\begin{tabular}{|c|c|c|c|c|}
\hline \multirow{2}{*}{$\begin{array}{c}\text { Date } \\
\text { of closest case }\end{array}$} & \multirow[b]{2}{*}{ Condition } & \multicolumn{3}{|c|}{$\mathrm{CO}_{2}(\mathrm{~mol} \%$, dry gas $)$} \\
\hline & & Measured & Thermodynamic & CFD \\
\hline 20-Jun & Baseline & $15.9 \%$ & $17.4 \%$ & $20.5 \%$ \\
\hline $23-$ Jun & Baseline+lowering $\mathrm{A} / \mathrm{F}$ & $16.2 \%$ & $17.1 \%$ & $20.3 \%$ \\
\hline $23-$ Jun & Baseline+lowest $\mathrm{A} / \mathrm{F}$ & $16.5 \%$ & $17.1 \%$ & $18.8 \overline{8}$ \\
\hline $17-\mathrm{Jun}$ & High Firing Rate & $15 \overline{7} 0$ & 1750 & 010 \\
\hline $16-\mathrm{Jun}$ & High Firing Rate+Low A/F & $15.7 \%$ & $17.3 \%$ & $20.5 \%$ \\
\hline & & & & \\
\hline 15-Jun & Low Firing Rate & $16.7 \%$ & $17.9 \%$ & $19.9 \%$ \\
\hline & Low Firing Rate + Low $\mathrm{A} / \mathrm{F}$ & & & $-19.2 \%$ \\
\hline$\overline{21}-\overline{-J u n}$ & $\overline{\text { Low Swirl }}$ & $16.0 \%$ & $-\overline{17.5 \%}$ & $20 . \overline{5 \%}$ \\
\hline
\end{tabular}

Table 3-12 Measured vs. calculated $\mathrm{CO}_{2}$ values in the product gas from the gasifier. The measured $\mathrm{CO}_{2}$ values are those measured at the scrubber exit

\begin{tabular}{|c|c|c|c|c|}
\hline \multirow{2}{*}{$\begin{array}{c}\text { Date } \\
\text { of closest case }\end{array}$} & \multirow[b]{2}{*}{ Condition } & \multicolumn{3}{|c|}{$\mathrm{CO}$ (mol \%, dry gas) } \\
\hline & & Measured & Thermodynamic & CFD \\
\hline 20-Jun & Baseline & $7.6 \%$ & $6.6 \%$ & $2.9 \%$ \\
\hline $23-\mathrm{Jun}$ & Baseline+lowering $\mathrm{A} / \mathrm{F}$ & $7 . \overline{5 \%}$ & $7.4 \%$ & $3.5 \%$ \\
\hline 23 -Jun & Baseline+lowest $\mathrm{A} / \mathrm{F}$ & $7.4 \%$ & $8.0 \%$ & $6.3 \%$ \\
\hline$\overline{17}$-Jun & High Firing Rate & $7 . \overline{8 \%}$ & $6.5 \%$ & $3.5 \%$ \\
\hline 16 -Jun & High Firing Rate+Low A/F & $7 . \overline{9 \%} \%$ & $7.0 \%$ & $2.9 \%$ \\
\hline 15-Jun & Low Firing Rate & $5 . \overline{6 \%} \%$ & $5 . \overline{7} \%$ & $2 . \overline{2} \%$ \\
\hline & Low Firing Rate $+\mathrm{L}$ & & & $4.6 \%$ \\
\hline $21-\overline{J u n}^{-}$ & $\overline{\text { Low Swirl }}-\overline{-}$ & $7.0 \%$ & $6.2 \%$ & $2.8 \%$ \\
\hline
\end{tabular}

Table 3-13 Measured vs. calculated $\mathrm{CO}$ values in the product gas from the gasifier. The measured $\mathrm{CO}$ values are those measured at the scrubber exit. 
Final Technical Report Rev. 0

DE-FC26-04NT42259

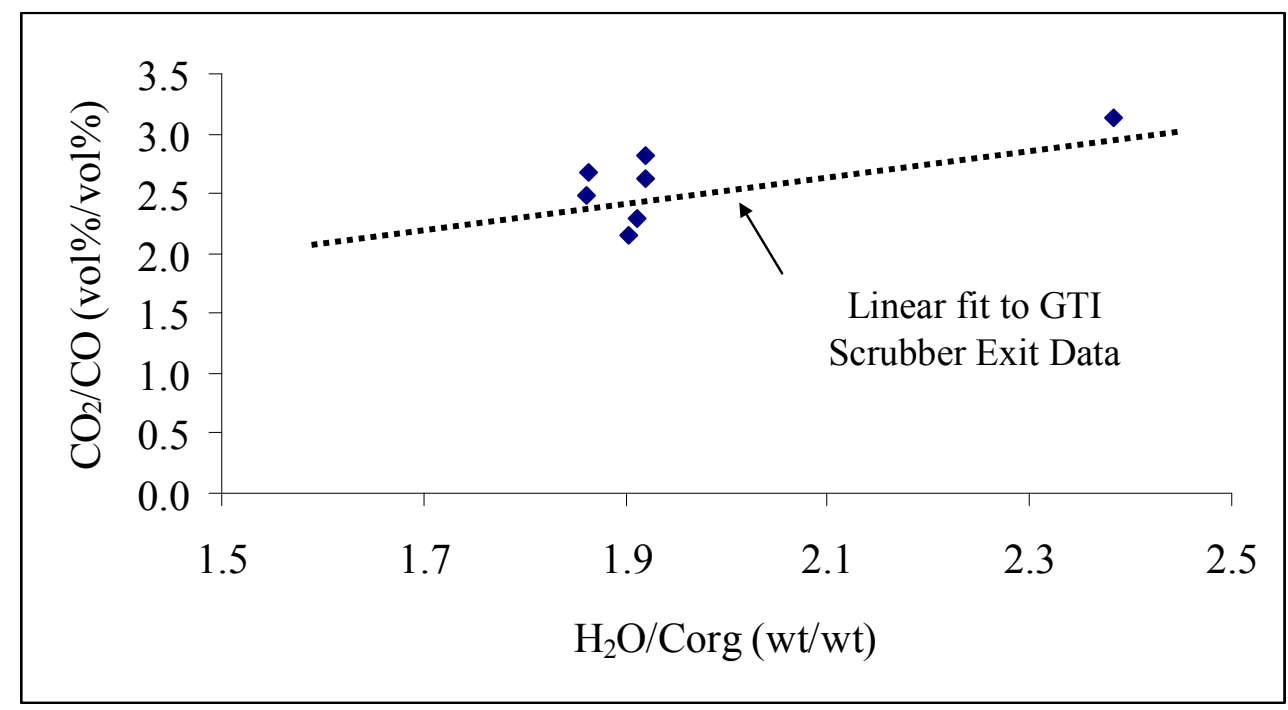

Figure 3-20 Comparison of the thermodynamic model predicted $\mathrm{CO}_{2} / \mathrm{CO}$ ratio in gasifier product vs. $\mathrm{H}_{2} \mathrm{O}$ /Corg in gasifier feed with linear fit to GTI gas analysis given in Figure 3-5.

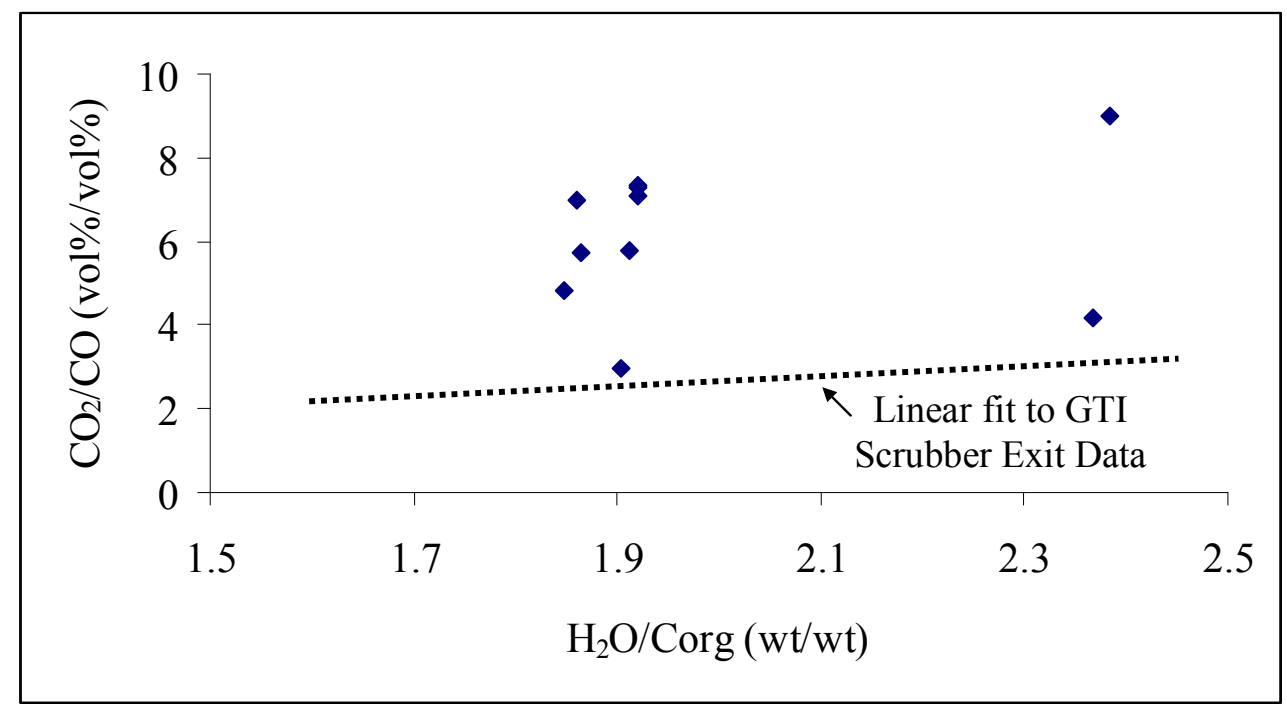

Figure 3-21 Comparison of CFD model predicted $\mathrm{CO}_{2} / \mathrm{CO}$ ratio in gasifier product vs. $\mathrm{H}_{2} \mathrm{O}$ /Corg in gasifer feed with linear fit to GTI gas analysis given in Figure 3-5.

The measured values for $\mathrm{H}_{2}$ are higher than the calculated $\mathrm{H}_{2}$ concentrations by the thermodynamic and CFD models, Table 3-14. Based on discussions with GTI at the time of sampling, there were several cases of clearly high $\mathrm{H}_{2}$ values after the venturi; therefore, the measured $\mathrm{H}_{2}$ concentrations are likely higher than actually present, but the reason is not certain. The difference between the $\mathrm{H}_{2}$ concentrations predicted by the thermodynamic and 
Final Technical Report Rev. 0

DE-FC26-04NT42259

CFD calculations are due to the differences in the water gas shift model assumptions as well as differences in the concentration of $\mathrm{CH}_{4}$, Table 3-15. The $\mathrm{CH}_{4}$ concentrations in the thermodynamic calculations were set to the same values as measured. The measured values for $\mathrm{CH}_{4}$ are likely quite accurate as the values by the mill instrumentation agreed well with the $\mathrm{CH}_{4}$ concentrations measured by GTI.

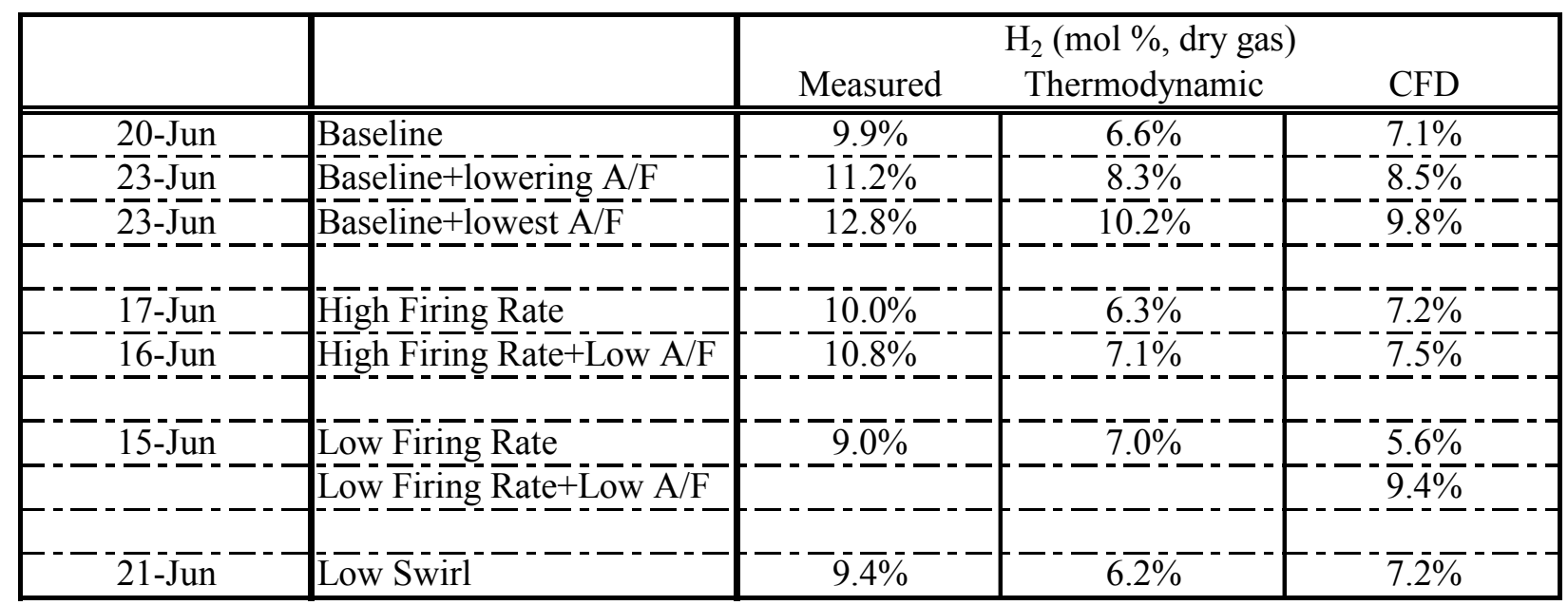

Table 3-14 Measured vs. calculated $\mathrm{H}_{2}$ values in the product gas from the gasifier. The measured $\mathrm{H}_{2}$ values are those measured at the scrubber exit.

\begin{tabular}{|c|c|c|c|}
\hline \multirow{2}{*}{$\begin{array}{c}\text { Date } \\
\text { of closest case }\end{array}$} & \multirow[b]{2}{*}{ Condition } & \multicolumn{2}{|c|}{$\mathrm{CH}_{4}(\mathrm{~mol} \%$, dry gas $)$} \\
\hline & & Measured & CFD \\
\hline 20-Jun & Baseline & $0.40 \%$ & $0.48 \%$ \\
\hline $23-$ Jun & Baseline+lowering $\mathrm{A} / \mathrm{F}$ & $0.59 \%$ & $0.58 \%$ \\
\hline $23-\mathrm{Jun}$ & Baseline+lowest $\mathrm{A} / \mathrm{F}$ & $0.82 \%$ & $0 . \overline{76} \%$ \\
\hline$\overline{17}-\overline{\mathrm{Jun}}-$ & $--\overline{1}:--\bar{D}--$ & $=-\overline{0} 0-7$ & \\
\hline 17-Jun & High Firing Rate & $0.40 \%$ & $0.45 \%$ \\
\hline - - 16 -Jun & High Firing Rate + Low A/F & $0.49 \%$ & $0.50 \%$ \\
\hline $15-$ Jun & Low Firing Rate & $0.53 \%$ & $0 . \overline{47} \%$ \\
\hline & Low Firing Rate+Low $\mathrm{A} / \mathrm{F}$ & & $0.75 \%$ \\
\hline$\overline{21}-\overline{-J u n}$ & $\overline{\text { Low Swirl }}-\overline{-}$ & $0 . \overline{2} \%$ & $0 . \overline{48 \%} \%$ \\
\hline
\end{tabular}

Table 3-15 Measured vs. calculated $\mathrm{CH}_{4}$ values in the product gas from the gasifier. The measured $\mathrm{CH}_{4}$ values are those measured at the scrubber exit.

Table 3-16 shows the measured concentration of $\mathrm{H}_{2} \mathrm{~S}$ compared to those calculated by thermodynamics and the CFD model. The measured concentrations are higher than those calculated, but show the same trends such as an increase in concentration with a lowering of the $\mathrm{A} / \mathrm{F}$ ratio. The spray from the venturi may well have interfered with the $\mathrm{H}_{2} \mathrm{~S}$ analysis at 
Final Technical Report Rev. 0 DE-FC26-04NT42259

the venturi exit, but because $\mathrm{H}_{2} \mathrm{~S}$ is removed in the scrubber, this data was thought to more accurately represent the gasifier exit composition than the $\mathrm{H}_{2} \mathrm{~S}$ concentration measured downstream of the scrubber. Both the CFD model and thermodynamic calculations give approximately the same $\mathrm{H}_{2} \mathrm{~S}$ concentrations indicating that thermodynamics likely does a reasonable job describing the distribution between $\mathrm{H}_{2} \mathrm{~S}$ and smelt for the New Bern gasifier.

\begin{tabular}{|c|c|c|c|c|}
\hline \multirow{2}{*}{$\begin{array}{c}\text { Date } \\
\text { of closest case }\end{array}$} & \multirow[b]{2}{*}{ Condition } & \multicolumn{3}{|c|}{$\mathrm{H}_{2} \mathrm{~S}$ (mol \%, dry gas) } \\
\hline & & Measured & Thermodynamic & CFD \\
\hline 20-Jun & Baseline & $0.25 \%$ & $0.17 \%$ & $0.24 \%$ \\
\hline $23-$ Jun & Baseline+lowering $\mathrm{A} / \mathrm{F}$ & $0.36 \%$ & $0.22 \%$ & $0.25 \%$ \\
\hline 23 -Jun & Baseline+lowest $\mathrm{A} / \mathrm{F}$ & $0.44 \%$ & $0.33 \%$ & $0.27 \%$ \\
\hline 17-Jun & High Firing Rate & $0.40 \%$ & $0 . \overline{17} \%$ & $0.24 \%$ \\
\hline 16-Jun & High Firing Rate+Low A $/ \bar{F}$ & $0.55 \%$ & $0.19 \%$ & $0.25 \%$ \\
\hline $15-$ Jun & Low Firing Rate & $0.29 \%$ & $0 . \overline{22} \%$ & $0.22 \%$ \\
\hline & Low Firing Rate+Low $\mathrm{A} / \mathrm{F}$ & & & $0.25 \%$ \\
\hline$\overline{21}-\overline{-J u n}$ & $\overline{\text { Low Swirl }}-$ & $0 . \overline{24} \%$ & $0.16 \%$ & $0 . \overline{2} 4 \%$ \\
\hline
\end{tabular}

Table 3-16 Measured, thermodynamically and CFD calculated $\mathrm{H}_{2} \mathrm{~S}$ values in the product gas from the gasifier. The measured $\mathrm{H}_{2} \mathrm{~S}$ values are those measured at the venturi exit.

The CFD model over-predicted the amount of unburned carbon, Table 3-17. This indicates that the kinetic models for char gasification are too slow or the residence time at temperature is too low. The CFD model predicts that the top section of the reactor is very cool so it is possible that this results in a low residence time at temperature or it may be that the kinetic model for char gasification is simply too slow. Future CFD calculations of the New Bern gasifier should consider a faster rate model for char gasification. Other than the reaction kinetics and residence time, the droplet size also has a significant impact on the unburned carbon prediction. As noted earlier (section 3.4.4) PSL used the droplet size predicted by Simulent's spray modeling. In the cases with varying A/F ratio at baseline firing rate, the CFD model predicts first an increase in unburned carbon and then a decrease. This is different from the measured trend of increasing unburned carbon with decreasing A/F ratio. This discrepancy suggests that the residence time, temperature profile and/or reaction kinetics in the CFD model needs to be adjusted as part of future work. 
Final Technical Report Rev. 0 DE-FC26-04NT42259

\begin{tabular}{|c|c|c|c|}
\hline \multirow{2}{*}{$\begin{array}{c}\text { Date } \\
\text { of closest case }\end{array}$} & \multirow[b]{2}{*}{ Condition } & \multicolumn{2}{|c|}{ Unburned C (mass \% in smelt) } \\
\hline & & Measured & CFD \\
\hline 20-Jun & Baseline & $0.13 \%$ & $5.99 \%$ \\
\hline 23 -Jun & Baseline+lowering $\overline{\mathrm{A}} / \mathrm{F}$ & $0.35 \%$ & $7 . \overline{46 \%} \%$ \\
\hline 23 -Jun & Baseline+lowest $\mathrm{A} / \mathrm{F}$ & $0.92 \%$ & $5.58 \%$ \\
\hline 17-Jun & High Firing Rate & $0.47 \%$ & $4 \overline{71} \%$ \\
\hline 16-Jun & High Firing Rate + Low $\mathrm{A} / \mathrm{F}$ & $1 . \overline{08} \%$ & $7 . \overline{58} \%$ \\
\hline & & & \\
\hline $15-\mathrm{Jun}$ & Low Firing Rate & $0.50 \%$ & $4.03 \%$ \\
\hline & Low Firing Rate + Low $\mathrm{A} / \mathrm{F}$ & & $2.44 \%$ \\
\hline & & & \\
\hline $21-J u n$ & Low Swirl & $2.00 \%$ & $5.59 \%$ \\
\hline
\end{tabular}

Table 3-17 Measured vs. CFD predicted unburned carbon in smelt (mass fraction).

In general, the measured and calculated values of gasifier product concentrations show reasonable response trends to changing operating conditions. The mass-energy balances and models indicate that the actual reactor temperature is significantly hotter than measured. Reducing the reactor temperature will increase thermal efficiency and likely result in longer refractory life. It will also result in more of the sulfur leaving the gasifier as $\mathrm{H}_{2} \mathrm{~S}$.

Finally, there are two areas where it appears possible to make improvements in the CFD model: the water gas shift reaction appears to be better represented by equilibrium rather than by kinetic calculations used in the CFD model, this is likely due to the very rapid kinetics resulting from the presence of sodium in the black liquor char. Secondly, the kinetics for char gasification should be increased in the CFD model of the New Bern gasifier to better represent the extent of carbon burn-out that is actually measured.

\subsubsection{CFD Model predictions for reactor temperature and velocity distribution}

In addition to the comparisons of product gas composition and temperature between the model predictions and the measurements, the distributions of temperature and velocity in the reactor by the CFD modeling are shown here. Figure 3-22 shows CFD predictions for the temperature distributions in the gasifier firing at normal load with different air/fuel ratios. The reactor has a higher temperature in the mid and lower part. Both exit gas temperature and the maximum temperature increases as the air/fuel ratio increases. 
Final Technical Report Rev. 0 DE-FC26-04NT42259
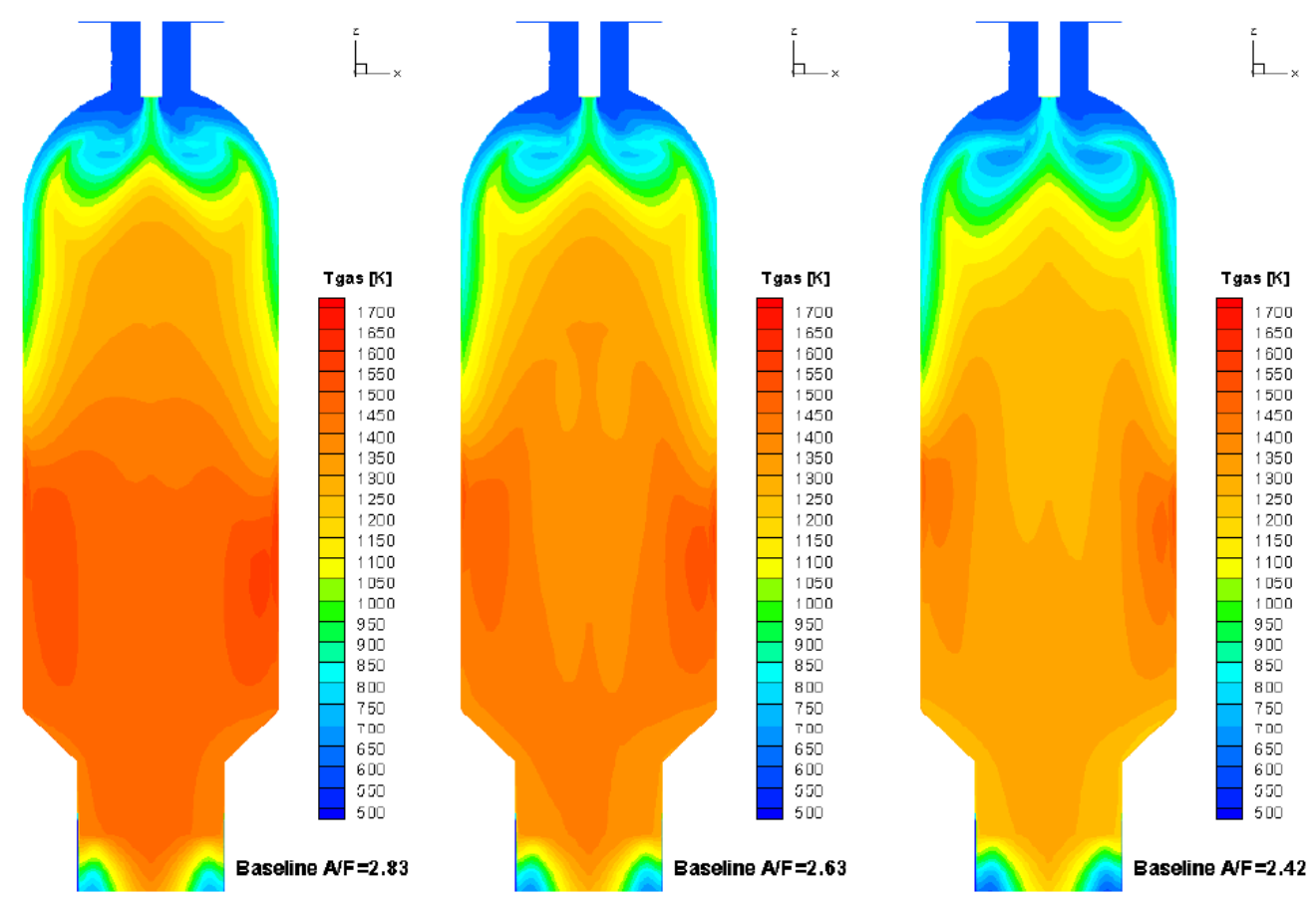

Figure 3-22 CFD predicted gas temperature in the gasifier at different air/fuel ratio

The CFD predicted impact of firing rate on the temperature distribution is seen in Figure 3-23 and Figure 3-24 for two different A/F ratios. At high air fuel ratio, the gas temperature distribution appears similar at mid and high firing rate but becomes less uniform at low firing rate. At low air fuel ratio, on the other hand, the impact of firing rate is significant. The product gas temperature is higher at high firing rate and the temperature is further nonuniform at low firing rate. The non-uniformity of the temperature at a low firing rate is believed a result of different flow pattern in the dome area, as shown by the vertical velocity distributions in Figure 3-25. There is a big recirculation zone under the dome at the reactor inlet and the flow appears unstable. The CFD model predicted impact of swirl level on the gas temperature is shown in Figure 3-26. It is seen that the gas temperature distribution becomes further non-uniform when the swirl is reduced. 
Final Technical Report Rev. 0 DE-FC26-04NT42259
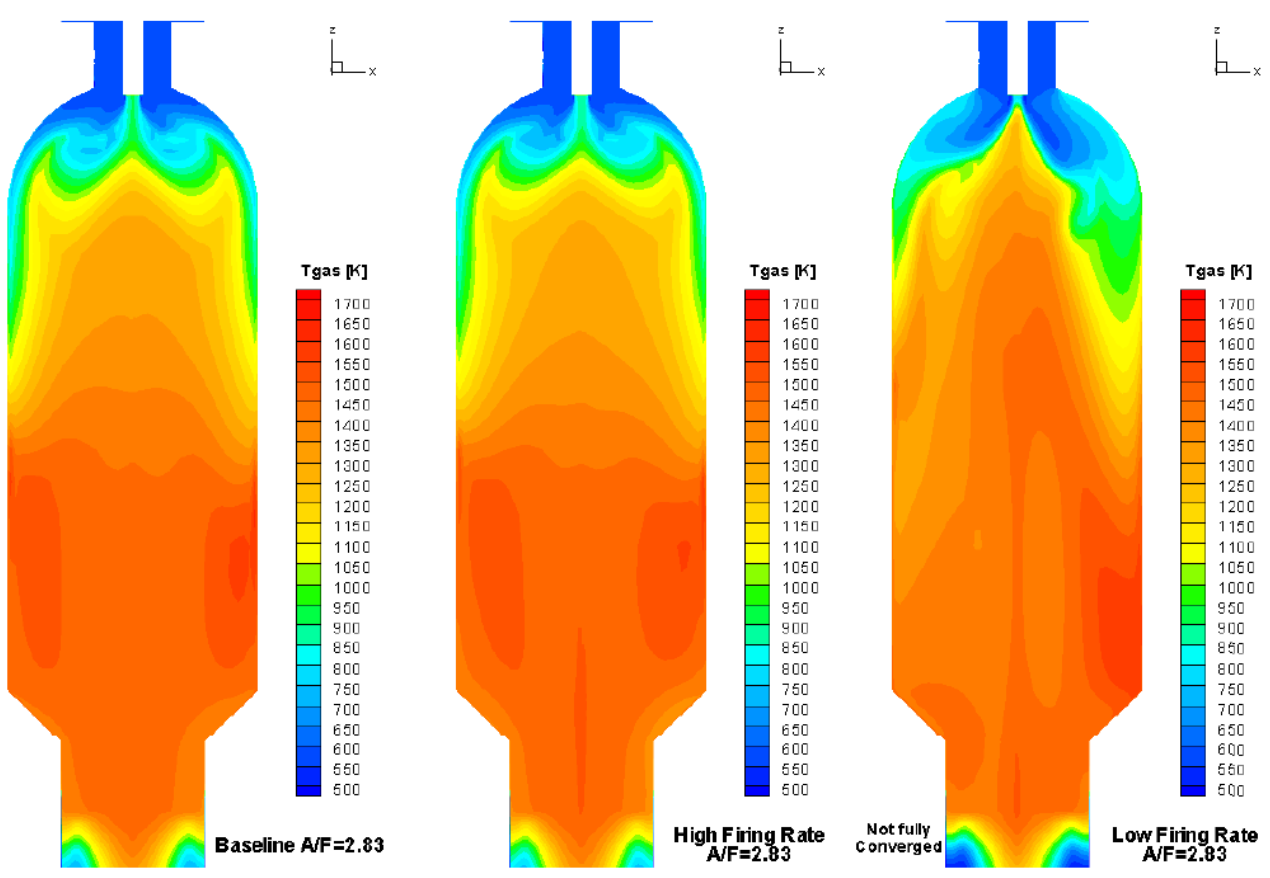

Figure 3-23 CFD predicted gas temperature at three firing rates with $A / F=2.83$
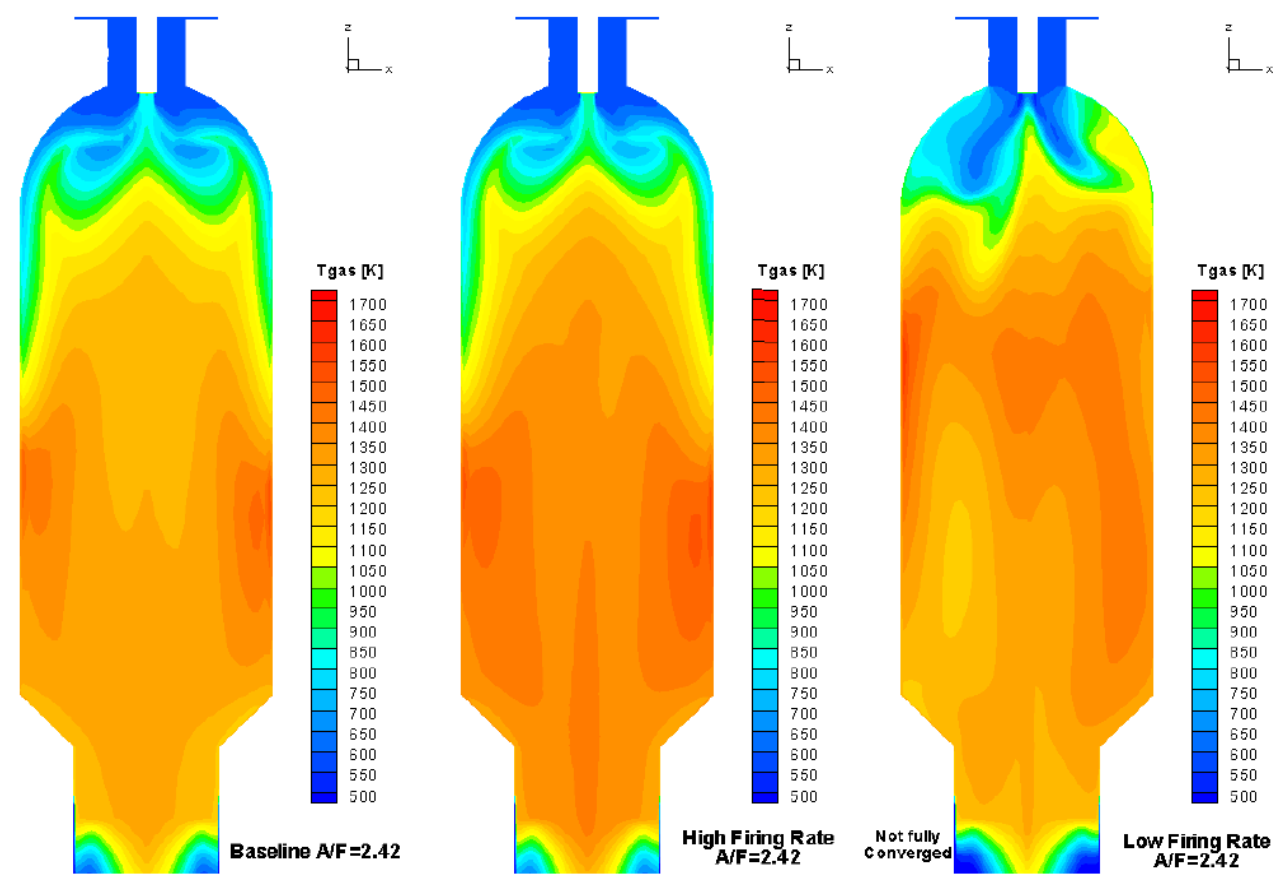

Figure 3-24 CFD predicted gas temperature at three firing rates with $\mathrm{A} / \mathrm{F}=\mathbf{2 . 4 2}$ 
Final Technical Report Rev. 0 DE-FC26-04NT42259

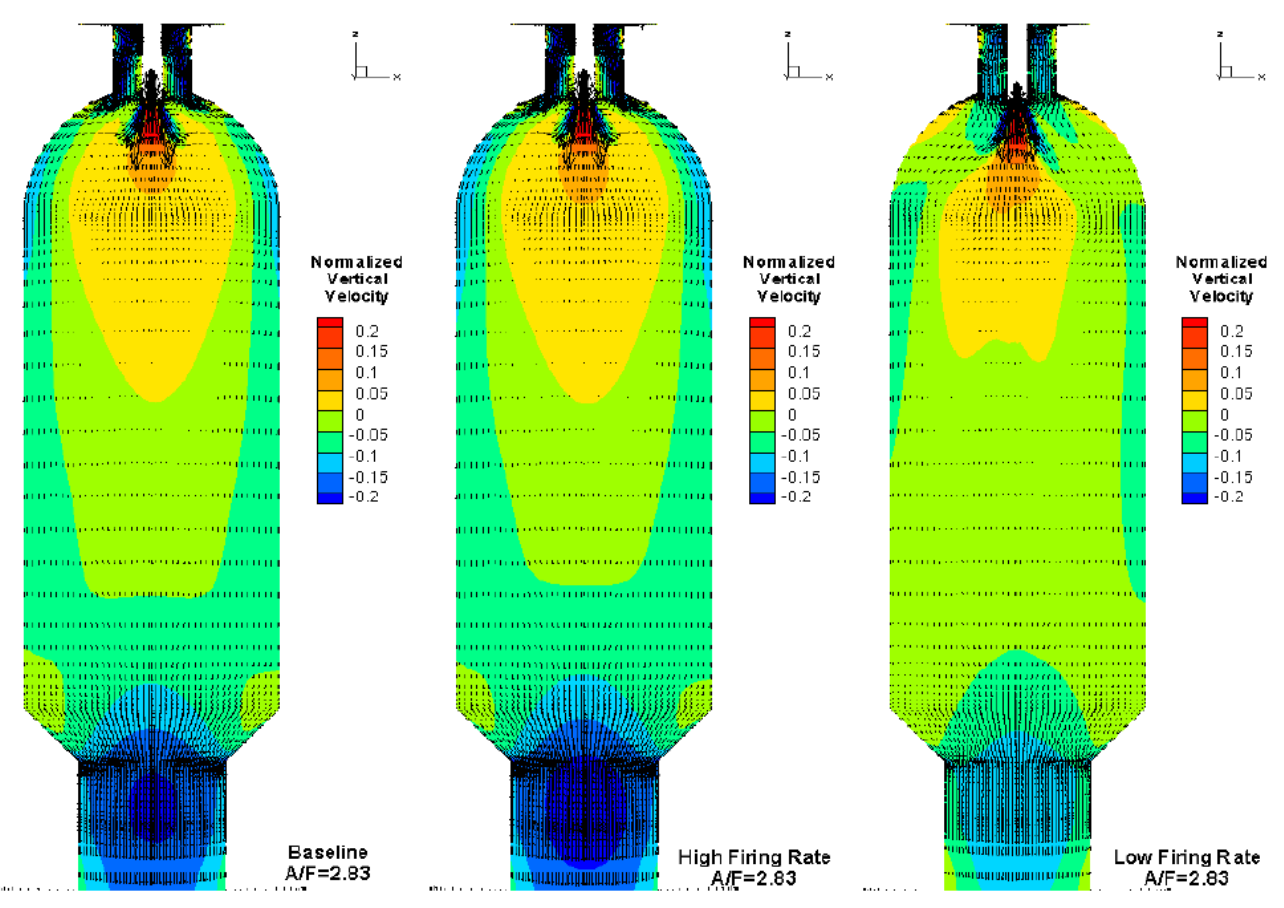

Figure 3-25 CFD predicted velocity distribution at three firing rate with $\mathrm{A} / \mathrm{F}=\mathbf{2 . 8 3}$
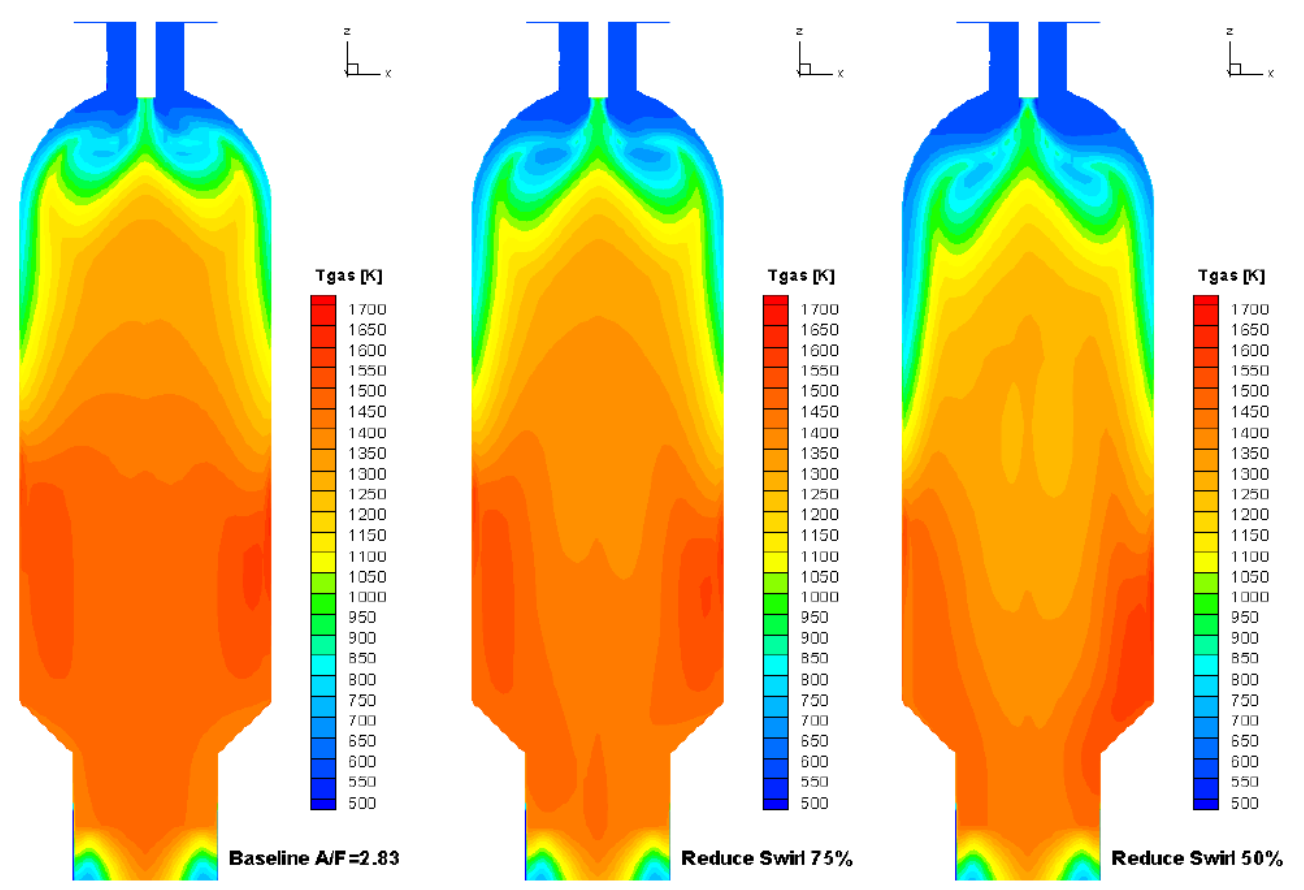

Figure 3-26 CFD predicted gas temperature distribution at three swirl levels 


\section{Final Technical Report Rev. 0 \\ DE-FC26-04NT42259}

\subsection{Reactor temperature measurement}

Reliability of the thermocouple system currently employed in the New Bern gasifier has not been good. The current technology typically has a life expectancy of four to eight months. Redundant installations are required to ensure that at least one unit is always in operation. The original plan called for design, implementation, and testing of alternative temperature measurement techniques during Phase I of the project. This proved impractical due the lack of commercial experience or offerings for the extremely harsh black liquor gasifier environment. Ultimately three alternative designs were considered and two of these fabricated. Only one of these has been tested at the writing of this report.

\subsubsection{Infrared System}

A design was developed for an infrared pyrometer method to measure reactor process temperature. The key advantage of an infrared technique is that no electronics sits inside the harsh reactor environment. The challenge is maintaining a clear field of view for the optical sensor. An infrared technique had been tried in 1987 at New Bern, but was abandoned due to this difficulty. In a proposed new concept, the infrared optical sensor would sit in a special manifold and measure the inside surface temperature of a ceramic tube inserted through the ceramic lining.

This type of design depends upon maintaining the integrity of the ceramic tube. If the tube breaks, hot corrosive gases will enter and the instrument will fail directly or due to "fogging" of the IR translucent lens. Based on previous experience at New Bern, maintaining the integrity of similar ceramic inserts is very challenging for several reasons; e.g., differential expansion between the reactor steel shell and refractory, thermal cycling, refractory hot surface spalling, smelt freezing and melting during shutdown and restart.

Furthermore, this type design has been deemed unsuitable for applications in pressurized reactors. In fact a similar system was built and tested outside the reactor environment in Piteå. At a HAZOP prior to installation in Chemrec's pressurized gasifier pilot in Piteå, it was determined to constitute a risk for gas leak if the IR translucent frit would break. The safety measures needed to cope with this risk were not considered worth the benefits compared to other alternatives at hand.

For these reasons further work on this type design was abandoned.

\subsection{2 “Slip-cast” Thermocouple}

The second alternative considered was a thermocouple solution where the thermocouple is imbedded in a solid, gas tight ceramic cover material which is resistant to the black liquor smelt. The "slip-cast" production method produces a very tight, high density well formed ceramic bodies is well known for other applications. After extensive trials to have this type of 
Final Technical Report Rev. 0

DE-FC26-04NT42259

thermocouple produced the idea was dropped. The key reason was the difficulty to find a place which could make the ceramic elements at the required length. It was also concluded that it would be very difficult to make the ceramic tubes sufficiently straight to fit the holes in the ceramic lining. Under production the material to be sintered is put under ultra high pressure and it needs to be absolutely homogeneous with respect to density. If this is not the case the thin element would come out crooked when all voids (unevenly distributed) are moved out of the material during compression.

\subsubsection{Commercial solution from entrained flow coal gasifiers}

An alternative way forward was to seek experiences from the industry dealing with slagging coal gasifiers at 1300 to $1500 \mathrm{deg}$ C. A commercial supplier was identified who had proven thermocouple design and application experience with entrained flow gasifiers. The supplier worked together with the project team to adapt their thermocouple design to the slagging black liquor gasifier environment.

An alternative design (AD) thermocouple was designed by the supplier specifically for service in the New Bern gasifier. An illustration of the AD thermocouple is shown in Figure 3-27. Two of these instruments were fabricated and installed during the October 2007 shutdown along with one original design (OD) thermocouple. One of the two AD units failed and was replaced by an OD type during a May 2008 outage. The other unit has seen more than one year of operation and was still in operation at the time of this report (November 2008). The AD thermocouples have shown a faster response time compared to the original reference system and tend to indicate $10-40^{\circ} \mathrm{C}$ hotter temperatures (see Figure 3-28). From reliability standpoint the $\mathrm{AD}$ thermocouple has proven to be at least equal to and perhaps better than the current technology. 
Final Technical Report Rev. 0

DE-FC26-04NT42259

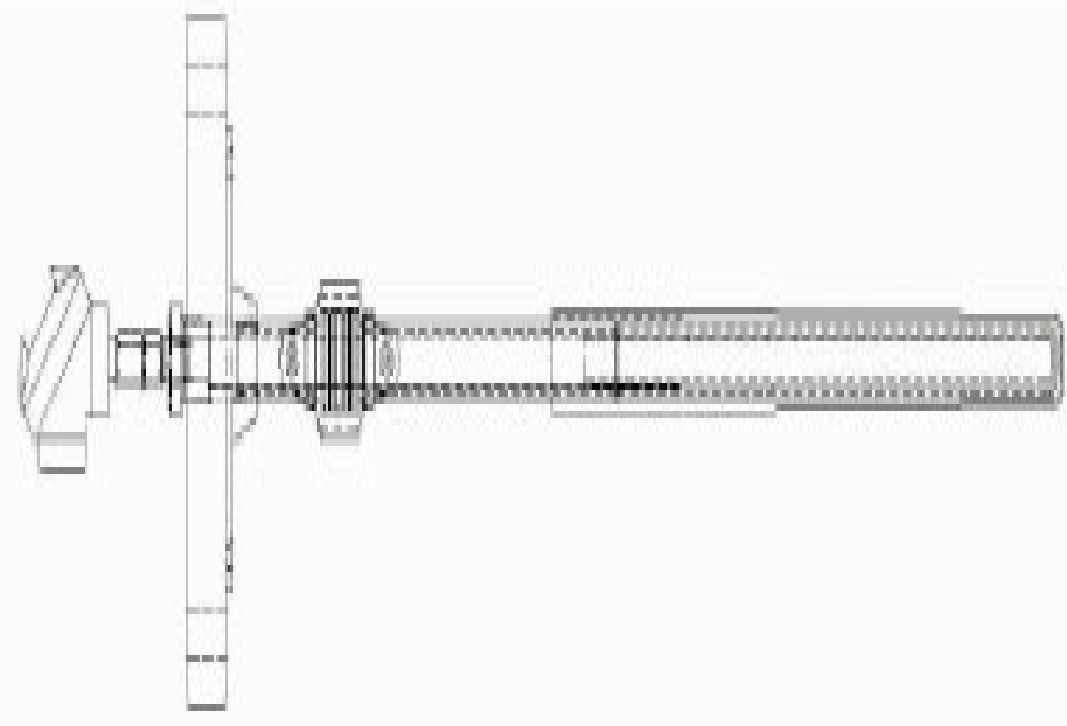

Figure 3-27 Alternative Thermocouple Design

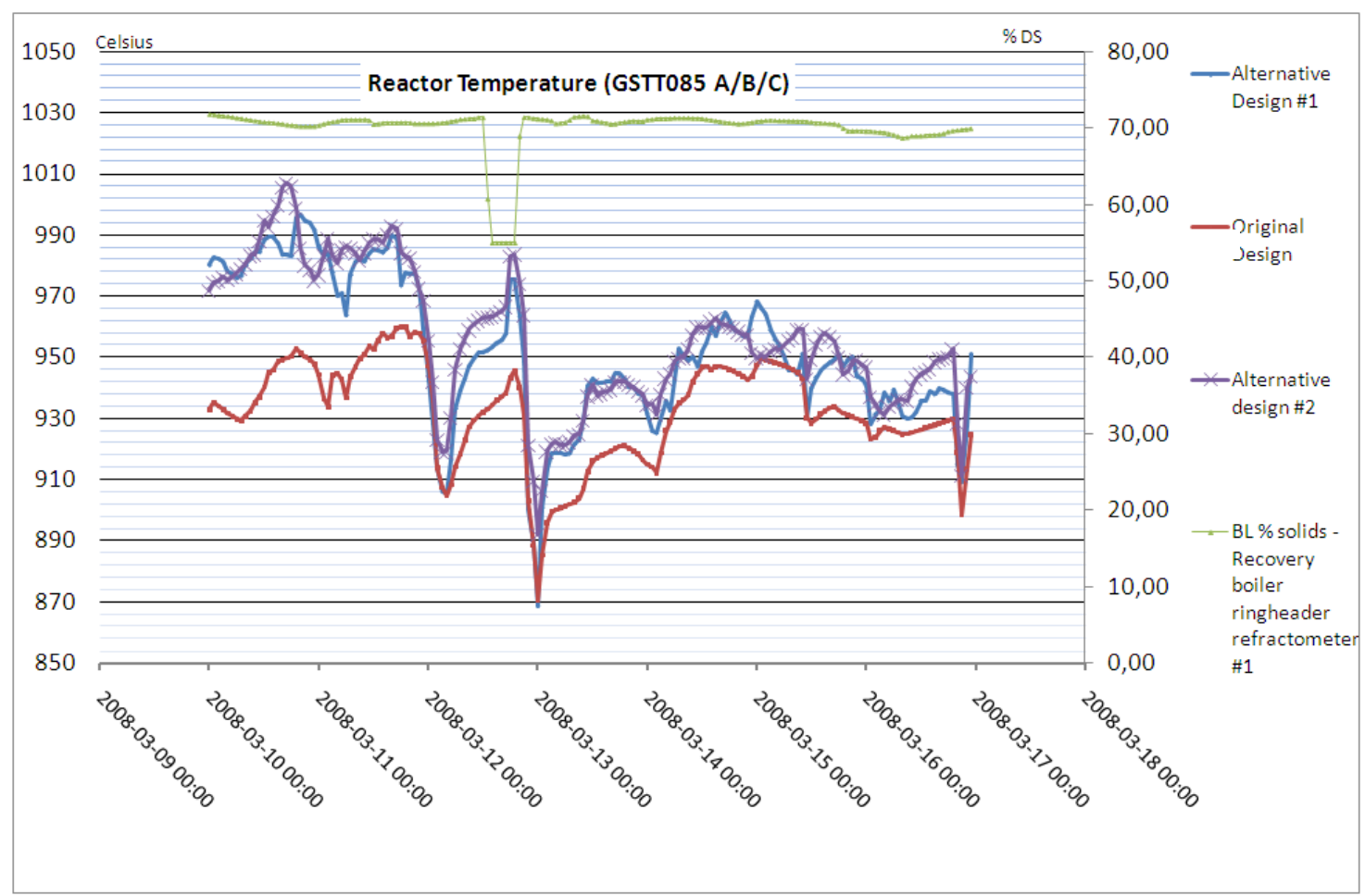

Figure 3-28 Comparison of outputs from original (OD) and alternate (AD) design thermocouples 
Final Technical Report Rev. 0

DE-FC26-04NT42259

\section{Task 2 - Improvements to the black liquor burner system}

The gasifier burner system is comprised of a black liquor nozzle and air distributor. The Phase I objective was to develop an improved burner concept design and procurement package for implementation in Phase II. The project team used the PSL and Simulent modeling capabilities developed in Task 1 to evaluate alternative means to improve overall gasifier performance and efficiency through improved burner system designs. Results from Chemrec's nozzle test rig in Piteå, Sweden along with nozzle CFD simulation conducted at ETC were also used to direct the work. Practical design alternatives were selected and a design, engineering, and procurement package prepared for implementation in Phase II of the project.

In Phase II the development process was completed and the burner improvements procured, installed and field tested. The proposed improvement incorporated both: a) modified and new black liquor spray nozzles for improved droplet generation, and b) a design modification for more uniform air distribution.

The results are organized as follows:

- Nozzle development

- Nozzle testing

- Burner air system upgrades (Distribution and pre-heating)

The results from the task 1 modeling and field testing activities suggested there was significant opportunity to improve gasifier performance through improvements to the burner design; i.e., to allow operation at lower air to fuel ratio while maintaining green liquor quality. In particular, the modeling work suggested that uneven air distribution and a non-optimized black liquor droplet size distribution force operators to compensate by running with higher air to fuel ratios (=higher reactor temperatures and lower efficiency). This mode of operation leads to higher operation and maintenance costs and reduced equipment reliability.

Therefore improvement to burner design became the primary focus of Phase II work with the aims to:

- Reduce power consumption (due to lower air flow required and lower cooling demand in scrubber)

- Extend refractory life (due to lower temperature)

- Improve green liquor quality

- Increase cold gas efficiency or higher fuel gas heating value of the product gas

- Lower maintenance costs (due to refractory and cooled support ring)

- Reduce downtime (due to refractory and cooled support ring maintenance) 
Final Technical Report Rev. 0

DE-FC26-04NT42259

Given the limited phase II budget, the work was directed toward modifications to the existing air distributor and black liquor burner nozzles rather than major replacements.

The mill also implemented an air/fuel ratio control strategy in the DCS during phase II. Though not explicitly part of the project phase II work plan, this was clearly driven by phase I results which demonstrated the importance and opportunity of maintaining lower air to fuel ratio in the gasifier.

\subsection{Black Liquor Nozzle Design and Testing}

Of course all nozzle development work ultimately aims at producing a nozzle which evenly distributes a cloud of droplets over the reactor cross-section, with all droplets in a narrow and well controlled size distribution. Preferably this capability is maintained over a large range of turndown and with low atomizing steam requirements and low pressure drop. Two improved nozzle pathways were pursued:

- The first was focused on incremental improvements to the existing T-type nozzle. This was done by analyzing the spray characteristics of the status quo T-nozzle both experimentally in the Piteå test rig and using the Simulent and ETC modeling tools. Deviations from the "ideal" condition were noted and proposed design modifications were evaluated using the modeling tools.

- The second pathway was directed at significant modifications to the existing platform and was dubbed the "New Concept Nozzle". This pathway used the CFD-modeling performed to generate a new Y-type concept nozzle that theoretically came closer to the goal of more narrow and well controlled size distribution.

\subsubsection{Incremental Improvements to T-nozzles}

One early result of both the Simulent and ETC modeling work suggested that black liquor was not uniformly distributed to the nozzle periphery prior to injection. Experimental and modeling analysis of the spray distribution suggested that this non-uniformity may be causing a "tail" in the size distribution containing relatively large droplets. If these larger droplets were forcing the operators to run at higher air to fuel ratio to complete burn-out, then there would be significant benefit to eliminating this characteristic of the existing nozzle design.

Chemrec directed ETC to conduct CFD model examinations of the existing and New Bern nozzle configuration and to propose modifications to even out the flow of black liquor entering the injector. Figure 4-1 below shows results of this work for the existing New Bern nozzle and six alternative design modifications. The flow was divided into four quadrants, Q1 to Q4 around the nozzle circumference. The figure shows the variation in flow between the quadrants for the original nozzle and six alternatives. In the existing design used in New Bern 
Final Technical Report Rev. 0 DE-FC26-04NT42259

today Q1 and Q4 added to about 66\% of the black liquor flow while Q2 and Q3 only had about $33 \%$. For the cases shown, if appears that the "big conduits" alternative best fulfill the criteria of uniform flow. During 2006 a number of new concepts for black liquor "conduits" were tested with CFD and one concept was chosen for optimization. In the new concept, three design parameters were picked for optimization. The target function was the uniformity of the flow distribution around the circumference of the atomizing chamber. A response surface method was used to optimize the three parameters and the final design improved the flow distribution substantially. Based on this work, Chemrec and ETC developed an alternative design where the flow of droplets leaving the hole of the nozzle is virtually even; the deviation from a theoretically even flow $(4 \times 25 \%)$ is less than $2 \%$ for any quadrant. This new design was designated $\mathrm{T} \# 1$.

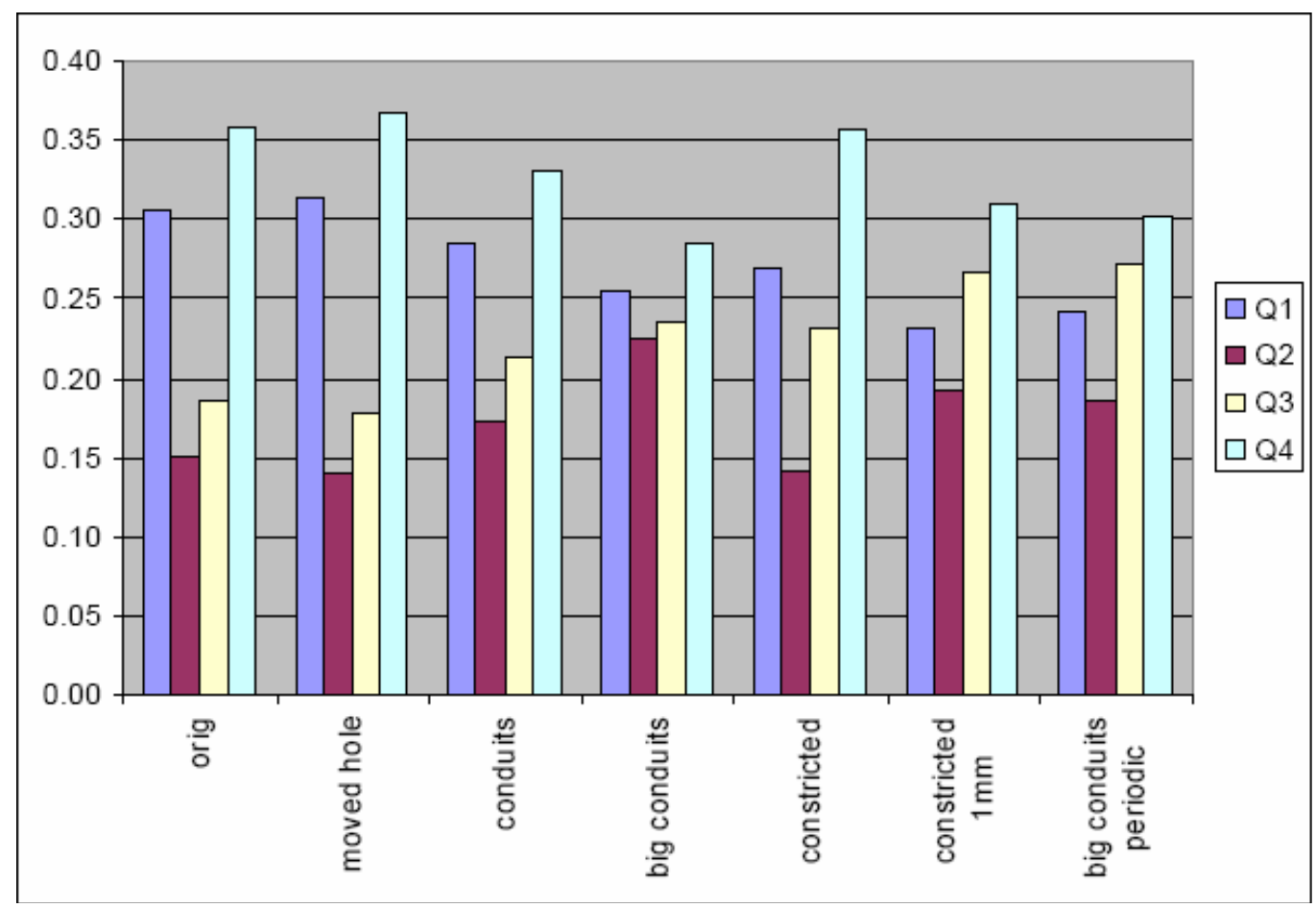

Figure 4-1 ETC CFD modeling results show distribution of flow at nozzle entrance for original and six alternative designs.

Two T\#1 nozzles were fabricated with the same design at local shops in Sweden and the US respectively. The T\#1 nozzle was evaluated during a February 17-March 27, 2007 test campaign. The results from these test runs have been analyzed (see section 4.1.3). Though not totally conclusive, there was evidence that the implemented changes in the T\#1 nozzle were leading in the right direction. Therefore the concept was further developed leading to T\#2 and $\mathrm{T \# 3}$ design concepts. Prior to release for fabrication, single nozzle versions of these were tested in the ETC test rig in Piteå. As a result, the T\#2 concept was released for fabrication and field testing during a second field test period in Feb-Mar, 2008. As indicated in the report 
Final Technical Report Rev. 0 DE-FC26-04NT42259

from the second test period (see section 4.1.4) the results were promising but not to the point where the existing standard T-nozzle could be economically replaced.

\subsubsection{New Y-Concept Nozzles}

In order to understand the potential for improvement, PSL replaced the baseline spray distribution with a uniform liquor spray. Figure 4-2 shows a comparison of the baseline case where all the droplets have the same injection velocity and initial droplet diameter (in this case 200 micron). Comparing the two baseline modeling results we noted that the maximum gas temperature in the gasifier is lower when using the uniform liquor spray. Also the unburned combustible (char) in the green liquor is lower in the uniform spray case. The final product gas temperatures for the two sprays are very close. These modeling cases demonstrated that there are opportunities to improve the gasifier performance and to make the temperature distribution more uniform by manipulating the liquor spray. 
Final Technical Report Rev. 0 DE-FC26-04NT42259
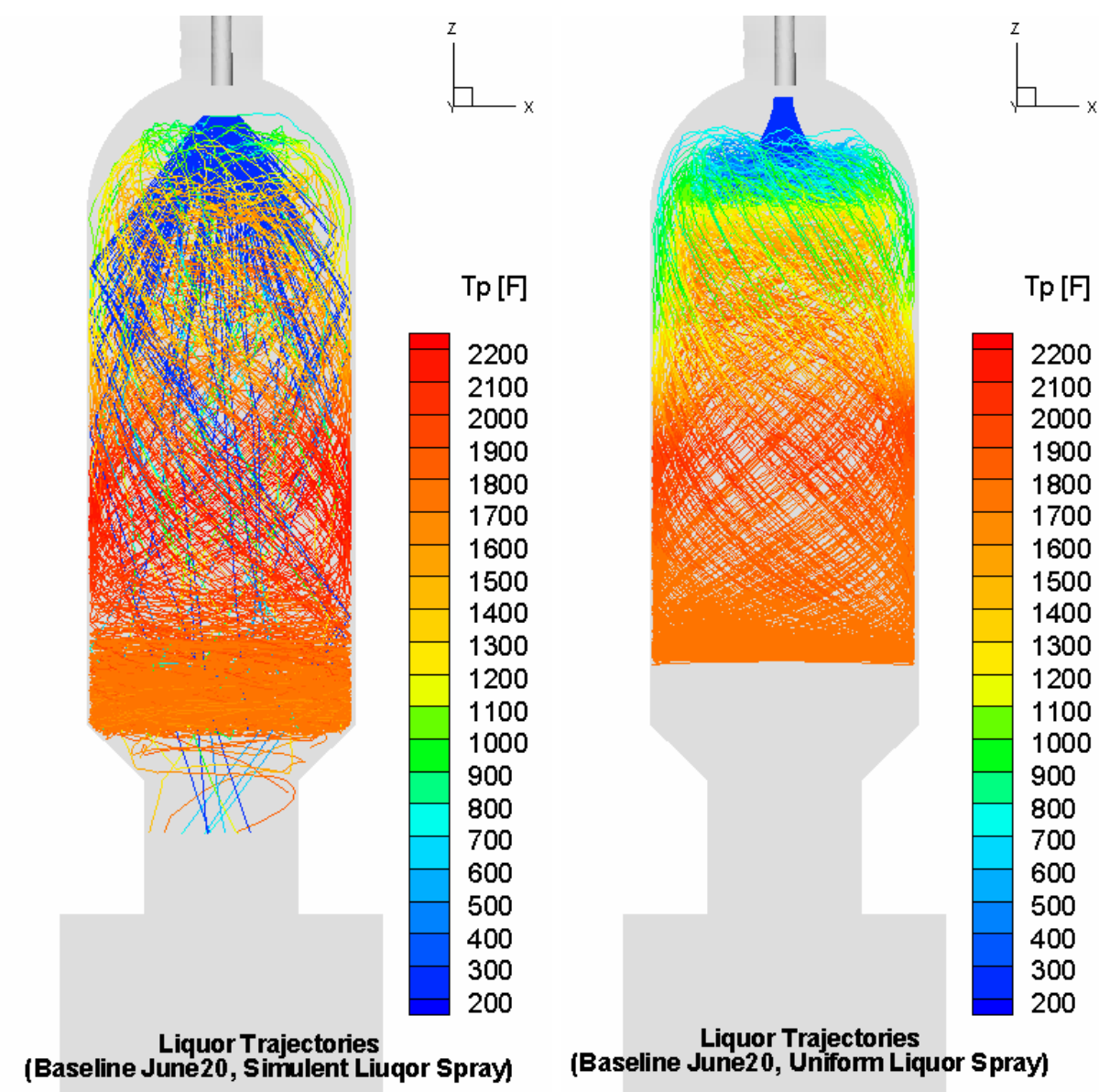

\section{Figure 4-2 CFD comparison of baseline and uniform droplet distributions}

Simulent developed a new black liquor nozzle concept requiring significant modifications to the existing "T" design. Simulent's CFD simulations of the existing nozzle suggested the following problems:

- A circulation zone in the existing nozzle core increases the possibility of sedimentation of the solid particles in the black liquor,

- Non-uniform distribution of liquor to the atomization chamber (same problem addressed by Chemrec-ETC above),

- Atomization chamber design promotes pulsations which produce a very broad size distribution.

Simulent's new concept nozzle design attempted to address each of these deficiencies. Preliminary simulations of the new concept nozzle produced a narrower size distribution, reduced mean drop size by $30 \%$, and also reduced droplet dispersion (see Figure 4-3). 
Final Technical Report Rev. 0 DE-FC26-04NT42259

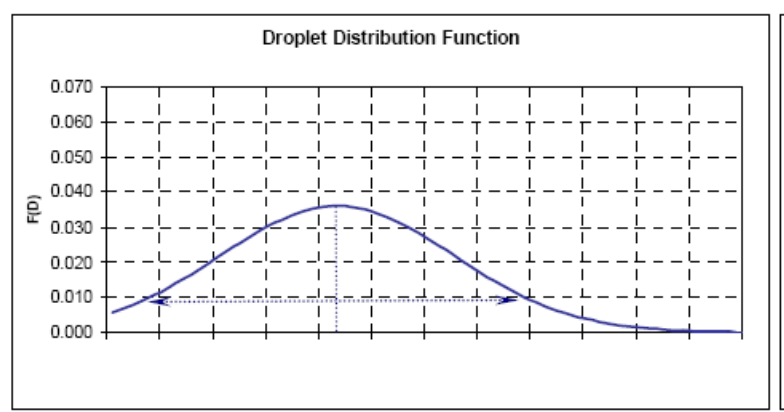

Existing Nozzle

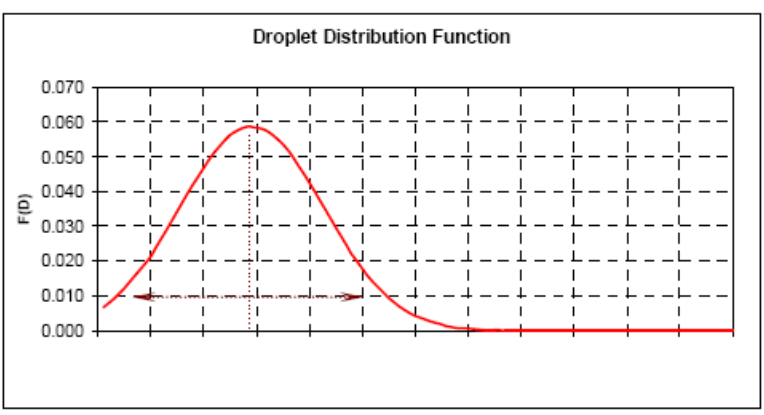

New Nozzle

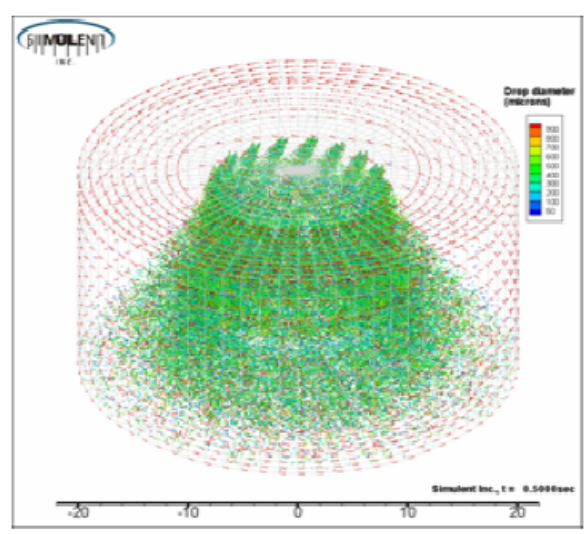

Existing Nozzle

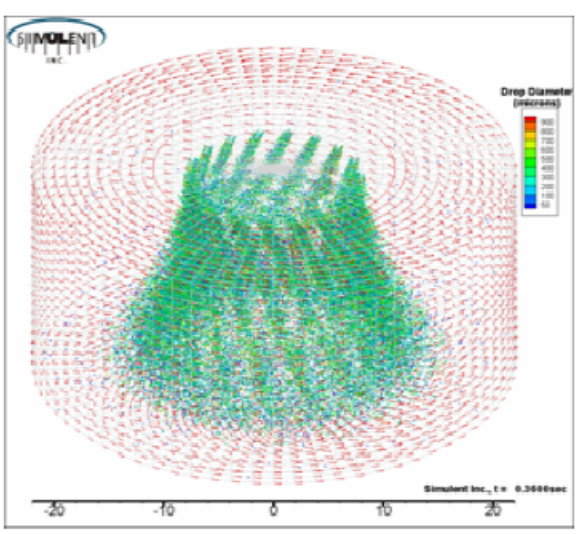

New Concept Nozzle

Figure 4-3 Comparison of Simulent's concept nozzle with existing nozzle.

PSL simulated the new nozzle concept in the full reactor CFD model. Results suggested that the proposed new concept design worked better in terms of quality of product gas and green liquor. Examples of the CFD simulations are shown in Figures 4-4 and 4-5. 
Final Technical Report Rev. 0 DE-FC26-04NT42259
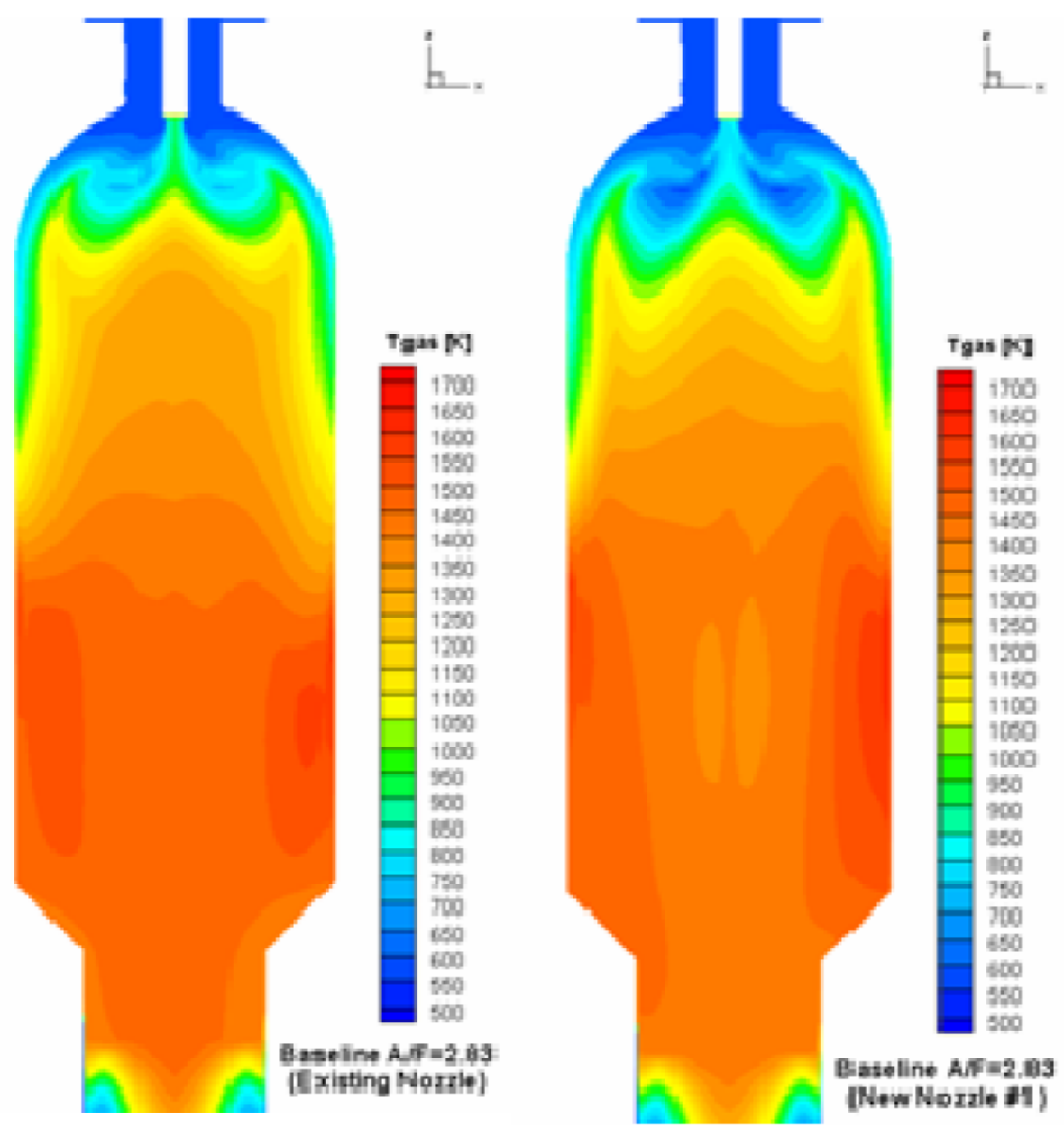

Figure 4-4 CFD comparison of reactor temperatures for the existing and new Simulent nozzles. 
Final Technical Report Rev. 0 DE-FC26-04NT42259
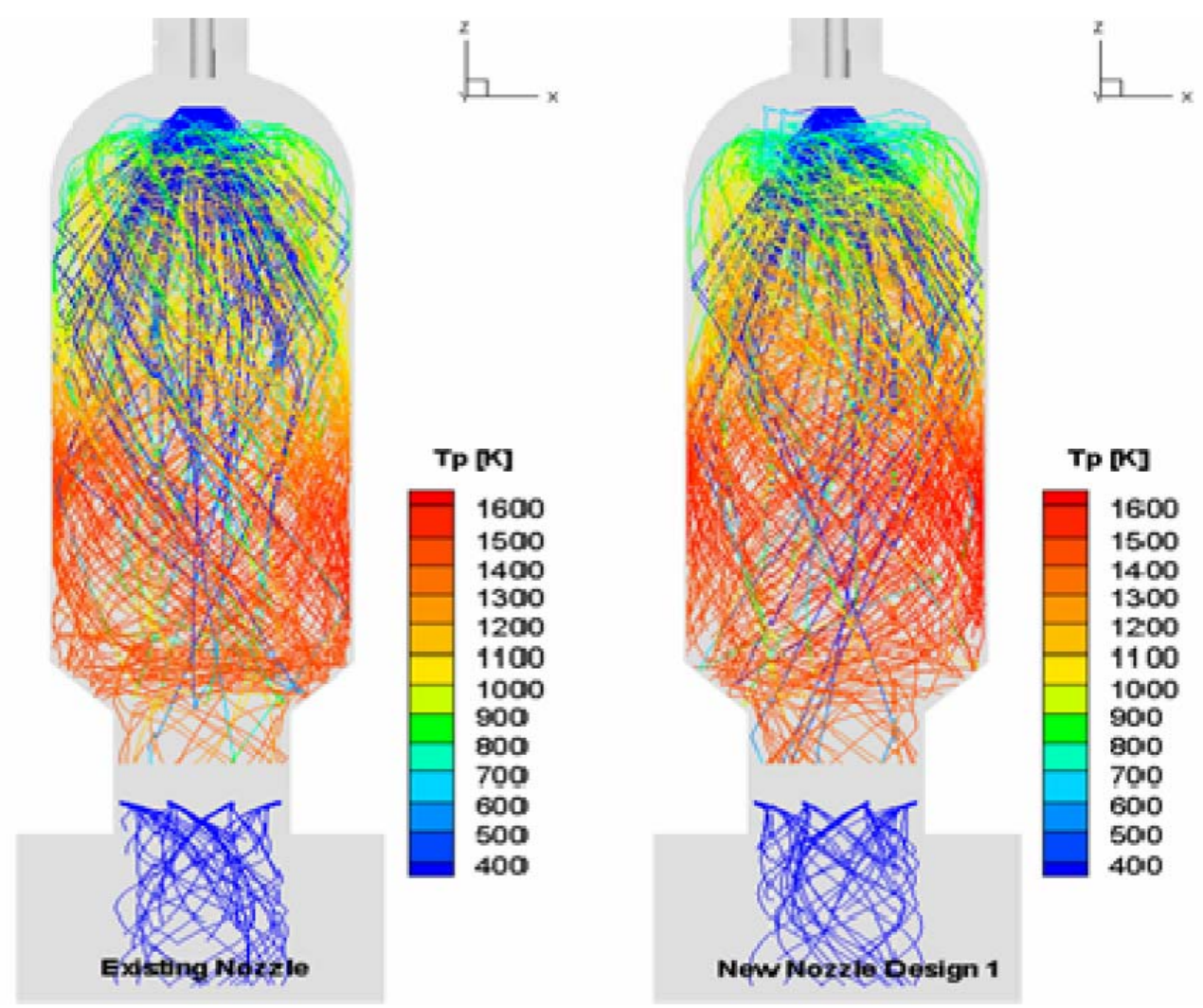

Figure 4-5 CFD comparison of droplet trajectories for the existing and new Simulent nozzles.

The Simulent design is based on a Y-type nozzle. The existing New Bern T-type nozzle has 18 individual internally steam-atomized nozzles mounted in a circle. The Y-type nozzle was designed using Simulent's advanced CFD simulation software. A cross section of one such nozzle is illustrated in Figure 4-6 below. The flow path of the black liquor was studied at three levels through the passage, A-C. 
Final Technical Report Rev. 0

DE-FC26-04NT42259

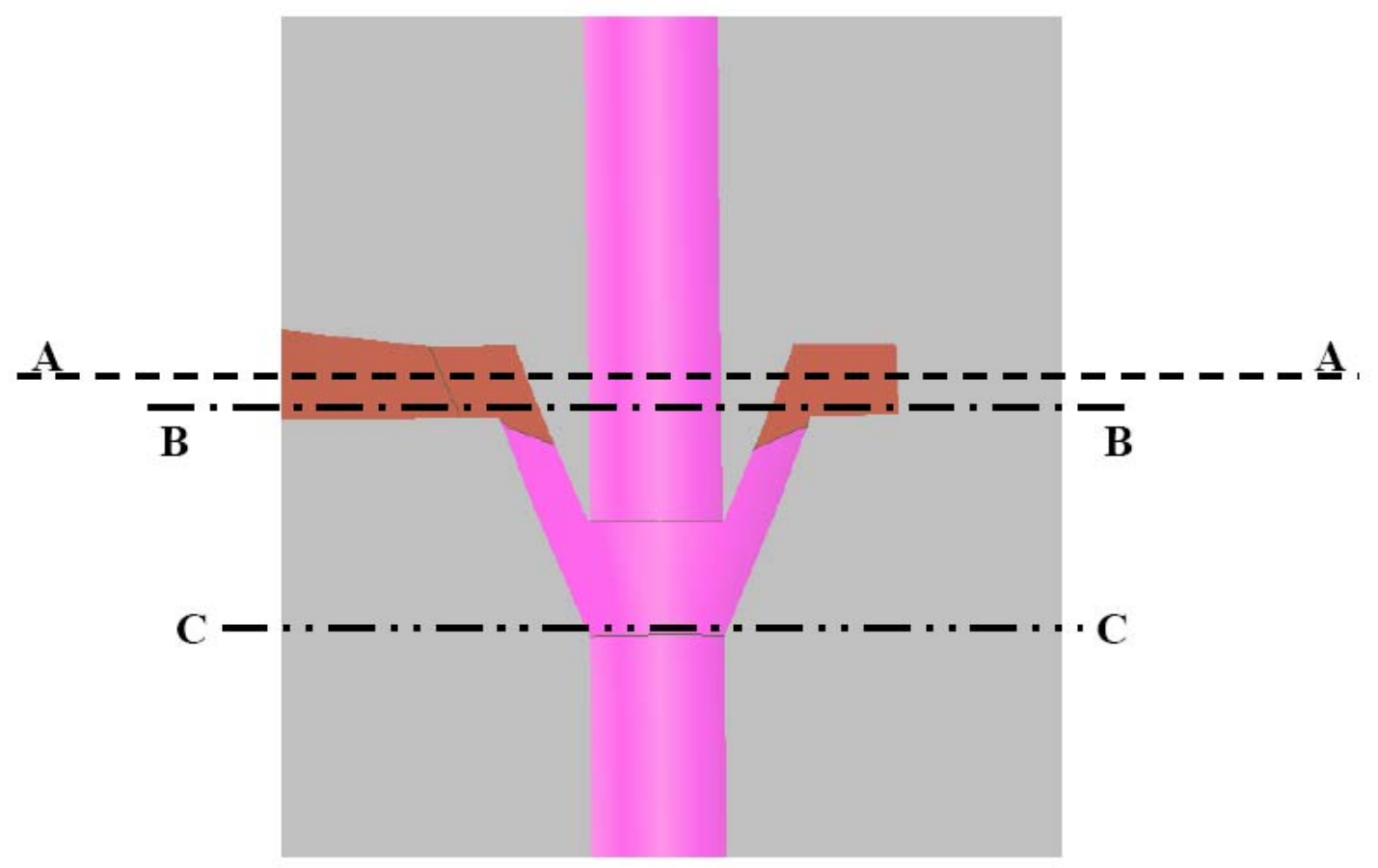

\section{Figure 4-6 CFD simulation area for one hole of a Y-type black liquor nozzle}

The black liquor flow for section A-A is illustrated in Figure 4-7. Just as in the case of the Ttype, the uneven flow distribution around the circle hole at the nozzle inlet level (A-A) is one of the key features addressed in the design effort. In the case of the Y-nozzle development, optimization of the design was ultimately determined by the impact on outlet size distribution as predicted by Simulent's advanced CFD spray model. This differs from the development of the T-type nozzles. Although both the Y-type and T-type nozzles were designed using CFD techniques, the size distribution impacts for the T-nozzles were actually measured at ETC's nozzle test facility in Piteå 
Final Technical Report Rev. 0 DE-FC26-04NT42259

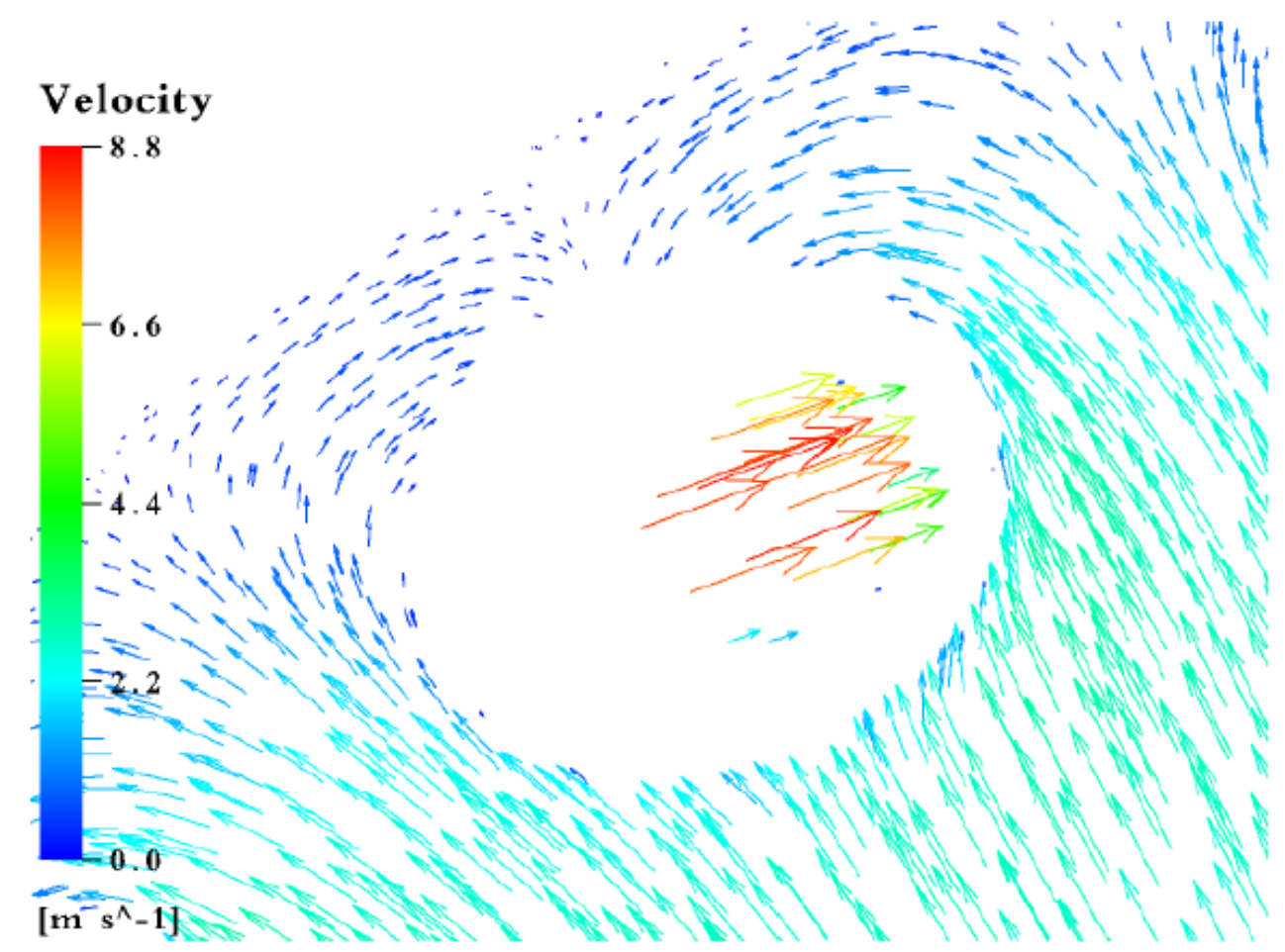

Figure 4-7 CFD simulation for black liquor flow at level A-A according to Figure 4-6

Two principally different Y-type concepts were developed, Y\#1 and Y\#2. Ultimately both were released for fabrication during September 2007. Fabrication of the Y-type nozzles is considerable more complex than the T-type, requiring very sophisticated $\mathrm{CNC}$ techniques and tight tolerances. The US supplier which supplied one of the T\#1 nozzles and normally supplies the standard nozzles to New Bern declined to bid on the new Y-designs. The Swedish supplier who supplies nozzles to Chemrec's Piteå plant and who also supplied the second T\#1 nozzle agreed to the fabrication. The Y\#1 and $\mathrm{Y} \# 2$ nozzles were supplied to New Bern for the second nozzle test period in Feb-Mar 2008. Results are presented in section 4.1.4.

\subsubsection{Nozzle Field Test Results: February - March 2007}

The primary objective of the February to March 2007 field testing was to compare performance of the new T\#1 nozzle to the standard T-type used in the New Bern reactor. The test plan was set up to elucidate the differences between the current and modified nozzle design. In particular, green liquor quality was measured as a function of varying air/fuel and atomizing steam use for each nozzle. The testing began with establishment of a reference baseline condition using a brand new standard $18 \mathrm{~T}$ nozzle. In each test, the liquor flowrate was set at $45 \mathrm{gpm}$ and the air and/or steam flow rates were reduced in steps until the green liquor quality worsened and the dregs would not settle (as determined by Imhoff cone tests). 
Final Technical Report Rev. 0 DE-FC26-04NT42259

Both the Swedish and US manufacture versions of the T\#1 nozzle were tested; although only one day of testing was available for the US version.

The primary analytical results included the dregs settling characteristics and composition. Dregs settling was qualitatively assessed and quantitatively measured using the Imhoff cone test. In addition the green liquor total suspended solids (TSS) were measured and the inorganic and organic (carbon content) composition of collected dregs were analyzed

In Table 4-1 the starting point and the point at which the dregs principally do not settle are indicated. The target firing rate for the test period was set by mill liquor inventories and priorities. During the February/March test period this corresponded to around $45 \mathrm{gpm}$. The firing rate was kept constant during this period.

\begin{tabular}{ccccc}
\hline Date & Nozzle & Test Conditions & Air flow (kpph) & Stm. flow (kpph) \\
\hline 17-Feb-07 & std 18T & Baseline ( 45gpm) & 47.0 & 6.1 \\
18-Feb-07 & std 18T & Baseline & 41.5 & 6.1 \\
19-Feb-07 & mod 18T SWE & Baseline / red A/F & $45.0 \searrow 39.9$ & 6.0 \\
20-Feb-07 & std 18T & Baseline & 44.5 & 6.1 \\
21-Feb-07 & std 18T & Baseline & 40.2 & 6.1 \\
22-Feb-07 & mod 18T SWE & Reduced steam & 45.0 & $5.7 \searrow 4.7$ \\
23-Feb-07 & mod 18T SWE & Red. steam and A/F & $42.0 \searrow 40$ & $5.3 \searrow 4.8$ \\
24-Feb-07 & std 18T & Reduced steam & 45.0 & $5.9 \searrow 4.9$ \\
- & - & - & - & - \\
27-Mar-07 & mod 18T US & Reduced A/F & $44.5 \searrow 40.0$ & 6.5 \\
\hline
\end{tabular}

Table 4-1 Test Conditions for Feb/Mar 2007 nozzle testing

Part way through the testing period the mill's annual shutdown was taken. During the shutdown a diffuser plate was installed in the gasifier air inlet to promote more uniform air distribution (see section 4.2.1). The plan was to repeat the February tests with the air distribution plate in place. However, unexpected problems occurred following the restart and commencement of the 2 nd test was delayed. Only a single nozzle test was carried out with the diffuser plate in place on March 27. This was also the only test with the US fabricated T\#1 nozzle.

Generally, the trials showed no significant overall difference between the standard and modified nozzles. There were some positive aspects that needed to be further addressed and verified in future tests. For instance, as shown in Figure 4-8, the modified 18T nozzle tended to show better Total Suspended Solids (TSS) compared to the standard 18T nozzle at some air to fuel ratios, but the results were mixed. 
Final Technical Report Rev. 0

DE-FC26-04NT42259

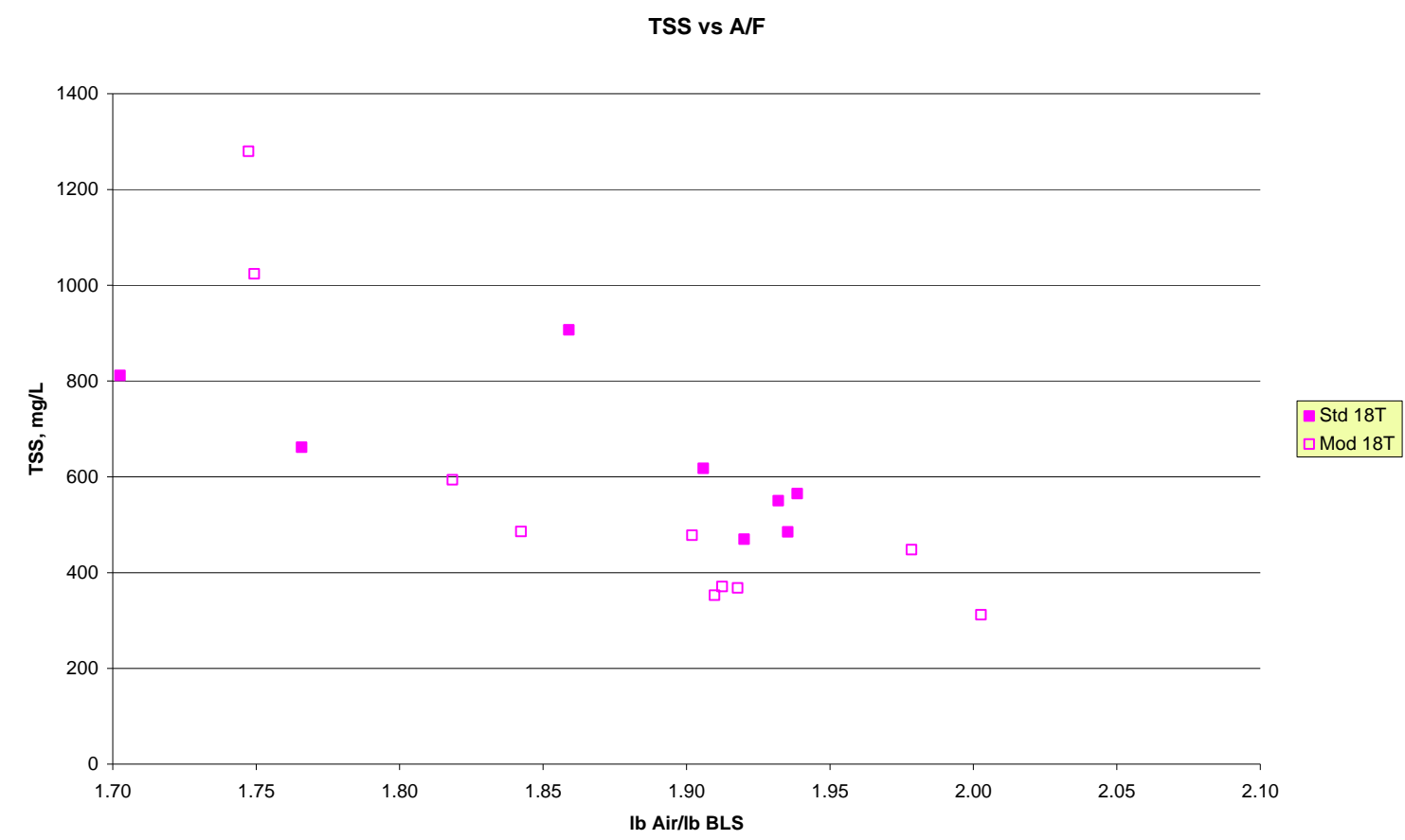

Figure 4-8 Total Suspended Solids versus A/F ratio for the standard and modified 18T (T\#1) nozzle

In the Figure 4-9, a few samples taken at constant $\mathrm{A} / \mathrm{F}(\sim 1.93)$ for various atomizing steam loads are shown. Lowering atomizing steam flow and pressure is believed to reduce erosion of the nozzle and prolong its time in service. For the mill, lower steam requirements also mean lower operating costs. The atomizing steam was lowered in distinct steps until the green liquor quality was unacceptable. The results cannot be deemed as general, although they indicate that the modified nozzle performs better than the standard nozzle at the selected operating conditions. It should be noted that the $\mathrm{A} / \mathrm{F}$ was slightly higher (1.95) for the standard nozzle compared to the modified nozzle where the ratio was lower (1.91). 
Final Technical Report Rev. 0

DE-FC26-04NT42259

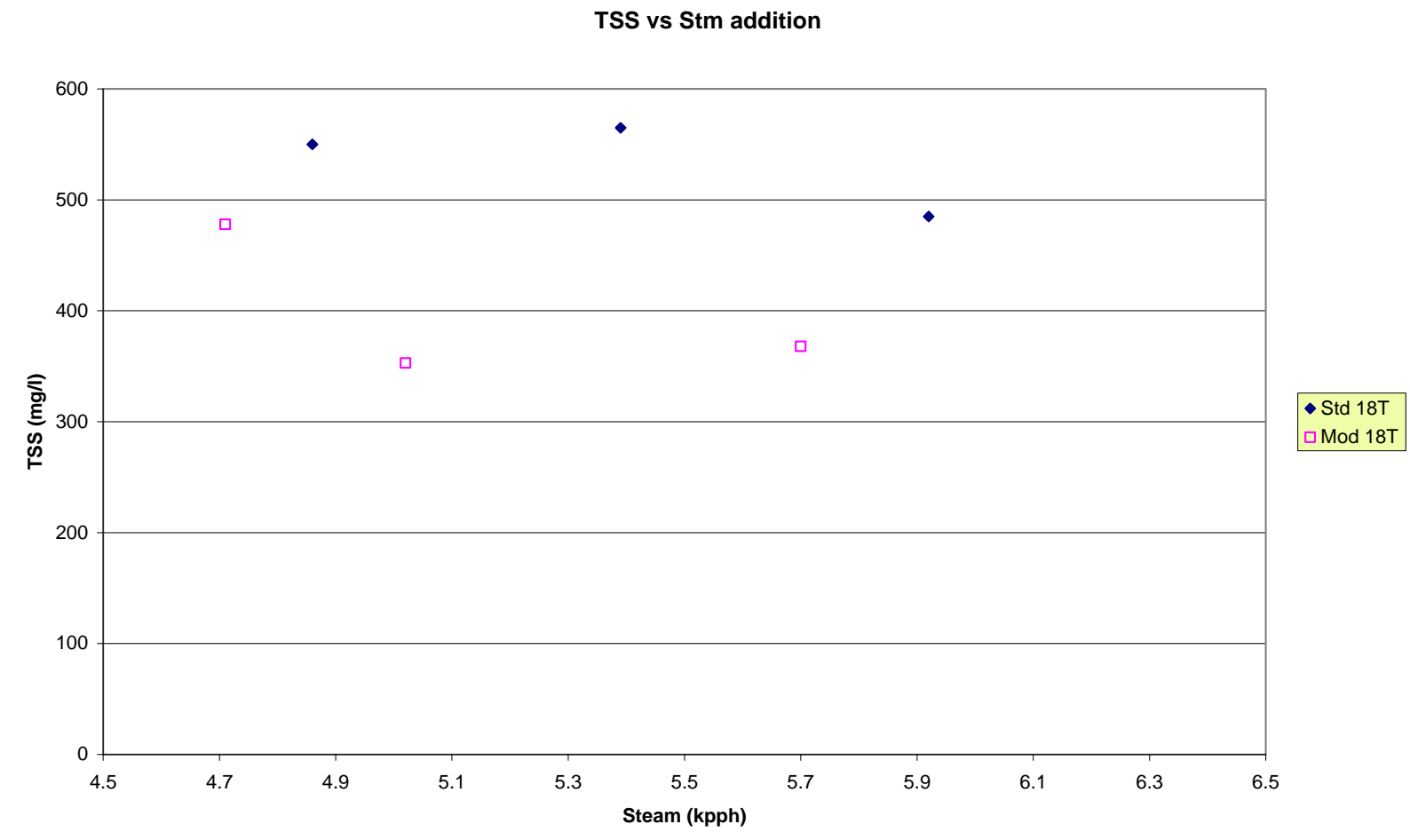

Figure 4-9 TSS vs steam addition at constant (A/F ratio) for the standard and modified $18 \mathrm{~T}$ (T\#1) nozzle

Looking in more detail at the dregs composition some differences between the two nozzles are revealed. The organic carbon content in the dregs was measured and is shown in Figure 4-10. The dregs contained $14-55 \%$ of organic carbon. As expected, the organic carbon content in dregs increases as the $\mathrm{A} / \mathrm{F}$ ratio is decreased. The modified nozzle gave somewhat higher dregs organic carbon contents than the standard nozzle. This means a somewhat lower carbon conversion and poorer settling and filterability characteristics. 
Final Technical Report Rev. 0

DE-FC26-04NT42259

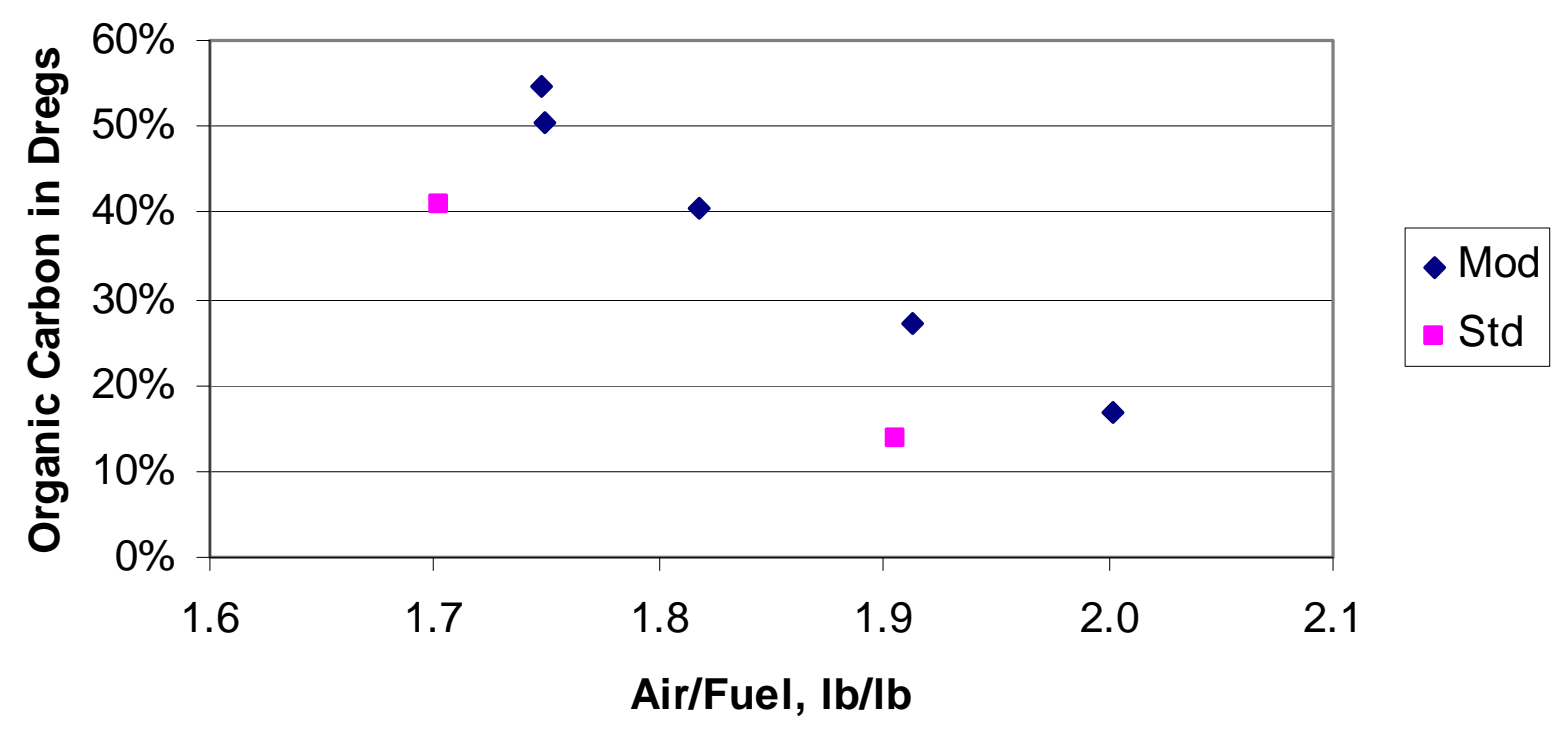

Figure 4-10 The dregs organic carbon content given as a function of $\mathrm{A} / \mathrm{F}$ ratio for the standard and the modified $\mathrm{T} \# 1$ nozzle

An important measure for the efficacy of the gasification is the fraction of input liquor carbon that remained un-burnt. In addition, it had been observed in earlier tests that higher carbon fraction and hence lower inorganic fraction of dregs may reduce green liquor quality by producing poorer settling and less filterable dregs. Figure 4-11 depicts the fraction of liquor carbon that was found as organic carbon in the green liquor dregs. This fraction varied between 0.1 and $1.2 \%$, and it increased as expected when the air-to-fuel ratio was decreased. 
Final Technical Report Rev. 0

DE-FC26-04NT42259

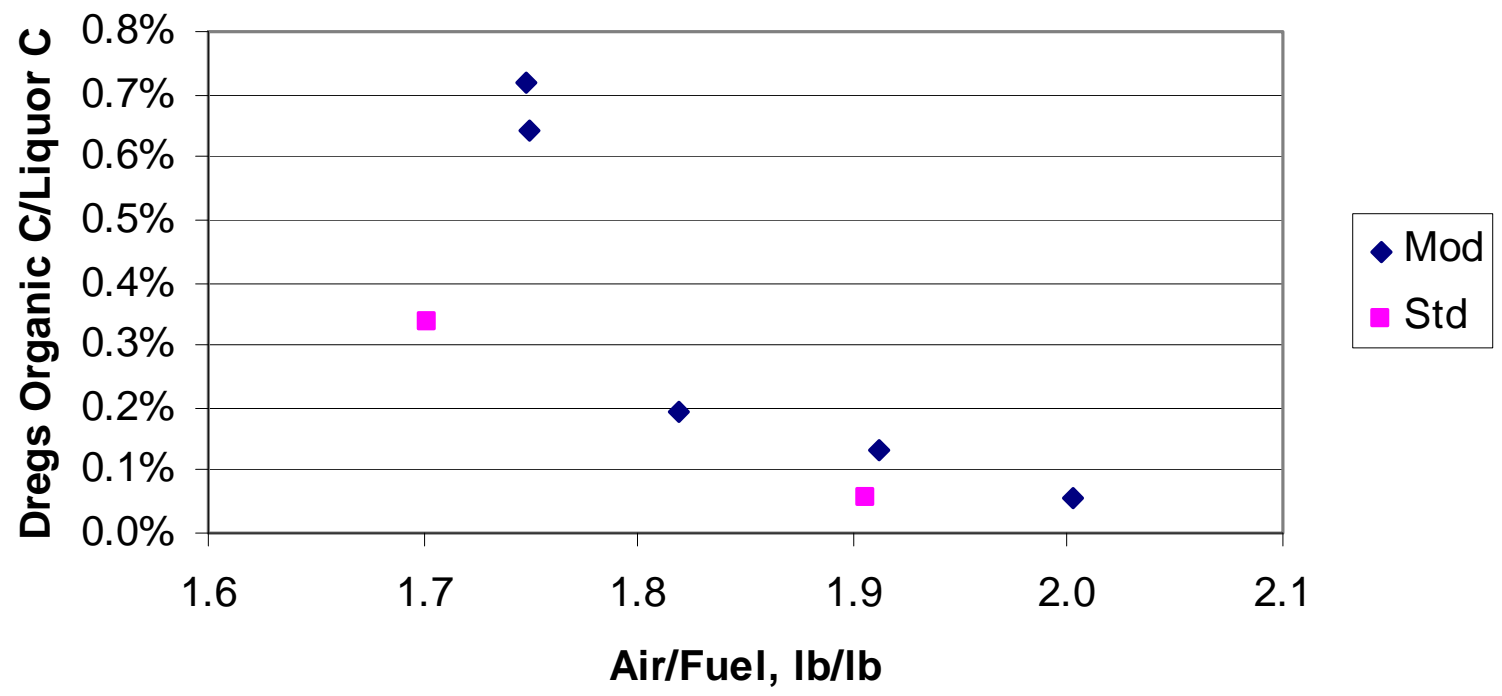

Figure 4-11 Fraction of black liquor carbon remaining as organic carbon in the green liquor

The March test period was meant to be a repeat of the February test period, except that a new air distribution plate was installed. Also during the shutdown, the vertical position of the liquor nozzle was checked and adjustments were made. Unfortunately, problems were experienced following the restart. Ultimately the problems were attributed to the design of the air distributor plate (see section 4.2.2). Only one test was conducted in March. Even though the results were in line with the February tests, it was difficult to compare due to the other changes mentioned above.

In summary, the modified $\mathrm{T} \# 1$ nozzle did not offer any significant improvement over the standard $18 \mathrm{~T}$ nozzle. Although atomizing steam requirement for the new nozzle appeared slightly less than for the standard nozzle, the TSS and dregs organic content were higher for the T\#1 nozzle at lower air/fuel.

\subsubsection{Nozzle Field Test Results: February - March 2008}

During the period 18th February to the 7th March 2008 a second nozzle test period was carried out. The test-plan in brief was;

- To establish a baseline operation case with the reference Standard 18 T Nozzle then to be compared with:

- Test Nozzle T-type, T\#2, developed together with ETC (Nozzle with extra steam turbulence) 
Final Technical Report Rev. 0 DE-FC26-04NT42259

- Test Nozzle Y-type, Y\#1, developed together with Simulent (inlet holes directed tangential)

- Test Nozzle Y-type, Y\#2, developed together with Simulent (inlet holes directed radial)

As in the past, the critical acceptance criterion for nozzle performance used is acceptable Imhoff cone measurements of dregs settling as a measurement of Green Liquor (GL) quality.

The actual test-runs made are listed in Table 4-2. The Imhoff cone results for each test along with the black liquor firing rate are shown in Figure 4-12. Generally, below $100 \mathrm{ml} / 1$ is considered good settling behaviour and above $250 \mathrm{ml} / 1$ unacceptable. During normal operation the mill operators take action between 125-175 ml/1 depending on other conditions. and described for each nozzle in the subsequent sub-sections.

\begin{tabular}{|c|c|c|c|c|}
\hline Test Description & Nozzle & Test Start & Test End & $\begin{array}{c}\text { Test } \\
\text { duration } \\
\text { (hours) }\end{array}$ \\
\hline Baseline & Std 18T & 2-21-08 1:00 PM & 2-21-08 2:00 PM & 1,00 \\
\hline Baseline & Std 18T & 2-21-08 2:30 PM & 2-21-08 3:00 PM & 0,50 \\
\hline Baseline & Std 18T & 2-21-08 3:00 PM & 2-21-08 3:30 PM & 0,50 \\
\hline Baseline & Std 18T & 2-21-08 4:00 PM & 2-21-08 5:00 PM & 1,00 \\
\hline Baseline & Std 18T & 2-21-08 5:45 PM & 2-21-08 6:15 PM & 0,50 \\
\hline ETC Swirler, & ETC T\#2 & 2-23-08 10:30 AM & 2-23-08 1:10 PM & 2,67 \\
\hline ETC Swirler & ETC T\#2 & 2-23-08 1:50 PM & 2-23-08 4:10 PM & 2,33 \\
\hline stableperiod & ETC T\#2 & 2-24-08 2:30 AM & 2-24-08 9:30 AM & 7,00 \\
\hline low A/F & ETC T\#2 & 2-24-08 10:30 AM & 2-24-08 11:30 AM & 1,00 \\
\hline lower A/F & ETC T\#2 & 2-24-08 12:28 PM & 2-24-08 1:55 PM & 1,45 \\
\hline Counterswirler, & $\mathrm{Y \# 1^{ \circ }}$ & 2-25-08 4:50 PM & 2-25-08 5:40 PM & 0,83 \\
\hline $\begin{array}{l}\text { period to reflect } \\
\text { sample/ Baseline }\end{array}$ & Std 18T & 2-28-08 4:00 AM & 2-28-08 10:00 AM & 6,00 \\
\hline $\begin{array}{l}\text { period to reflect } \\
\text { sample/ Baseline }\end{array}$ & Std 18T & 2-28-08 1:00 PM & 2-28-08 5:00 PM & 4,00 \\
\hline $\begin{array}{l}\text { period to reflect } \\
\text { sample/ Baseline }\end{array}$ & Std 18T & $2-29-084: 00 \mathrm{AM}$ & 2-29-08 9:30 AM & 5,50 \\
\hline $31 \mathrm{gpm}$ & $\mathrm{Y \# 2}$ & 3-5-08 3:00 PM & 3-5-08 10:00 PM & 7,00 \\
\hline $45 \mathrm{gpm}$ & Y\#2 & 3-6-08 7:50 AM & 3-6-08 8:10 AM & 0,33 \\
\hline $45 \mathrm{gpm}$ high steam & Y\#2 & 3-6-08 8:50 AM & 3-6-08 9:00 AM & 0,17 \\
\hline
\end{tabular}

Table 4-2 Test conditions for Feb/Mar 2008 nozzle trials 
Final Technical Report Rev. 0

DE-FC26-04NT42259

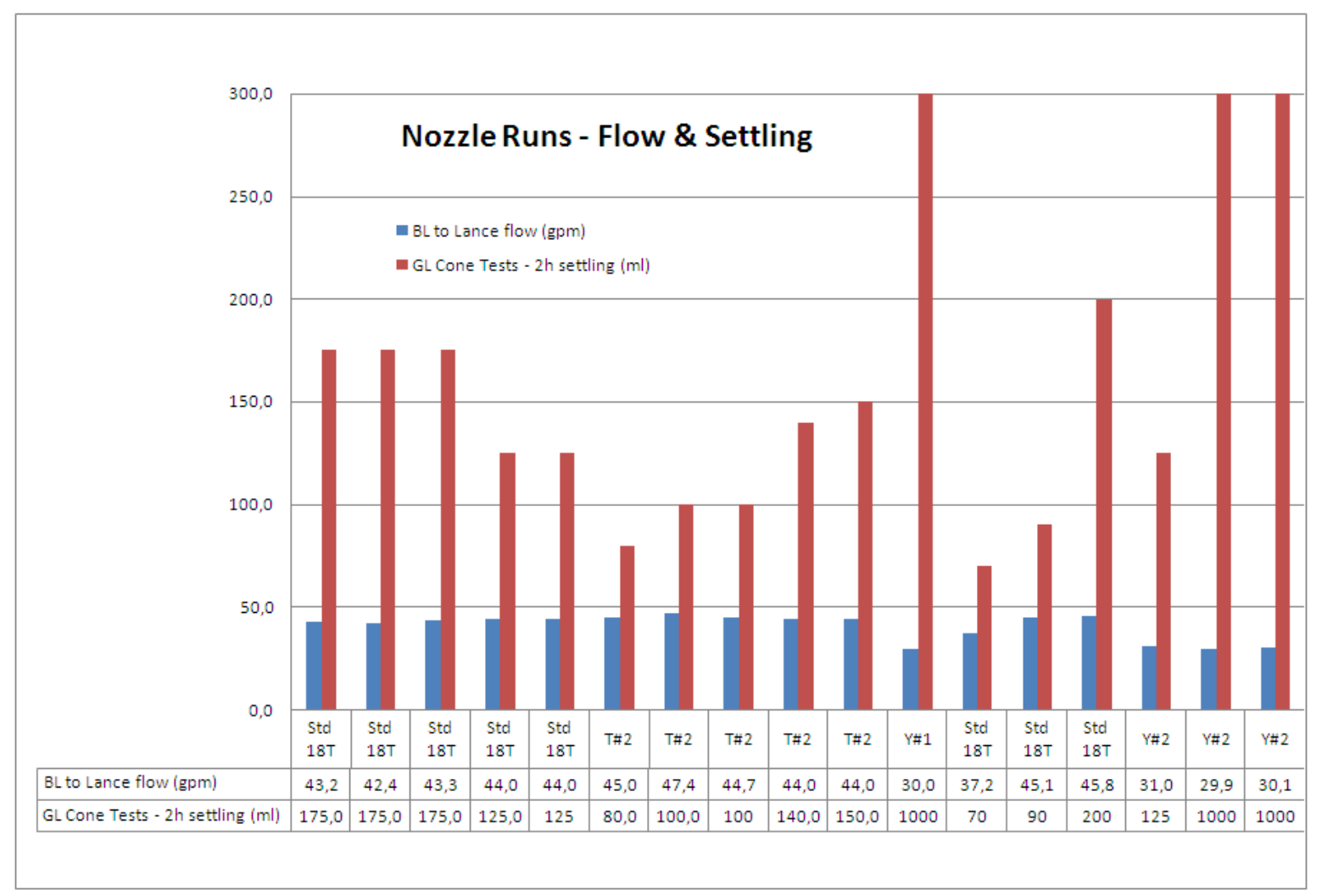

Figure 4-12 Imhoff cone settling results and black liquor flows during Feb/Mar 2008 nozzle trials.

\subsubsection{Instrumentation and sampling}

Several green liquor samples were collected for each test run. As in previous trials, key analyses included Total Suspended Solids as well as dregs inorganic and organic (carbon) compositions,

Composite black liquor, condensate and weak wash samples representing more than one test run were taken to be used as input for the mass-balance calculations. The planned product gas sampling included analyses by a Gas Chromatograph (GC) on-site. But the GC did not work, sampling of the gas in glass-containers was necessary. These were shipped to IPST for off-site analyses. These analyses results and material balances summaries are included in Appendix 2.

\subsubsection{Reference: Standard 18T Nozzle}

The current standard 18T nozzle is a result of nozzle testing work in Chemrec's demonstration units operated in Sweden during the late 1980's and early 1990's and further development at the New Bern unit in the late 1990's. This nozzle has been used without any 
Final Technical Report Rev. 0 DE-FC26-04NT42259

major modifications since then. A typical flame picture from operation of the standard 18T nozzle and the resultant green liquor is shown in Figure 4-13.

The general dregs settling measured with Imhoff cone after $2 \mathrm{~h}$ in the New Bern Mill typically look like the picture below from 21-Feb-2008. At normal operation the amount of dregs varies, but operators take corrective action if the settled dregs level in the Imhoff cone goes above the $120-150 \mathrm{ml} / 1$ level (unless it is due to a known operation disturbance.)

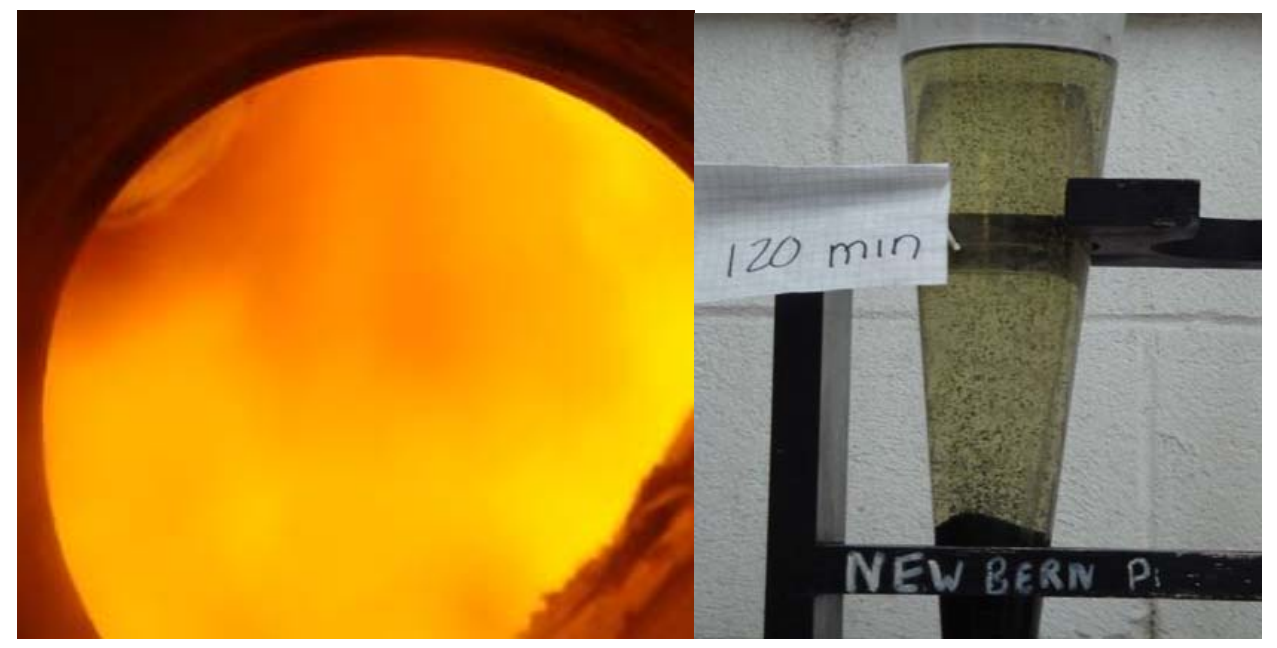

Figure 4-13 The flame picture is taken approx 15.00 2008-mar-06. The flow rate is 50 gpm black liquor and the nozzle pressure in the $25-30$ psig range. Typical Imhoff cone after $2 \mathrm{~h}$ in the New Bern Mill, the picture is from 21-Feb-2008

\subsubsection{T\#2 Nozzle with Steam Swirler}

The latest modified ETC T-jet nozzle differs from the standard 18T in two ways:

1. The black liquor channel around the holes is modified to facilitate a more even distribution of black liquor from all sides of the injection hole periphery.

2. An insert has been placed in the steam-channel which induces a swirl into the steam flow prior to contacting the black liquor. This swirling motion yields a higher turbulence where the black liquor film is expected to break up.

This nozzle principle was tested in ETC's nozzle test facility for spray pattern and particle size distribution prior to fabrication. The model test showed a slightly better size distribution in terms of less material going in the largest droplets compared to the standard 18T.

The nozzle performed well during tests on March 23rd with a flow of $45 \mathrm{gpm}$ and settling in the $100-150 \mathrm{ml} / 1$ region. In the evening (approx $5 \mathrm{PM}$ ) the $23 \mathrm{rd}$ the flow was increased to 47 
Final Technical Report Rev. 0

DE-FC26-04NT42259

gpm, but as a peak of bad settling liquor was observed the operators cut back to below $45 \mathrm{gpm}$ again at $10 \mathrm{PM}$.

The most interesting observation about the $\mathrm{T} \# 2$ test result is the lower steam consumption compared to the standard nozzle. The T\#2 steam-swirler uses about $30 \%$ less steam for atomization compared to the standard $18 \mathrm{~T}$ nozzle at the $45 \mathrm{gpm}$ black liquor flow-rate. The swirler insert restricts the steam-flow, but apparently this is compensated with improved efficiency in breaking up the black liquor at flows up to $45 \mathrm{gpm}$. A possible explanation for the observed bad settling at the increased $47 \mathrm{gpm}$ black liquor flow could be that the lower steam flow is not sufficient at that higher black liquor flow rate.

\section{T\#2 Nozzle conclusion}

The observed reduction in steam consumption equals $900 \mathrm{~kg} / 2000 \mathrm{lb}$ steam per hour in savings at $45 \mathrm{gpm}$. Hence this nozzle shows promise but need further development and testing.

\subsubsection{Y\#1 (tangential design) -Counter Air-Swirler}

The key characteristic of this specific nozzle compared to the standard 18T are:

1. The steam meets the black liquor in a Y configuration instead of a $\mathrm{T}$.

2. The nozzles outlet holes are $36 \%$ smaller in diameter compared to the Standard $18 \mathrm{~T}$, yielding a much higher pressure drop for the same flow.

3. Due to a design error, the Y\#2 nozzle induced a tangential swirl which was opposite to the incoming swirling air and to the standard nozzle swirl direction.

Only the first of those three characteristics were the intention of the designers at Simulent. The outlet hole diameter after the steam injection was reduced (compared to Standard 18T) based on CFD modeling results. The pressure drop impact of that size reduction was never checked and turned out to be too high. The counter-air swirling rotation given to the black liquor was a drawing error. Unfortunately this mistake was not discovered until the nozzle was fabricated.

Prior experience with the black liquor and air in counter swirling modes was negative from tests made in the demonstration booster in Sweden in the mid nineties. Since no precise data was available other than negative comments, it was decided to have this one tested anyway as it was already fabricated and use it to verify that the negative experience was not due to some other factor.

The test was very brief. The performance was so very bad that reactor temperature could not be maintained. The black liquor back pressure drop was also considerably higher than for the standard 18T nozzle due the smaller outlet hole size mentioned above. Although the high pressure drop may have contributed to the Y\#1 nozzle's poor performance, based on 
Final Technical Report Rev. 0

DE-FC26-04NT42259

comparison with the subsequent Y\#2 nozzle tests, it seems obvious that counter-rotating black liquor and air flows were the key factor.

\section{Y\#1 (tangential design) Nozzle conclusion}

The test confirmed with absolute clarity that the process cannot be operated with opposed rotations of black liquor and air swirl.

\subsubsection{5 $\underline{\text { Y\#2 (radial design) }}$}

The radial Y-jet is was also designed by Simulent based on CFD studies.

When the radial Y\#2 is compared to the counter swirling Y\#1-jet, it shares the Yconfiguration, the outlet hole size (and therefore increased pressure drop), but in this design the jets go straight outward, without any rotation induced to the black liquor at all. The outward spray angle is the same as achieved in the standard 18-T nozzle (and Y\#1 nozzle), just without the tangential velocity component. This design was selected for testing in part because fabrication is considerably less complex than for the Y\#1 (tangential design).

Nozzle Y\#2 was operated on 31 gpm of black liquor flow for almost $24 \mathrm{~h}$. The black liquor pressure at this low flow was about twice the reference 18-T nozzle back-pressure. The steamflow corresponded to $30-50 \%$ of the demand for the reference nozzle. A picture of the green liquor for this mode of operation is also included in the pictures below. Note the very fine suspended solids in the clear phase above the settled dregs in Figure 4-14. After 12-15 h of operation at $30 \mathrm{gpm}$ problems were observed in the down-stream causticizing operation of the mill. Hence this mode of operation cannot be considered sustainable from the mill standpoint.

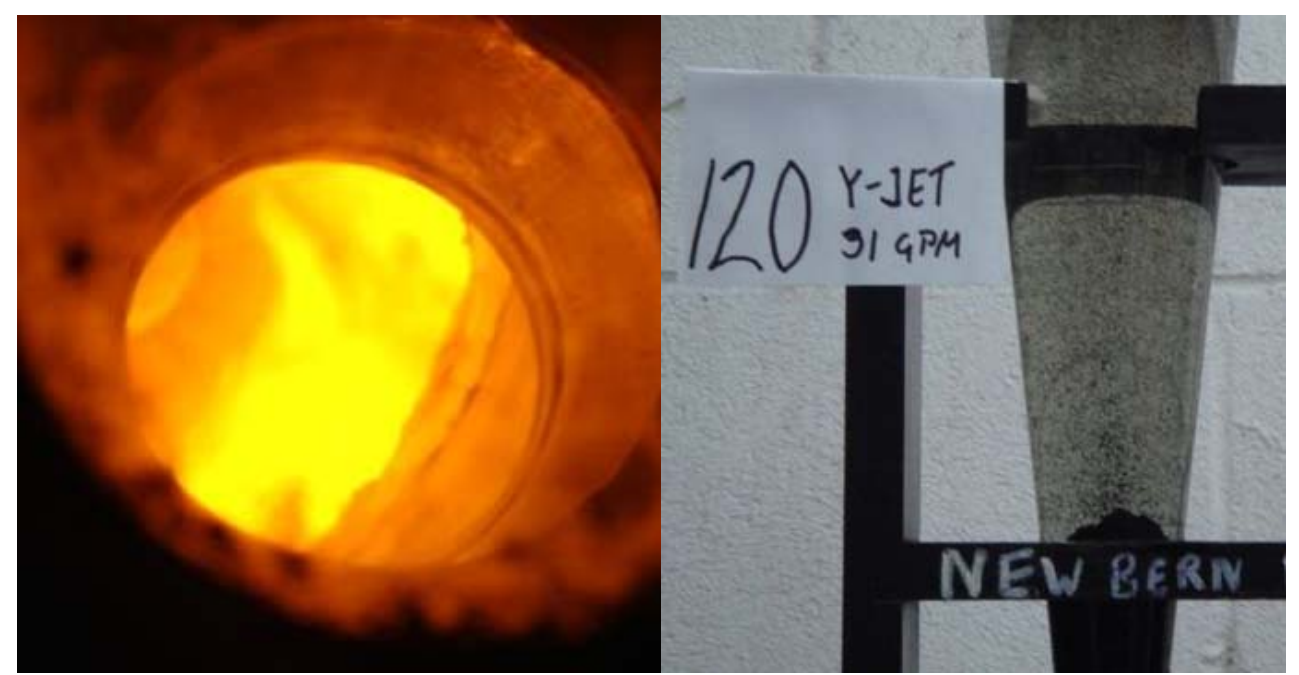

Figure 4-14 Flame picture for the radial Y-jet below was taken at $31 \mathrm{gpm}$. The green liquor Imhoff cone from the same test, note the very fine particles in the clear phase. 


\section{Final Technical Report Rev. 0 \\ DE-FC26-04NT42259}

After $24 \mathrm{~h}$ the operators tried to raise the flow to $45 \mathrm{gpm}$ (Figure 4-15 left). The black liquor pressure then rose to three times the normal for the reference nozzle. At this increased flow rate, the green liquor contained high levels of char particles. This trend could not be reversed by increased atomizing steam flow (Figure 4-15 right) so the test was terminated shortly thereafter.

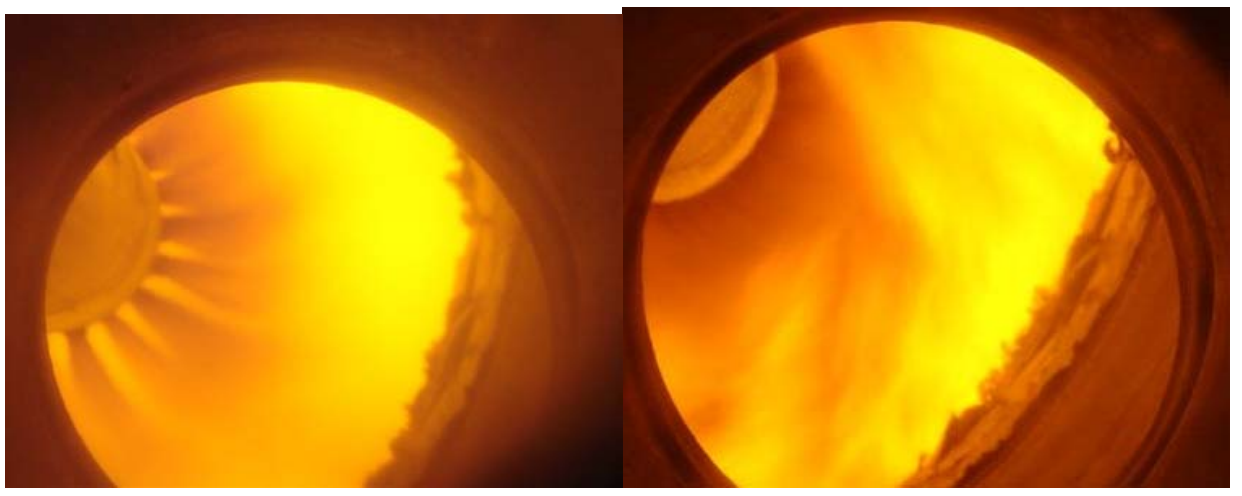

Figure 4-15 Radial Y-jet 45 gpm, the dark streaks from the nozzle are interpreted as jets of black liquor coming out. Maximised steam flow to the left.

The Y\#2 nozzle operation was provisional at the lower flow (31 gpm), though fine particles in the green liquor prevented sustained operation. The Y\#2 nozzle was also very sensitive to steam flow changes and the back-pressure of the black liquor was 2-3 times higher than usually observed for the Standard 18T. Subsequently, it was clarified that Simulent had intended to have about the same black liquor back pressure drop as in the reference nozzle. When checked after the test was performed the CFD model correctly predicted the pressure drop observed in the field trials.

The fine particles noticed in the clear phase may result from initial short-circuiting flow pattern in the reactor probably seen in the operation of the counter-swirling nozzle (Black liquor and air having opposite rotations).

\section{Y\#2 Nozzle conclusion}

The first conclusion is that nozzle Y\#2 does not perform as well as the standard 18T; it is very sensitive to steam setting and does not work at all above 30 gpm black liquor flow. Although it worked marginally at $30 \mathrm{gpm}$, the resultant green liquor had a slow settling residue in the clear phase causing problems downstream in the mill.

The second conclusion is that at the 30 gpm level it had very low steam consumption and it is obviously not optimized regarding pressure drops, exit speed and steam flow. Simulent have completed a suggested re-design and the nozzle is being modified while this report is written. Before a final judgment can be passed on this nozzle, modifications need to be completed and a re-test performed. 
Final Technical Report Rev. 0

DE-FC26-04NT42259

\subsection{Air Distribution Upgrade Design and Testing}

\subsubsection{Air Distributor Upgrade Design}

During Phase I, CFD modeling work suggested there maybe an uneven distribution of air entering the gasifier reactor. Due to the sub-stoichiometric nature of the process, any uneven distribution of air or fuel can be particularly detrimental to gasifier performance. Different air to black liquor ratios within the gasifier volume may lead to operation of the plant based on the least favourable gasification condition; i.e., adding air to compensate for low air to fuel ratio (poor carbon conversion) in one sector of the reactor will lead to higher overall reactor temperature and lower efficiency than would be necessary if the air and liquor were evenly distributed.

CFD analyses of the existing air distributor at the New Bern plant indicated uneven flow distribution in the 18 swirl register slots up to $+/-10 \%$. Figure 4-16 shows one set of CFD results indicating poor distribution of air entering the gasifier reactor for the existing/current configuration (the violet and dark blue lines) and calculations for a "plate and diverter" configuration (yellow line) showing a much more uniform distribution.

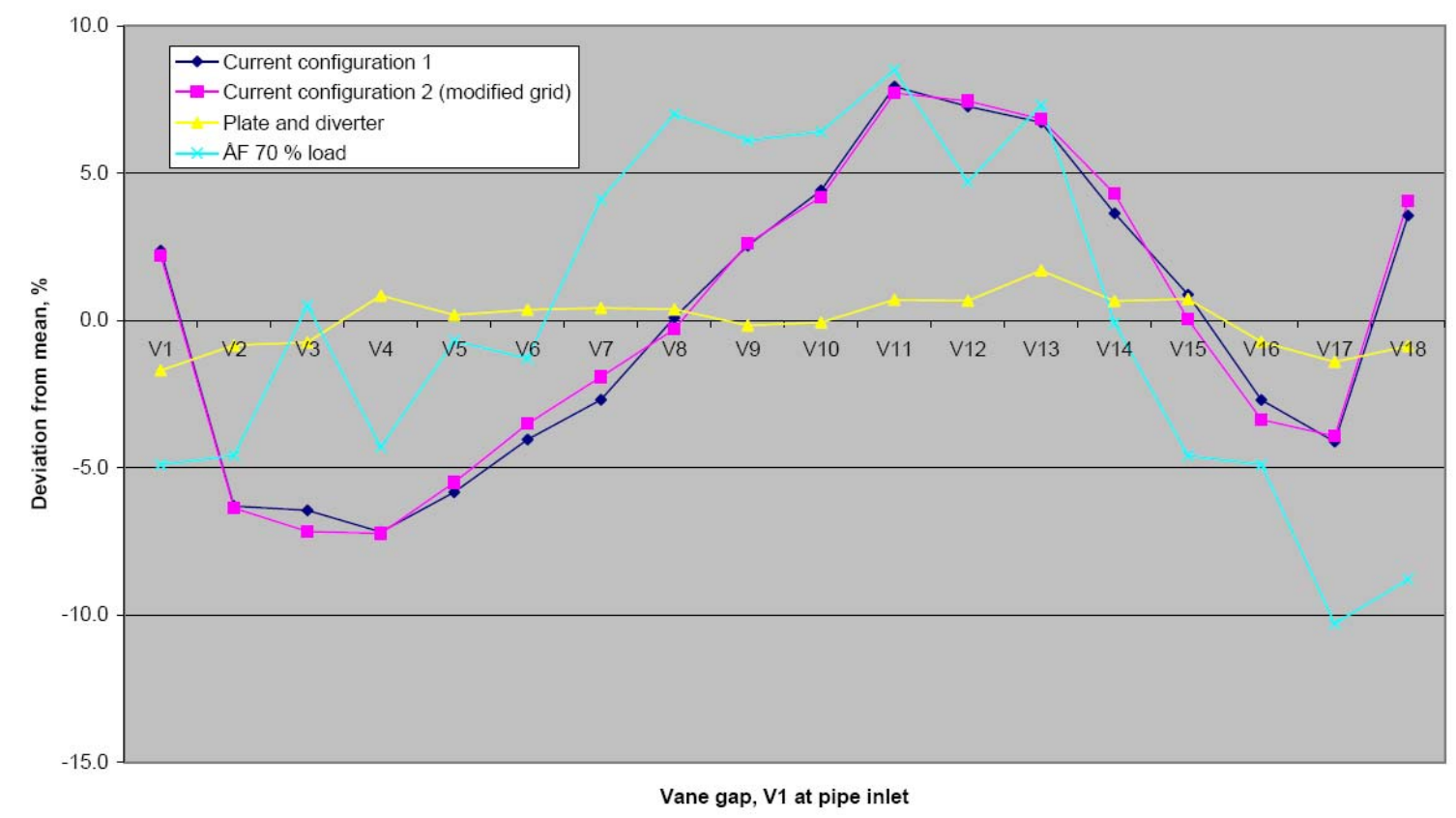

Figure 4-16 CFD results demonstrate poor air distribution entering reactor and potential improvement.

CFD design work was undertaken for two different methods of producing more uniform airflow through modifications to the existing air plenum. One approach involved the addition 
Final Technical Report Rev. 0

DE-FC26-04NT42259

of a set of diverter plates to the existing air plenum as illustrated in Figure 4-17. A second approach involved addition of a "porous/perforated" plate to the air plenum to force increased pressure drop and thereby more uniform flow distribution. Various combinations of these approaches were also modelled and evaluated.

Although some of the combined approaches gave the best overall results, the projected improvements over the perforated plate option alone were marginal; especially when the difficulty and cost of implementation were factored in. It was decided to implement the perforated plate modification. A detailed design was developed; fabrication bids were solicited and awarded. The perforated plate was installed during the March 2007 and field testing undertaken as described below.

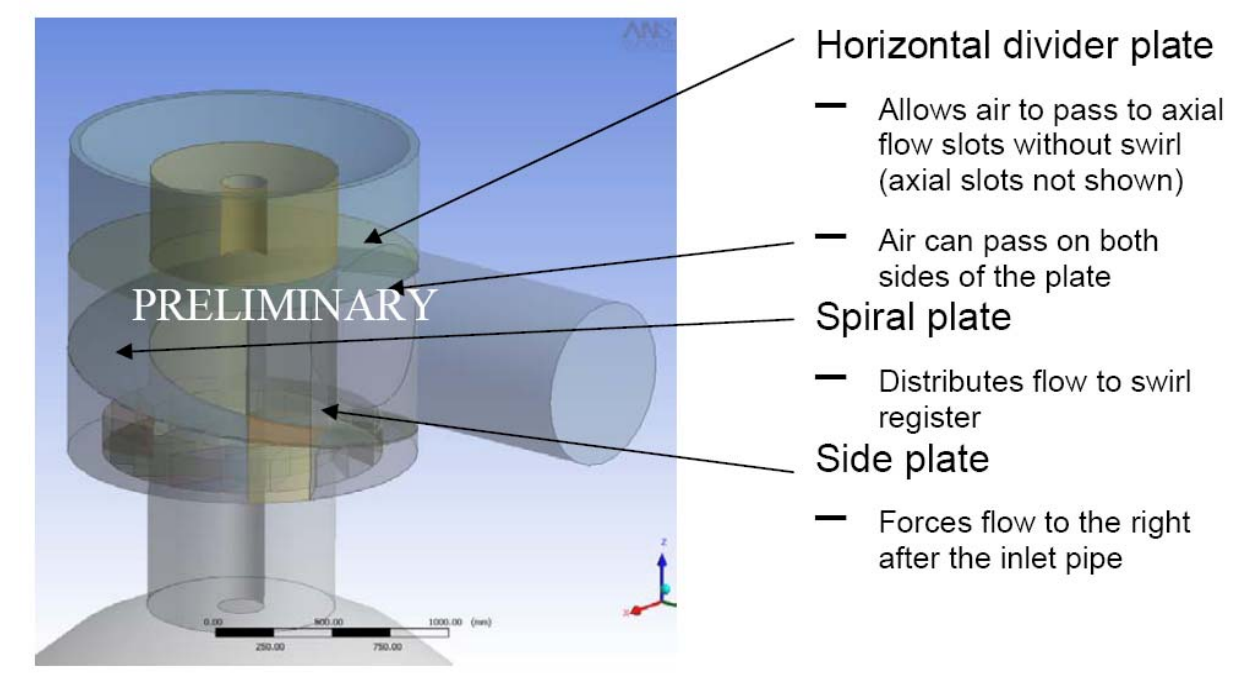

Figure 4-17 Illustration of diverter plates added to existing air plenum

\subsubsection{Improved Air Distribution Field Test Results}

The perforated plate designed to improve and even out the inlet air distribution by increasing the pressure drop over the swirl register was installed during the mill's annual shutdown in March 2007. The plan was to operate the gasifier at the same conditions following the shutdown as before to compare the operating results (Note this is the same test period during which the T\#1 nozzle was being evaluated).

The installation of the plate resulted in difficulties for the operators to produce good green liquor following start-up. The cause was found to be significant air leakage through the gap between the inner cylinder wall and the new plate. Since the inner cylinder is design to move 
Final Technical Report Rev. 0

DE-FC26-04NT42259

up and down, some clearance was built into the design. However, subsequent inspection revealed that the gap was much larger than planned for based upon as-built drawings.

Since the pressure drop is increased by the diffuser plate only part of the air flow went through the swirl register. Remaining air flow entered axially into the reactor and negatively impacted green liquor quality through interaction with the black liquor spray. Without the plate, pressure drop is lower and thus very little air by-passes the swirl register.

The above is confirmed by pressure drop measurements shown in Figure 4-18. The overall pressure drop with the perforated plate installed is significantly lower than the design value of $1.7 \mathrm{psi}$ at 54,000 pph airflow, signifying that too much air is finding another pathway.

\section{Pressure Drop - Air Inlet to Gasifier Outlet (pt031-pt100)}

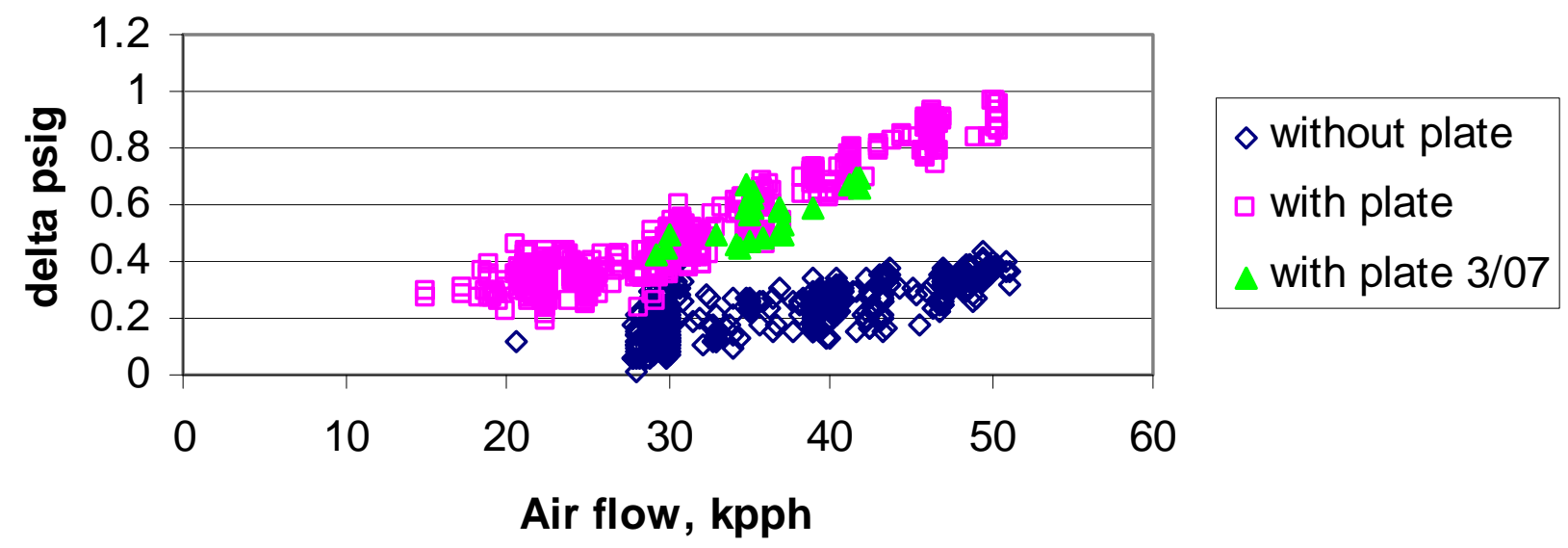

Figure 4-18 Pressure drop over air inlet with and without perforated diffuser plate

As a result of the above mentioned difficulties with green liquor quality the gasifier was shutdown and the plate removed in April 2007. Subsequently, Chemrec completed design of a device which will hinder the air slip/leakage and still allow the inner air plenum cylinder to move freely up and down. However, the present standpoint is not to recommend reinstallation of the device. The work with an air-to-fuel ratio controller in the DCS software and the general operational achievement in reducing the operational temperature predominantly to a range below $1000^{\circ} \mathrm{C}\left(1830^{\circ} \mathrm{F}\right)$ have removed the main argument at normal load. The remaining argument is if this device would facilitate a load increase. That potential benefit must be weighed against the production risk if the device does not work properly and/or causes a reduction in availability due to an extra stop. 
Final Technical Report Rev. 0

DE-FC26-04NT42259

\subsection{Improved Air to Fuel Ratio Control}

Though not explicitly part of the project phase II work scope, the importance of air to fuel ratio on gasifier performance was highlighted by phase I project results. As a result, the mill implemented an improved air to fuel ratio control strategy in November 2007. Since implementation the gasifier operating temperature has been more stable and generally reduced by $50-100^{\circ} \mathrm{F}$ to less than $1850^{\circ} \mathrm{F}$. Besides positively impacting thermal efficiency, the expectation is that lower operating temperatures will significantly improve refractory and cooled support ring reliability. It's too early to see the results on refractory life, but cooled support ring reliability improved dramatically in 2008. At least part of this improvement is expected to be due to lower reactor operating temperatures and therefore outlet smelt temperatures as discussed later in section 5.3.

Using their equilibrium model, Chemrec has estimated that reducing reactor operating temperature from $1010^{\circ} \mathrm{C}\left(1850^{\circ} \mathrm{F}\right)$ to $980^{\circ} \mathrm{C}\left(1795^{\circ} \mathrm{F}\right)$ at 250 tonne $\mathrm{DS} /$ day black liquor firing rate increases total heating value of fuel gas to the mill's power boiler by about $1 \mathrm{MW}$. This represents an equivalent fuel savings of $100 \mathrm{~kg} / \mathrm{h}$ of \#6 fuel oil consumed in the mill's \#2 power boiler. 
Final Technical Report Rev. 0

DE-FC26-04NT42259

\section{$5 \quad$ Task 3 - Process reliability - green liquor and condensate scaling}

Project Task 3 was directed at developing a fundamental understanding of the mechanisms leading to scaling and plugging in both the gasifier green liquor and condensate circulation circuits. Once the fundamental causes were understood, the project team planned to conduct engineering analysis and implement practical operational or hardware solutions.

\subsection{Condensate plugging \& scaling investigation and measures}

\subsubsection{Calcium Balance}

During each test in the June 2005 matrix, 10 process stream samples were taken and analyzed for calcium, among other elements. Calcium balances were performed and an example is given in Figure 5-1. Accumulation of $\mathrm{CaCO}_{3}$ scale in the equipment may be the main reason for poor calcium balance closure. Analysis of deposits collected in the condensate circulation during this project and earlier samples analyzed by Weyerhaeuser indicate composition with greater than $80 \% \mathrm{CaCO}_{3}$. Sources of calcium are considered below and then fouling mechanisms in two troublesome regions are discussed. 
Final Technical Report Rev. 0

DE-FC26-04NT42259

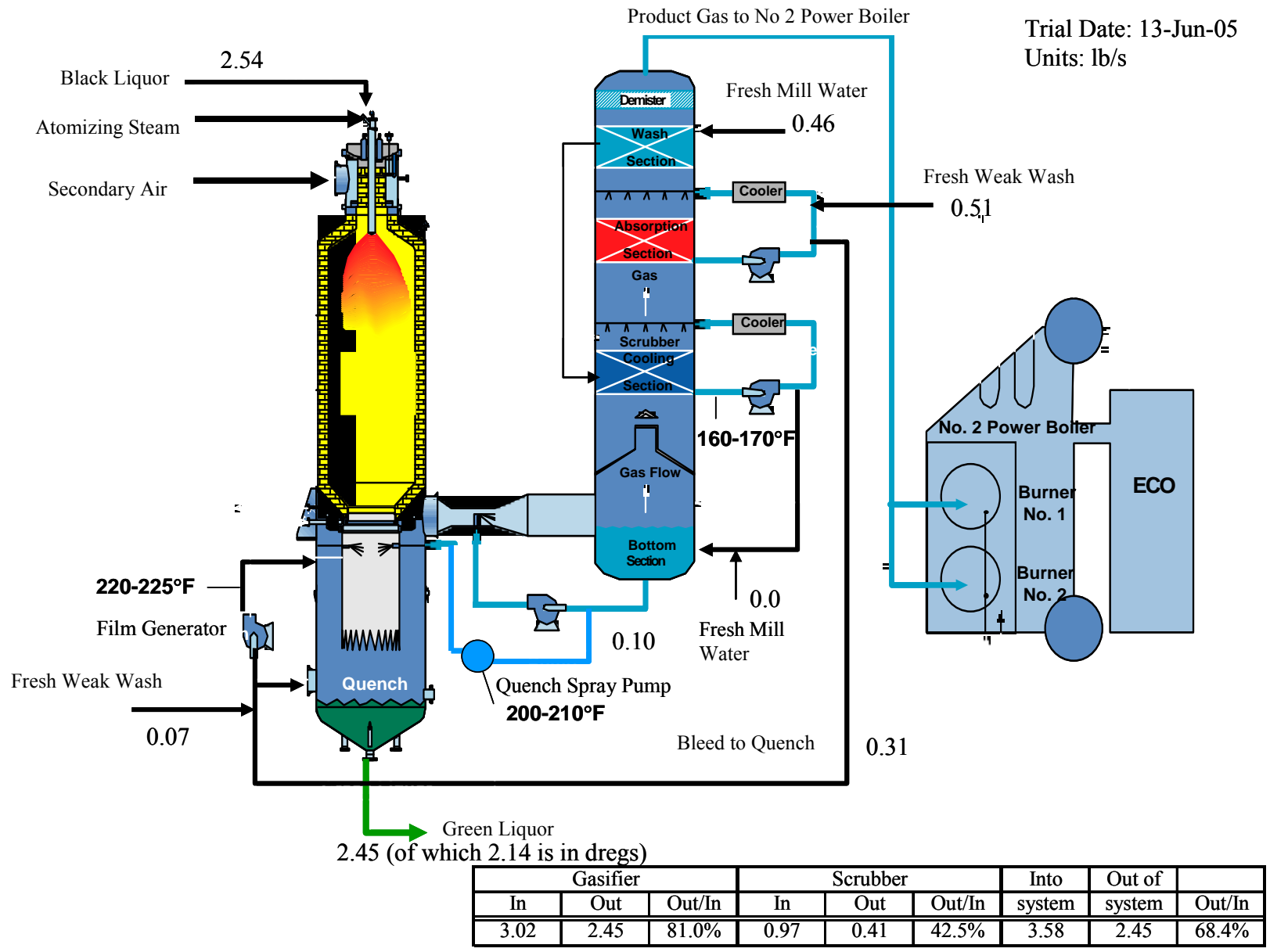

Figure 5-1 Example calcium balance results based on trial flow data and stream composition analysis; stream values are given in lb/s; stream temperatures are indicated in bold.

In order for calcium to form scale, it must precipitate from a soluble form onto a surface. Because $\mathrm{CaCO}_{3}$ has an inverse solubility relation with temperature, $\mathrm{CaCO}_{3}$ scales tend to form on surfaces that are hotter than the fluid stream, e.g., heat exchangers. If conditions of $\mathrm{pH}$ and temperature in a stream favour insoluble $\mathrm{CaCO}_{3}$, and the stream is at equilibrium, then $\mathrm{CaCO}_{3}$ will exist as fine suspended particles and will not form scale.

Based on the data in Figure 5-1, about $71 \%$ of the calcium entering the gasifier system comes from the black liquor; whatever form of calcium exists in the black liquor, it will be converted to $\mathrm{CaCO}_{3}$ during the gasification process. About $16 \%$ of the calcium enters with the fresh weak wash at the two points indicated in Figure 5-1; the source is likely fine lime mud particles $\left(\mathrm{CaCO}_{3}\right)$ that pass through filters in the recausticizing process. The $\mathrm{pH}$ of this stream is sufficiently high that very little $\mathrm{Ca}^{2+}$ will be available to form scale. About $13 \%$ of 
Final Technical Report Rev. 0 DE-FC26-04NT42259

the calcium enters with fresh mill water make up at the two points indicated in Figure 5-1; the source is primarily free $\mathrm{Ca}^{2+}$ ions that can exist at $\mathrm{pH}$ 7. This calcium and lesser amounts of magnesium are commonly referred to as water "hardness." When fresh water is mixed with heated alkaline streams, the $\mathrm{Ca}$ will eventually precipitate as $\mathrm{CaCO}_{3}$, but the process will be limited by mixing and crystallization kinetics. Under certain conditions, discussed below, the free $\mathrm{Ca}^{2+}$ ions in fresh mill water can lead to surface deposition in the gasifier condensate and green liquor system. Once a surface layer of $\mathrm{CaCO}_{3}$ is formed on equipment then it serves as a "growth template" for scale and result in steady accumulation of deposits.

\subsubsection{Condensate spray system fouling}

An episode of severe fouling of the pump that delivers high pressure gasifier condensate to the quench sprays occurred following the 2005 field test period. Three samples of scale were collected from the pump. The scale was determined to be $>90 \mathrm{wt} . \% \mathrm{CaCO}_{3}$. The average composition of the stream from the scrubber sump was determined from analysis of green liquor and condensate system samples collected during the test matrix. This composition was input to the Weyerhaeuser non-ideal equilibrium software NAELS to predict equilibrium solubility of calcium species as a function of temperature. Figure 5-2 shows that for the range of temperatures from the scrubber sump to the sprays, the only stable form of calcium at the stream $\mathrm{pH}$ of 9 is $\mathrm{CaCO}_{3}$. Based on recent monitoring at the mill, the temperature of this condensate varies from a minimum of $160^{\circ} \mathrm{F}$ in the circulating condensate bleed to quench to a maximum of $200-210^{\circ} \mathrm{F}$ within the quench pump housing (see process sketch in Figure 5-1).

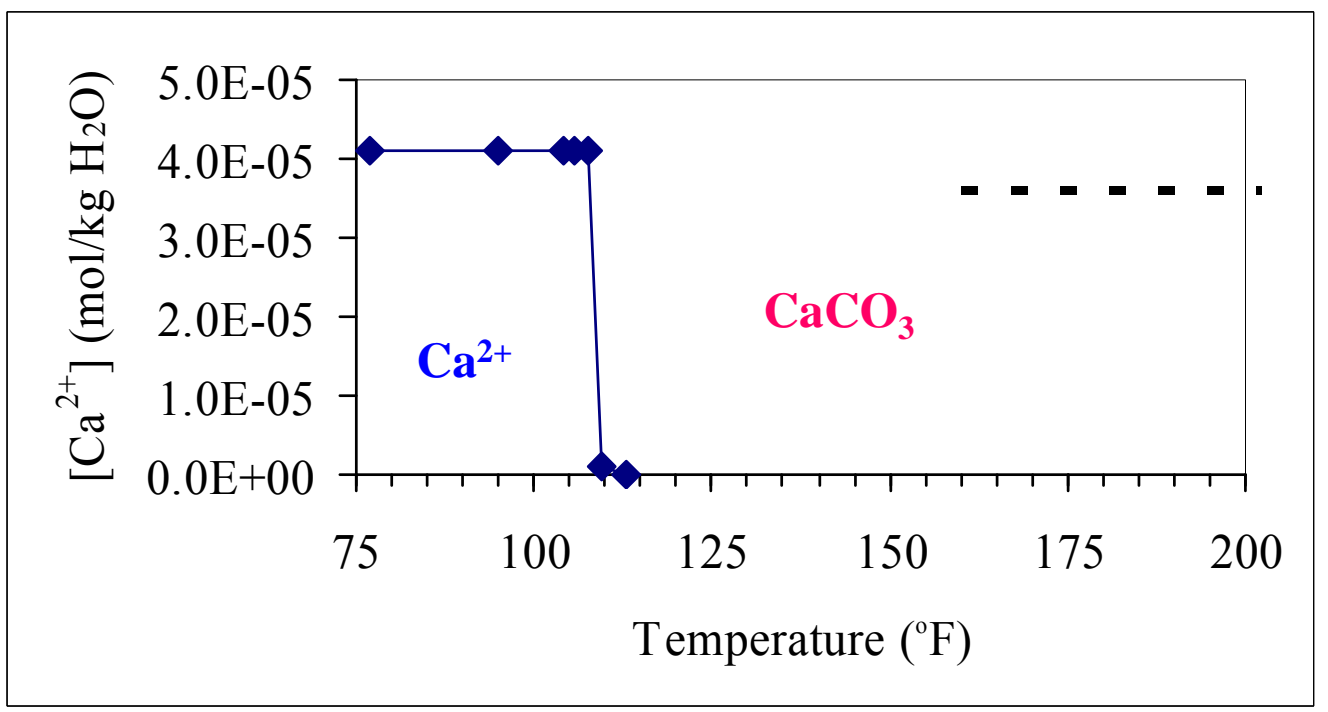

Figure 5-2 Predicted $\mathrm{CaCO}_{3}$ solubility as a function of temperature for condensate to quench sprays based on June 20, 2005 baseline data. Dashed line indicates average $\mathrm{Ca}^{2+}$ level for stream and range of temperatures in quench spray system. 
Final Technical Report Rev. 0 DE-FC26-04NT42259

The severe fouling incident followed a time when mill operations had directed mill water to the pump gland seal (instead of the normal recirculation off the pump discharge) and connected a mill water hose to the pump suction after the pump began to foul to maintain the quench spray capacity. The $\mathrm{Ca}^{2+}$ in the mill water combined with available $\mathrm{CO}_{3}{ }^{-}$ions in the condensate (approximately $5.7 \times 10-3 \mathrm{~mol} \mathrm{CO}_{3}{ }^{-}$per $\mathrm{kg} \mathrm{H}_{2} \mathrm{O}$ exist in this stream; $5 \%$ of the total carbonate, the remaining $95 \%$ is in the form $\mathrm{HCO}_{3}{ }^{-}$at $\mathrm{pH}$ 9) to form scale at the hot surfaces within the high pressure quench spray pump.

Mill personnel have reviewed trends in fresh mill water make up to the scrubber and scaling rate in the condensate system, as indicated by pump speed and discharge pressure. The scaling appears to occur steadily over the course of months as opposed to step changes associated during the on/off nature of the scrubber bottom make-up. This suggests that some $\mathrm{Ca}^{2+}$ in the mill water continuously introduced at the top of the scrubber persists through the cooling section and into the quench spray pump. A mitigation strategy for normal operation would therefore be to use a distilled source of make up, e.g., clean evaporator condensate, or install an ion-exchange system, i.e., water softener, on the water supply to the scrubber top.

\subsubsection{Green liquor system fouling}

Another region prone to $\mathrm{CaCO}_{3}$ fouling is the green liquor recirculation pump and film generator that cools the quench tube at the exit of the gasifier. A small amount of fresh weak wash is mixed with the raw green liquor near the pump suction in the gasifier quench, but average measured raw green liquor composition was used for the purposes of the solubility prediction. The solubility diagram calculated by the NAELS software is given in Figure 5-3. $\mathrm{CaCO}_{3}$ is the only species likely to exist in this stream, as the temperature of the circulating green liquor system is greater than $220^{\circ} \mathrm{F}$, and the total sodium content of the stream is below $3 \mathrm{~mol} / \mathrm{L}$. Historical analysis of deposits removed from the circulating green liquor pump and film generator indicate composition to be $\mathrm{CaCO} 3$ and not pirssonite (a double salt of sodium and calcium carbonate, $\left.\mathrm{Na}_{2} \mathrm{Ca}\left(\mathrm{CO}_{3}\right)_{2} \cdot 2 \mathrm{H}_{2} \mathrm{O}\right)$. 
Final Technical Report Rev. 0

DE-FC26-04NT42259

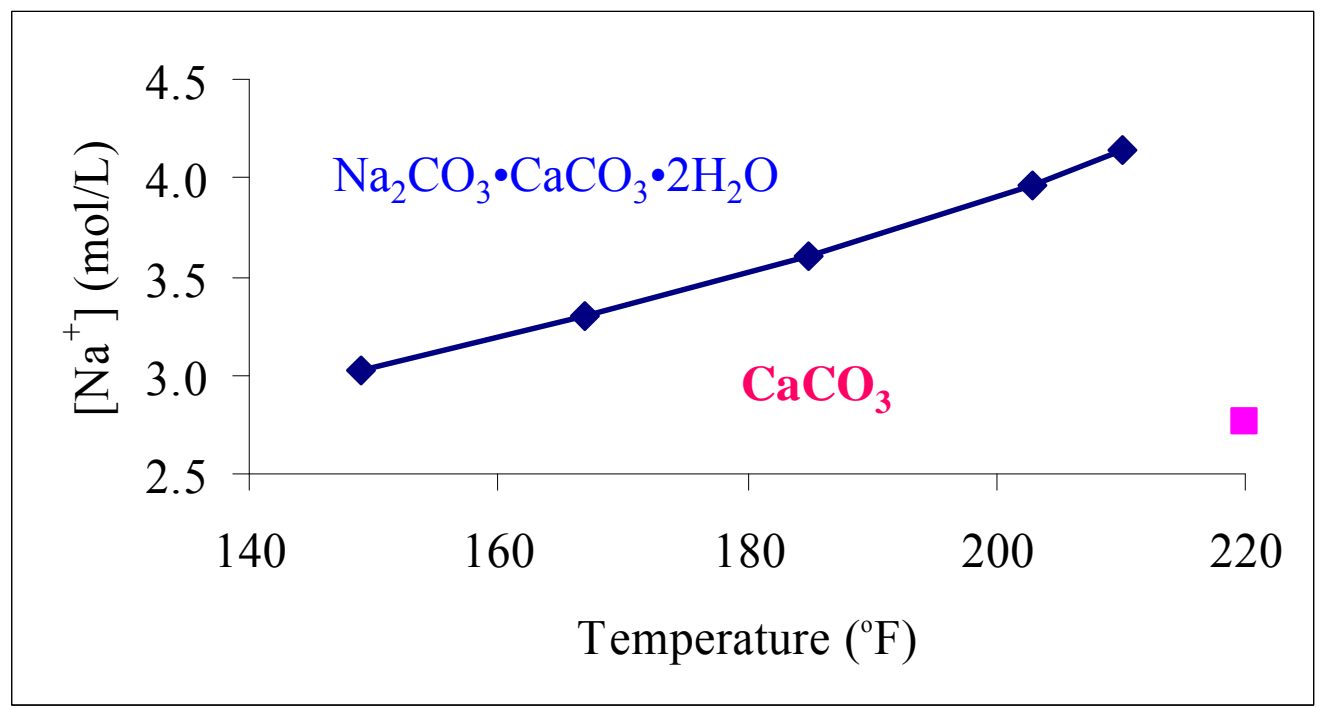

Figure 5-3 Predicted $\mathrm{CaCO}_{3}$ and pirssonite solubility as a function of temperature for circulating green liquor based on average composition data. Filled square indicates average sodium concentration and minimum temperature of raw green liquor.

Fresh weak wash was evaluated as a possible source of $\mathrm{Ca}^{2+}$ ions into this flow loop; three spot $\mathrm{pH}$ measurements were made in May 2006 with a range of 11.48 to 11.64. For $\mathrm{pH}>$ 11.5 , less than $0.1 \%$ of the total calcium will be in the form of $\mathrm{Ca}^{2+}$ ions and the total calcium measured was only $9 \mathrm{mg} / \mathrm{kg}$ of weak wash, so this does not appear to be an important source.

The mill staff identified another potential source of $\mathrm{Ca}^{2+}$ ions. During acid washes of the causticizing equipment, approximately monthly, the acid wash liquor is added to the weak wash tank. This may briefly drop the weak wash stream $\mathrm{pH}$ and greatly increase the calcium input in the form of dissolved deposits. Trials have not yet been conducted to rule this out. However, currently the most likely source of calcium that forms $\mathrm{CaCO}_{3}$ deposits in the green liquor and condensate system remains the fresh mill water cascading down through the scrubber into the condensate circulation at the bottom of the scrubber, into the gasifier via the quench sprays, and ultimately into the green liquor dissolving tank at the bottom of the gasifier.

\subsubsection{Evaluation of practical solutions to green liquor and condensate scaling/plugging problems}

The mill began adding an anti-scale polymer to the green liquor recirculation loop in November 2005. Based on visual comparison after the September 2004 and March 2006 shutdowns, the extent of scale deposition in the green liquor loop was much less following the polymer addition. The green liquor recirculation pump speed has historically provided a real- 
time indicator of scaling in this system, and the data in Figure 5-4 provides further evidence that the polymer additive is effective at mitigating scaling within the green liquor recirculation circuit and film generator.

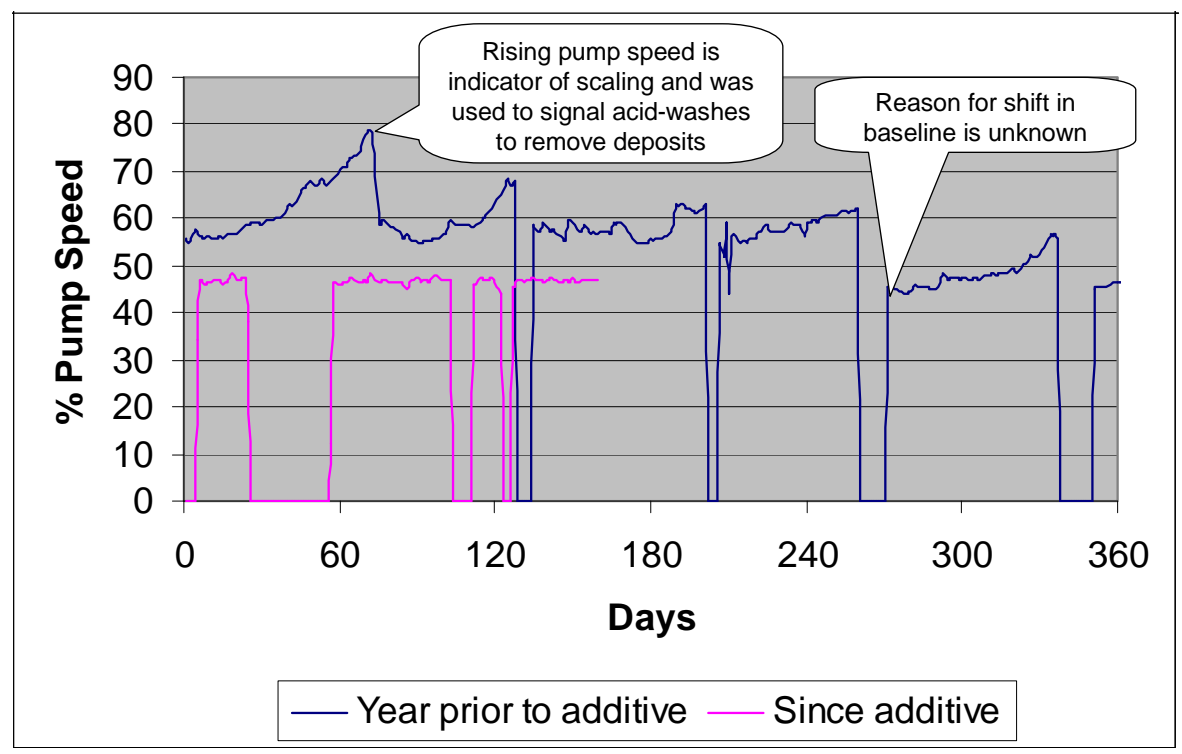

Figure 5-4 Daily average green liquor recirculation pump speed showing typical rising trends caused by $\mathrm{CaCO}_{3}$ scale deposition. Period of time sine anti-scale additive has been applied does not show this characteristic trend.

The success of the anti-scale polymer in the green liquor loop, and a lessening of scale related problems in the condensate system have mitigated the need for the mill to consider other alternatives for scale mitigation. If either of these problems should become more acute, or too expensive to treat by chemical additives, options recommended by this work included:

$\sqrt{ }$ Treatment or replacement of mill water make-up to the top of the scrubber. As mentioned above, this is the most likely source of $\mathrm{Ca}^{2+}$ ions in both the condensate and green liquor circulation loops.

$\sqrt{ }$ Evaluate and modify the addition of acid wash liquor to the weak wash tank. Although less likely than the mill water contribution, it's possible periodic drops in weak wash $\mathrm{pH}$ may be contributing $\mathrm{Ca}^{2+}$ ions to the green liquor system.

\subsection{Indirect cooled quench tube}

The original project budget included development and implementation of an indirectly cooled quench pipe (ICQP). This was considered as an alternative means to avoid the scaling and 
Final Technical Report Rev. 0

DE-FC26-04NT42259

reliability problems associated with the existing directly cooled quench pipe. The existing design depends on recirculation of green liquor to generate a cooling film where hot gases and smelt exit the reactor. With an ICQP the existing quench tube and green liquor film generator would be replaced by an indirectly cooled system. The ICQP design, cost estimate, and procurement package were prepared in Phase I of the project. This was not carried through to implementation due DOE's Phase II budget reduction.

During Phase I of the project the design goals for an ICQP were developed. A conceptual design was developed and constructability reviews were held with three potential suppliers. Input on alternative materials of construction was received from the Swedish Corrosion Institute and Oak Ridge National Labs. Based on these inputs the conceptual design was updated and a technical purchase specification prepared and sent to three potential bidders. A design was also prepared for the balance of plant (pumps, foundations, motors, starters, piping, valves, instrumentation and controls, insulation, etc.).

Due to the DOE Phase II budget reduction, the project team decided not to proceed with implementation of the ICQP and focus instead on burner improvements. However, it is worth noting that many of the design improvements developed for the New Bern ICQP have been successfully implemented in Chemrec's pressurized DP-1 pilot plant in Piteå, Sweden.

\subsection{Cooled Support Ring (ORNL MPLUS Projects)}

A significant challenge for the re-design of the indirectly cooled quench tube is that the existing Cooled Support Ring (CSR) has not performed satisfactorily. The front face of the ring appears to corrode rapidly and develop leaks which have forced shut down reactor on several occasions. The heat transfer and corrosion mechanisms for the environment of the CSR and the quench tube are not fully understood, resulting in designs which have not performed well. Past experience and investigation of CSR failures have led us to believe that heat transfer, and especially the local conditions of the smelt flow have a critical impact on the life of the CSR. The smelt flow depends a lot on the geometry of the reactor outlet refractory, just upstream of the CSR. If the refractory lining upstream of the CSR has irregularities due to local failure of blocks then the liquid smelt will tend to form thick concentrated streams (in the "valleys" created by the damaged refractory) rather than a thin uniform film around the outlet. The concentrated streams of smelt carry a lot more thermal energy relative to a thin film, and may potentially raise local temperature and corrosion rates on the CSR surface.

In order to address these issues, the project team collaborated with researchers at the Oak Ridge National Laboratories (ORNL) on two (MPLUS funded) projects. The first project aimed at better understanding the heat transfer in the CSR. The second project used FEM analysis to study the stress distribution in the refractory lining in the reactor outlet region. 
Final Technical Report Rev. 0

DE-FC26-04NT42259

The results of the first project have shown that of the three mechanisms of heat transfer to the CSR (radiation, gas convection, and smelt convection), the heat transfer by the smelt is the dominating component. Since the smelt is in contact with the hot refractory immediately upstream of the CSR, there is no opportunity for the CSR to be protected by a thermal boundary layer, and the heat transfer rates are very high. These heat transfer rates are significantly affected by the thickness of the smelt stream flowing across the CSR. On the water side (inside the ring) heat is removed by convection. It is highly likely that given the pressure and the flow rate of the water, the heat transfer in the water side is by forced convection in the sub cooled boiling regime. In this regime, if the ring face temperature (heat flux from the hot side) increases beyond a certain limit, called the critical heat flux (CHF), the inner surface of the face 'dries out', resulting in loss of local cooling rate, high wall temperature and associated corrosion rate. Figure 5-5 shows the critical heat flux for the current operational conditions of the CSR. The red dot corresponds to the typical operating mass flux of cooling water and internal pressure in the ring.

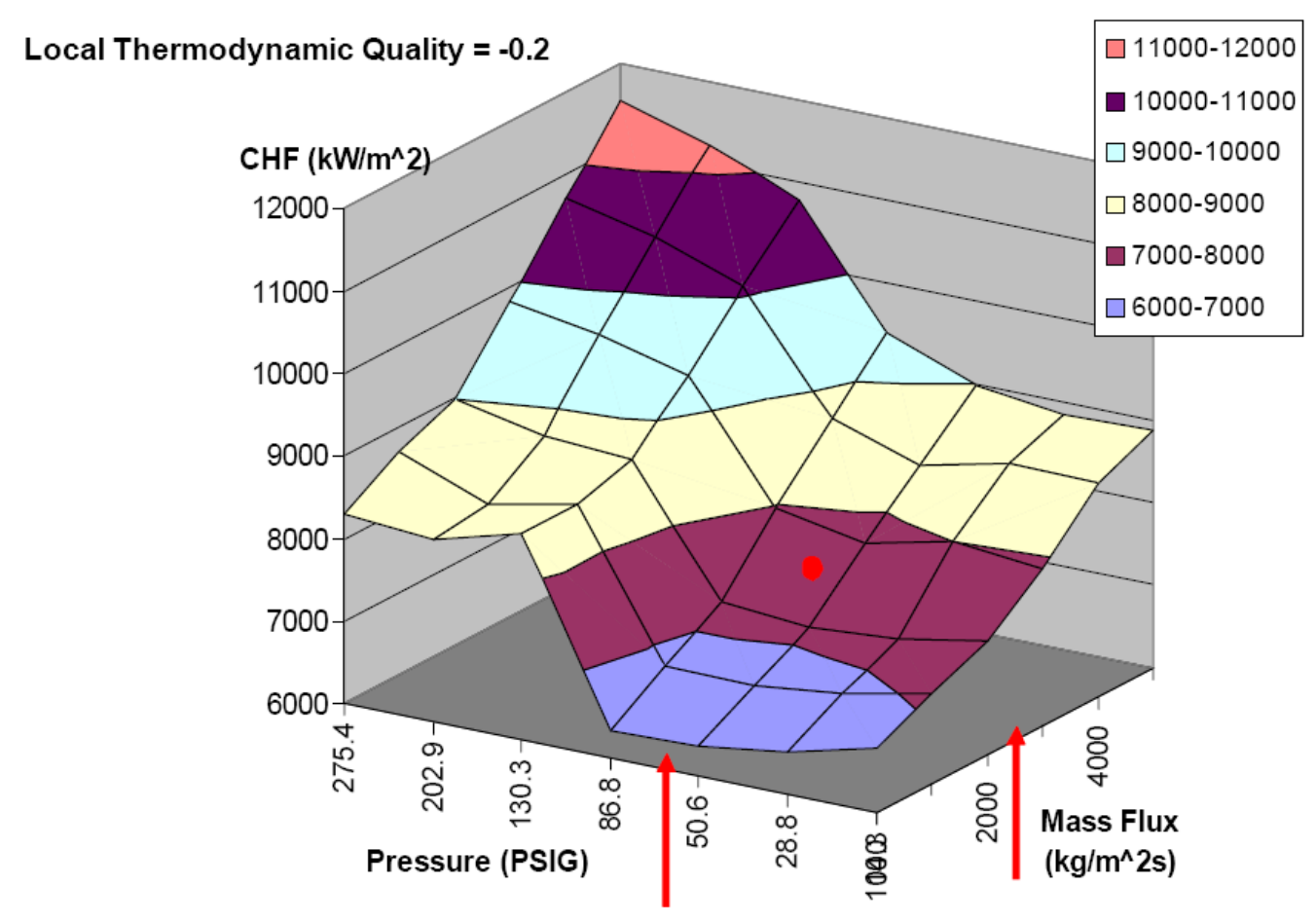

Figure 5-5 Cooled support ring critical heat flux (CHF)

Base on Figure 5-5, for current flow rate and pressure, CHF occurs between 7 to $8 \mathrm{MW} / \mathrm{m}^{\wedge} 2$. This limit is higher than the heat flux estimated for the gas convection and radiation, but lower than that for convection by the hot smelt (this is a function of the thickness of the smelt layer). It can be seen from Figure 5-5 that increasing cooling water mass flux and/or pressure will increase the critical heat flux, and result in more robust heat transfer capability. 


\section{Final Technical Report Rev. 0}

DE-FC26-04NT42259

Recommendations by the ORNL researchers were as follows

- Raise the melting point of the smelt. This may allow for a frozen protective surface to form on the CSR. We discussed some means to accomplish this, but this does not seem feasible at present.

- Add $\mathrm{NaOH}$ to the liquor to reduce the corrosiveness of the smelt. This does not seem to be a viable option at present.

- Change the configuration/location of the inner baffle to reduce the open area which will increase the velocity of the cooling water. This would have to be done in a way to avoid increasing the pressure drop through the ring. This should be considered when designing the next ring.

- Increase the pressure and flow rate of the cooling water.

- Reduce the CSR hot surface thickness. This reduces the temperature gradient across the wall thickness and the 'hot face' temperature.

- Add a sacrificial plate to the top of the ring between the ring and Row 1B refractory. This would reduce the heat transfer from the refractory to the upper cooled surface of the ring.

- Evaluate the external piping to the CSR for elimination of as many 90 degree elbows as practical. Replace with long radius bends to reduce system pressure losses and to increase coolant flow rate and pressure to the CSR.

- Consider modifications to the design of the outlet refractory that ensure more uniform distribution of smelt flow out of the reactor and minimize smelt heat flux to the cooled support ring.

The second ORNL MPLUS project focused on analysis of refractory stress distribution in the reactor outlet region. ORNL researchers developed a detailed, two-dimensional Finite Element Model (FEM) of the gasifier outlet region based on the geometry, materials, and operating conditions in the New Bern gasifier. The FEM analysis confirmed what already had been observed in practice, namely that the refractory bricks were constrained geometrically and volumetric expansion causes them to fail in the buckling mode. This buckling failure produces a non-uniform refractory surface in the reactor outlet which in turn leads to nonuniform smelt distribution and thereby contributes to CSR failures. Several design alternatives to relieve refractory stresses were considered in the FEM analysis. Although none of these alternatives proved practical to implement directly, the understanding gained through this analysis contributed to our understanding of the underlying problem and potential solutions.

Based in part on the above analysis, the New Bern mill has worked together with Chemrec on several design changes including improvements in the outlet refractory and CSR design which have been implemented over the past couple of years. As a result, downtime related to problems in the outlet region of the gasifier (CSR and refractory) have dramatically decreased. 
Final Technical Report Rev. 0

DE-FC26-04NT42259

\subsection{Reliability development}

The New Bern mill has directed considerable effort at improving reliability of gasifier operation over the past several years. As shown in Figure 5-6, current gasifier availability ${ }^{9}$ is up to $94 \%$. Much of this improvement has been due to better refractory materials and design. This work has been documented elsewhere $[1,2,3,4,5]$. Certainly, the work done within the framework of this DOE project has also contributed significantly to improved gasifier reliability.

\section{New Bern Booster 1st May 2007 to 30th April 2008}

availibility $\quad$ CSR failure Other Unscheduled Maintenance \& failure

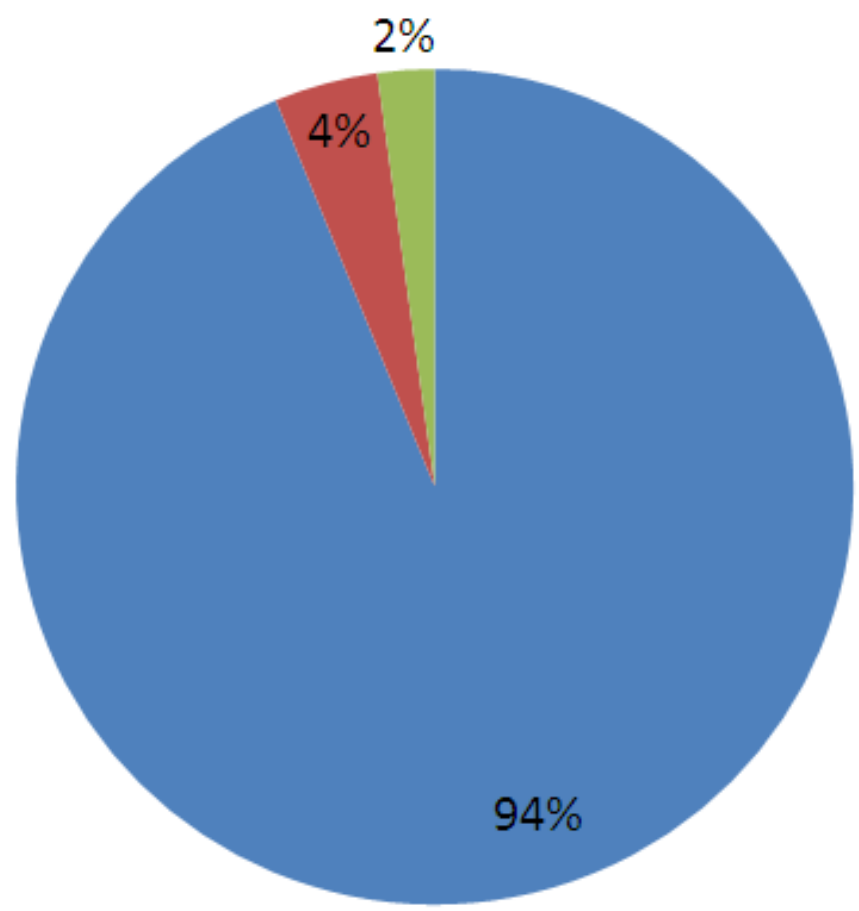

Figure 5-6 New Bern gasifier reliability, May 2007 through April 2008

\footnotetext{
${ }^{9}$ Availability (\%) $=1$-(Stop time due to failure or unscheduled maintenance) $/($ Calendar time- planned maintenance-external stop causes)\%. Note this definition removes scheduled maintenance (i.e. annual downtime) from both the numerator and the denominator.
} 
Final Technical Report Rev. 0

DE-FC26-04NT42259

\section{Task 4 - Process Integration in the Pulp Mill}

Green liquor produced in the gasifier represents about $15 \%$ of the total green liquor flow in the New Bern mill. Historically, the different character of the gasifier green liquor, and specifically the "dregs" in gasifier green liquor have caused reliability and operational problems in downstream process (e.g. green liquor clarification, dregs washing, and white liquor filtration). During Phase I of the DOE project an extensive effort was directed at characterizing gasifier green liquor dregs. As with other tasks, the originally envisioned Phase II scope for this task was significantly reduced by the DOE budget reductions. During Phase II a green liquor filter cloth test stand was designed, fabricated, and installed. Samples of filter cloth were acquired from suppliers and exposed to the New Bern gasifier green liquor. Results of this work are presented below.

\subsection{Green Liquor Dregs Characterization}

Composite samples of dregs were collected from the raw green liquor during each gasifier test conducted between June 13 and 24. The dregs were recovered from the green liquor at IPST via filtration with qualitative paper filters of $25 \mathrm{um}$ nominal pore size. The dregs were then washed with reagent water until the filtrate $\mathrm{pH}$ was below 7 , then air dried prior to analysis.

Small samples were extracted with dichloromethane to determine the quantity of high molecular weight hydrocarbons present. The small quantities of extracted residue 0.5-0.8 wt. $\%$ of oven-dried dregs mass had no appreciable color or odor. This suggests there is little oil and tar associated with the dregs.

Portions of the air-dried sample were oven-dried at $105^{\circ} \mathrm{C}$ and then ashed at $525^{\circ} \mathrm{C}$. The weight loss at $525^{\circ} \mathrm{C}$ is attributed to combustion of organics and elemental C. All inorganic carbonates are expected to remain in the ash residue fraction. The ash residues were butterscotch brown in color.

A summary of the dregs characteristics for each test condition is given in Table 6-1. 
Final Technical Report Rev. 0

DE-FC26-04NT42259

Table 6-1 Comparison of dregs characteristics for June 2005 test conditions

\begin{tabular}{|c|c|c|c|c|c|c|c|c|c|}
\hline Test Date & Test Condition & $\begin{array}{l}\text { Black Liquor } \\
\text { Flow (1) } \\
\text { gpm }\end{array}$ & $\begin{array}{c}\text { Corrected } \\
\text { Air/Fuel } \\
\text { Ib air/lb d.s. }\end{array}$ & $\begin{array}{l}\text { Raw Green } \\
\text { Liquor Flow } \\
\text { gpm }\end{array}$ & $\begin{array}{c}\text { GL Total } \\
\text { Suspended } \\
\text { Solids } \\
\mathrm{mg} / \mathrm{L}\end{array}$ & $\begin{array}{c}\text { GL Cone } \\
\text { Tests - 2h } \\
\text { Settling (2) } \\
\text { ml }\end{array}$ & $\begin{array}{c}\text { Dregs } \\
\text { Unburned } \\
\text { Carbon (3) } \\
\text { wt. \% }\end{array}$ & $\begin{array}{c}\text { Dregs Bulk } \\
\text { Density } \\
\text { g/cm3 }\end{array}$ & $\begin{array}{c}\text { Unburned } \\
\text { Carbon from } \\
\text { Gasifier (4) } \\
\text { lb/hr }\end{array}$ \\
\hline $06 / 13 / 05$ & Baseline & 50 & 2.85 & 158 & 374 & $70-90$ & 40.7 & 0.101 & 12.0 \\
\hline $06 / 14 / 05$ & Lowering $\mathrm{A} / \mathrm{F}$ & 50 & 2.63 & 147 & 685 & $130-200$ & 64.6 & 0.052 & 32.6 \\
\hline $06 / 15 / 05$ & Low Firing Rate & 30 & 2.82 & 94 & 259 & $50-60$ & 21.4 & & 2.6 \\
\hline $06 / 16 / 05$ & High Firing Rate (lower A/F) & 54 & 2.74 & 180 & 1468 & $>1000$ & 81.5 & 0.031 & 107.7 \\
\hline $06 / 17 / 05$ & High Firing Rate & 54 & 2.83 & 179 & 484 & $80-130$ & 55.5 & 0.050 & 24.1 \\
\hline $06 / 20 / 05$ & Baseline Repeat & 50 & 2.81 & 161 & 348 & & 44.9 & 0.106 & 12.6 \\
\hline $06 / 21 / 05$ & Reduce Swirl to $70 \%$ & 50 & 2.77 & 158 & 2804 & $>1000$ & 91.3 & 0.033 & 202.1 \\
\hline $06 / 22 / 05$ & Reduce Atm Steam Press & 50 & 2.85 & 150 & 1127 & $>1000$ & 73.3 & 0.040 & 62.0 \\
\hline $06 / 23 / 05$ & Repeat Baseline & 50 & 2.76 & 151 & 344 & & 39.6 & 0.076 & 10.3 \\
\hline $06 / 23 / 05$ & Lowest A/F & 49 & 2.42 & 166 & 1177 & & 82.4 & 0.035 & 80.5 \\
\hline $06 / 24 / 05$ & Lowest A/F+ Atm Steam to 135psig & 50 & 2.42 & 148 & 1194 & $>1000$ & 76.1 & 0.038 & 67.5 \\
\hline $06 / 24 / 05$ & Lowest A/F+ Atm Steam to $145 \mathrm{psig}$ & 50 & 2.41 & 150 & 1268 & $>1000$ & 78.9 & 0.051 & 75.2 \\
\hline
\end{tabular}

Notes:

$1 \quad$ Uncorrected

2 Values $>1000 \mathrm{ml}$ indicate unacceptable green liquor quality for removal by mill's clarifier.

3 Taken as loss on ignition at 525C

4 Calculated from raw GL flow, total suspended solids, and unburned carbon content of dregs 
Final Technical Report Rev. 0 DE-FC26-04NT42259

The organic content of the dregs varied significantly (21-91 wt. \%) among the samples, but corresponded logically with the test conditions; e.g., the low swirl and lowest A/F ratio cases had the highest organic carbon contents (82-91\%), low firing rate had the lowest organic carbon content (21\%), and the three baseline samples had good agreement (40.7, 44.9, $39.6 \%$ ). This is an important data set for correcting the total suspended solids values that were measured on-site during the test matrix into more meaningful unburned carbon values needed for CFD model correlation. Composite samples of dregs were collected from the raw green liquor during each gasifier test conducted between June 13 and 24.

An element scan on the inorganic portion of the dregs samples remaining after ashing at $525^{\circ} \mathrm{C}$ was performed by ICP-AES. The inorganic portion of the dregs consisted mostly of calcium (10-16 wt. \%), magnesium (9-13 wt. \%), and sulfur (5-13 wt. \%). The sulfur is presumably in the form of sulfate. Other elements that were present in quantities greater than 0.5 wt. \% were $\mathrm{Fe}, \mathrm{Mn}, \mathrm{Al}, \mathrm{Si}, \mathrm{Na}$, and $\mathrm{Zn}$ (listed in order of decreasing abundance). The balance of the samples is assumed to be primarily oxygen in the form of metal oxides, refractory compounds, insoluble sulfates and carbonates.

An approximate bulk density was determined for each filtered composite dregs sample (reported in Table 6-1). Decreasing density clearly correlated with increasing unburned carbon content. Furthermore, it was observed that green liquor samples with greater than 750 $\mathrm{mg} / \mathrm{L}$, failed to settle in the Imhoff cone tests conducted on site during the June 2005 testing. As shown in Figure 6-1, the samples that failed to settle all had unburned carbon content in excess of $70 \mathrm{wt} . \%$ and density below $0.05 \mathrm{mg} / \mathrm{cm} 3$. The sample with highest unburned carbon content was also the case of highest TSS and very poor settling (reduced swirl condition). 
Final Technical Report Rev. 0

DE-FC26-04NT42259

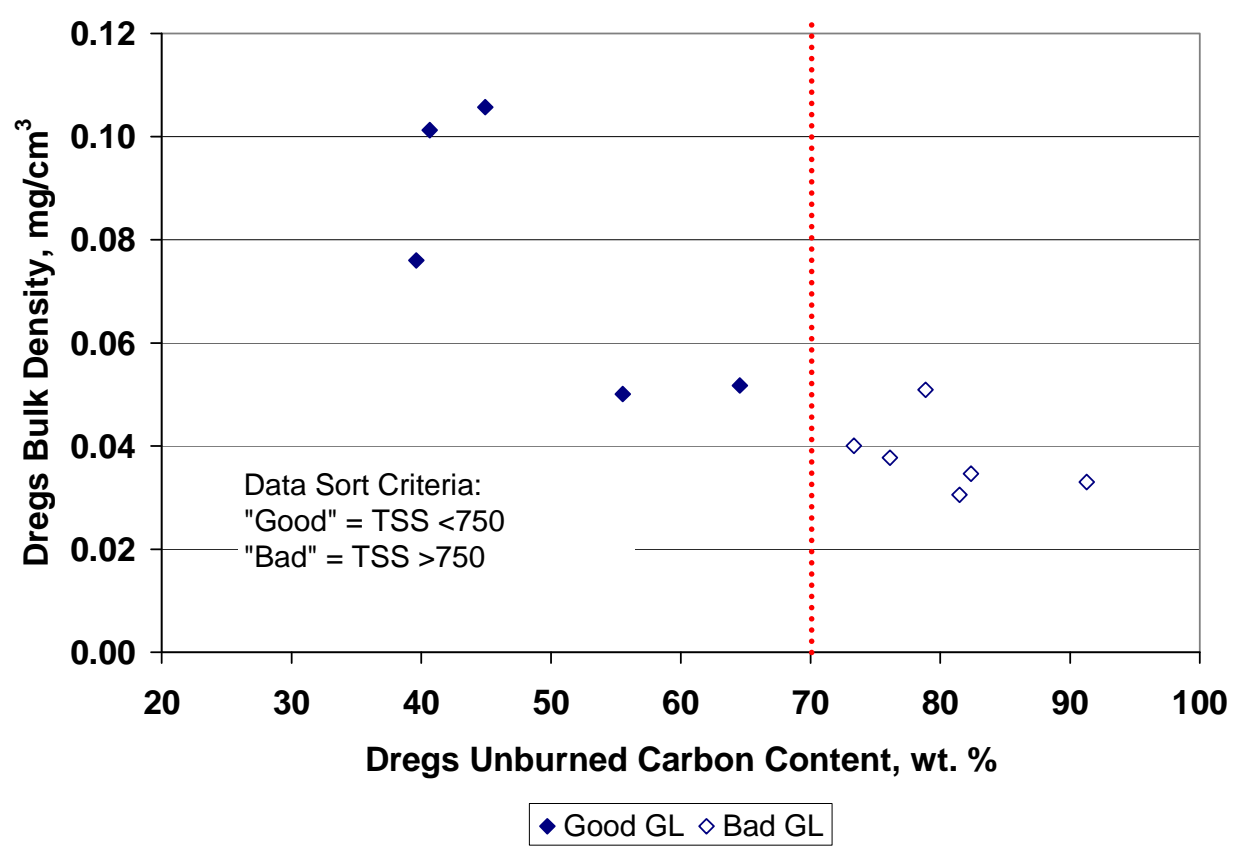

Figure 6-1 Measured bulk density of dregs vs. unburned carbon content with data grouped by acceptable dregs settling criteria (TSS $<750 \mathrm{mg} / \mathrm{L}$ ).

\subsection{Dregs Morphology}

Samples of dregs from the baseline condition, as well as lowest and highest unburned carbon content were inspected by scanning electron microscopy (SEM) for insight into dregs settling behavior. The solids were carefully separated from the green liquor and allowed to air-dry prior to SEM observation so as to minimize physical changes.

Representative images of isolated dregs particles from these three conditions are shown in Figure 6-2. The highest unburned carbon content sample (Figure 6-2a) appears to be almost entirely composed of thin, flat flakes of random shape. Several distinct 50-100 $\mu \mathrm{m}$ spheres were also observed in this sample (some hollow, as in Figure 6-2b). There are obvious crystalline and amorphous mineral components in the flakes at the baseline condition (Figure 6-2c); some of these particles had curved surfaces. The lowest carbon content sample was composed of flakes that were thicker, more heavily loaded with mineral matter, and more clearly curved than the other samples (Figure 6-2d). The curvature and pattern of tears suggest these are fragments of 100-500 $\mu \mathrm{m}$ hollow spheres. 
Final Technical Report Rev. 0

DE-FC26-04NT42259

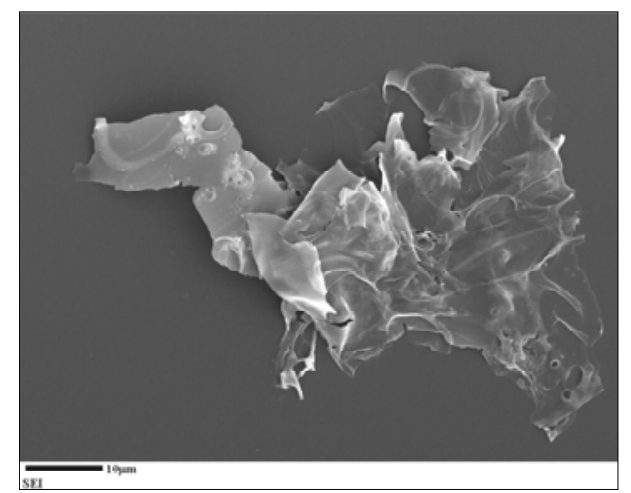

a. $6 / 21 / 05$ Reduced Swirl $($ ash $=8.7 \%)$

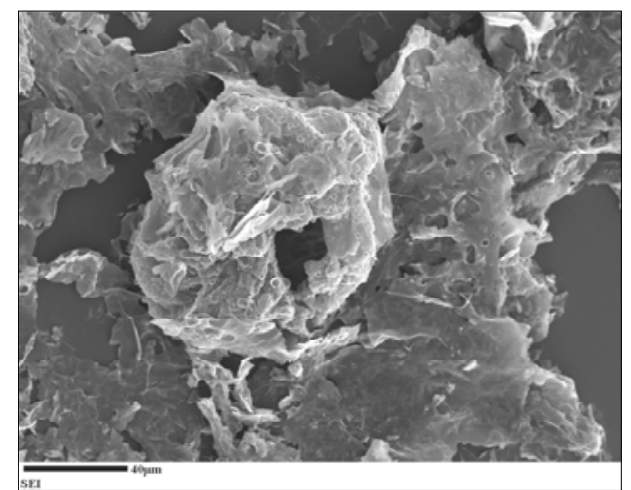

b. $6 / 21 / 05$ Reduced Swirl (ash $=8.7 \%$ )

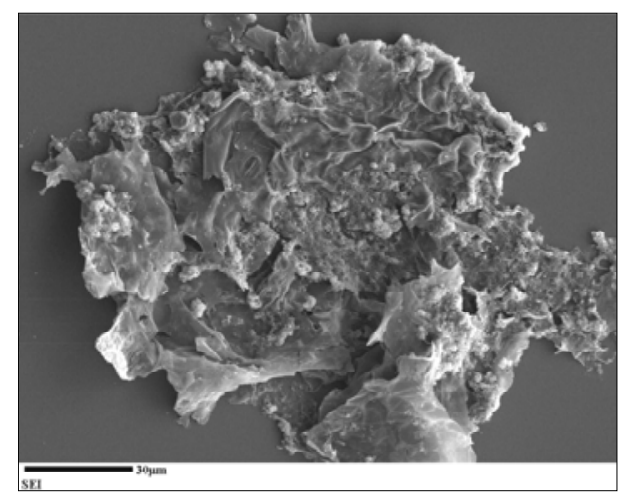

c. $6 / 13 / 05$ Baseline $(\mathrm{ash}=59.3 \%)$

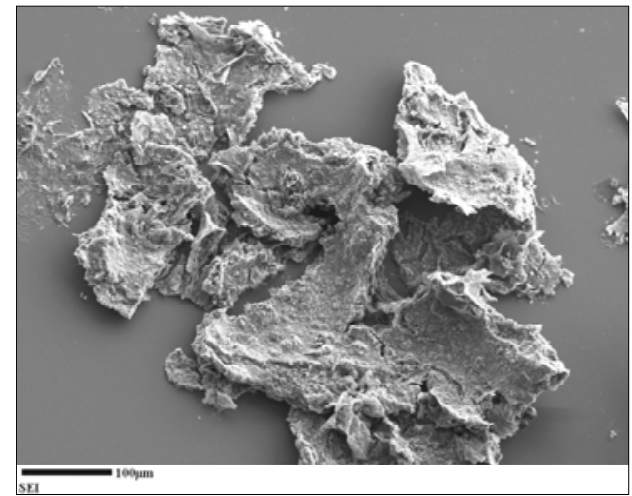

d. $6 / 15 / 05$ Low Firing Rate $($ ash $=78.6 \%)$

Figure 6-2 Selected SEM photomicrographs of individual particles isolated from composite dregs samples from indicated mill test conditions.

Based on our laboratory experience with swelling of single drops of black liquor and gasification of pulverized black liquor solids, we expect that the form of unburned char particles (dregs) to be hollow spheres. After consideration of many SEM images, we conclude that the flake-like particles observed in the samples are in fact fragments of crushed hollow spherical particles. It is reasonable to expect that fragile char particles can be damaged by the violent action of the quench sprays and the raw green liquor transfer pumps. The samples with higher ash content (low unburned carbon) would tend to form thicker, stronger shells and retain more of the spherical appearance. The very thin fragments from the samples with high unburned carbon would be more easily deformed and flattened during the drying process used to prepare the dregs for SEM observation. 
Final Technical Report Rev. 0

DE-FC26-04NT42259

\subsection{Evaluate alternatives for dregs treatment}

Total unburned carbon leaving the gasifier boundary was estimated from the average raw green liquor flow rate, the measured TSS values, and the unburned carbon content of the dregs samples. This value ranged from $2.6 \mathrm{lb} / \mathrm{hr}$ at the low load condition to $202 \mathrm{lb} / \mathrm{hr}$ at the reduced swirl condition (see Table 6-1). Figure 6-3 shows the unburned carbon as a function of load and air/fuel ratio. Mill experience indicates that gravity settling in clarifier tanks is not effective at conditions forming high levels of low-density dregs (region above the dotted horizontal line in Figure 6-3). The practical implication for current operation is that the air/fuel ratio must be maintained at greater than 2.5 at base load conditions and greater than 2.8 at highest load.

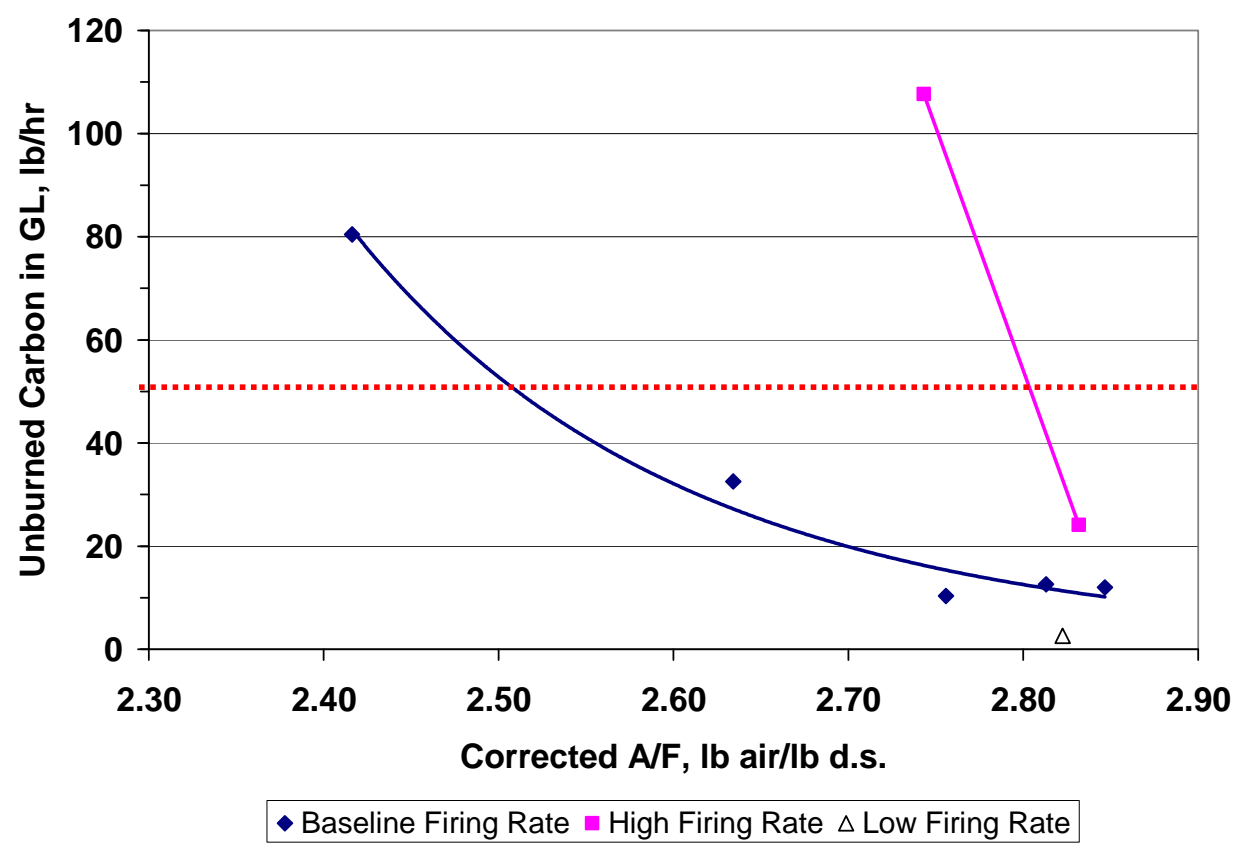

Figure 6-3 Calculated unburned carbon leaving gasifier boundary vs. corrected air/fuel ratio and operating load.

Atomizing steam pressure was adjusted in two of the trials; the impacts are shown in Figure 6-4. At high air/fuel ratio, raising steam pressure resulted in an increase in unsettleable carbon; while at lowest air/fuel ratio, increasing steam pressure reduced unburned carbon, but there was not sufficient pressure applied to move the operating back to an acceptable range. 
Final Technical Report Rev. 0

DE-FC26-04NT42259

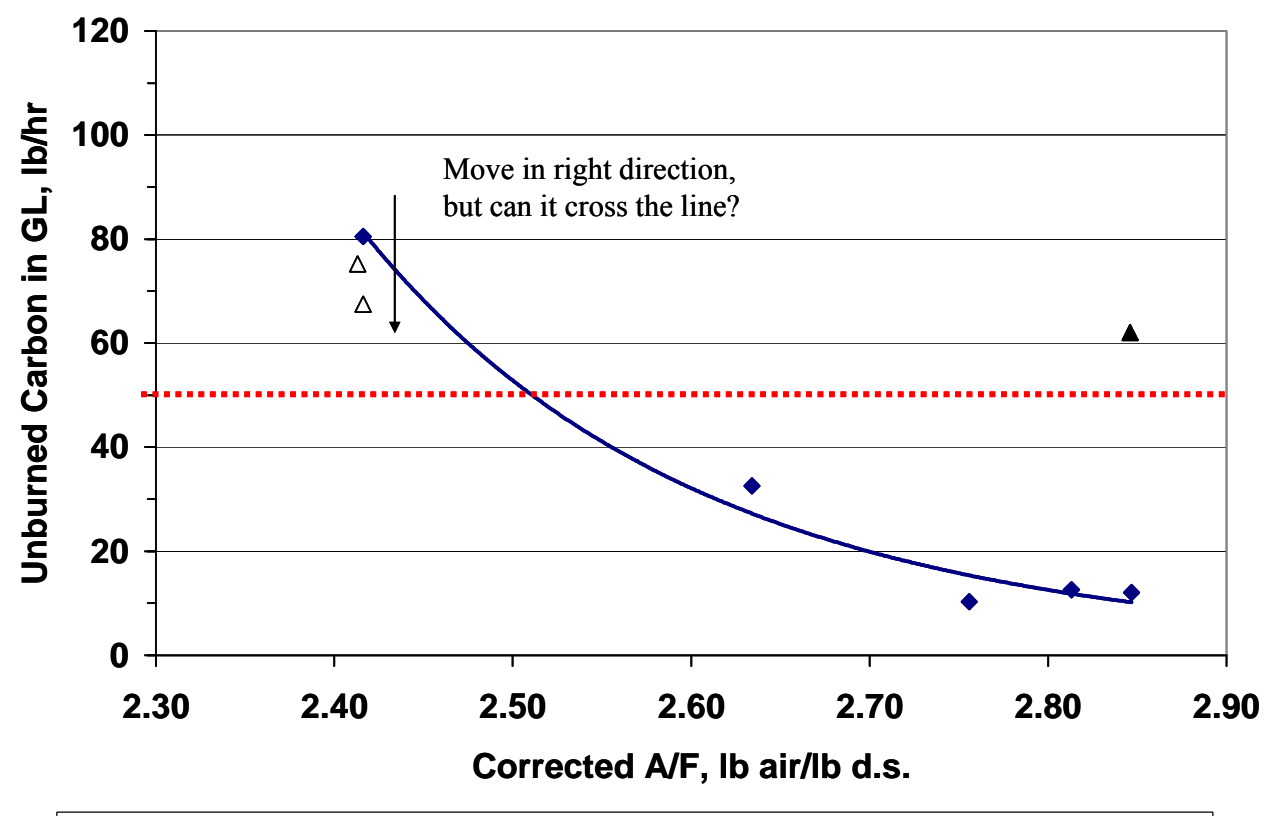

- Baseline Firing Rate $\Delta$ Reduce Steam $\mathrm{P}$ at High A/F $\Delta$ Raise Steam $\mathrm{P}$ at Low A/F

Figure 6-4 Calculated unburned carbon leaving gasifier boundary vs. corrected air/fuel ratio and atomizing nozzle steam pressure.

As mentioned earlier, we have determined that dregs settling tendency is primarily a function of their density and that the individual dregs particles are predominantly 50-500 $\mu \mathrm{m}$ flakes. A barrier filter designed to remove this material may allow continuous operation of the New Bern gasifier at lower air/fuel ratios and correspondingly lower operating temperatures. This would benefit both thermal efficiency and refractory life. An evaluation of green liquor filter cloth is discussed later.

Another possible mechanical solution would be a hydraulic density classifier or "hydrocyclone." This could be designed to reject the low-density dregs particles from the raw green liquor leaving the gasifier quench.

Burner nozzle characterization work and modeling has suggested there is a fraction of droplets from the spray nozzles which is comparably large in diameter. It is likely that these large droplets are not fully gasified and are a significant source of the dregs in the raw green liquor. The Phase II direction that is best aligned with DOE project objectives is to test alternative nozzle concepts that could produce a more uniform drop size distribution that would reduce dregs levels allowing operation at lower air/fuel ratios. The benefits of running at lower $\mathrm{A} / \mathrm{F}$ are longer refractory life resulting from reduced operating temperature, and reduced fossil fuel use in the power boiler resulting from increased fuel quality of the gasifier product gas. 
Final Technical Report Rev. 0

DE-FC26-04NT42259

\subsection{Green Liquor Filter Cloth Testing}

Well established methods exist for dealing with dregs from recovery boiler green liquor; both clarification and filtration are practiced in pulp mills today. As noted earlier, the dregs component in Chemrec green liquor behave differently and are particularly sensitive to how the gasifier is operated. Dregs settling for Chemrec produced green liquor is often slower than for traditional recovery boiler green liquor dregs. At times this has caused problems in New Bern's green liquor clarifier and subsequent downstream causticizing processes.

For this reason filtration has been considered as an alternative means of removing dregs from the Chemrec green liquor. In 1999, a series of trials were conducted at New Bern to determine the "filterability" of the Chemrec green liquor using a standard Metso (at that time Kvaerner) test method. The results indicated that the "filterability" of Chemrec green liquor dregs is better than recovery boiler green liquor dregs produced at the same time. Similar results have been observed for green liquor dregs produced in Chemrec's pressurized pilot plants at Piteå, and Skoghall. However, there is no previous experience with how filter media will stand up to long term exposure in the Chemrec green liquor. In particular, there was a concern tar compounds, found in very low concentrations in the Chemrec green liquor, might degrade the polypropylene filter media used in conventional green liquor filters.

In order to test how filter media would stand up to long term exposure to Chemrec green liquor, a test stand was fabricated and installed at New Bern plant in spring 2007. The test stand was designed to take a slip stream of green liquor off the green liquor recirculation loop and pass it over samples of filter media held in the test vessel. No attempt was made to actually filter the green liquor in the test stand. Figure 6-5 shows the arrangement and location of the filter cloth test loop. 
Final Technical Report Rev. 0

DE-FC26-04NT42259

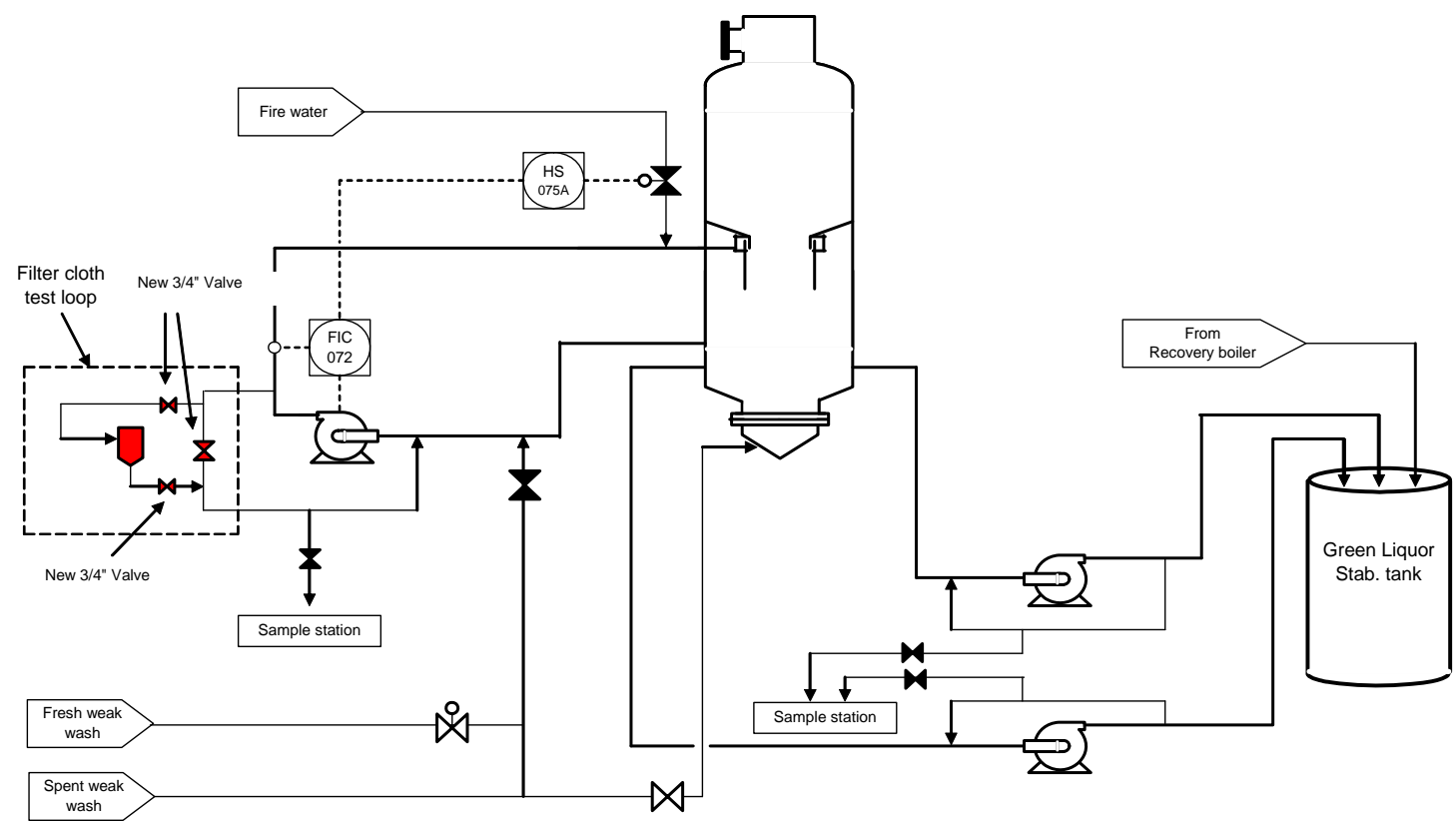

Figure 6-5 Schematic showing location of green liquor filter cloth test stand

Filter cloth samples were provided by two suppliers. These were fitted into the test vessel and green liquor was then circulated over the filter cloths. After 8 weeks of operations the filter cloths were removed from the test vessel and flushed with hot water and put in a mild acid bath for 6 hrs. A modified version of Metso's method for measurement of filterability for green liquor dregs was then applied to both exposed and unexposed samples of the filter media. In Metso's standard test, a standard filter paper is used rather than filter cloths. Three tests were performed.

- Filterability of green liquor from the recovery boiler and the Chemrec Gasifier (standard filter paper).

- Filterability of Chemrec green liquor using a unexposed filter cloths.

- Filterability of Chemrec green liquor using a exposed filter cloths.

The term filterability is a parameter used by Metso and is measured in their filterability kit for lime mud and dregs. The filterability kit measures the specific drain resistance for a bed of particles. Normally permeability is used, but since it is not practical to use in this applications the parameter filterability has been introduced and is defined as the permeability, $\mathrm{K} * 10^{13}$, derived from Darcy's law.

The filterability test on the green liquor from the recovery boiler shows that the average filterability is 0.8 . This is higher then the tests done in January 1999 when the average filterability was 0.6 . The filterability test on the Chemrec green liquor shows that the average 


\section{Final Technical Report Rev. 0 \\ DE-FC26-04NT42259}

filterability is 1.5 , same as the test done in January 1999 . Filterability of green liquor is normally in the range of $0.2-2.0$. Where below 1.0 is considered poor filterability and above 1.0 is considered good filterability. The filterability test on new unexposed filter cloth shows that the average filterability is 0.3 . The filterability test on the exposed filter cloth shows that the average filterability is 0.55 . The filtered green liquor from the filterability tester was very dark for the exposed filter cloth, indicating that dregs were passing into the filtered green liquor. The filtered green liquor from the unexposed filter cloth was clear as is the normal situation for filtered green liquor; see photo in Figure 6-6.

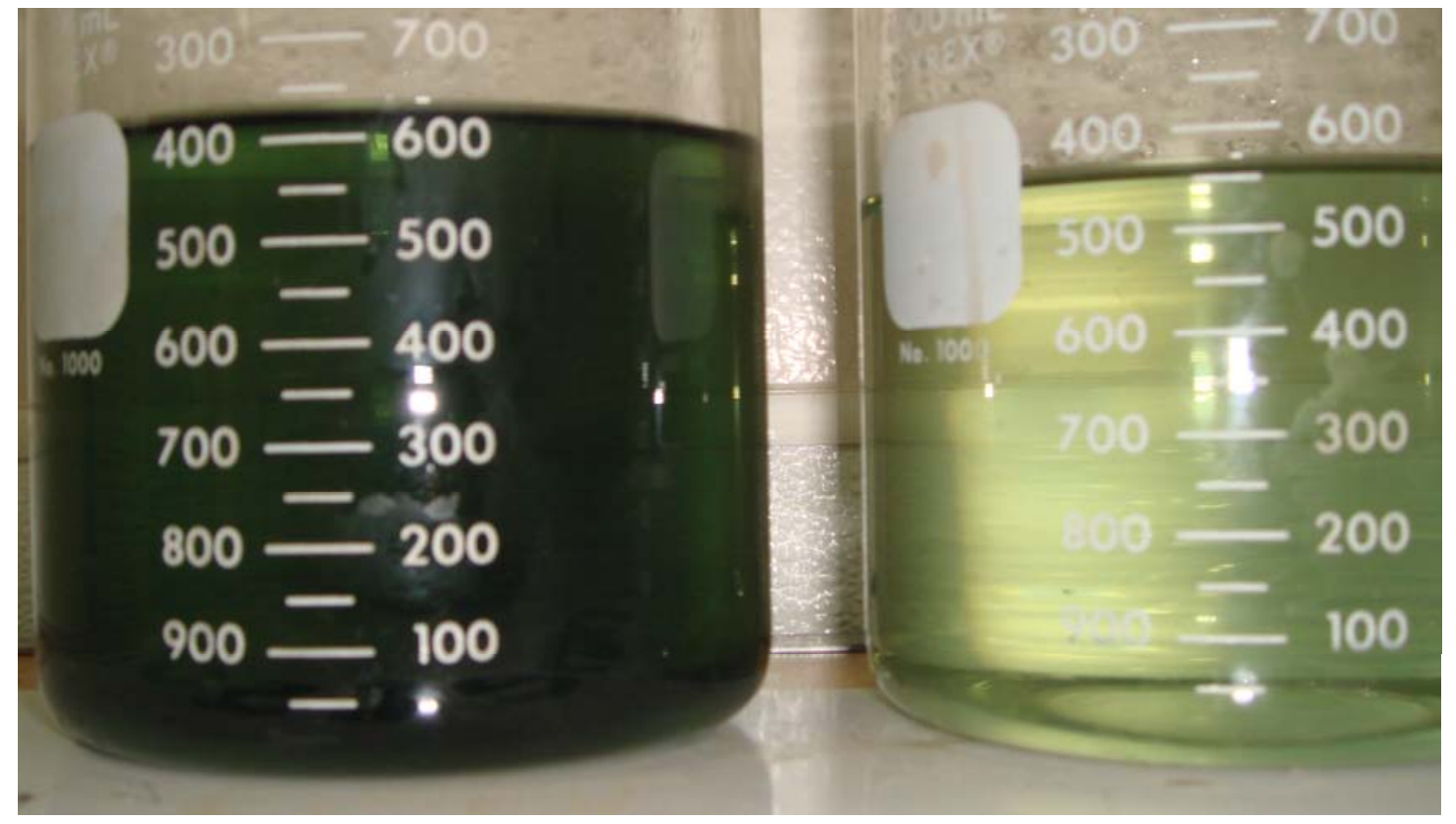

Figure 6-6 Photo comparing filtrate from exposed (left) and unexposed filter cloths.

A repeat trial was planned and carried out in February 2008. In the February 2008 test the filter cloth was exposed to Chemrec green liquor for 16 days. After exposure, the filter cloth was flushed with hot water and put in a mild acid bath for $6 \mathrm{hrs}$. As with the earlier results, this shorter trial indicated slightly higher "filterability" on the exposed filter cloth compared to the unexposed reference. This might suggest that the polypropylene material used in the filter cloth was starting to change its properties. However the overall conclusion was that no significant change in the filter cloth performance was observed for this short exposure.

This limited testing suggests that polypropylene type filter media normally used in green liquor filters may degrade with long term exposure to Chemrec green liquor. Further testing would be necessary to validate and understand this, but clearly alternatives types of filter cloth would need to be explored. 
Final Technical Report Rev. 0

DE-FC26-04NT42259

\subsection{Short Time Contactors}

The New Bern booster scrubber column consists of two unit operation stages. The first stage is gas cooling which condenses water content out of the fuel gas. The objective of the second stage is to absorb $\mathrm{H}_{2} \mathrm{~S}$ with circulating weak wash absorption fluid. Getting both high $\mathrm{H}_{2} \mathrm{~S}$ absorption efficiency together with high $\mathrm{H}_{2} \mathrm{~S}$ selectivity has proven difficult. The equilibrium condition for selective absorption of $\mathrm{H}_{2} \mathrm{~S}$ over $\mathrm{CO}_{2}$ is not favourable depending on process conditions and chosen absorption fluid. There will be co-absorption of 1 to 4 moles of $\mathrm{CO}_{2}$ for every mole of absorbed $\mathrm{H}_{2} \mathrm{~S}$. Both spray and packed type scrubbers have been tried in New Bern. The fuel gas in New Bern is burned in a power boiler with an $\mathrm{SO}_{2}$ scrubber, and the $\mathrm{SO}_{2}$ scrubber reagent is recycled to the weak black liquor. Because sulphur is recaptured in this manner, optimizing scrubber performance has not been a priority.

The original project plan included pilot testing of a new concept "short contact" time scrubber. The concept was based in laboratory experiments carried out by VTT, Finland. They had shown that through the use of reduced contact times between product gas and the absorbing liquid $\mathrm{H}_{2} \mathrm{~S}$ absorption is favourable to the rate for $\mathrm{CO}_{2}$. In phase I of this project, a design was developed for a short time contractor scrubber test facility. The engineering and procurement went through all stages from conceptual design, detail design, inquiries, request for quotes, and bids reception.

Bid evaluations were performed for numerous bids received for the major process equipment items. An example design by LAPCO is shown in Figure 6-7. Penta Engineering was subcontracted to conduct a process hazard classification review. Based on this review, it was determined that it would be necessary to modify the bids for the positive displacement blower. P\&IDs were produced for the new short-time contactor plant. A concept for the control scheme was decided upon. Process criteria, a piping service index, and pipe and valve specifications were agreed upon. A plant general arrangement concept was agreed upon. It was determined that mist eliminator sections from Lechler, similar to those being used in the pressurized gasifier pilot plant, could be obtained from Lechler's North American company, even though the plates would be fabricated in Germany. The required spray nozzles are commercially available in North America. It was determined that there were no foreseeable obstacles to build and run a test facility of this type at the New Bern plant. 
Final Technical Report Rev. 0

DE-FC26-04NT42259

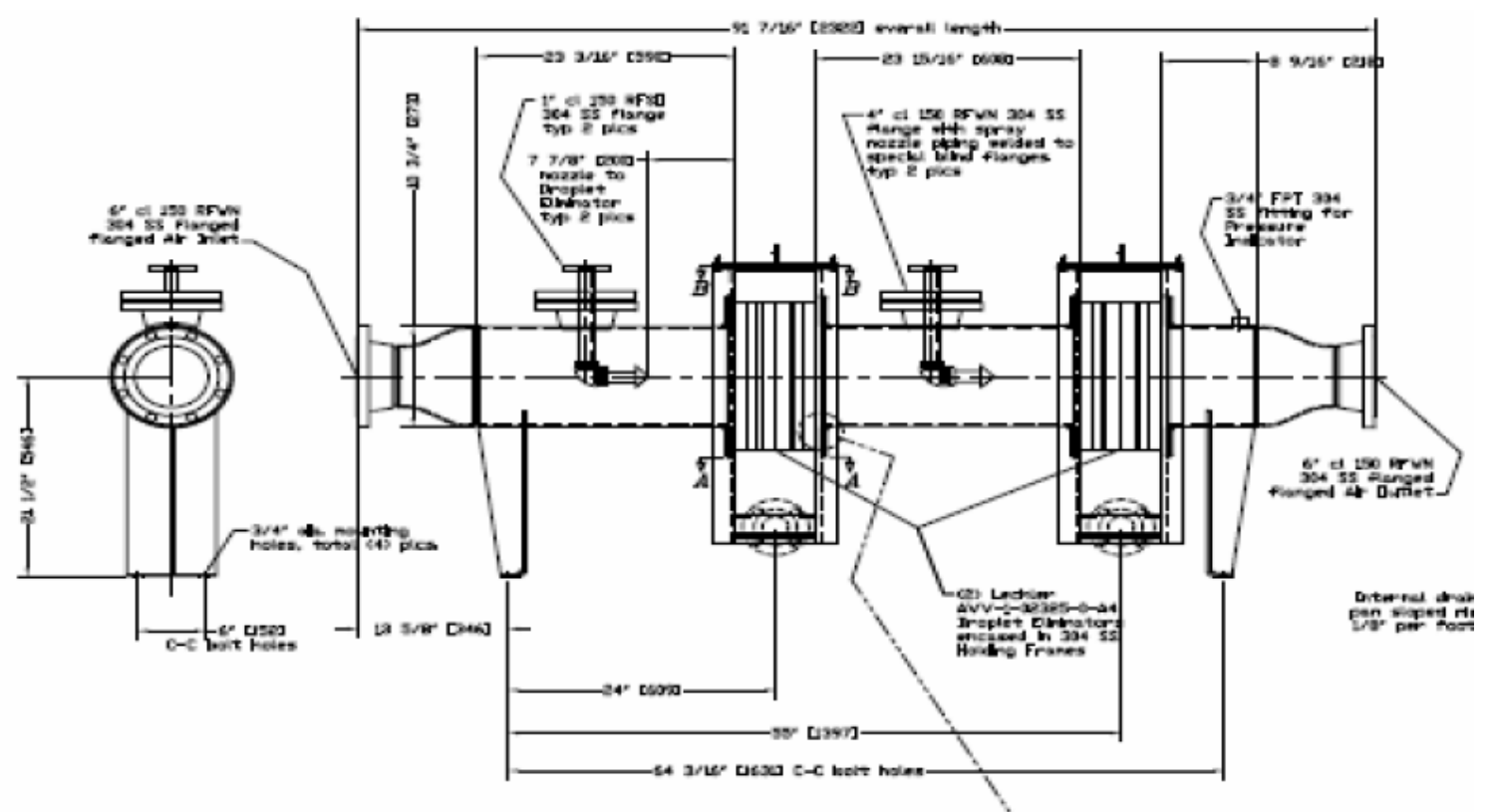

Figure 6-7 Short time contactor design from LAPCO

Due to DOE Phase II budget reductions this task was abbreviated. The work done in phase I was used to develop a budget estimate for total installed cost, but this was not taken forward to implementation and testing in phase II.

A three stage short-time contactor system is included in Chemrec's DP-1 pressurized pilot plant in Piteå. This has been tested with various scrubber solutions (e.g., green liquor, low Active Alkali green liquor, weak wash, etc...) with very promising results. $\mathrm{H}_{2} \mathrm{~S}$ absorptions of more than $60 \%$ in one stage have been observed. The raw gas has a $\mathrm{H}_{2} \mathrm{~S}$ concentration around $1.3 \%$ and $\mathrm{CO}_{2}$ around $30 \%$. Selectivity's well over 10 have been measured. Selectivity means that if $\mathrm{H}_{2} \mathrm{~S}$ has been reduced by $60 \mathrm{vol} \%$ and $\mathrm{CO}_{2}$ by $6 \mathrm{vol} \%$ then the selectivity is 10 . 
Final Technical Report Rev. 0

DE-FC26-04NT42259

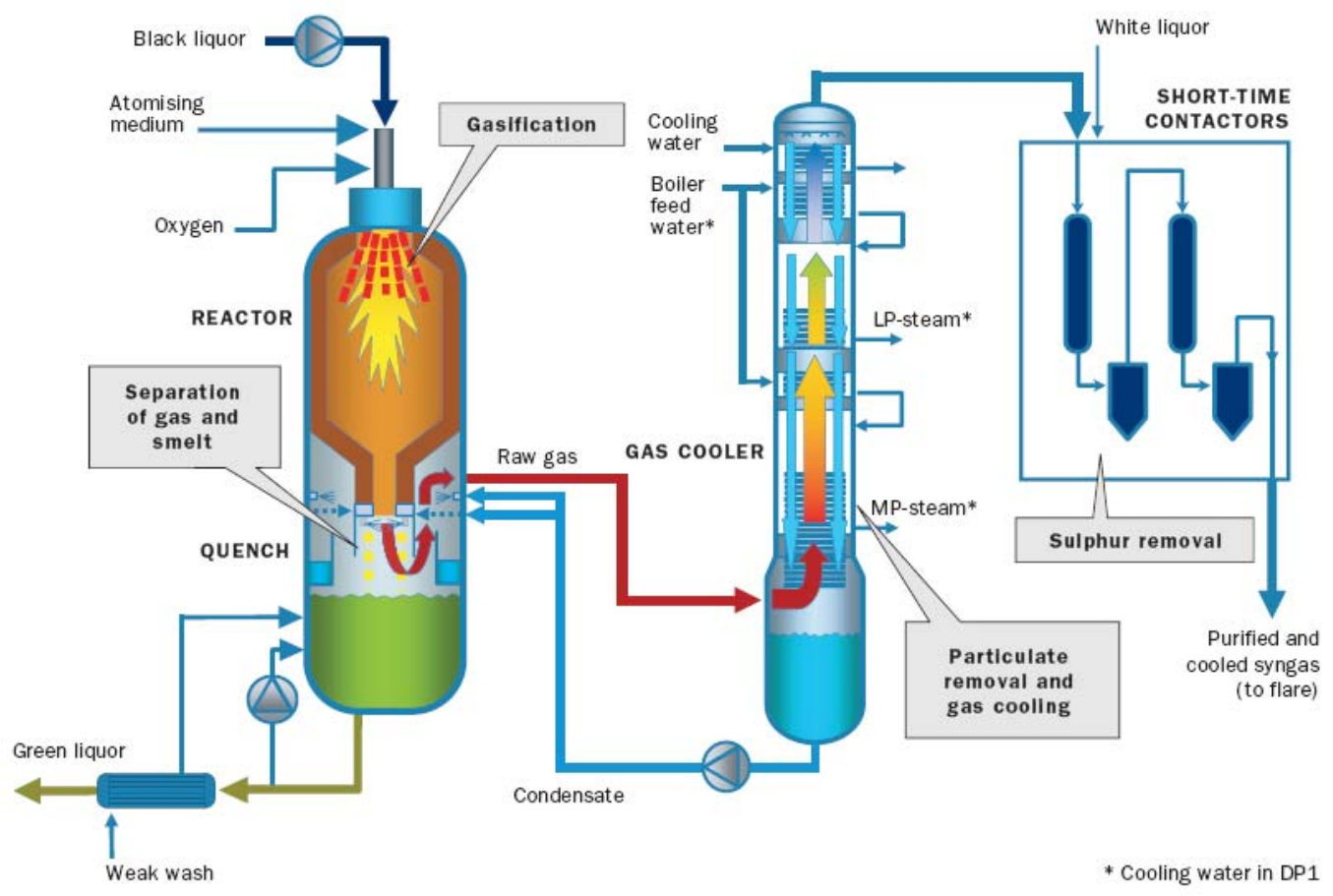

Figure 6-8 Schematic of Chemrec's DP-1 pilot facility in Piteå Sweden 
Final Technical Report Rev. 0

DE-FC26-04NT42259

\section{$7 \quad$ Summary of Task Results}

The overall goal of the project was to advance the state of high temperature black liquor gasification development. During the performance period of this contract, October 2004 through March 2008, the reliability and performance of the New Bern gasifier improved significantly. However, in addition to the work effort associated with this project, the New Bern gasifier plant has received increased attention in a number of areas. Since the results of this project are intermingled with the total effort, it is hard to break-out specific contributions to the overall success, but surely taken as a whole the project has met the stated objective. The following is summary of results by project task.

\subsection{Task 1 - The development of and correlation of CFD modeling tools to the New Bern demonstration facility}

Key Task 1 efforts included:

- Reactor modeling and correlations to field test results, including system material- \& energy-balances

- Nozzle spray modeling and validation

- Temperature Measurement System

The aim of Task 1 was to develop a CFD modeling capability which predicted gasifier processes with sufficient accuracy to be a useful tool in identifying and evaluating options for improved performance. The CFD model tools developed included both a detail model for the black liquor spray nozzle (Simulent model) and an overall gasifier reactor model (PSL model). Together these models predict processes occurring within the gasifier reactor including: black liquor droplet formation and steam injection, the mixing of black liquor sprays with incoming air, gasification reactions and chemistry, smelt and product gas flows through and out of the gasifier reactor.

The need for validation with respect to real plant data and existing process simulation tools was a fundamental activity in this work. Difficulties in getting data from plant instruments to match simulated data were overcome through adjustments to instrument values using element $(\mathrm{S}, \mathrm{Na}, \mathrm{C})$ and energy balances over the plant. A side benefits of this effort included improvements in field measurements.

Measurement of droplet generation in the current nozzle at Chemrec's test facility in Sweden and modeling of the same with Simulent's CFD code was a key part of the overall work. Work with the real nozzle in the test facility revealed important insight in droplet size distribution and led to increased emphasis on measures which mitigate the formation of large droplets and served as design for Task 2. 
Final Technical Report Rev. 0

DE-FC26-04NT42259

Overall outputs from the CFD model correlated reasonably well with changes in field data measurements. Both the overall reactor and spray models provided insight into the gasifier processes and proved useful in setting direction and evaluating options for improvements in the gasifier burner system. However, neither model should be considered fully predictive and there are known short comings in the underlying algorithms.

Different types of temperature measurement instruments for the hot reactor were also investigated. One of the new type instruments was implemented and has been giving good readings between October 2007 and October 2008. This is a significant improvement in reliability of previous instruments.

\subsection{Task 2 - The black liquor burner system}

Key Task 2 efforts included:

- Nozzle development

- Nozzle testing

- Burner air system upgrades

The primary goal of Task 2 was to design and implement improvement in the black liquor burner system that would lead to improved process performance and reliability. Based on the field test and modeling results of Task 1, this effort was directed at burner improvements that would enable operation at lower air to fuel ratio without compromising green liquor quality; i.e. lower overall reactor temperature yield improved thermal efficiency and reliability. The project team used the modeling tools developed in Task 1 and Chemrec's nozzle test facility to design black liquor nozzle and air delivery improvements directed optimizing droplet size distribution, mixing black liquor with air and an even flow pattern throughout the reactor volume.

Four new nozzle designs and one air distribution modification were designed and field tested. Unfortunately, none of the nozzle improvements produced a significant performance enhancement over the standard status quo nozzle. One of the nozzles did show a decrease in atomizing steam consumption and therefore a small improvement in overall energy efficiency. Testing of the air distribution modification had to be interrupted due to air bypassing which was not accounted for in the design. An improved design has been developed, but it has not been possible to retest this prior to writing of this report.

Chemrec plan to continue with some of the developments started in Task 2 after the end of the DOE sponsored period. There are good reasons to believe that the proposed nozzle shapes will be more efficient than the one currently in use. The air distribution device is important, but due production risk and current improved operation of the gasifier the motivation to implement process alterations has become less critical. 
Final Technical Report Rev. 0

DE-FC26-04NT42259

\subsection{Task 3 - Process Reliability - Green liquor \& condensate scaling}

Key Task 3 efforts included:

- Plugging and scaling investigation in green liquor and condensate systems

- Design of an indirectly cooled quench tube

Scaling and plugging in the green liquor and condensate recirculation circuits has caused considerable downtime since the plant started-up in 1987. Besides the downtime and expense of acid washing, scaling in the green liquor system has led to failures of the quench pipe in the reactor outlet. Understanding the root causes of this scaling behavior was a key outcome of this work. Furthermore, an alternative design for an indirectly cooled quench pipe was developed as an alternative to circulating green liquor as is currently practiced.

Equilibrium modeling lead to the conclusion that $\mathrm{CaCO}_{3}$ scaling is the culprit in both the green liquor and condensate systems. Based on field test results and balances, the likely source of $\mathrm{Ca}^{++}$in both cases is mill water used as make-up on the gasifier scrubber column. The mill is currently successfully treating the green liquor scaling problem with a chemical additive. The condensate scaling problems has been mitigated by operational changes that have minimized make-up mill water into that loop. If either of the scaling problems should reoccur, or chemical additive costs become excessive, the project has recommended treating the mill water make-up to the scrubber or replacing it with evaporator condensate.

To eliminate the green liquor circulation all together would of course eliminate the scaling which earlier has caused downtime. It would also eliminate the need for a green liquor pump which is normally undesirable in green liquor handling systems. Therefore the project included the design (originally also fabrication and installation) of an indirectly cooled quench pipe (ICQP) cooled with cooling water. Although this was not implemented at New Bern due to the successes mentioned above and the DOE Phase II budget cuts, a similar design has been successfully implemented and is in operation at Chemrec's pressurized pilot facility in Piteå, Sweden.

\subsection{Task 4 - Process Integration in mill - Dregs characterization}

Key Task 3 efforts included:

- Green liquor dregs characterization

- Investigation of green liquor filter cloth performance

- Design short contact time slip stream test stand

The dregs in green liquor from the New Bern gasifier are very different than dregs in green liquor from the recovery boiler. At times the poor settling characteristic of the gasifier dregs 
Final Technical Report Rev. 0

DE-FC26-04NT42259

has caused operational problems in the mill's green liquor clarifiers and downstream causticizing equipment. The field testing and dregs characterization work showed the strong relationship between quantity of dregs as function of gasifier firing rate and particularly air to fuel ratio. Perhaps more importantly, the carbon content of gasifier dregs dramatically increases with reduced the air to fuel ratio. Dregs with greater than $70 \%$ carbon content exhibited poor settling behavior due to their lower density.

SEM investigation of dregs morphology indicate the dregs are in fact flakes of carbon with varying inorganic content depending upon the factors mentioned above. These flakes are most likely fragments of swollen spherical char particles formed from individual black liquor droplets. One hypothesis is that these fragments come from a "wing" of larger droplets in the size distribution seen in the nozzle experiments at Chemrec's test facility. This is the basis for much of the nozzle design work in Task 2.

Another means to deal with the gasifier dregs would be to filter them from the green liquor. Previous work had indicated that gasifier dregs had good "filterability," but there was an outstanding question of how filter cloths used in conventional green liquor applications would hold up in the gasifier green liquor. Based on test results under this task, commercial green liquor filter cloth material seem to deteriorate when exposed long term to gasifier green liquor. Alternate material composition may work better and further tests would therefore be necessary.

Getting both high $\mathrm{H}_{2} \mathrm{~S}$ absorption efficiency together with high $\mathrm{H}_{2} \mathrm{~S}$ selectivity has proven difficult with the current scrubber design at New Bern. The equilibrium condition for selective absorption of $\mathrm{H}_{2} \mathrm{~S}$ over $\mathrm{CO}_{2}$ is not favorable. A design and procurement package was prepared for a "short contact time" slip stream test stand during Phase I of the project. This was not implemented in Phase II due to the DOE budget reduction. A short contact time scrubber has been implemented successfully at Chemrec's pressurized pilot facility in Piteå, Sweden. 
Final Technical Report Rev. 0

DE-FC26-04NT42259

\section{Conclusions and Recommendations}

The overall goal of the project was to advance the state of high temperature black liquor gasification development. During the performance period of this contract, October 2004 through March 2008, the reliability and performance of the New Bern gasifier improved significantly. However, in addition to the work effort associated with this project, the New Bern gasifier plant has received increased attention in a number of areas. Since the results of this project are intermingled with the total effort, it is hard to break-out specific contributions to the overall success, but surely taken as a whole the project has met the stated objective. Some specific results have been summarized above in section 7 .

Chemrec will continue to collaborate with the New Bern mill on gasifier performance and reliability improvements. This will include efforts directed at increasing plant availability, reducing maintenance costs, increasing energy efficiency, and increasing capacity. In particular, the following elements of this DOE sponsored project will likely see further action in the future:

- Work with field instruments to improve plant operations. Regular follow-up and feed back to mill operations.

- Lower steam consumption for atomization - additional tests with the steam swirled nozzle are planned

- Further work with nozzle concepts initiated during this project.

- Further work with nozzle spray angle

- Reinstall the air distribution device - depends upon a suitable opportunity can be worked out with the mill

- Further work on thermocouples and alternate temperature measurement solutions.

The New Bern gasifier is a commercial operation fully integrated with the New Bern Cellulose Fiber facility production. The potential benefits of any change will always be weighed against the potential production risks. Obviously all testing and development work has been and will continue to be closely coordinated with and approved by the New Bern mill operations team. They have been most accommodating during this DOE sponsored project, but it is recognized their highest priority is meeting the production requirements.

Much of this DOE sponsored work has already influenced the design and testing at Chemrec's pilot facility in Piteå, Sweden. This O2-blown, pressurized (to 30 bar), 20 tonne solids per day pilot has been in operation since 30 September 2005. To date (end October 2008) it has achieved more than 7300 total hours of operation with the longest continuous run being 23 days. Some of the areas where the Pitea pilot has benefited from this DOE sponsored project are noted below: 
Final Technical Report Rev. 0

DE-FC26-04NT42259

- The pilot plant has operated successfully with an indirectly cooled quench pipe (ICQP) since February 2008. Experience gained in development of the New Bern plant ICQP design was carried forward to the Piteå, plant design. In fact the pilot ICQP operates at higher temperatures than designed for in New Bern and has thus far presented no operational problems.

- The Piteå pilot facility has short contact time scrubbers similar to the design developed for the New Bern test program. Although the New Bern test stand design was not carried forward to implementation, the units in Piteå have operated with very promising results with respect to high $\mathrm{H}_{2} \mathrm{~S}$ selectivity.

- Chemrec has worked closely with ETC on development of a full CFD simulation of the Piteå pilot plant. This effort has interacted with the knowledge gained from the New Bern CFD modeling and validation effort. Chemrec use this CFD modeling capability regularly to interpret test results and propose operational and hardware changes. This has been particularly true with regard to burner developments. Over time this CFD modeling capability will improve based on correlation with pilot testing and will serve a key role in technology scale-up.

Certainly if the New Bern facility chooses to pursue upgrades in any of these areas, the knowledge gained from the DOE sponsored work and Chemrec's Pitea pilot will provide a sound basis for design. More importantly, this DOE project has played a role in advancing the overall state of high temperature gasification technology toward the ultimate biorefinery role where it will someday replace recovery boilers. Chemrec are currently in the process of upgrading the Pitea facility to produce DME to fuel a fleet Volvo trucks. The upgraded plant is scheduled to be on stream 1Q 2010 and produce about 5 tons of DME per day. The fleet test will be carried out during $21 / 2$ years. Furthermore, plans for larger demonstration facilities are undergoing feasibility engineering evaluation for NewPage's Escanaba mill in the U.S. and the Smurfit Kappa facility in Piteå, Sweden.

\section{Patents and Publications}

The Weyerhaeuser project team did not apply for any patents related to this project or technology.

The Weyerhaeuser project team did publish two articles related to work done under this project $[15,16]$.

\section{Acknowledgements}

This project was a team effort in every aspect. It could not have been accomplished without the hard work, dedication, and cooperation of numerous individuals and organizations. 
Final Technical Report Rev. 0

DE-FC26-04NT42259

Weyerhaeuser gratefully acknowledges funding provided by the U.S. Department of Energy under cooperative agreement DE-FC26-04NT42259. Many thanks to our NETL project officer, Larry Rath, for his guidance and counsel on both technical and administrative matters.

Weyerhaeuser offers sincere appreciation to our subcontractors for their contributions and cost sharing on this project. We offer our special thanks to the following individuals for their exceptional work effort and willingness to work collaboratively across organizational boundaries:

- Chemrec AB: Ingvar Landälv (PI), Daniel Barry, Morgan Bielecki, Lars Andersson, Ragnar Stare

- The Institute of Paper Science and Technology at Georgia Tech: Christopher Verrill ${ }^{10}$ (PI), Kristiina Iisa ${ }^{11}$ (PI), Nikolai DeMartini, Steve Lien, Alan Ball, Scott Sinquefield

- Process Simulation Ltd: Jerry Yuan (PI), Martha Salcudean

- Simulent Inc.: Nasser Ashgriz (PI), Vala Mehdi-Nejad

- Swedish Energy Technology Centre, Piteå (working under direction of Chemrec AB): Fredrik Engström, Markus Marklund, Rikard Gebart

The project team offers special thanks to the operations and maintenance staff at the New Bern Cellulose Fibers mill. This project was based on the use of the New Bern gasifier as a test platform for process evaluation and improvements. Obviously, the mill's support and cooperation were critical to the successful achievement of the project objectives.

We also wish to acknowledge the very professional support provided by The Gas Technology Institute during the field testing portion of this work. We extend special thanks to William Farthing for his leadership and direction of this effort. GTI's contribution to this project was sponsored under a separate DOE project award DE-FC36-03GO13175.

Weyerhaeuser would like to acknowledge support provided by personnel from Oak Ridge National Labs. We very much appreciate Jim Keiser's input on materials issues and for the modeling work conducted by Gorti Sarma and Gary Giles. This latter activity was coordinated with this project but received separate funding from ORNL's MPLUS funding platform.

Special thanks to Zia Abdullah from Weyerhaeuser for his technical contributions and insights regarding the CFD modeling work and other aspects of this work.

\footnotetext{
${ }^{10}$ Currently with International Paper Company

${ }^{11}$ Currently with the National Renewable Energy Laboratory, Golden, CO
} 
Final Technical Report Rev. 0

DE-FC26-04NT42259

\section{Project Cost Summary}

\begin{tabular}{|c|c|c|c|c|c|c|}
\hline & $\begin{array}{l}\text { Overall } \\
\text { Budget }\end{array}$ & $\begin{array}{c}\text { Total Actual } \\
\text { Cost }\end{array}$ & $\%$ Budget & $\begin{array}{l}\text { DOE Cost } \\
\text { Share }\end{array}$ & $\begin{array}{l}\text { Participant } \\
\text { Cost Share }\end{array}$ & $\begin{array}{c}\text { Participant } \\
\text { Cost Share\% }\end{array}$ \\
\hline Weyerhaeuser & $\$ 639,793$ & $\$ 654,613$ & $102 \%$ & $\$ 96,224$ & $\$ 558,389$ & $85 \%$ \\
\hline GTRC & $\$ 315,028$ & $\$ 335,188$ & $106 \%$ & $\$ 246,535$ & $\$ 88,653$ & $26 \%$ \\
\hline Chemrec & $\$ 682,919$ & $\$ 740,445$ & $108 \%$ & $\$ 281,354$ & $\$ 459,091$ & $62 \%$ \\
\hline Simulent & $\$ 240,375$ & $\$ 240,357$ & $100 \%$ & $\$ 184,642$ & $\$ 55,715$ & $23 \%$ \\
\hline PSL & $\$ 180,271$ & $\$ 180,271$ & $100 \%$ & $\$ 130,000$ & $\$ 50,272$ & $28 \%$ \\
\hline Total & $\$ 2,058,385$ & $\$ 2,150,874$ & $104 \%$ & $\$ 938,754$ & $\$ 1,212,120$ & $56 \%$ \\
\hline $\begin{array}{l}\text { Phase I \& II DOE Budget } \\
\% \text { DOE Budget Spent }\end{array}$ & $\begin{array}{r}\$ 938,754 \\
100.0 \%\end{array}$ & & & & & \\
\hline
\end{tabular}

\section{References}

1. KEISER, J. R., MEISNER, R. A. HEMRICK, J. G., GOROG, J. P., LEARY, W. R., BROWN, C. A., GUPTA, A., MCGOWAN, K. A., Recent Experience with Structural Materials in Commercial Scale Black Liquor Gasifiers, International Chemical Recovery Conference Proceedings, Quebec City, May 2007.

2. HOFFMANN, C.M.; KEISER, J.R. AND HUBBARD, C.R., "Characterization of the Degradation Behaviour of High Alumina Silica-Bonded Refractory Used as Gasifier Lining for Black Liquor Gasification”, CRADA Final Report C/ORNL/97-0481, January, 1999.

3. PEASCOE, R.A.; KEISER, J.R.; HEMRICK, J.G.; BRADY, M.P.; SACHENKO, P.; HUBBARD, C.R.; OTT, R.D.; BLUE, C.A. AND GOROG, J.P., "Materials Issues in High Temperature Black Liquor Gasification”, 2003 TAPPI Fall Technical Conference, Chicago, IL, October 26-30, 2003.

4. J.R. KEISER, R.A. PEASCOE, J.G. HEMRICK, C.R. HUBBARD, P.F. TORTORELLI AND B.A. PINT, "Performance of Materials in Black Liquor Gasification Environments", Paper 04251, CORROSION/2004, New Orleans, LA, March 28-April 1, 2004.

5. KEISER, J.R.; HEMRICK, J.G.; PEASCOE-MEISNER, R.A. AND HUBBARD, C.R., "Studies and Selection of Containment Materials for High-Temperature Black Liquor Gasifiers", Paper 53-2, 2006 TAPPI Engineering, Pulping and Environmental Conference, Atlanta, GA, November 5-9, 2006.

6. PERLACK, R. D., WRIGHT, L. L., TURHOLLOW, A. F., GRAHAM, R.L., STOKES, B. J., ERBACH, D. C., "Biomass as Feedstock for a Bioenergy and Bioproducts Industry: The Feasibility of a Billion Ton Annual Supply," a joint study sponsored by the USDA and DOE, prepared by ORNL, available at http://www.osti.gov/bridge, April 2005. 
Final Technical Report Rev. 0

DE-FC26-04NT42259

7. "Forest Products Industry Technology Roadmap," prepared by Agenda 2020 Technology Alliance, under joint sponsorship of American Forest \& Paper Association and U.S. DOE, available at www.agenda2020.org, July 2006

8. SMITH, P., CHRISTIANSEN, G., OSCARSSON, B., "North America's First Commercial Black Liquor Gasification Plant", 1996 TAPPI Engineering Conference Proceedings, Chicago.

9. BROWN, C., SMITH, P., HOLMBAD, N., CHRISTIANSEN, G., HESSEBORN, B., "Update of North America's First Commercial Black Liquor Gasification Plant Operating Experience and the Future", 1997 TAPPI Engineering Conference Proceedings, Nashville.

10. CHRISTIANSEN, G., "Update of North America's First Commercial Black Liquor Gasification Plant", PaperAge Advanced Learning Seminar, January 19-22, 1997.

11. BROWN, C., HUNTER W., "Operating Experience at North America's First Commercial Black Liquor Gasification Plant", 1998 International Chemical Recovery Conference Proceedings, Tampa.

12. ERICKSON, D., BROWN, C., "Black Liquor Gasification - Operating Experience at Weyerhaeuser, New Bern NC", TAPPI Journal, September 1999, pp 48-50.

13. BROWN, C., LANDÄLV, I., "The Chemrec Black Liquor Recovery Technology - A Status Report", 2001 International Chemical Recovery Conference Proceedings, Whistler, B.C.

14. BROWN, C., ABDULLAH, A., LEARY, R., GOROG, J.P., "The Chemrec Black Liquor Gasifier at New Bern - A Status Report," 2004 International Chemical Recovery Conference Proceedings, Charleston.

15. JUAN, J., STROPKY, D., SALCULDEAN, M., IISA, K., ABDULLAH, Z., BROWN, C., "Modeling of Black Liquor Gasification in an Entrained Flow Gasifier," International Chemical Recovery Conference Proceedings, Quebec City, May 2007.

16. BROWN, C., IISA, K., DEMARTINI, N., ASHGRIZ, N., MEHDI-NEJAD, V., LANDÄLV, I., YUAN, J., "Advancing Black Liquor Gasification at New Bern," International Chemical Recovery Conference Proceedings, Quebec City, May 2007. 
Appendix \#1

GTI Quarterly Report 7 (DE-FC36-03G013175) 


\section{Quarterly Progress Report}

Project Title: Biomass Gasification Research Facility

Award Number: DE-FC36-03G013175

Status: Project activities during the reporting period were focused on field measurements at the Chemrec ${ }^{\mathrm{TM}}$ black liquor gasifier at New Bern, North Carolina. The analytical suite assembled for this test, which occurred from June $13-24$, included an Industrial Monitor and Control Corporation (IMACC) Fourier transform-infrared (FT-IR) spectrometer, a Stanford Research Systems (SRS) QMS300 Mass Spectrometer (MS), a Varian $\mu \mathrm{GC}$, and an integrated Gas Chromatograph, Mass Selective Detector, Flame Ionization Detector and Sulfur Chemiluminescence Detector (GC/MSD/FID/SCD) system recently acquired from Wasson-ECE. Throughout the test period, syngas extracted downstream of the venturi scrubber was successfully conveyed to each of these analyzers after being filtered, depressurized, heat traced, and in some cases, diluted. Each instrument returned near real-time analyses of the syngas stream.

\section{Progress in Past Quarter:}

The majority of work during the past quarter focused on preparing for, and making online syngas measurements during a series of gasification tests performed at the Chemrec $^{\mathrm{TM}}$ Gasifier at the Weyerhaeuser Pulp Mill in New Bern, North Carolina from June $13-24,2005$. This report provides details of the setup and execution of these measurements. The majority of syngas characterization data obtained during this test campaign will be presented in later reports.

Characterization of the Chemrec $^{\mathrm{TM}}$ black liquor gasifier - During June 2005, the project team participated in a series of tests at the Chemrec ${ }^{\mathrm{TM}}$ Gasifier at the Weyerhaeuser Pulp Mill in New Bern, North Carolina. The specific objectives for participation in this test were to:

- Extract representative syngas samples

- Condition syngas samples without losses or altered composition

- Deliver continuous process gas samples to analyzers and batch samplers

- Accommodate QA/QC spike and recovery protocols

- Obtain and report time-averaged and near real-time measurements of major gas constituents, sulfur species, and hydrocarbon species.

A general schematic diagram of the Chemrec $^{\mathrm{TM}}$ gasifier identifying the location where syngas was extracted for analysis is presented in Figure 1. A sample port was available downstream of the venturi scrubber to extract process gas for on-line analysis. The process gas contained about $40 \%$ to $60 \%$ water vapor by volume, and was at a pressure 
of only about $7 \mathrm{psig}$ and a temperature of about $225^{\circ} \mathrm{F}$ at the point of extraction.

Therefore, heating and dilution of this sample stream was incorporated into the sample conditioning system. GTI designed a sample extraction, conditioning, and transport system to serve as an interface between the sampling location and the suite of on-line analyzers assembled for the field characterization.

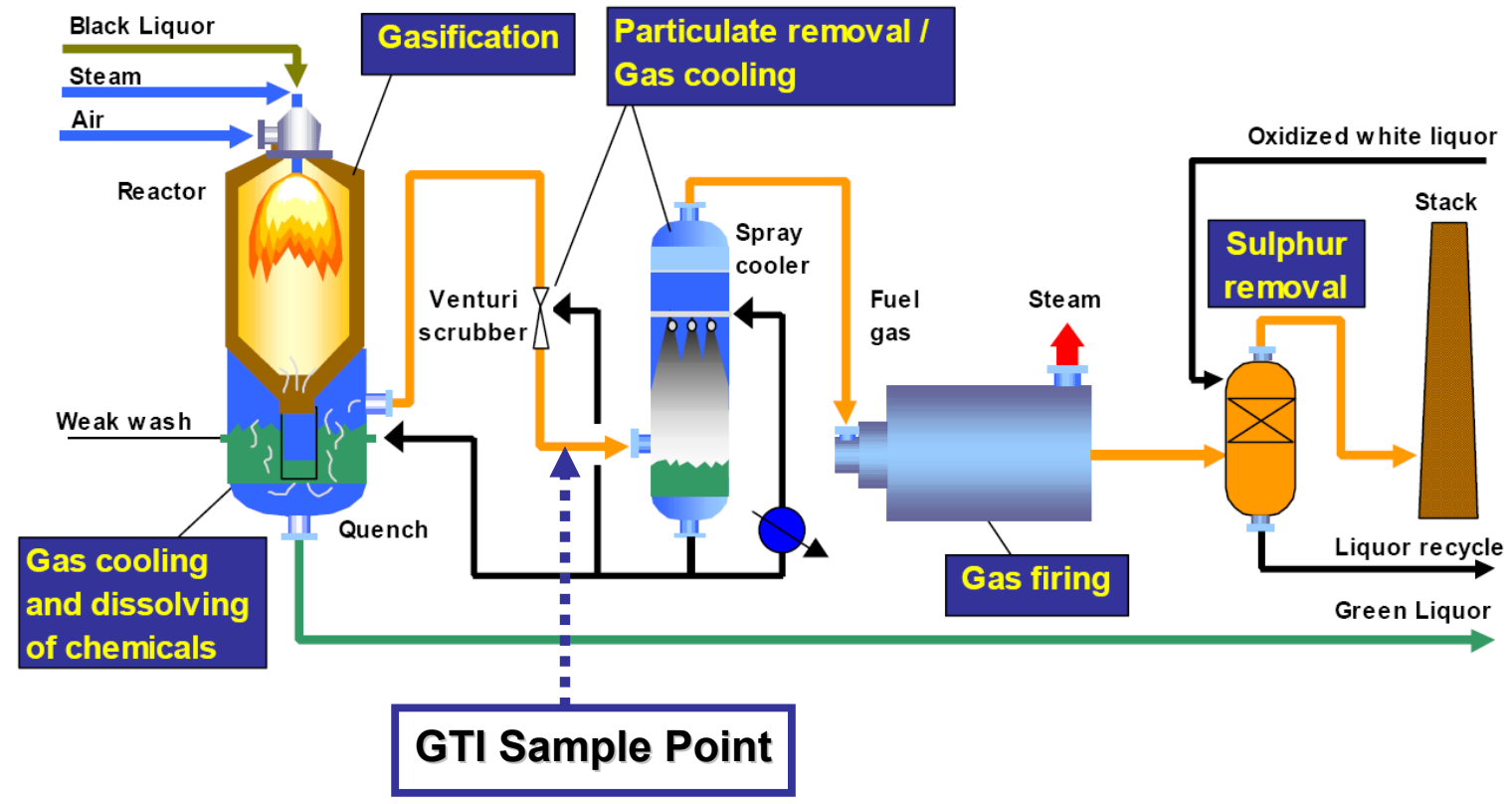

Figure 1. New Bern black liquor gasifier

The suite of analyzers assembled for these tests, which are discussed in more detail in project reports issued under Contract No. DE-FC36-02G012024, included:

- a Stanford Research Systems (SRS) QMS300 Mass Spectrometer (MS)

- an integrated Gas Chromatograph, Mass Selective Detector, Flame Ionization Detector and Sulfur Chemiluminescence Detector (GC/MSD/FID/SCD) system acquired from Wasson-ECE

- an Industrial Machine and Control Corporation (IMACC) Fourier-transform infrared spectrometer (FT-IR)

- a Varian micro gas chromatograph with thermal conductivity detector ( $\mu \mathrm{GC})$.

Description of the Sample extraction, conditioning, and transport system - Figure 2 presents a schematic diagram of the extraction, conditioning, and transport system that was set up at the gasifier site prior to the start of testing. The general approach was to keep the extracted gas hotter than the process line from which it was extracted, and to make use of the pressure of the syngas in the Chemrec $^{\mathrm{TM}}$ process to drive the gas sample through the plumbing in the interface system. In-line orifices placed at various 
points in the system reduced gas pressure and metered gas flow. Transducers reported the pressure drop across these orifices to digital display meters. Manually operated valves were used to direct and regulate sample flows to the various analyzers. The sample lines were externally heated and insulated, and thermocouples were placed both inside the gas stream and on the outside surfaces of the sample lines. All of the lines through which syngas passed, with the exception of dump lines used to vent excess syngas flow, were pretreated with the Silcosteel ${ }^{\circledR}$ passivation process, and then heattraced and insulated on site to prevent condensation. The Dilution Cooling Unit (DCU) was used in this field application to add preheated nitrogen to the already hot syngas sample stream to lower the dew point of the sample stream delivered to the analyzers without altering its temperature. The specific need for this reduction in dew point was the potential for condensation of water in the GC/MSD/FID/SCD and the $\mu G C$. The dilution factors used during the two week test period were 10:1 and 20:1. The syngas sample stream directed to the MS and the FT-IR was often undiluted, since the operation of these two instruments precluded any water condensation during analysis.

The GTI sample probe was inserted into the process stream through a shut-off ball valve that was already installed on the Chemrec ${ }^{\mathrm{TM}}$ process pipe. The extracted syngas was heated to about $185^{\circ} \mathrm{C}\left(365^{\circ} \mathrm{F}\right)$ for transport to the on-line analyzers. A sheath around the main sample line was used in conjunction with two seal glands and a vented dump line to allow the GTI probe to be inserted or removed from the process while the process was operating. The insulated sample probe is shown installed in the process piping in Figures 3 and 4.

The syngas sample stream passed vertically up through the probe and through the shutoff valve shown in Figure 4, and made a $90^{\circ}$ turn at the top of the probe. After passing through the $47 \mathrm{~mm}$ filter indicated in Figure 2, a pressure transducer, visible in Figure 5, was used to measure the absolute pressure of the syngas in the sample transport line. An in-line orifice used to reduce the pressure of the sample stream to a level acceptable to the rest of the sample conditioning equipment was located just downstream of the tee connection to the pressure transducer.

The sample probe was connected to the rest of the sample conditioning and analysis equipment through two 25-foot heated sample hoses - the syngas transport line and the purge nitrogen line (visible in Figures 5 and 6). The heated purge nitrogen line was connected to the sample line in the probe just upstream of the $47 \mathrm{~mm}$ filter. A flow of heated nitrogen was used to purge the sample probe during times when syngas was not being conveyed to the analyzers through the sample conditioning system. The syngas transport line maintained the temperature of the syngas at about $185^{\circ} \mathrm{C}$ on its way to the sample distribution and dilution plumbing (Figures 6 and 7). 
The sample distribution and dilution plumbing used to distribute the sample stream to the four analyzers either with or without dilution is visible, before it was insulated, in the photographs (Figures 6 and 7), but can be more clearly understood by examining the schematic diagram presented in Figure 2. The flowrate of the nitrogen used to dilute the syngas entering the DCU was metered and controlled by two mass flow controllers. One controller set the main dilution flow rate, and the second controller set the flow of nitrogen through the annular sheath around the syngas sample entry tube into the DCU body. These two nitrogen streams were preheated before entering the DCU. The flow rates of the syngas sample streams directed to the analyzers was regulated by manual adjustment of excess sample flow through unheated vent lines. 


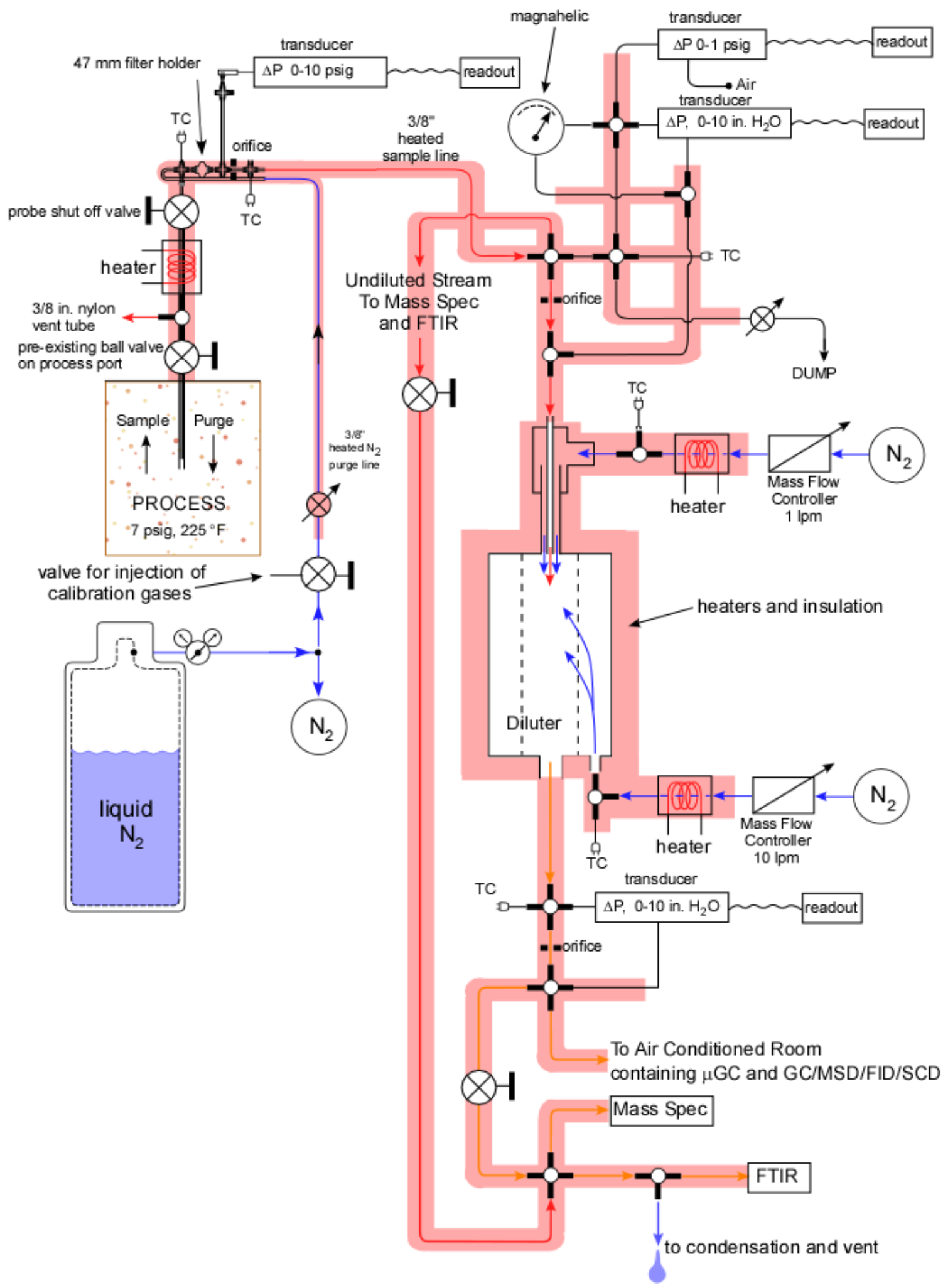

Figure 2. Sample extraction, conditioning, and transport system that provided an interface between the Chemrec ${ }^{\mathrm{TM}}$ gasification process and the GTI suite of on-line analyzers. 


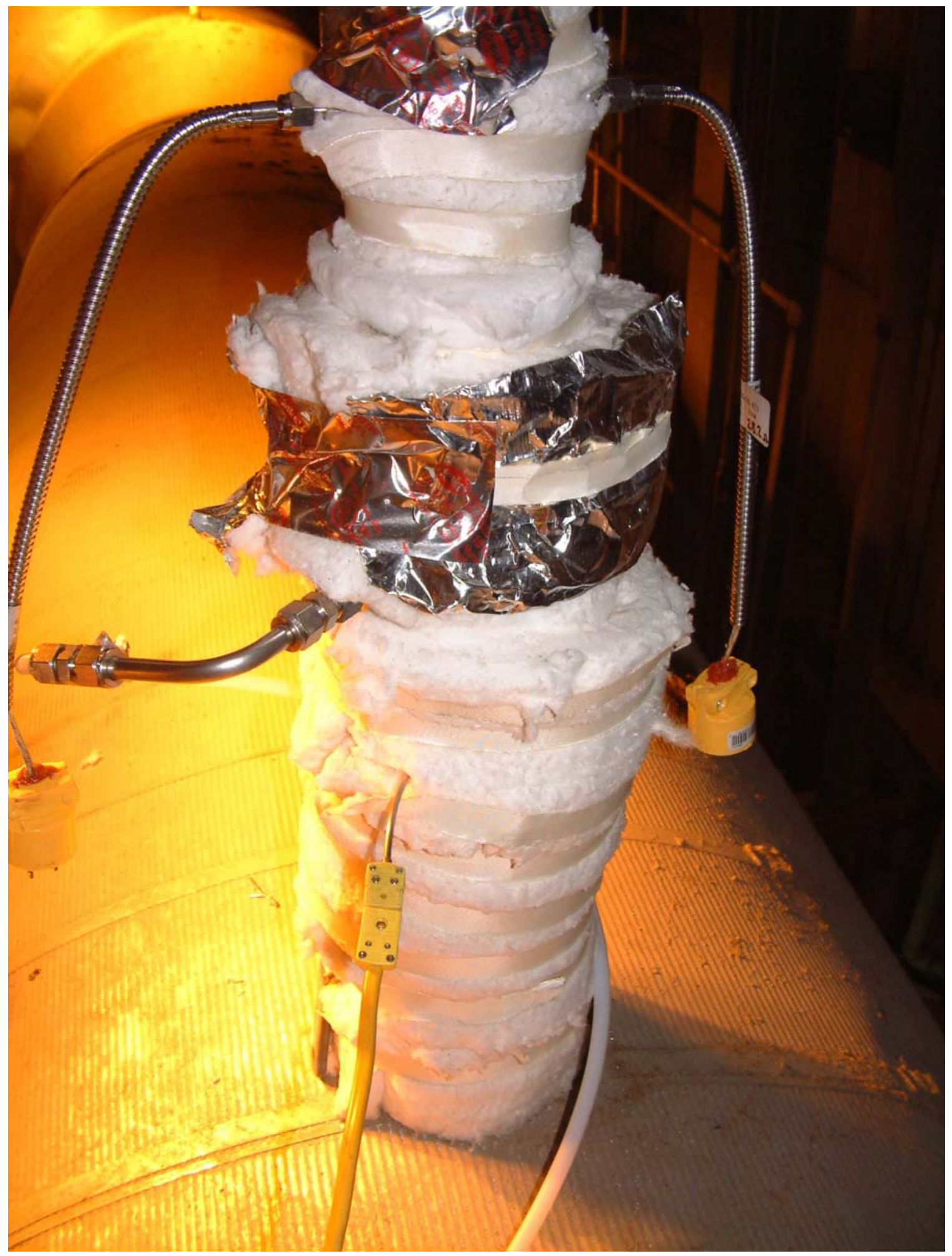

Figure 3. Heated, insulated GTI sample probe inserted into the gasifier process pipe. 


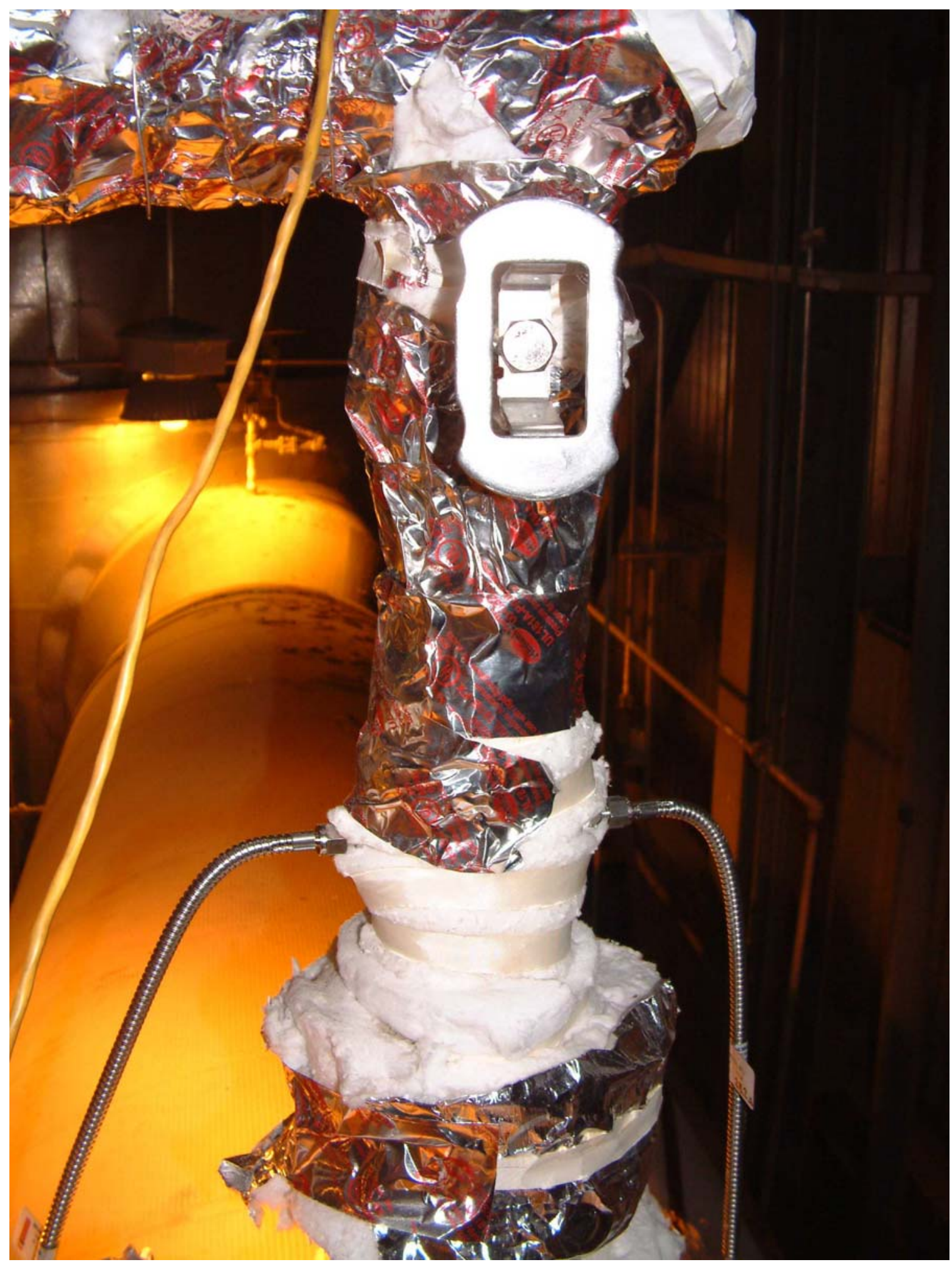

Figure 4. Upper portion of the heated, insulated GTI sample probe showing the handle of the shutoff valve. 


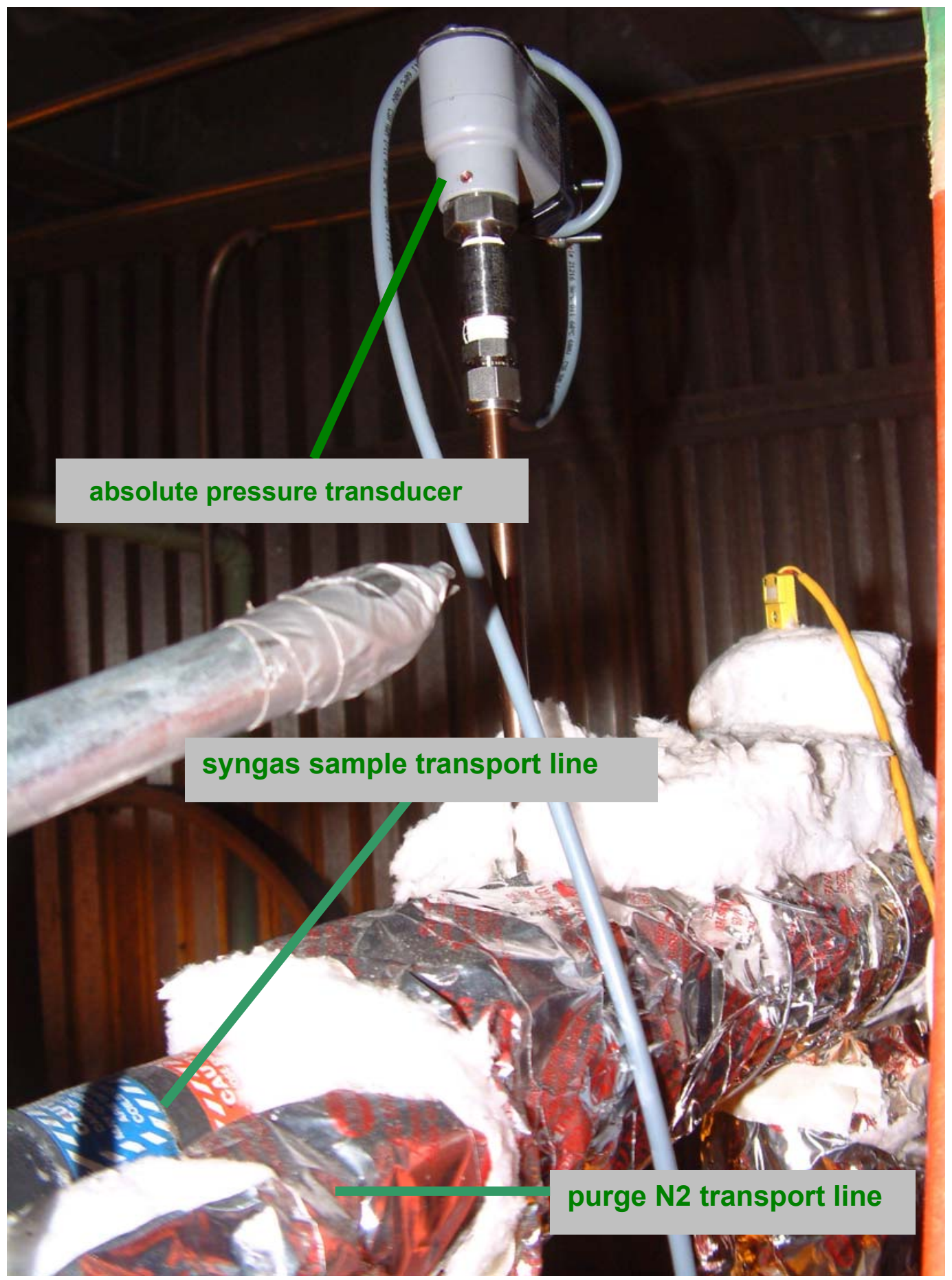

Figure 5. Upper portion of the sample probe showing the absolute pressure transducer and the attachment of the heated syngas and purge nitrogen transport lines. (The $47 \mathrm{~mm}$ filter housing and the in-line orifice are located in the sample line but are hidden underneath the insulation.) 


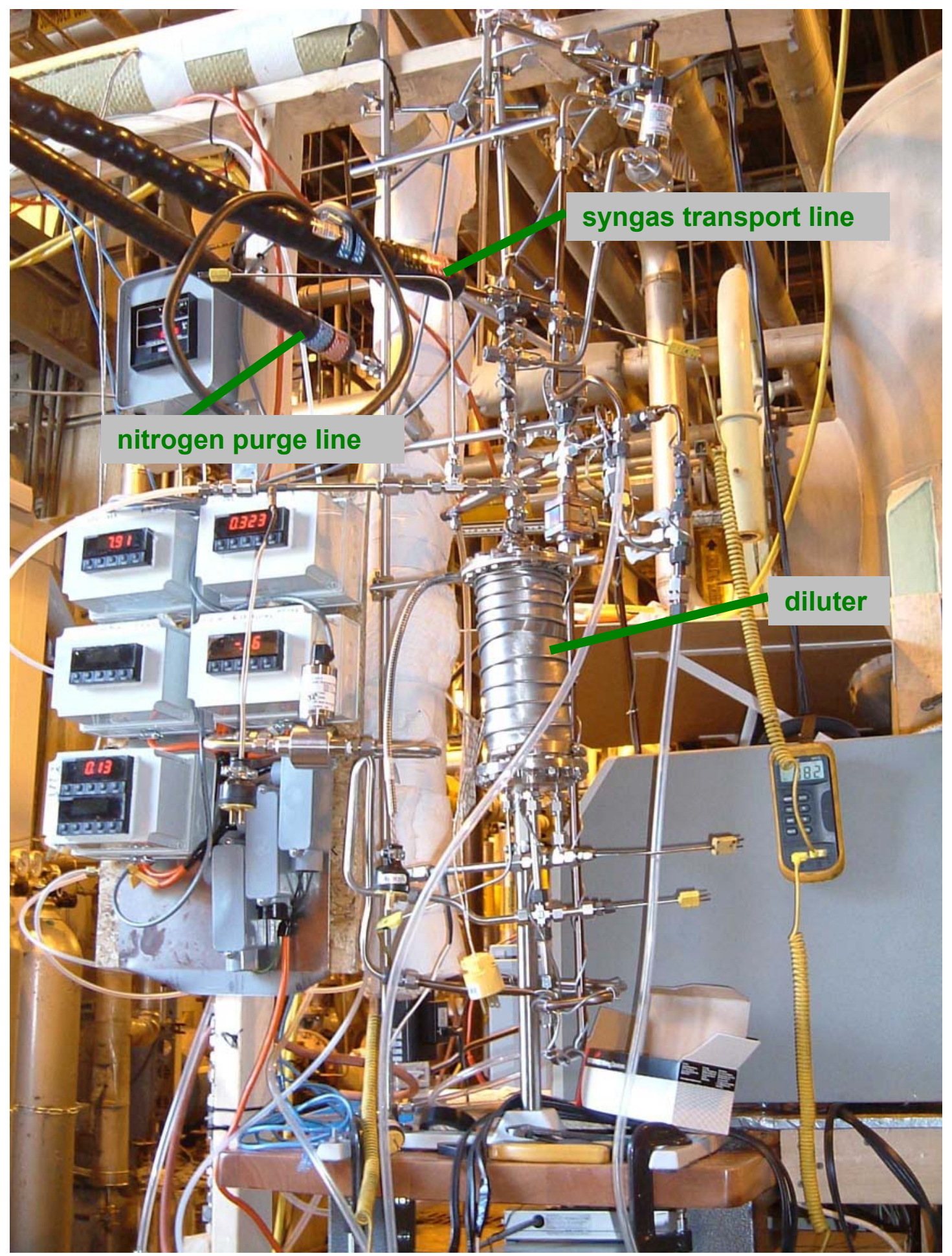

Figure 6. Sample distribution plumbing and diluter prior to insulation. 


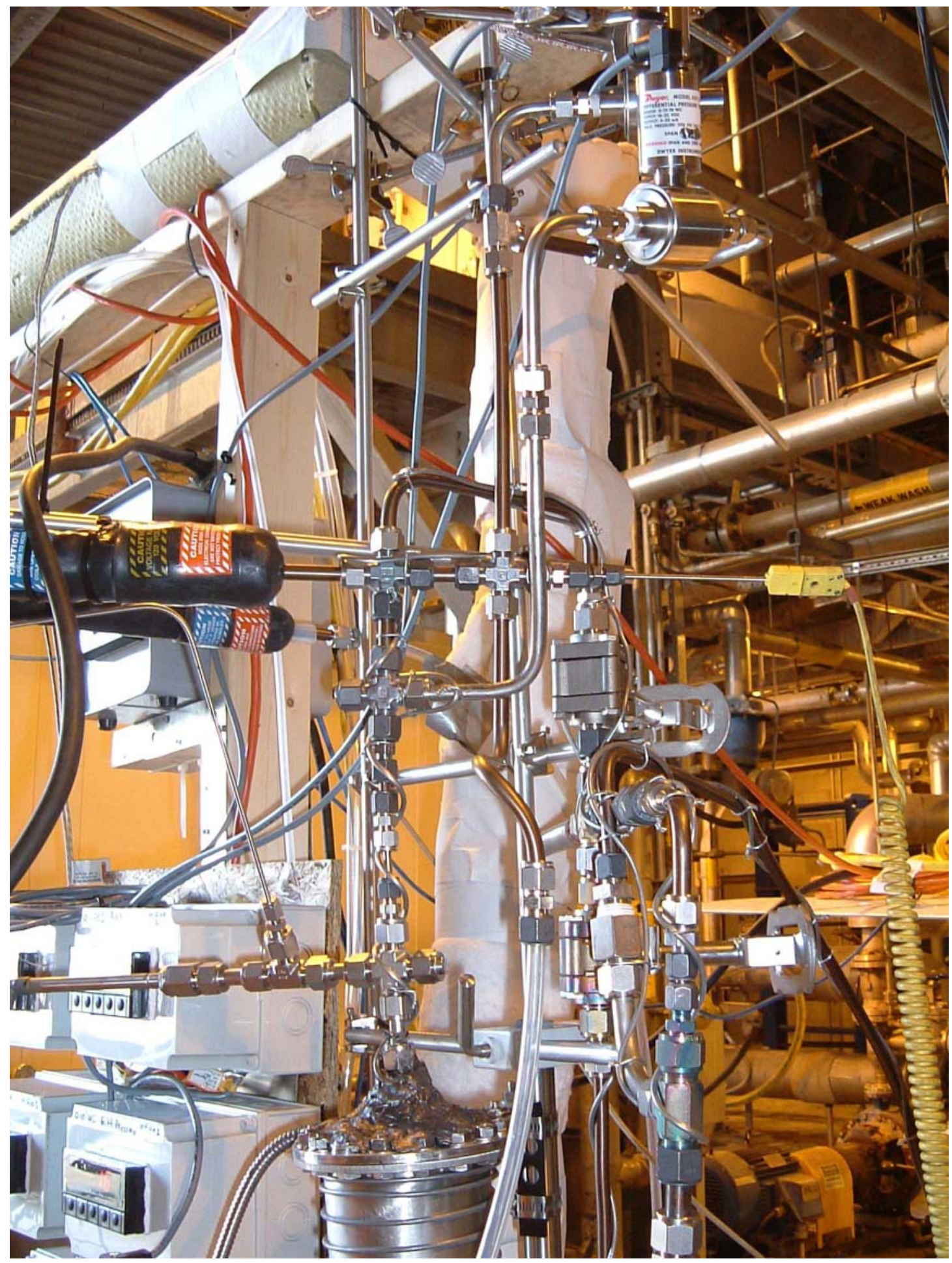

Figure 7. Close up of sample distribution plumbing and diluter prior to insulation. 
As shown in Figure 2, a portion of the heated syngas sample stream was conveyed into a portable, climate-controlled building that was purchased, and erected on site especially to house the GC/MSD/FID/SCD system and the Varian $\mu \mathrm{GC}$. The portable building is pictured in Figures 8 and 9. The GC/MSD/FID/SCD system and the Varian $\mu G C$ are shown installed in the building in Figures 10 through 13. A heated sample transport line carried the syngas sample stream into the building through the rear wall (opposite the door) for distribution to the GC/MSD/FID/SCD and the $\mu \mathrm{GC}$. Lines carrying the additional compressed gases needed for calibration and system operation also entered this building through its walls. The SRS MS and the IMACC FT-IR, which were located outside of the building, are shown in Figures 14 and 15.

Preliminary data and response of the on-line analysis suite - Although the majority of data from the June measurements have not been fully prepared for release, some of the data obtained with the SRS QMS300 Mass Spectrometer that quantify the major components of the syngas have been examined, and are presented in Figures 16 and 17. These data show the quick response of the on-line sampling approach to changes in gasifier operation.

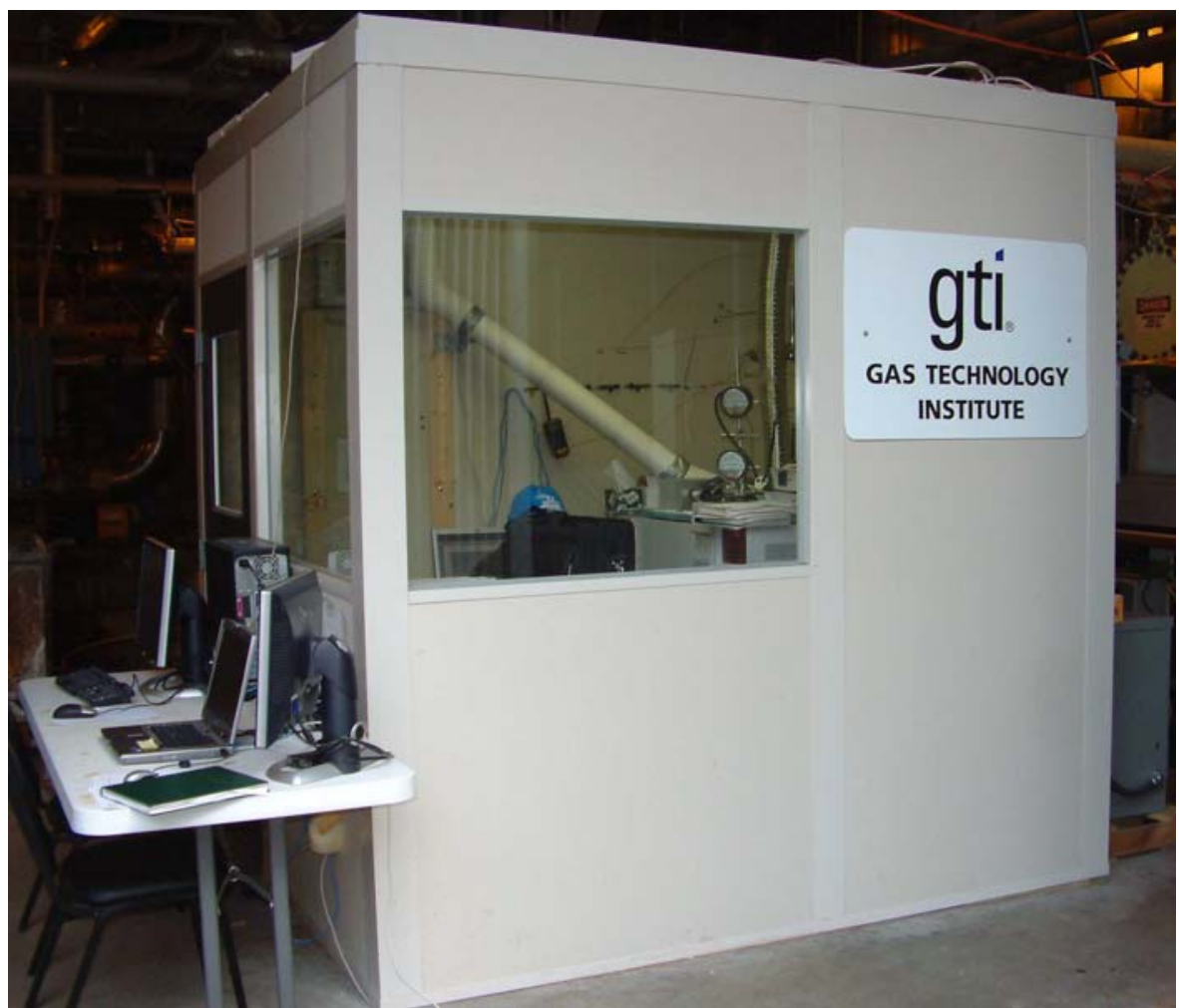

Figure 8. Climate-controlled building housing the GC/MSD/FID/SCD and the $\mu \mathrm{GC}$. 


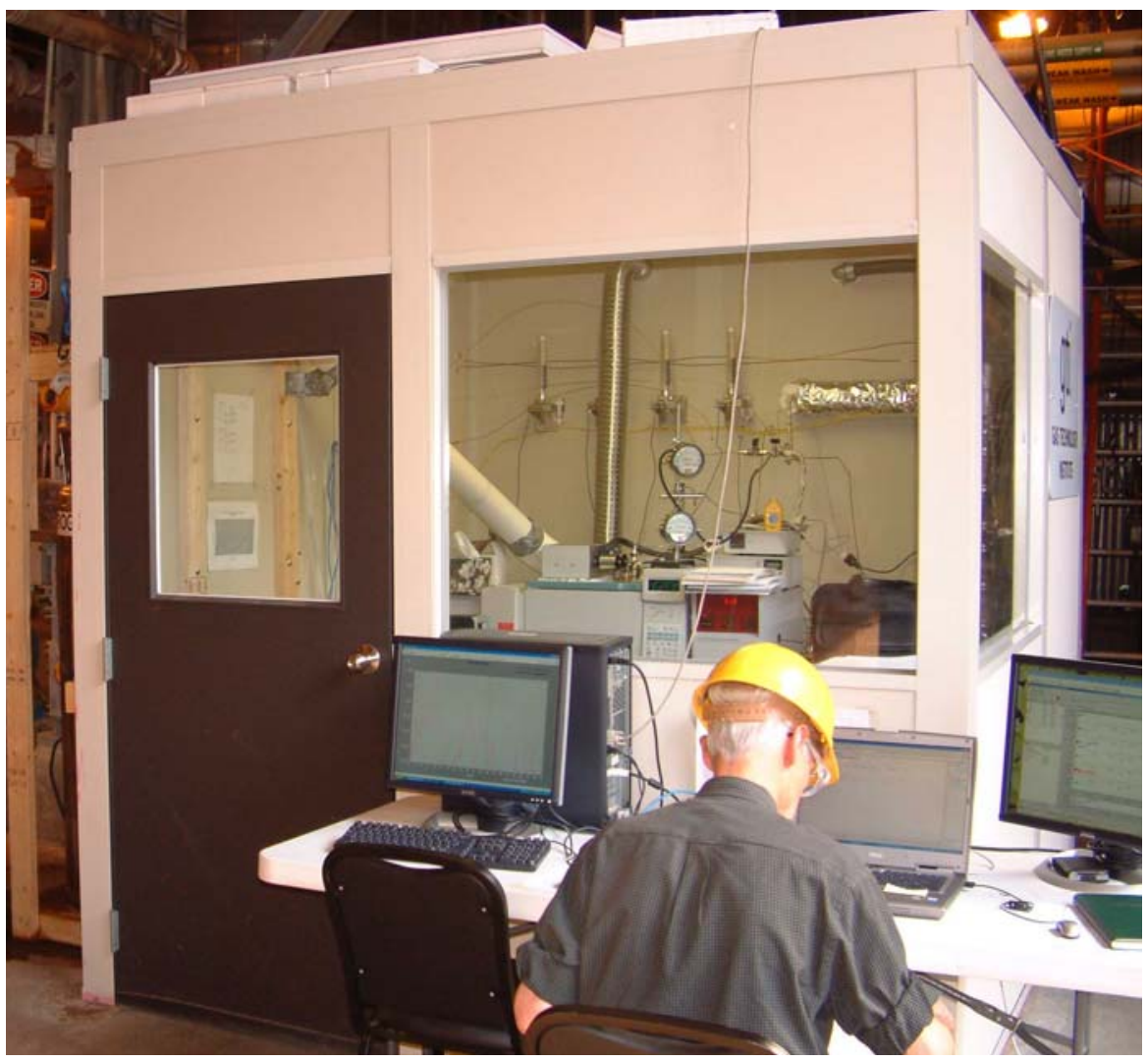

Figure 9. Front view of the climate-controlled building. 


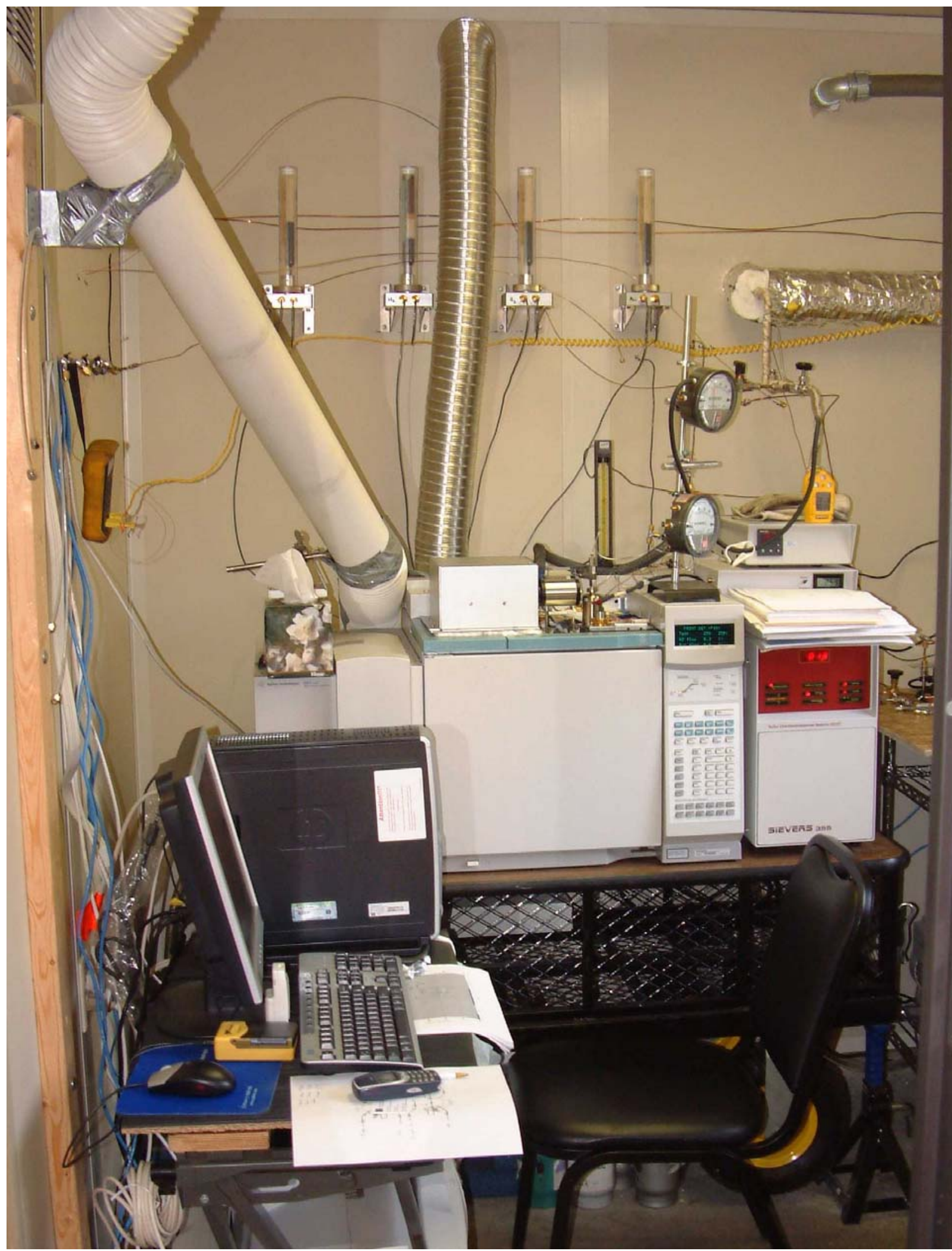

Figure 10. The Wasson-ECE GC/MSD/FID/SCD system. 


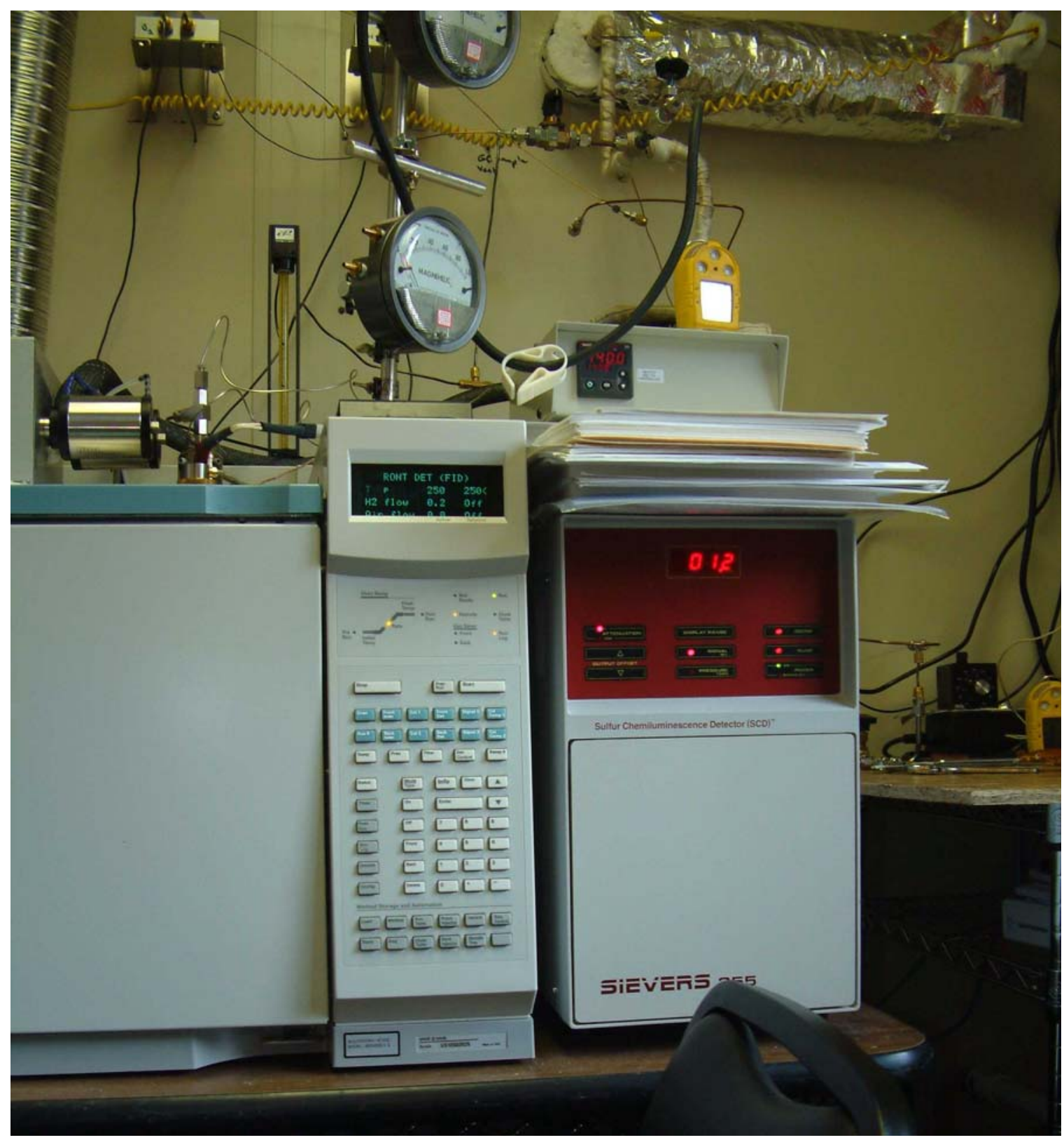

Figure 11. Close up view of the GC/MSD/FID/SCD system. 


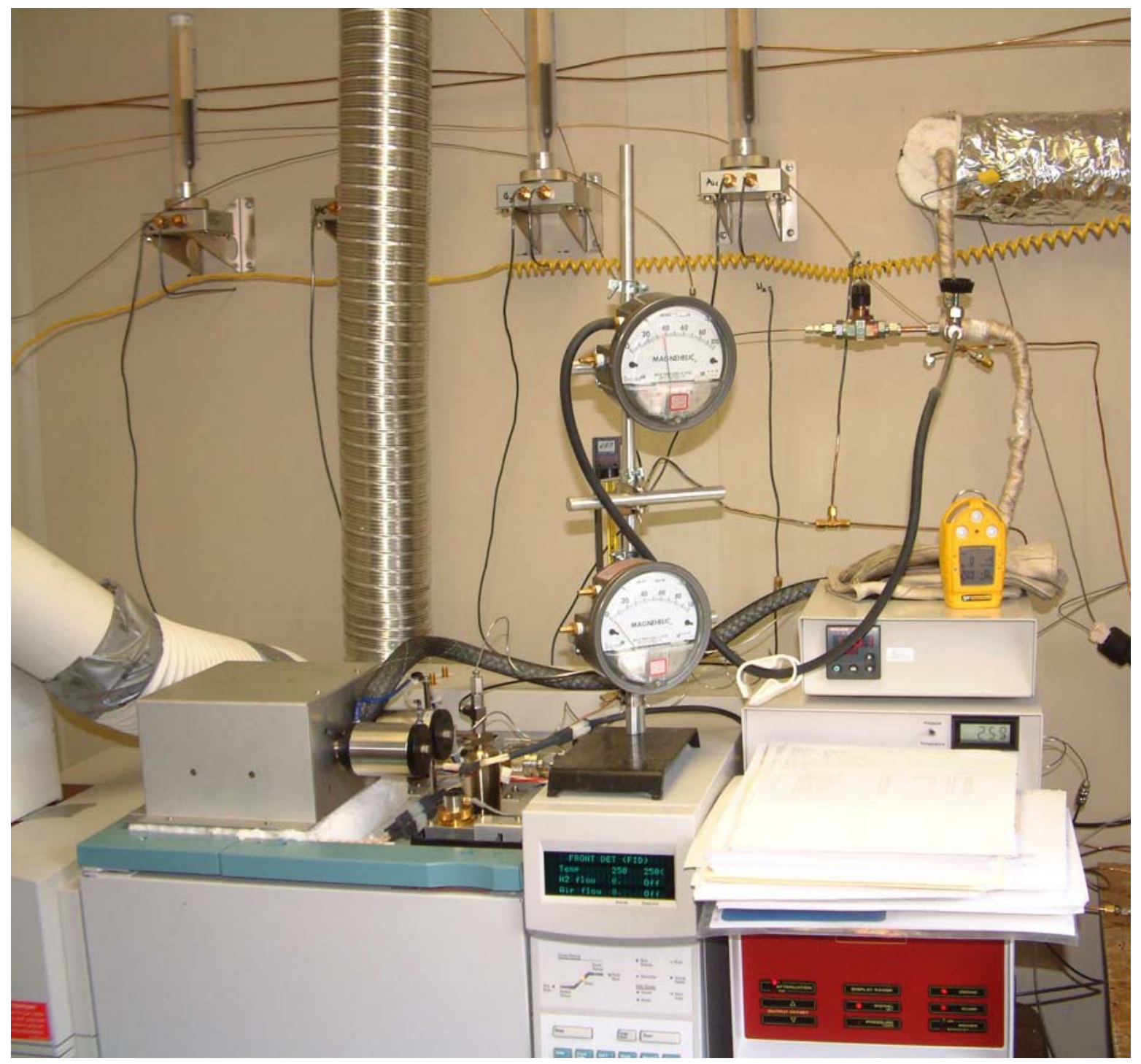

Figure 12. Distribution of calibration gases to the GC/MSD/FID/SCD system. 


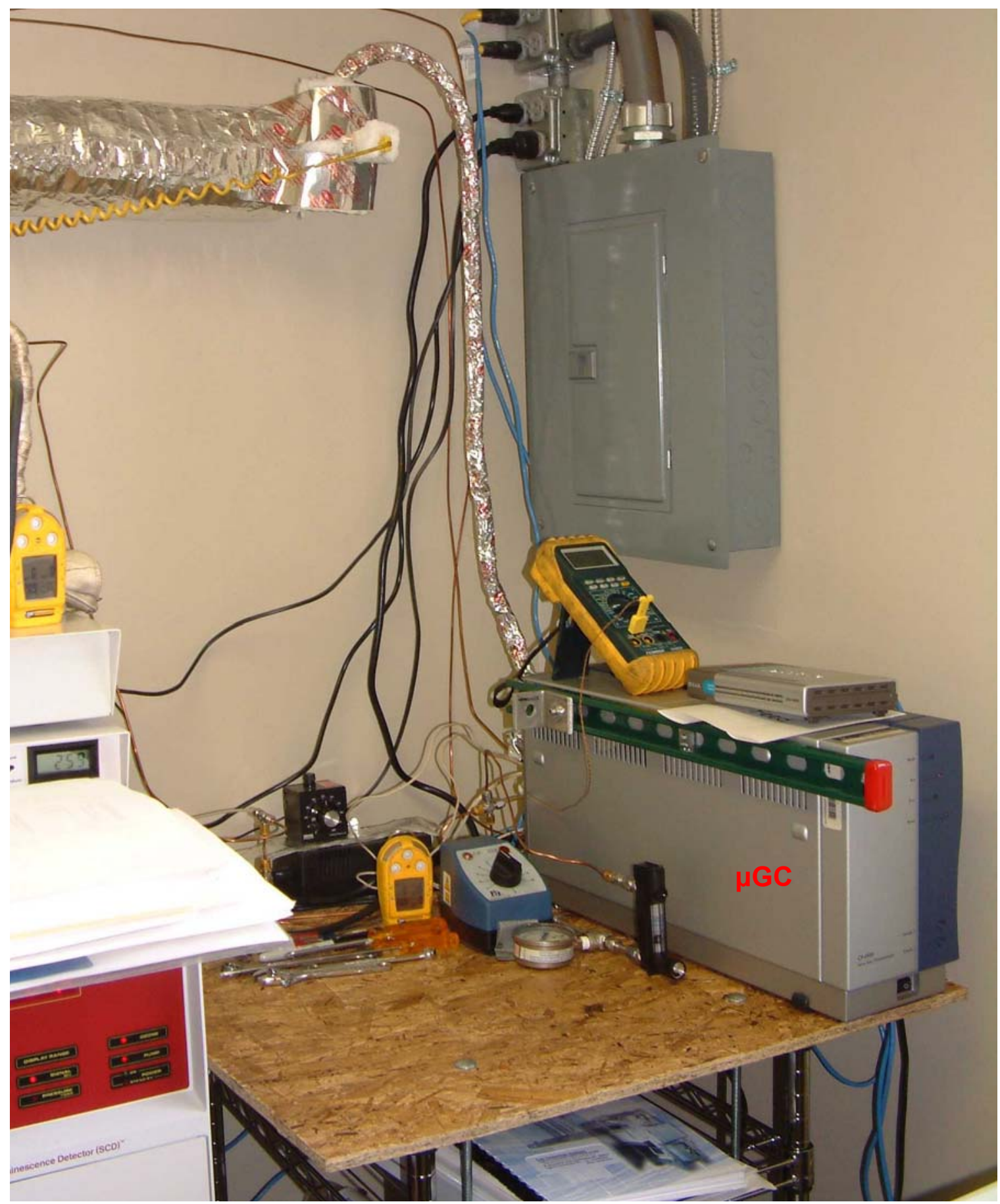

Figure 13. The Varian $\mu \mathrm{GC}$ installed in the climate-controlled building. 


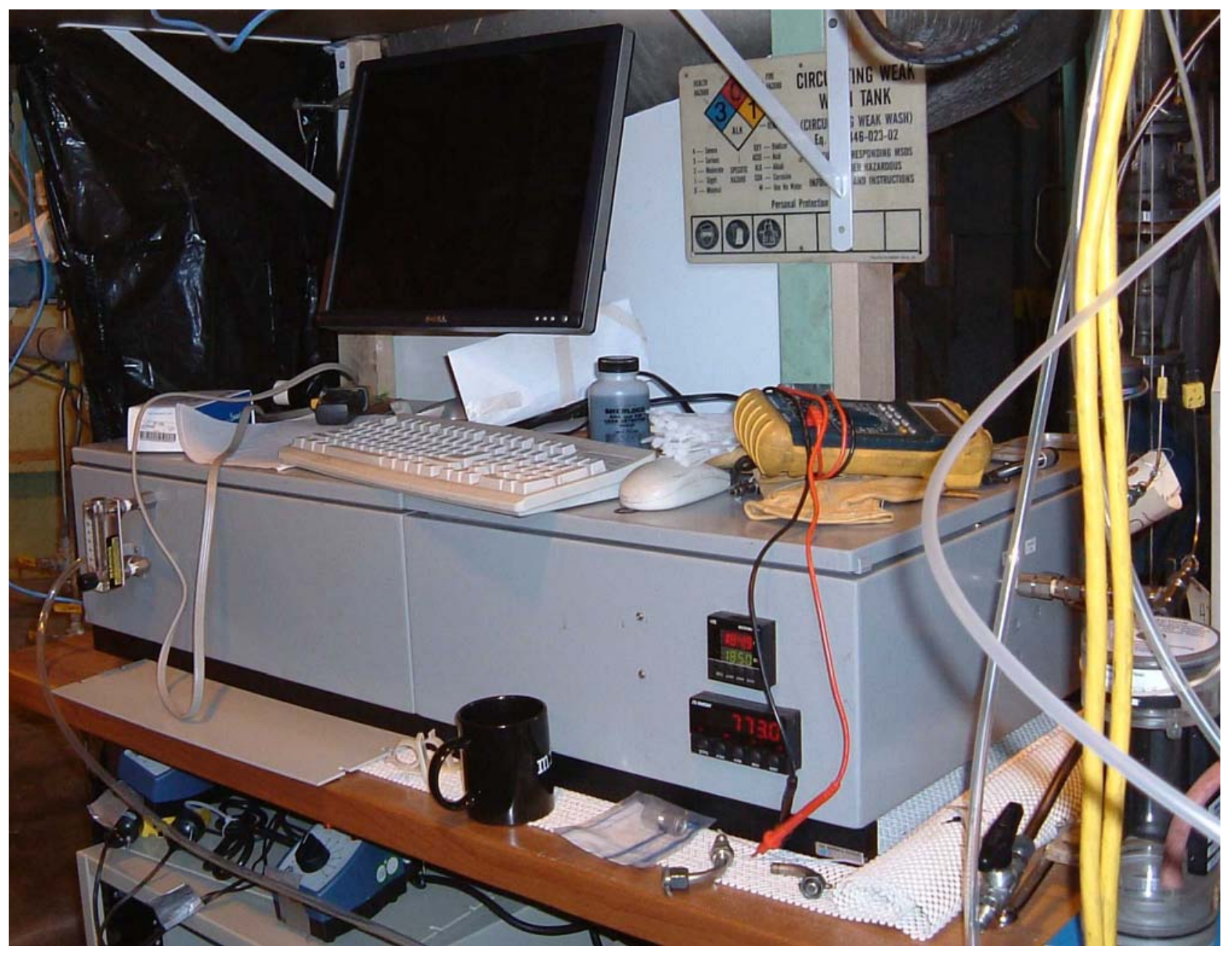

Figure 14. Preliminary installation of the IMACC FT-IR. 


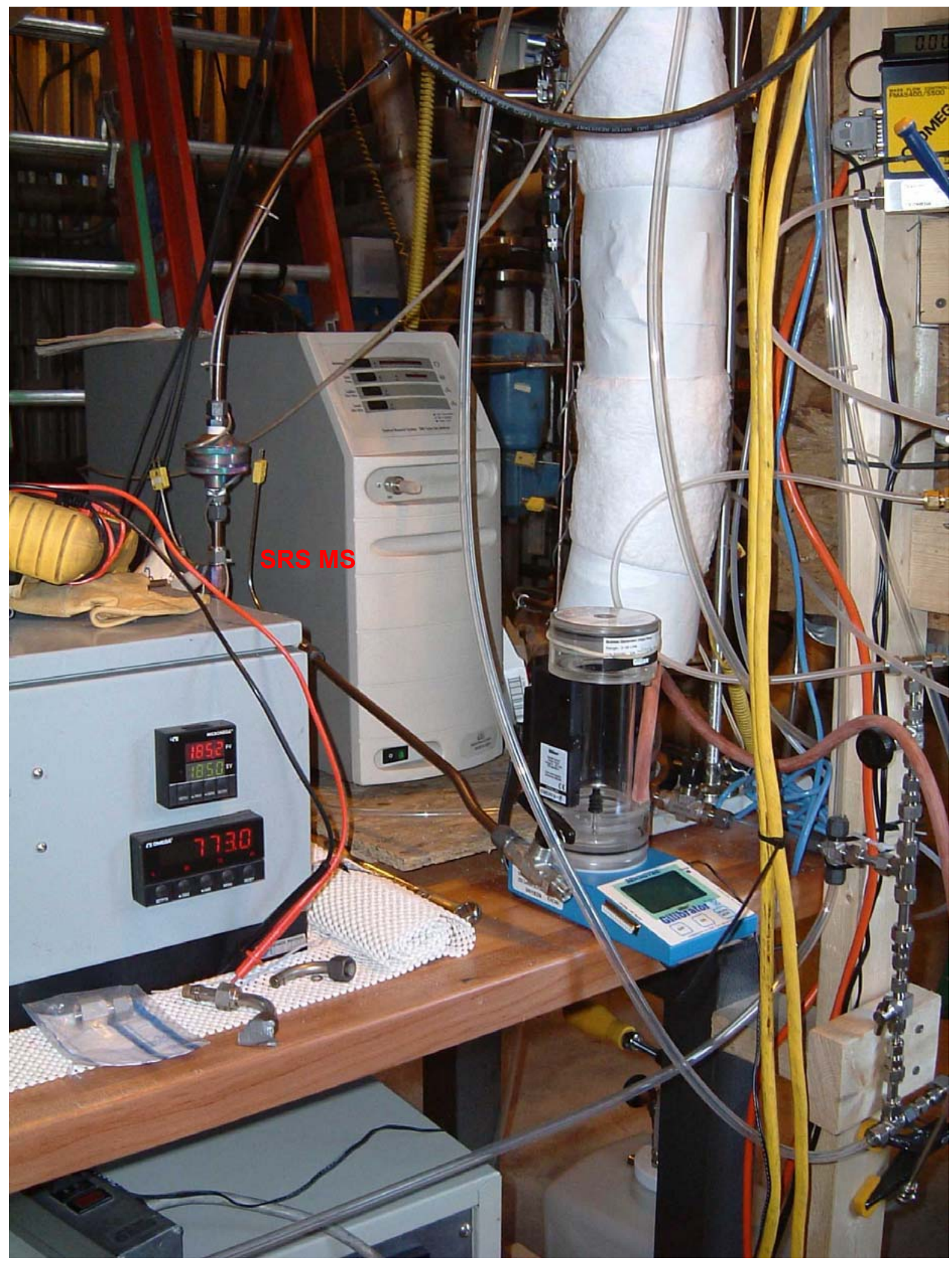

Figure 15. Preliminary installation of the SRS Mass Spectrometer. 


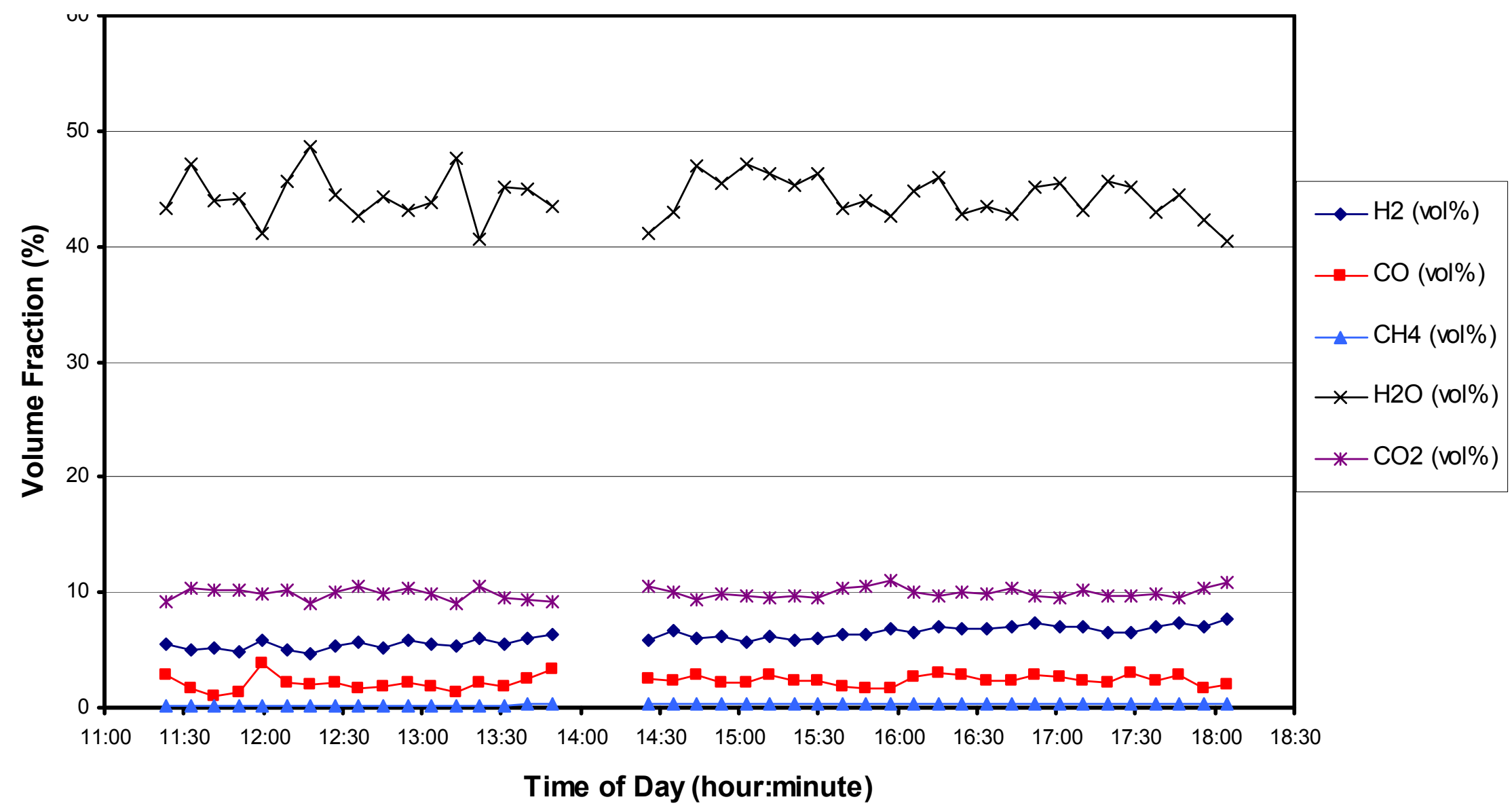

Figure 16. Composition of syngas produced on June 23, 2005 by the Chemrec ${ }^{\mathrm{TM}}$ black liquor gasifier as measured from compositional data obtained from the SRS QMS300 Mass Spectrometer. 


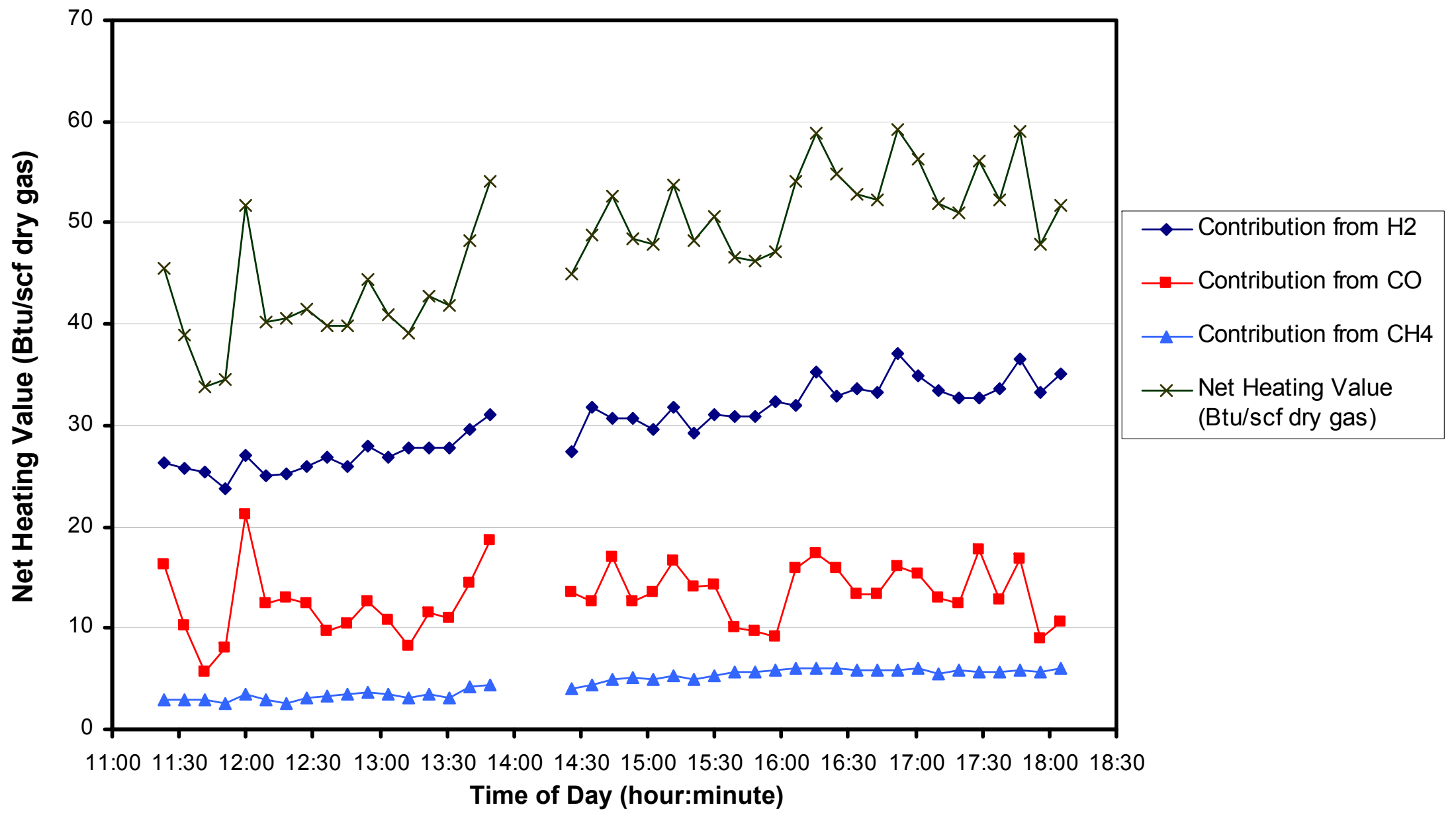

Figure 17. Heating value of syngas produced on June 23, 2005 by the Chemrec ${ }^{\mathrm{TM}}$ black liquor gasifier as computed from measured compositional data obtained from the SRS QMS300 Mass Spectrometer. 

Appendix \#2

IPST Quarterly Report 12 (abbreviated) 
Quarterly Technical Progress Report IPST-12 (abbreviated) Advancement of High Temperature Black Liquor Gasification Technology

Reporting Period Start Date: January 1, 2008

Reporting Period End Date: March 31, 2008

Principal Author: Kristiina Iisa

Contributing author: Nikolai DeMartini

Reporting Date: May 22, 2008

DOE Award Number: DE-FC26-04NT42259

GTRC Project Number: 11466C3

Submitted By: Georgia Tech Research Institute

Institute of Paper Science and Technology

$50010^{\text {th }}$ Street NW

Atlanta, GA 30332-0620 


\section{SUMMARY OF ACCOMPLISHMENTS THIS QUARTER}

- Georgia Tech participated in the third measurement campaign at New Bern gasifier. We took samples of green liquor, circulating condensate, and circulating weak wash, a as well as gas samples of the product gas. The liquid and gas samples were analyzed at Georgia Tech.

- The performance of the nozzles with respect to unburnt carbon in green liquor was assessed.

- The carbon mass balances during the experiments were evaluated.

- The dependence of product gas composition on air-to-fuel ratio was examined.

\section{EXPERIMENTAL}

During the measurement campaign at New Bern in February 2008, three nozzles were tested: the standard STD 18T nozzle, ETC swirler nozzle, and Simulent $25^{\circ}$ counterswirler nozzle. IPST/Georgia Tech collected liquid samples and made gas measurements during ten tests. The main process conditions (nozzle, air-to-fuel ratio, black liquor feed flow rate, steam flow rate) together with the dates and times when the IPST/Georgia Tech samples were collected are shown in Table 2.

The Simulent counterswirler nozzle failed in the tests. For the other two nozzles, the black liquor flow rates were kept constant (within $\pm 4 \%$ ) in all tests except for one in which a lower feed rate was used. The air-to-fuel ratios were varied in the range of 2.05-2.35. The steam flows were 35\% lower with the ETC swirler nozzle than with the standard nozzle.

The aim of the Georgia Tech work was to determine the performance of the nozzles based on the amount of unburnt carbon in green liquor. The carbon balance closures around the gasifier were evaluated as well.

Table 2. Experimental conditions during February 2008 tests.

\begin{tabular}{|l|l|c|c|c|}
\hline Nozzle & Date and Time & $\begin{array}{c}\text { Air/Fuel, } \\
\text { lb/lb DS* }\end{array}$ & $\begin{array}{c}\text { Steam, } \\
\text { lb/h }\end{array}$ & $\begin{array}{c}\text { Black liquor, } \\
1000 \mathrm{lb} \text { DS/d }\end{array}$ \\
\hline Std 18T & 2/21/08 13:35 & 2.16 & 5,441 & 555 \\
\hline Std 18T & 2/21/08 17:00 & 2.12 & 5,438 & 534 \\
\hline Std 18T & 2/28/08 9:45 & 2.32 & 5,432 & 382 \\
\hline Std 18T & 2/28/08 14:24 & 2.20 & 5,430 & 579 \\
\hline Std 18T & 2/29/08 8:25 & 2.12 & 5,440 & 570 \\
\hline ETC Swirler & 2/23/08 13:30 & 2.35 & 3,643 & 540 \\
\hline ETC Swirler & $2 / 23 / 0815: 45$ & 2.24 & 3,399 & 564 \\
\hline ETC Swirler & $2 / 24 / 08 ~ 9: 45$ & 2.17 & 3,355 & 562 \\
\hline ETC Swirler & $2 / 24 / 0814: 00$ & 2.05 & 3,701 & 548 \\
\hline ETC Swirler & 2/25/08 11:30 & 2.15 & 4,528 & 519 \\
\hline
\end{tabular}

*The air-to-fuel ratio is based on the uncorrected reading. 
Samples were taken of several liquid streams. The liquid samples taken and the analyses that were done at Georgia Tech are detailed in Table 3. The total suspended solids were measured both at the mill and at IPST.

Table 3. Chemical analysis performed for liquid samples.

\begin{tabular}{|l|l|}
\hline Stream & Measurements \\
\hline Fresh weak wash & Carbonate content \\
\hline Circulating condensate & Carbonate content \\
\hline Raw green liquor & Total suspended solids \\
\hline Dregs & Ash content, total carbon and carbonate carbon content \\
\hline Filtered green liquor & Carbonate content \\
\hline
\end{tabular}

Product gas samples were taken in glass bulbs that were equipped with special non-permeable septums, and the samples were analyzed for $\mathrm{CO}, \mathrm{CO}_{2}, \mathrm{H}_{2}, \mathrm{~N}_{2}, \mathrm{CH}_{4}$, and $\mathrm{H}_{2} \mathrm{~S}$ by gas chromatography at the IPST. Two gas samples were taken during each test run. 


\section{RESULTS \& DISCUSSION}

\section{Green Liquor Suspended Solids Analysis and Unburnt Carbon in Green Liquor}

A detailed discussion on the green liquor discussion is included in appendix B. Comparisons of the standard nozzle and the ETC swirler nozzle are shown in Figure 24 and Figure 25. With the exception of the run for the standard nozzle with the highest air-to-solid feed rate, all measurements were made at approximately the same black liquor feed rates. The steam rates were 35\% lower for the ETC swirler than for the standard nozzle.

Figure 24 shows the total suspended solids in $\mathrm{g} / \mathrm{l}$ and Figure 25 the fraction of liquor carbon that remained unburnt as organic carbon in the green liquor. The data for the standard nozzle at airto-fuel ratio of 2.2, which is circled in the figures, is believed to be erroneous and is ignored in the analysis. At any given air-to-solids feed ratio, the total suspended solids were slightly lower for the standard nozzle than for the ETC swirler nozzle (Figure 2). The fraction of unburnt carbon was clearly lower for the standard nozzle than for the ETC swirler nozzle (Figure 3). However, the steam flow was lower for the ETC swirler nozzle than for the standard nozzle, and it is not possible to claim which nozzle showed better performance. Both can be deemed to have adequate performance.

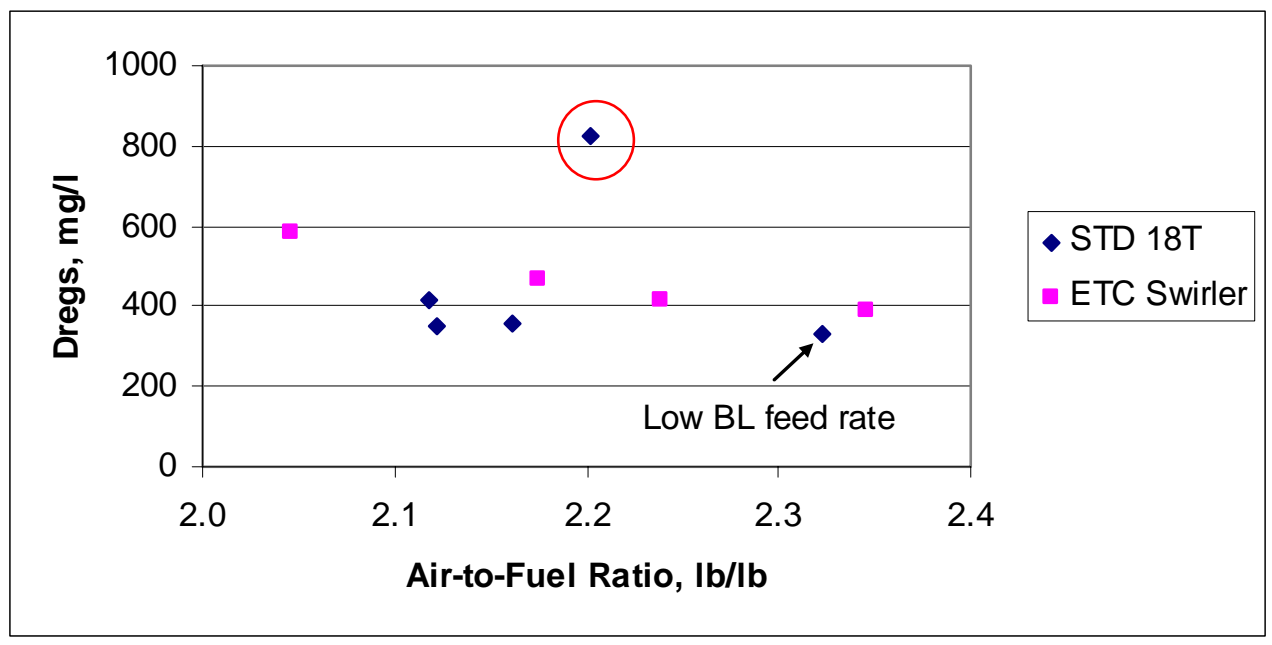

Figure 2. The total amount of suspended solids in green liquor for the standard STD 18T and the new Etc swirler nozzle. The comparison is based on the totals suspended solids measured at the IPST. 


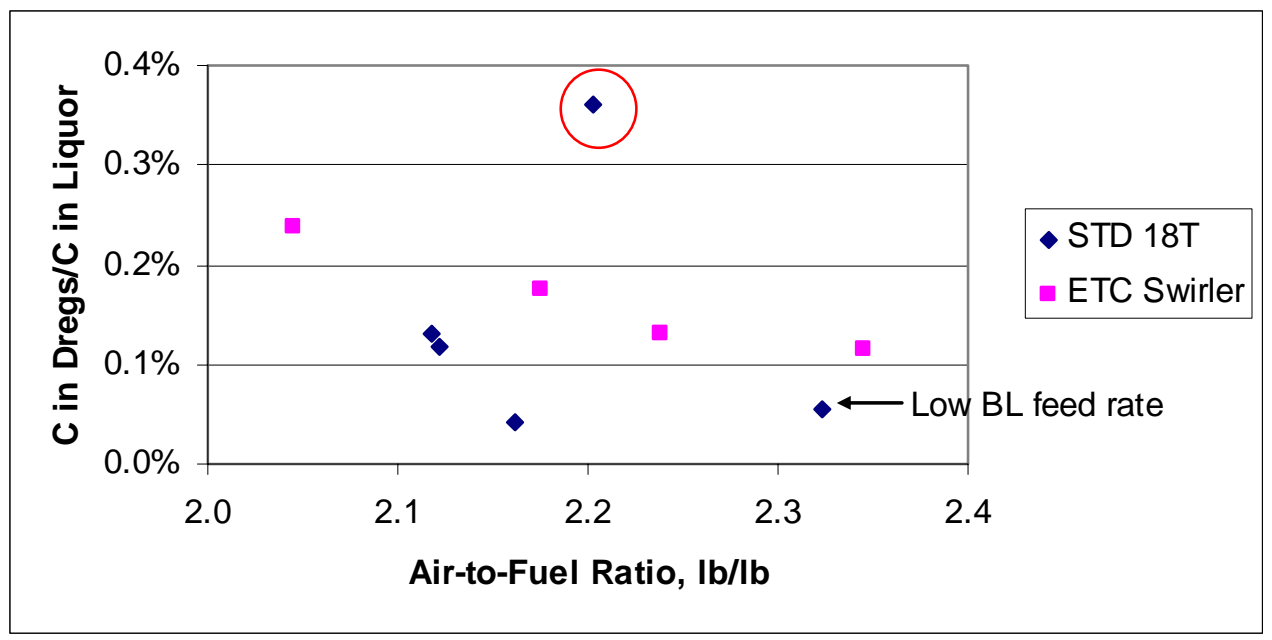

Figure 3. The fraction of liquor carbon exiting as organic carbon (unburnt carbon) with the green liquor. The comparison is based on the totals suspended solids measured at the IPST.

\section{$\underline{\text { Gas Analysis }}$}

The dry product gases were analyzed for $\mathrm{CO}, \mathrm{CO}_{2}, \mathrm{H}_{2}, \mathrm{CH}_{4}$, and $\mathrm{H}_{2} \mathrm{O}$. The sum of these gases exceeded $100 \%$ in all the gas samples. The sums were $102-110 \%$. This suggests a systematic error in either all the gas analysis results or one component. Since there was no evidence which gas component had a systematic error, the gas analysis results were normalized to $100 \%$ by reducing all gas contents. If there was a significant error in one component only, the concentrations of that component became thus overestimated and the concentrations of all other components underestimated. The $\mathrm{N}_{2}$ contents in the dry gas were close to $70 \%$, the $\mathrm{CO}, \mathrm{CO}_{2}$, and $\mathrm{H}_{2}$ contents all approximately $10 \%$, and the $\mathrm{CH}_{4}$ and $\mathrm{H}_{2} \mathrm{~S}$ contents less than $1 \%$. Since the error was $2-10 \%$, it seems likely that if only one analysis was in error that was $\mathrm{N}_{2}$. Therefore, it is possible that the reported nitrogen contents are high and that the contents of all other compounds are low. Assuming only $\mathrm{N}_{2}$ contents to be erroneous instead of normalizing everything to $100 \%$ would increase the contents of other gases by $2-10 \%$ (relative, not percentage points) and decrease the nitrogen contents by 1-5\% (relative, not percentage points).

The normalized gas analysis results are summarized in tabular format in Appendix A and in Figure 4 through Figure 9. In general, the nitrogen contents (Figure 4) increased as the air-to-fuel ratio was increased as expected. There was no difference between the two nozzles.

The hydrogen contents (Figure 5) slightly decreased as the air-to-fuel ratio increased which is also expected. The carbon dioxide and carbon monoxide contents (Figure 6 and Figure 7) remained relatively constant as the air-to-fuel ratio increased. For nitrogen and hydrogen, there were no consistent differences between the two nozzles. The carbon dioxide contents were higher and the carbon monoxide contents lower for the standard nozzle than for the new ETC swirler nozzle. This is likely due to the higher steam flow that was used with the standard nozzle. The extra steam increases the amount of oxygen in the system, and hence the ratio of $\mathrm{CO}_{2}$ to $\mathrm{CO}$ increases. 


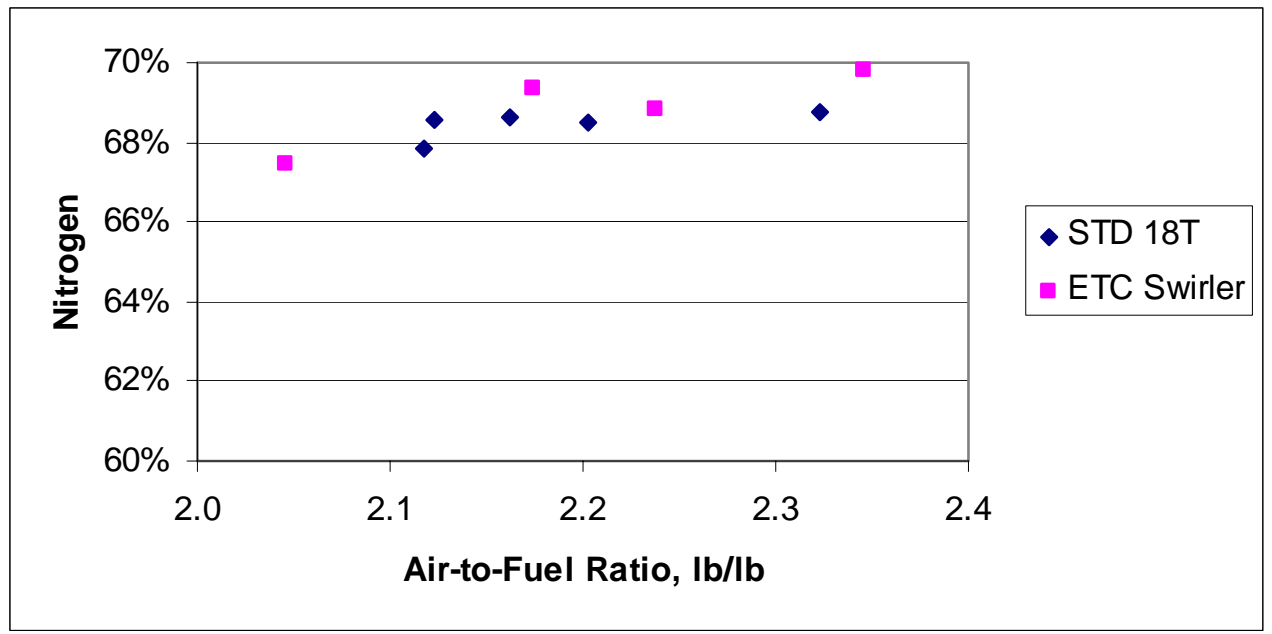

Figure 4. Nitrogen contents in the dry product gas.

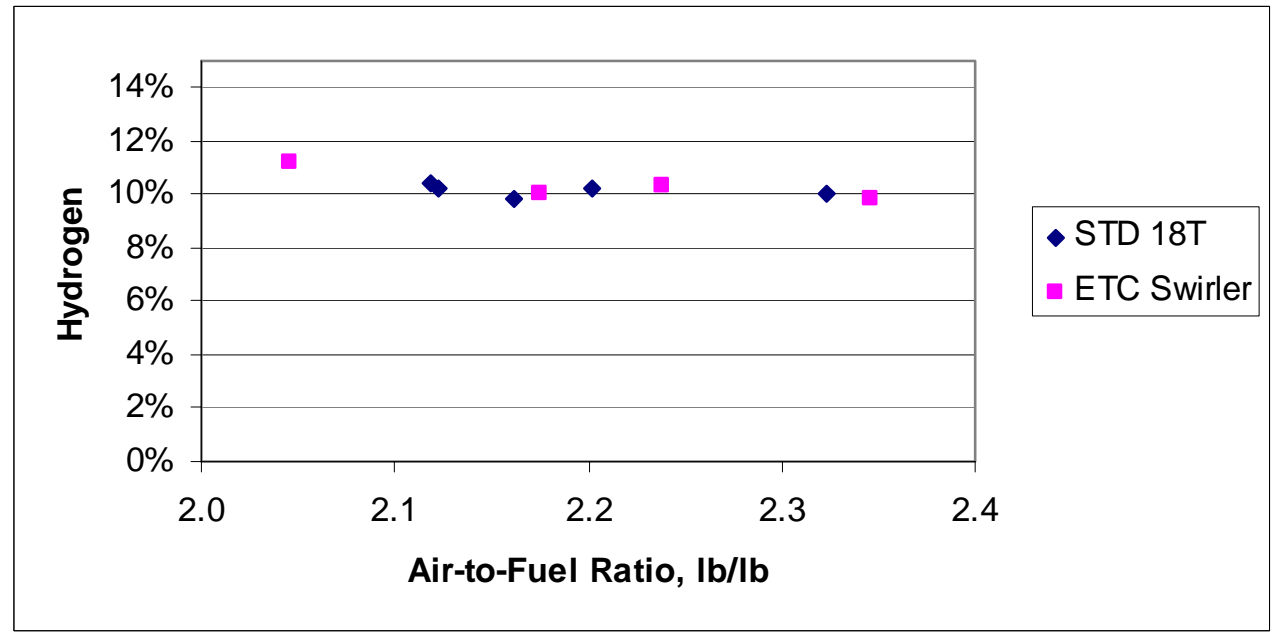

Figure 5. Hydrogen contents in the dry product gas.

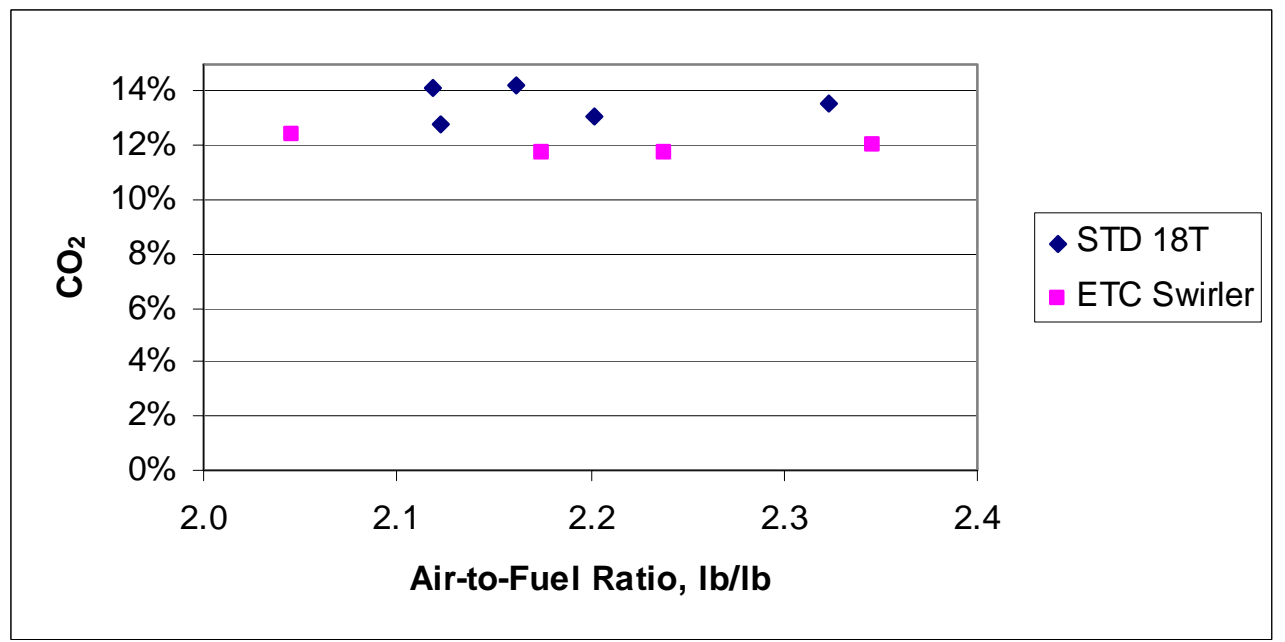

Figure 6. Carbon dioxide contents in the dry product gas. 


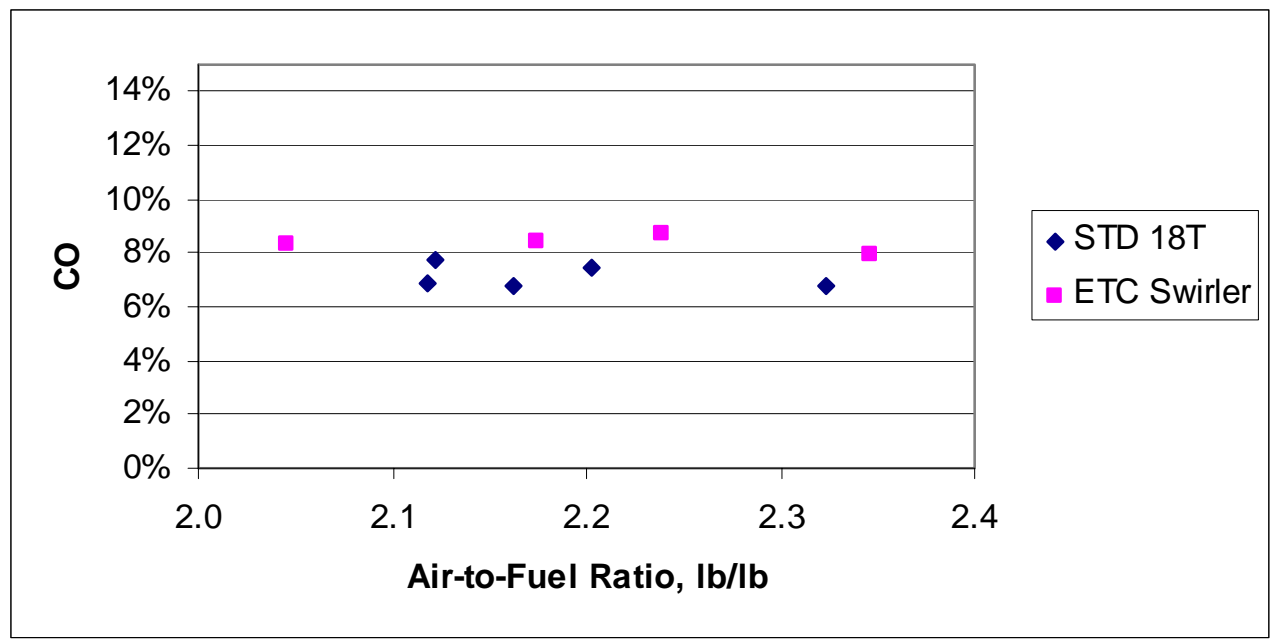

Figure 7. Carbon monoxide contents in the dry product gas.

The methane contents (Figure 8) were low, less than $0.8 \%$ in dry gas. In general, they decreased as the air-to-fuel ratio was increased. However, the run with the lower black liquor feed rate (the highest $\mathrm{A} / \mathrm{F}$ ratio with the standard nozzle) gave a higher methane content. This implies that the methane content depends on the residence time in the reactor, and that the methane content increases as residence time increases. With the main gas components $\left(\mathrm{CO}, \mathrm{CO}_{2}, \mathrm{H}_{2}\right)$, no significant variation with black liquor feed rate was observed. This is consistent with the common assumption that the $\mathrm{CO}, \mathrm{CO}_{2}$, and $\mathrm{H}_{2}$ contents are at water gas equilibrium but that the methane content is kinetically controlled.

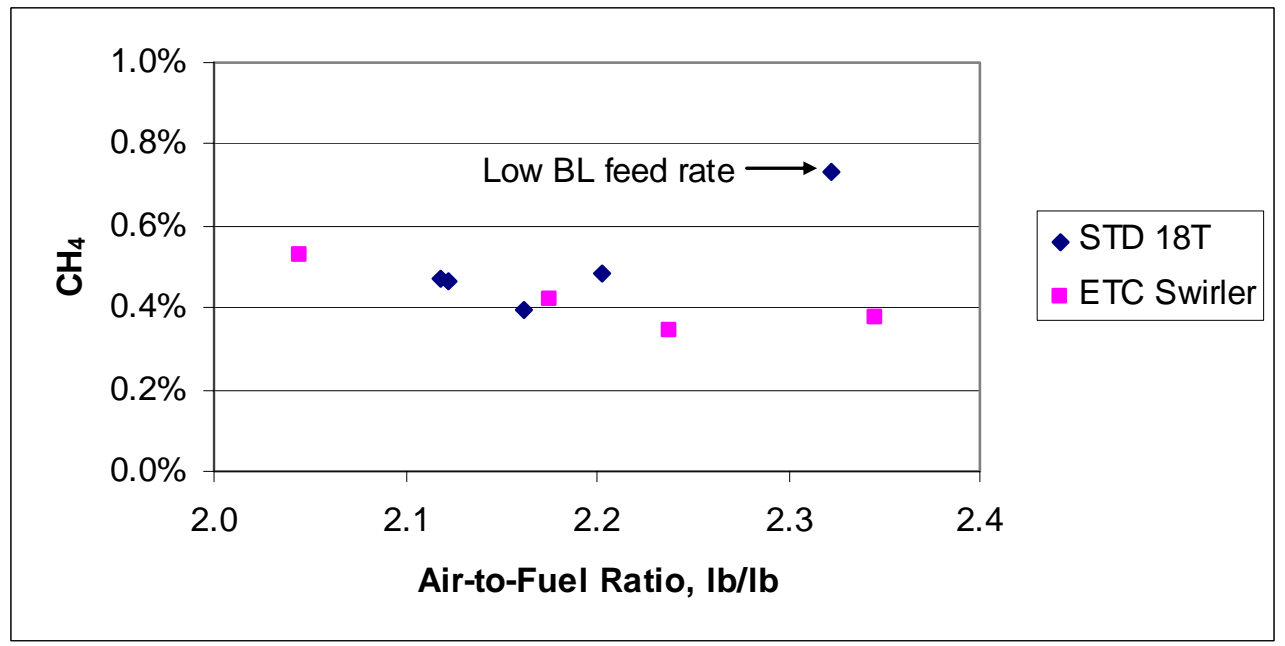

Figure 8. Methane contents in the dry product gas.

The hydrogen sulfide contents in the product gas varied from $0.05 \%$ to $0.25 \%$. There were no consistent patterns in the $\mathrm{H}_{2} \mathrm{~S}$ contents. The measurements were made in the product gas, i.e. after the scrubbers. A significant fraction of hydrogen sulfide is captured in the scrubber but the scrubber does not have a large impact on the concentrations of the other gases. The $\mathrm{H}_{2} \mathrm{~S}$ contents may have varied due to fluctuations in the process (either the gasifier or the scrubber). However, the $\mathrm{H}_{2} \mathrm{~S}$ contents may have been affected by the measurement technique as well. Hydrogen 
sulfide can become adsorbed on the walls of the measurement lines, and longer sample collection times may have been needed to obtain equilibrium in the lines. The reported gas contents are averages for two gas samples that were collected one after the other. In some cases, the first sample gave a higher $\mathrm{H}_{2} \mathrm{~S}$ content than the second gas sample. No such differences between the replicate measurements for other gas components were observed. For the two tests with $\mathrm{H}_{2} \mathrm{~S}$ contents of less than $0.1 \%$, the first measurement gave significantly lower values than the second one. The first measurements gave $0.01-0.02 \%$ and the second measurements $0.08 \%$ for both of these tests. For the experiments that gave higher $\mathrm{H}_{2} \mathrm{~S}$ values, there was in most cases only a minor difference in the two $\mathrm{H}_{2} \mathrm{~S}$ measurements.

The $\mathrm{H}_{2} \mathrm{~S}$ contents in the gas before and after the scrubber were measured by draeger tubes at the mill. The draeger tube readings showed also significant variation. The concentrations before the scrubber were $0.45-2.3 \%$ (average $0.9 \%$ ), and the product gas contents were $0.15-0.5 \%$ (average $0.3 \%$ ). The capture efficiencies as measured by the draeger tubes varied from $20 \%$ to $90 \%$, and the average was $60 \%$.

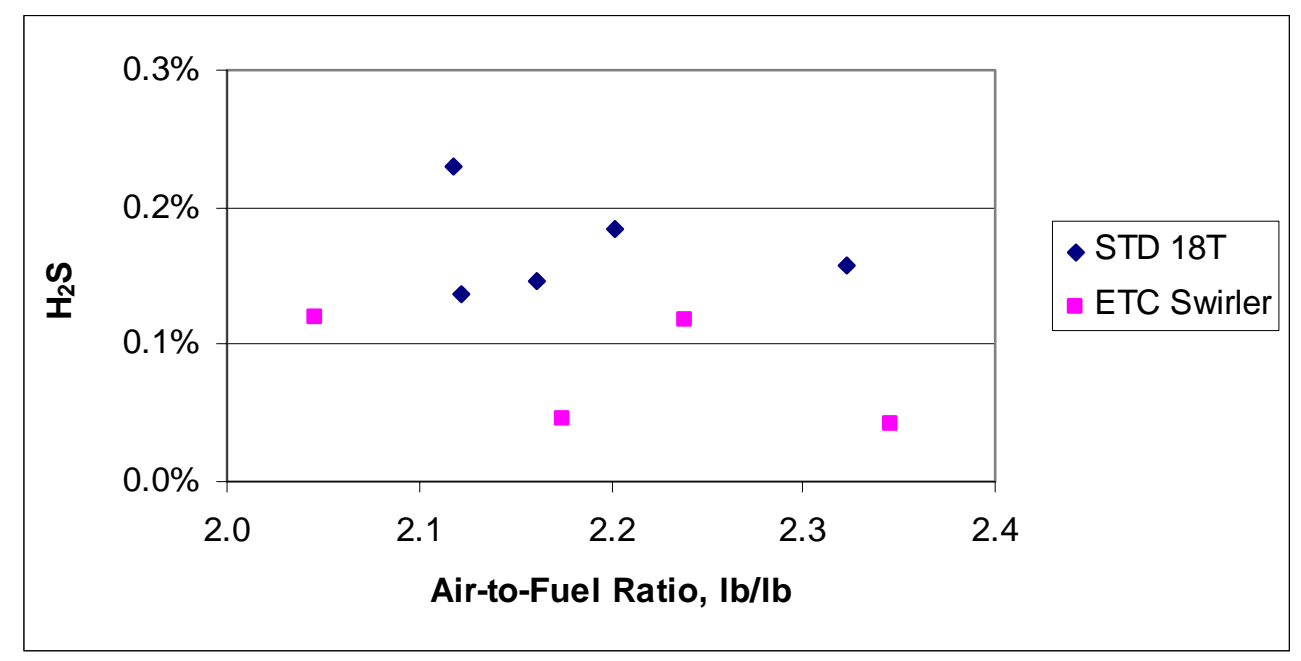

Figure 9. Hydrogen sulfide contents in the dry product gas.

\section{Carbon Balances}

The total mass, carbon, and nitrogen balances for the tests were evaluated. Two other test campaigns had been performed, one in 2005, and one in 2007. The campaign in 2005 included more measurements and more complete analysis of results than either the 2007 or the current campaign. The 2005 analysis included among others energy balances, analysis for minor components that could be used as tie elements, and gas analysis with multiple instruments. Based on the energy and component balances in 2005, it was concluded that the secondary air flow and the black liquor flows were both in error, and the flows were adjusted for the runs. The secondary air flow was increased by approximately $30 \%$ from the corrected value ( $17 \%$ from the uncorrected value) and the black liquor flow decreased by 10\%. In the 2007 campaign, when there was less information available, the uncorrected air flow rate was used, and it gave good (96-99\%) nitrogen balance closures. The carbon balances suggested that the black liquor flow rate should be reduced by $6 \%$. 
In the 2005 campaign it was determined that the true secondary air flow rate was $1.312 \mathrm{x}$ corrected air -0.58 . The reason for this deviation was not investigated after the 2005 campaign. Given that the orifice plate has not been changed and the calibration has not been changed, the same correction was applied to the secondary air. Table 4 through Table 6 show the total mass balance, carbon balance, and nitrogen balance closures using this correction and not correcting any other flows. The total mass flow out is about $90 \%$ of the mass flow in for the gasifierscrubber system (see Table 4). The carbon out was found to be about $83 \%$ of the carbon in (Table 5) and the nitrogen is close to balanced (Table 6). 
Table 4. Total mass flow in and out of the gasifier-scrubber system.

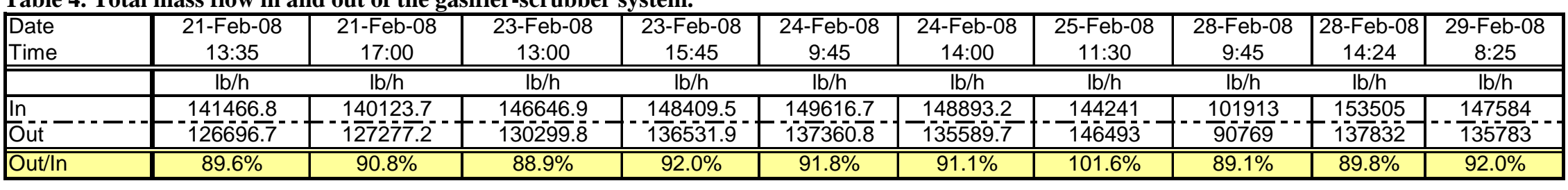

Table 5. Carbon balances

\begin{tabular}{|c|c|c|c|c|c|c|c|c|c|c|}
\hline \begin{tabular}{|l|} 
Date \\
Time \\
Nozzle
\end{tabular} & $\begin{array}{c}\text { 21-Feb-08 } \\
13: 35 \\
\text { Std 18T }\end{array}$ & $\begin{array}{c}\text { 21-Feb-08 } \\
17: 00 \\
\text { Std } 18 \mathrm{~T}\end{array}$ & \begin{tabular}{|c} 
23-Feb-08 \\
$13: 00$ \\
ETC Swirler
\end{tabular} & \begin{tabular}{|c|} 
23-Feb-08 \\
15:45 \\
ETC Swirler
\end{tabular} & \begin{tabular}{|c|}
$24-F e b-08$ \\
$9: 45$ \\
Std 18T
\end{tabular} & $\begin{array}{c}\text { 24-Feb-08 } \\
\text { 14:00 } \\
\text { ETC Swirler }\end{array}$ & $\begin{array}{r}25-F e b-08 \\
11: 30\end{array}$ & $\begin{array}{l}\begin{array}{r}28-F e b-08 \\
9: 45\end{array} \\
\text { Std 18T }\end{array}$ & \begin{tabular}{|c}
$28-F e b-08$ \\
$14: 24$ \\
Std 18T
\end{tabular} & \begin{tabular}{|r}
$29-$ Feb-08 \\
$8: 25$ \\
Std 18T
\end{tabular} \\
\hline $\ln$ & Ib C/min & Ib C/min & Ib C/min & Ib C/min & Ib C/min & $\mathrm{llb} \mathrm{C} / \mathrm{min}$ & $\mathrm{lb} \mathrm{C} / \mathrm{min}$ & $\mathrm{llb} \mathrm{C} / \mathrm{min}$ & Ib C/min & Ib C/min \\
\hline Black Liquor & 129.0 & 124.2 & 127.3 & 132.9 & 132.9 & 129.7 & 127.1 & 89.5 & 135.4 & 132.6 \\
\hline Air & 0.1 & 0.1 & 0.1 & 0.1 & 0.1 & $-\overline{0.1}$ & $0 . \overline{1}$ & 0.1 & $-\overline{0.1}$ & 0.1 \\
\hline Weak Wash & 0.4 & 0.4 & 0.4 & 0.5 & 0.5 & 0.5 & $0 . \overline{4}$ & 0.2 & 0.4 & 0.4 \\
\hline Total in & 129.5 & 124.6 & 127.9 & 133.5 & 133.5 & 130.3 & 127.6 & 89.8 & 136.0 & 133.1 \\
\hline Out & $\mathrm{lb} \mathrm{C/min}$ & $\mathrm{lb} \mathrm{C} / \mathrm{min}$ & $\mathrm{lb} \mathrm{C} / \mathrm{min}$ & $\mathrm{lb} \mathrm{C/min}$ & $\mathrm{lb} \mathrm{C/min}$ & lb C/min & $\mathrm{lb} \mathrm{C} / \mathrm{min}$ & $\mathrm{lb} \mathrm{C/min}$ & $\mathrm{lb} \mathrm{C/min}$ & $\mathrm{lb} \mathrm{C} / \mathrm{min}$ \\
\hline Green Liquor & 16.3 & 16.8 & 17.2 & 17.5 & 18.3 & 16.9 & 20.3 & 12.8 & 18.2 & 17.9 \\
\hline Product Gas & 91.6 & 87.0 & $90 . \overline{3}$ & 94.8 & $\overline{94.2}$ & 91.0 & $9 \overline{5.2}$ & 67.8 & 100.6 & $95 . \overline{9}$ \\
\hline Total out & 107.9 & 103.8 & 107.5 & 112.3 & 112.4 & 107.9 & 115.5 & 80.6 & 118.8 & 113.8 \\
\hline Out/In & $83.3 \%$ & $83.3 \%$ & $84.1 \%$ & $84.1 \%$ & $84.2 \%$ & $82.9 \%$ & 90.5\% & $89.7 \%$ & $87.3 \%$ & $85.5 \%$ \\
\hline
\end{tabular}

Table 6. Nitrogen balances

\begin{tabular}{|c|c|c|c|c|c|c|c|c|c|c|}
\hline $\begin{array}{l}\text { Date } \\
\text { Time } \\
\end{array}$ & $\begin{array}{c}21-F e b-08 \\
13: 35 \\
\end{array}$ & $\begin{array}{c}21-F e b-08 \\
17: 00 \\
\end{array}$ & $\begin{array}{c}23-F e b-08 \\
13: 00 \\
\end{array}$ & $\begin{array}{c}23-F e b-08 \\
15: 45 \\
\end{array}$ & $\begin{array}{c}24-F e b-08 \\
9: 45\end{array}$ & $\begin{array}{c}24-F e b-08 \\
14: 00 \\
\end{array}$ & $\begin{array}{c}25-F e b-08 \\
11: 30 \\
\end{array}$ & $\begin{array}{c}28-F e b-08 \\
9: 45 \\
\end{array}$ & \begin{tabular}{|c}
$28-F e b-08$ \\
$14: 24$ \\
\end{tabular} & $\begin{array}{c}29-F e b-08 \\
8: 25 \\
\end{array}$ \\
\hline & Ib $\mathrm{N}_{2} / \mathrm{min}$ & Ib $N_{2} / \min$ & Ib $N_{2} / \min$ & Ib $N_{2} / \min$ & $\mathrm{Ib} \mathrm{N} / \mathrm{min}$ & Ib $N_{2} / \min$ & Ib $N_{2} / \min$ & $\mathrm{Ib} \mathrm{N} / \mathrm{min}$ & $\mathrm{Ib} \mathrm{N} / \mathrm{min}$ & $\mathrm{lb} \mathrm{N}_{2} / \mathrm{min}$ \\
\hline In & 716.8 & 667.5 & 734.8 & 739.7 & . 728.3 & 649.4 & 712 & 513 & . 771 & 732 \\
\hline Oüūt & $68 \overline{8} .9$ & $\overline{6} 5 \overline{4} \overline{2}$ & $\overline{7} \overline{2} \overline{7} \overline{1}$ & $\overline{7} \overline{3} \overline{8} . \overline{5}$ & $\overline{74} \overline{4} .0$ & $\overline{6} \overline{78} . \overline{0}$ & $72 \overline{7}$ & 518 & $\overline{76} \overline{7}$ & 732 \\
\hline Out/In & $\overline{96.1 \%}$ & $\overline{98.0 \%}$ & $\overline{98.9 \%}$ & $\overline{999.8 \%}$ & $102.2 \%$ & $104.4 \%$ & $102.1 \%$ & $101.0 \%$ & $\overline{999.5 \%}$ & $100.1 \%$ \\
\hline
\end{tabular}


The total mass balance and carbon balance can be improved by e.g. increasing the product gas flow rate. This approach was tested. The product gas flow rate was adjusted for each test to give a $100 \%$ mass balance closure. The corrected product gas flow rate vs. the measured product gas flow rate is given in Figure 10. A linear correlation between the corrected and the measured product gas flow rates was obtained, and this equation was used to correct the product gas flow rates. The new total mass, carbon, and nitrogen balances are shown in Table 7 trough Table 9. The total mass balances (Table 7), and carbon balances (Table 8) are reasonable. The nitrogen balances are off, with about 20\% more out than going in (Table 9). It is probable that this is caused by an excessively high measured $\mathrm{N}_{2}$ concentration. As discussed earlier, it is likely that the reported nitrogen values are high.

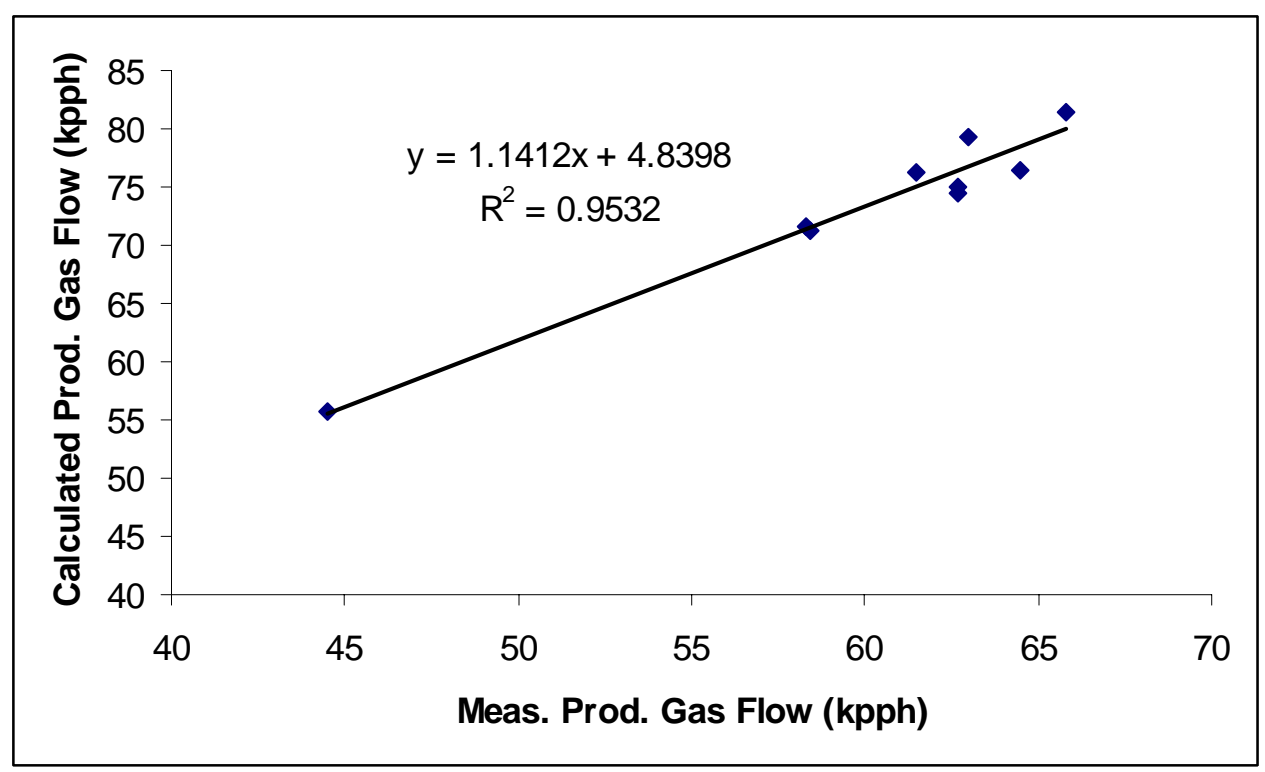

Figure 10. Calculated product gas flow rate based on balancing the total mass vs. the measured product gas flow. The counter swirl data (1 data point) was discarded.

The gas contents in the current tests are compared to those from the tests in 2005 in Figure 11 through Figure 15. The same correlation has been used for secondary gas in the two sets of experiments. In 2005, the black liquor flow rate was reduced by $10 \%$ but in these current tests, there is no correction to black liquor flow rate. In all the figures, the normalized gas contents from both years are graphed. The $\mathrm{N}_{2}$ values are significantly higher in the current tests than in those from 2005. The difference is about 6 percentage points (or $9 \%$ in relative values). The analyzed $\mathrm{CO}_{2}$ values are lower than in 2005, Figure 12, and may be a small reason for the carbon imbalance. Hydrogen and methane are a bit lower while carbon monoxide is similar. The tests in 2005 and 2008 show overall similar trends with respect to the gas contents.

This approach (similar correlation in inlet air flow as in 2005 and increase in product gas flow to close total mass balance) gave good carbon balance closures but $20 \%$ high nitrogen closures. While the comparison to 2005 measurements suggested that the nitrogen contents were likely too high they were unlikely high by as much as $20 \%$. Therefore, other (or alternate) adjustments would be needed as well. 
Table 7. Total mass balance based on 2005 correction for secondary air to the gasifier; an increased product gas flow rate based on the equation in Figure 1; and normalized gas analysis.

\begin{tabular}{|c|c|c|c|c|c|c|c|c|c|c|}
\hline \begin{tabular}{|l|} 
Date \\
Time \\
\end{tabular} & $\begin{array}{c}21-F e b-08 \\
13: 35 \\
\end{array}$ & $\begin{array}{c}21-F e b-08 \\
17: 00 \\
\end{array}$ & $\begin{array}{c}23-F e b-08 \\
13: 00 \\
\end{array}$ & $\begin{array}{c}23-F e b-08 \\
15: 45 \\
\end{array}$ & $\begin{array}{c}24-F e b-08 \\
9: 45\end{array}$ & $\begin{array}{c}24-F e b-08 \\
14: 00 \\
\end{array}$ & $\begin{array}{c}25-F e b-08 \\
11: 30 \\
\end{array}$ & $\begin{array}{c}28-F e b-08 \\
9: 45 \\
\end{array}$ & $\begin{array}{c}28-F e b-08 \\
14: 24 \\
\end{array}$ & $\begin{array}{c}29-F e b-08 \\
8: 25 \\
\end{array}$ \\
\hline & $\mathrm{lb} / \mathrm{h}$ & $\mathrm{llb} / \mathrm{h}$ & $\mathrm{llb} / \mathrm{h}$ & $\mathrm{lb} / \mathrm{h}$ & $\mathrm{lb} / \mathrm{h}$ & $\mathrm{Ib} / \mathrm{h}$ & $\mathrm{Ib} / \mathrm{h}$ & $\mathrm{Ib} / \mathrm{h}$ & $\overline{l i b / h}$ & $\mathrm{lb} / \mathrm{h}$ \\
\hline In & 141466.8 & 140123.7 & 146646.9 & 148409.5 & 149616.7 & 148893.2 & 144241 & 101913 & 153505 & 147584 \\
\hline Oüt & $1 \overline{40} 220.3$ & $\overline{1} \overline{40} 3 \overline{6} \overline{3.1}$ & $\overline{14} 4035.2$ & $1504 \overline{9} . \overline{1}$ & $15 \overline{1053.8}$ & 148661.4 & $16 \overline{0} \overline{08} \overline{7}$ & $\overline{10} \overline{1} \overline{892}$ & $15 \overline{19} \overline{3}$ & $\overline{149489}$ \\
\hline Out/In & $99.1 \%$ & $100.2 \%$ & $98.2 \%$ & $101.4 \%$ & $101.0 \%$ & $\overline{999.8 \%}$ & $111.0 \%$ & $100.0 \%$ & $999.0 \%$ & $101.3 \%$ \\
\hline
\end{tabular}

Table 8. Carbon mass balance based on 2005 correction for secondary air to the gasifier; an increased product gas flow rate based on the equation in Figure 1; and normalized gas analysis.

\begin{tabular}{|c|c|c|c|c|c|c|c|c|c|c|}
\hline $\begin{array}{l}\text { Date } \\
\text { Time } \\
\text { Nozzle } \\
\end{array}$ & $\begin{array}{c}\text { 21-Feb-08 } \\
\text { 13:35 } \\
\text { Std 18T } \\
\end{array}$ & \begin{tabular}{|c|}
$21-F e b-08$ \\
$17: 00$ \\
Std $18 T$ \\
\end{tabular} & \begin{tabular}{|c} 
23-Feb-08 \\
13:00 \\
ETC Swirler
\end{tabular} & \begin{tabular}{|c|} 
23-Feb-08 \\
$15: 45$ \\
ETC Swirler \\
\end{tabular} & $\begin{array}{c}\text { 24-Feb-08 } \\
9: 45 \\
\text { Std } 18 \mathrm{~T} \\
\end{array}$ & $\begin{array}{c}\text { 24-Feb-08 } \\
14: 00 \\
\text { ETC Swirler } \\
\end{array}$ & $\begin{array}{r}25-F e b-08 \\
11: 30\end{array}$ & $\begin{array}{r}28-F e b-08 \\
9: 45 \\
\text { Std 18T } \\
\end{array}$ & \begin{tabular}{|c|}
$28-F e b-08$ \\
$14: 24$ \\
Std 18T \\
\end{tabular} & $\begin{array}{r}29-F e b-08 \\
8: 25 \\
\text { Std 18T } \\
\end{array}$ \\
\hline $\ln$ & $\mathrm{lb} \mathrm{C/min}$ & $\mathrm{lb} \mathrm{C/min}$ & $\mathrm{lb} \mathrm{C/min}$ & $\mathrm{lb} \mathrm{C/min}$ & $\mathrm{lb} \mathrm{C/min}$ & lb C/min & $\mathrm{lb} \mathrm{C/min}$ & $\mathrm{lb} \mathrm{C/min}$ & Ib C/min & $\mathrm{lb} \mathrm{C/min}$ \\
\hline Black Liquor & 129.0 & 124.2 & 127.3 & 132.9 & 132.9 & 129.7 & 127.1 & 89.5 & 135.4 & 132.6 \\
\hline Air & 0.1 & $0 . \overline{1}$ & 0.1 & 0.1 & 0.1 & 0.1 & $0 . \overline{1}$ & 0.1 & 0.1 & 0.1 \\
\hline Weak Wash & 0.4 & 0.4 & 0.4 & 0.5 & 0.5 & 0.5 & $0 . \overline{4}$ & 0.2 & $\overline{0.4}$ & 0.4 \\
\hline Total in & 129.5 & 124.6 & 127.9 & 133.5 & 133.5 & 130.3 & 127.6 & 89.8 & 136.0 & 133.1 \\
\hline Out & $\mathrm{lb} \mathrm{C/min}$ & $\mathrm{Ib} \mathrm{C} / \mathrm{min}$ & $\mathrm{Ib} \mathrm{C/min}$ & $\mathrm{lb} \mathrm{C/min}$ & $\mathrm{lb} \mathrm{C} / \mathrm{min}$ & $\mathrm{lb} \mathrm{C} / \mathrm{min}$ & $\mathrm{Ib} \mathrm{C} / \mathrm{min}$ & $\mathrm{lb} \mathrm{C} / \mathrm{min}$ & $\mathrm{lb} \mathrm{C} / \mathrm{min}$ & $\mathrm{lb} \mathrm{C/min}$ \\
\hline Green Liquor & 16.3 & 16.8 & 17.2 & 17.5 & 18.3 & 16.9 & 20.3 & 12.8 & 18.2 & 17.9 \\
\hline Product Gas & $\overline{11} 1 . \overline{8}$ & 106.5 & $11 \overline{0} . \overline{0}$ & $1 \overline{1} \overline{5} . \overline{3}$ & $\overline{11} \overline{4} . \overline{7}$ & $1 \overline{11.4}$ & 116.0 & 84.8 & $1 \overline{22.2}$ & $1 \overline{1} \overline{6} . \overline{9}$ \\
\hline Total out & 128.1 & 123.3 & 127.2 & 132.8 & 133.0 & 128.3 & 136.3 & 97.5 & 140.4 & 134.8 \\
\hline Out/In & 98.9\% & 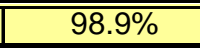 & 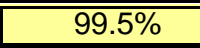 & 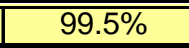 & $999.6 \%$ & 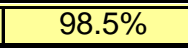 & $106.8 \%$ & $108.5 \%$ & $103.2 \%$ & $\overline{101.3 \%}$ \\
\hline
\end{tabular}

Table 9. $\mathbf{N}_{2}$ mass balance based on 2005 correction for secondary air to the gasifier; an increased product gas flow rate based on the equation in Figure 1 ; and normalized gas analysis.

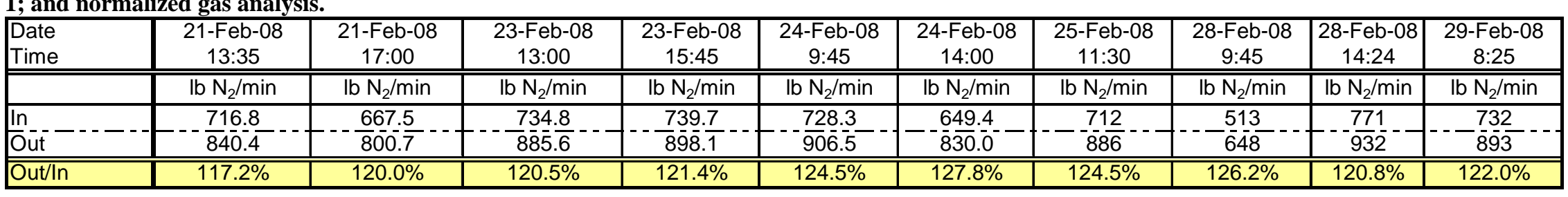




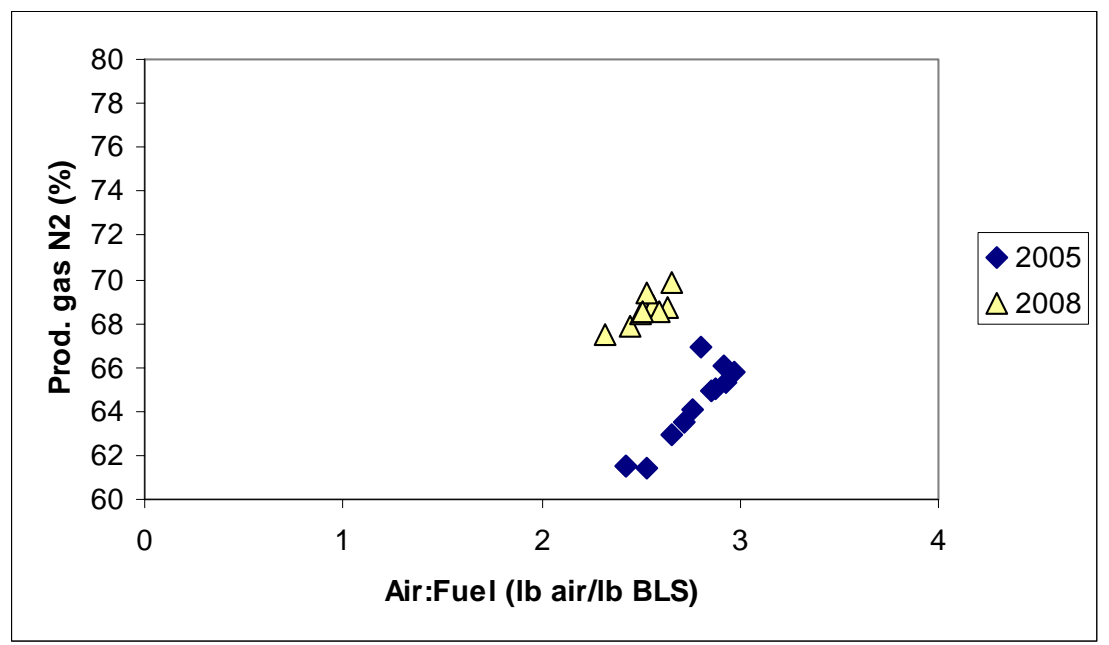

Figure 11. Comparison of 2005 and 2008 normalized values (gas compositions were adjusted proportionately so that the sum of the various components equaled $100 \%$ ) for $\mathbf{N}_{2}$ in the product gas from the scrubber.

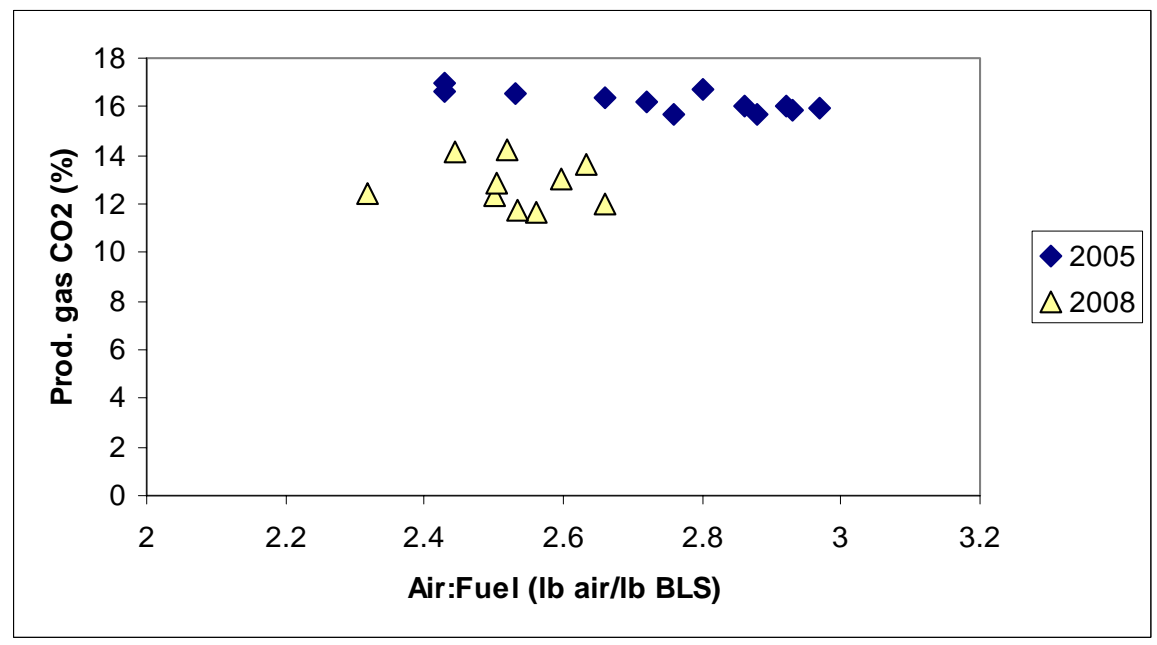

Figure 12. Comparison of 2005 and 2008 normalized values for $\mathrm{CO}_{2}$ in the product gas from the scrubber.

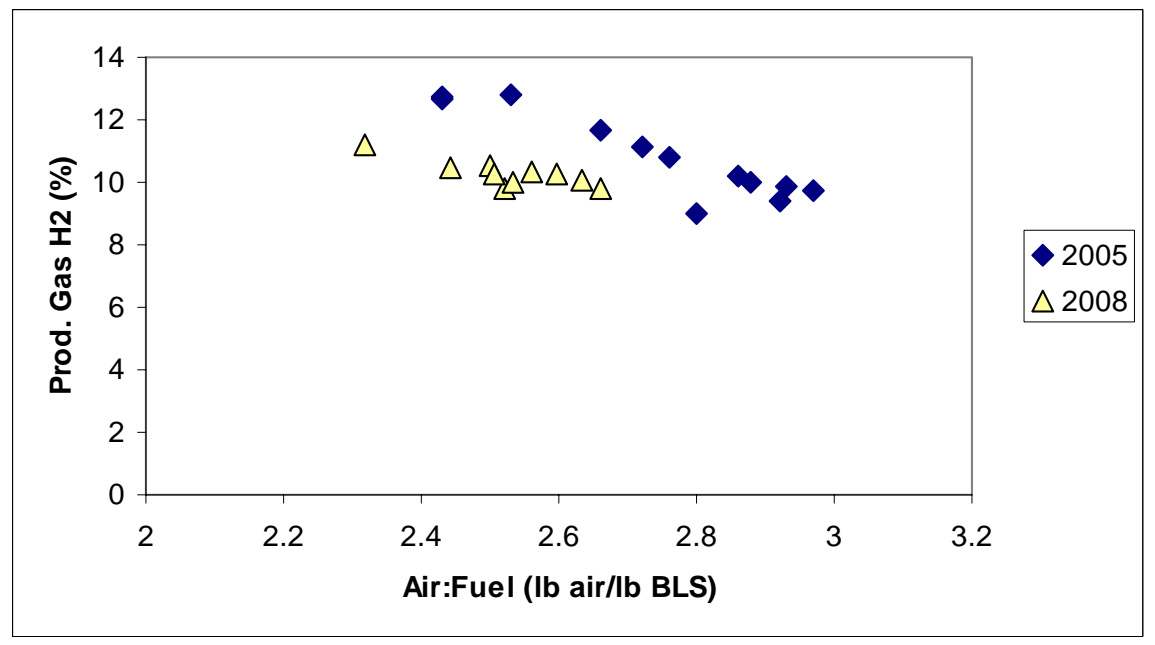

Figure 13. Comparison of 2005 and 2008 normalized values for $\mathrm{H}_{2}$ in the product gas from the scrubber. 


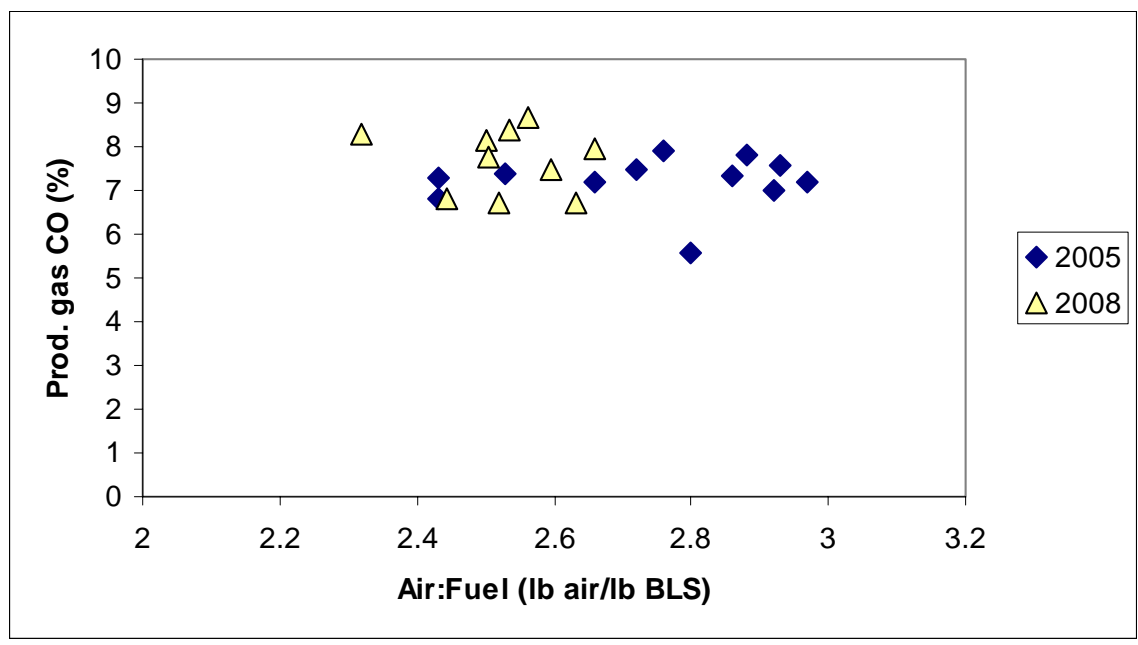

Figure 14. Comparison of 2005 and 2008 normalized values for $\mathrm{CO}$ in the product gas from the scrubber.

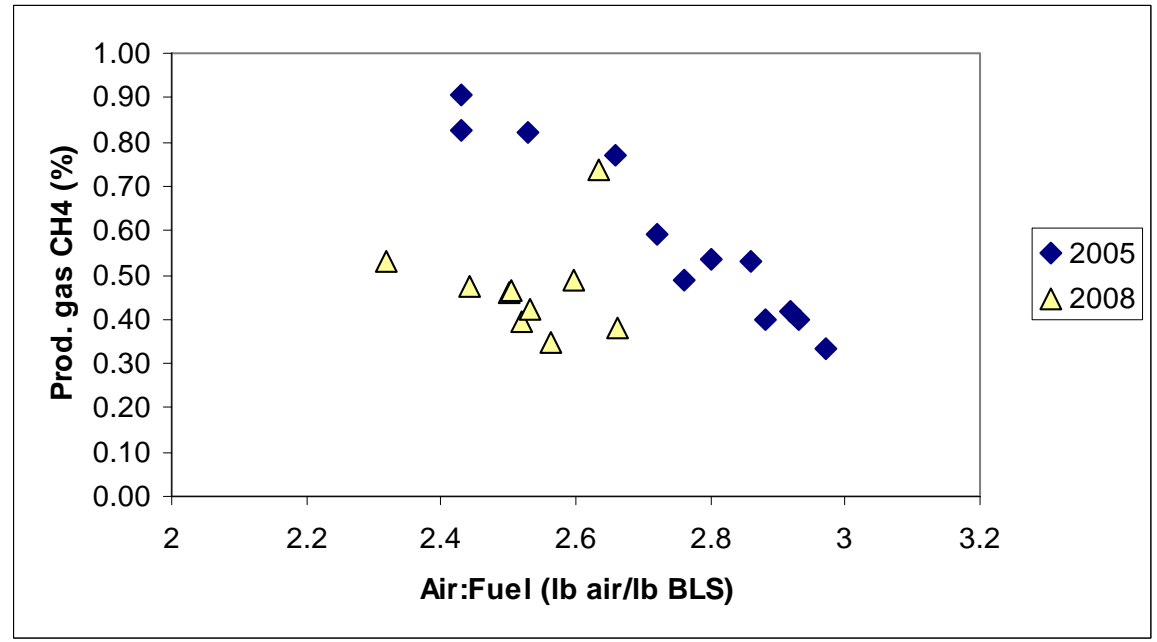

Figure 15. Comparison of 2005 and 2008 normalized values for $\mathrm{CH}_{4}$ in the product gas from the scrubber.

While many approaches were considered for completing the balances, two were seriously investigated. The first was reducing the inlet air. Using the mill's "corrected" air leads to a good total mass balance and nitrogen balance (within about 5\%), but a poor carbon balance. The carbon balance would then have to be achieved by an approximately $15 \%$ reduction in black liquor flow rate. Three things led to abandoning this approach:

- the lack of justification for using the mill "corrected" air given the findings of 2005 and the fact that the mill has not changed the orifice plate or calibration;

- the likelihood of $\mathrm{N}_{2}$ measurements being high;

- $\quad$ and the large extent of reducing the black liquor flow rate that would be required.

Adjustments in the gas composition were also considered because the nitrogen analysis was high and the $\mathrm{CO}_{2}$ values a bit lower than in 2005. However, each path explored lead to more uncertainty and more variables being changed without a clear reason for the changes. For this 
reason, the presented approach of using the 2005 correction for the inlet air and then increasing the product gas flow rate was chosen though it is recognized that this may be an oversimplification.

Energy balances were not a part of this effort and were not considered in balancing the system. Including energy balances would have been useful to give guidance for adjustments that were needed for mass balance evaluations. Additional analytical results would have been helpful for carbon balance closures as well. Elemental analysis of green liquor would have allowed the calculation of several mass balances (e.g. Na, V. Ca) and could have aided in determining an adjustment in black liquor or green liquor flow.

\section{CONCLUSIONS}

The dregs content and the amount of unburnt carbon in the green liquor were evaluated during measurements made with two nozzles at the New Bern gasifier: the standard 18T nozzle and a new ETC swirler nozzle. The black liquor solids feed rates were approximately the same in all of the test runs except in one. The steam flow was 35\% lower for the ETC swirler nozzle than for the standard nozzle.

Both nozzles performed well. At any given air-to-solids feed ratio, the total suspended solids were slightly lower for the standard nozzle than for the ETC swirler nozzle. The fraction of unburnt carbon was lower for the standard nozzle than for the ETC swirler nozzle. Because of the different steam flow rates, no firm conclusions whether the new nozzle showed better performance with respect to unburnt carbon than the standard nozzle can be made. Both can be deemed to have adequate performance. Ignoring the differences in the steam flow rates, the standard nozzle gave somewhat better performance (lower unburnt carbon at the same air-to-fuel ratio). However, the new nozzle operated at a lower steam flow rate, and the ability to operate at lower steam flows may be more important than any minor difference in the amount of unburnt carbon.

Nitrogen contents increased as the air-to-fuel ratio was increased and hydrogen contents decreased whereas $\mathrm{CO}$ and $\mathrm{CO}_{2}$ contents remained relatively constant. The carbon dioxide contents were higher and the carbon monoxide contents lower for the standard nozzle than for the new ETC swirler nozzle. This was likely due to the higher steam flow that was used with the standard nozzle. The extra steam increases the amount of oxygen in the system, and hence the ratio of $\mathrm{CO}_{2}$ to $\mathrm{CO}$ increases. Only the methane content was affected by black liquor flow rate. This supported the notion that methane concentration is kinetically controlled and that the $\mathrm{CO}$, $\mathrm{CO}_{2}$, and $\mathrm{H}_{2}$ contents are controlled by equilibrium.

No simple approach could be found that would have lead to good total mass, carbon, and nitrogen balances. The results suggested that the product gas flow rate was low, the measured nitrogen content high, and/or the black liquor flow rate was high. More detailed chemical analysis results and evaluation of energy balances would be required for better adjustment of the carbon balances. 
Appendix B.

\section{Dregs Analysis (Details)}

The total suspended solids (dregs) contents in green liquor were measured at the mill and later from samples transported to the IPST. At the IPST, the measurements were made after heating the samples to $80^{\circ} \mathrm{C}$. Both at the mill and at the IPST, the dregs contents were measured in duplicate. The IPST measurements differed on average $8 \%$ from each other and the mill measurements by $22 \%$.

The total suspended solids (dregs content) as functions of air-to-fuel ratio are shown in Figure 16 and Figure 17 for the standard nozzle and the swirler nozzle, respectively. For the ETC swirler nozzle (Figure 17), both mill and IPST measurements were available for only two points, and there was good agreement between the IPST and the mill measurements. For four of the five measurements for the standard nozzles (Figure 16), the mill and IPST measurements agreed well. For these cases, the values differed by less than $27 \%$. However, for the standard nozzle test with an air-to-fuel ratio of 2.16, the average dregs content measured at the mill was more than twice that measured at the IPST (840 vs. $340 \mathrm{mg} / \mathrm{l}$ ). For this test, the mill measurements also varied by more than a factor of two (466 and1220 mg/l). It is not known, why there was so much variation for this run. The other test with average dregs contents above $800 \mathrm{mg} / \mathrm{l}$, had the largest variation of any IPST measurement (36\%) but all measured dregs contents for this test were above $660 \mathrm{mg} / \mathrm{l}$.

For the ETC swirler nozzle, the dregs contents were all below $400 \mathrm{mg} / \mathrm{l}$ and decreased slightly as the air-to-fuel ratio increased. In general, the dregs contents are expected to decrease as the air-to-fuel ratio is increased, as was observed with this nozzle. Other factors such as steam flow and black liquor flow affect the dregs contents but these were kept constant for each nozzle. For the standard nozzle, the dregs contents show a conflicting pattern. Three of the five measurements gave dregs contents that were below $400 \mathrm{mg} / \mathrm{l}$ and decreased as the air-to-fuel ratio decreased. For the one point with the highly different dregs contents measured at the mill and the IPST, the higher value, which was measured at the mill, was above $800 \mathrm{mg} / \mathrm{l}$. Another point gave dregs contents above $800 \mathrm{mg} / \mathrm{l}$ in both measurements. The values above $800 \mathrm{mg} / \mathrm{l}$ do not conform to the expected behavior. The reason is not known. 


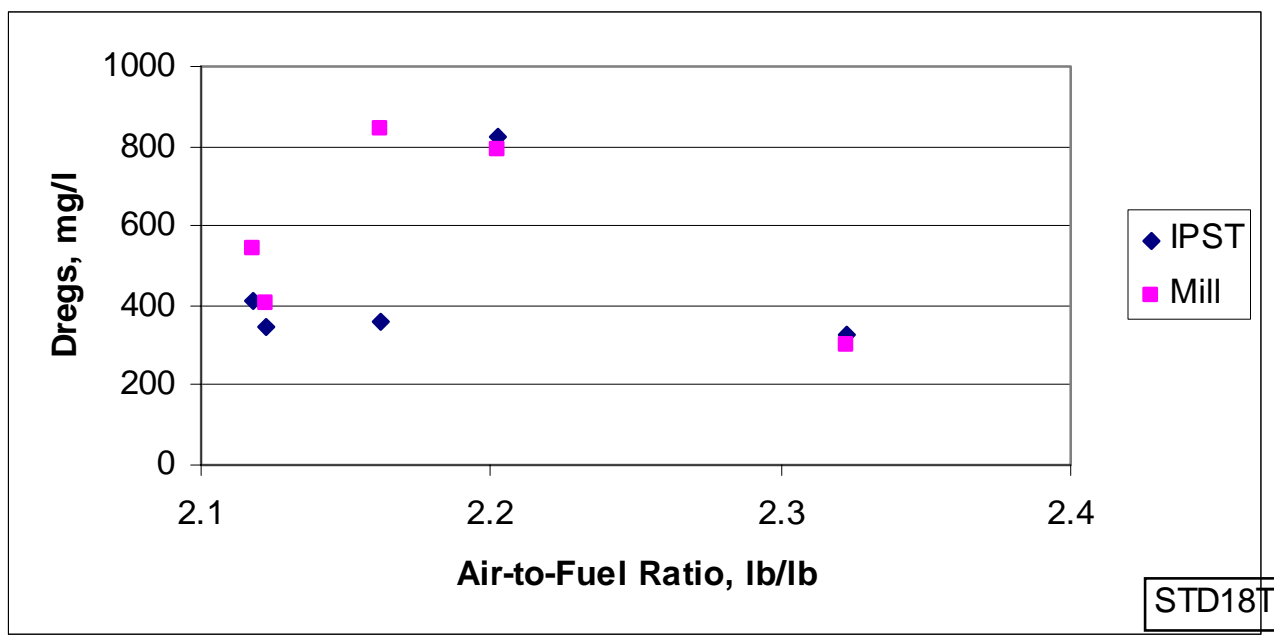

Figure 16. Dregs content in green liquors from tests with the standard nozzle STD 18T.

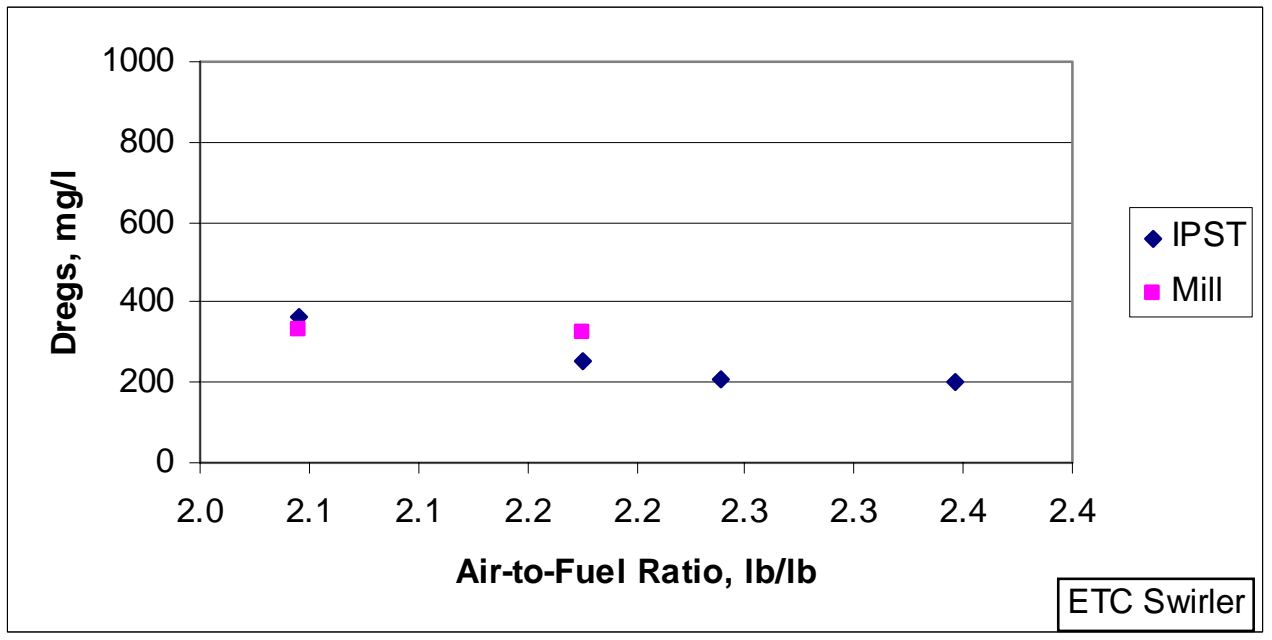

Figure 17. Dregs content in green liquors from tests with the new ETC swirler nozzle.

The ash contents in the dregs are illustrated in Figure 18. The ETC swirler nozzle shows the expected trend: the dregs ash contents increases as the air-to-fuel increases. For the standard nozzle, the two tests which gave high dregs contents do not follow the same trend. Ignoring these two data points, the dregs ash contents increased as the air-to-fuel ratio increased, which is the expected trend. There was little difference between the two nozzles. 


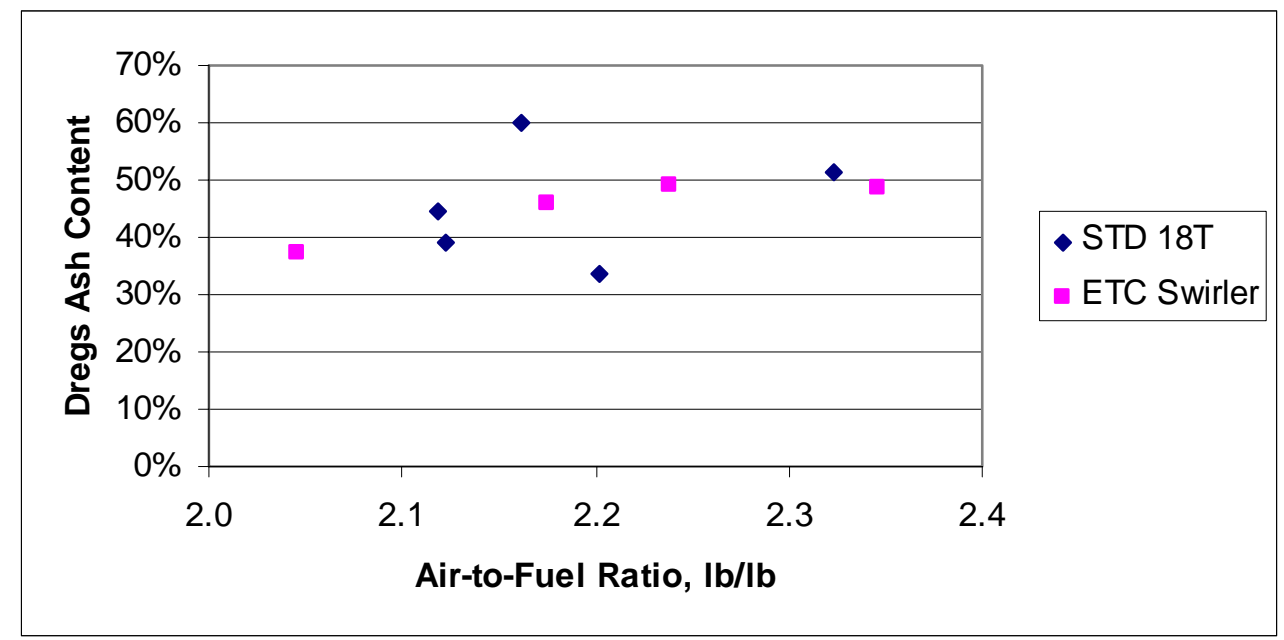

Figure 18. The ash content in the dregs.

The organic carbon contents of the dregs are shown in Figure 19. For the ETC swirler nozzle, the dregs organic content decreased as the air-to-fuel ratio increased as expected. The standard nozzle gives no clear trends. Ignoring the two points with the high dregs contents, the organic carbon contents decreased as the air-to-fuel ratio increased for this nozzle as well.

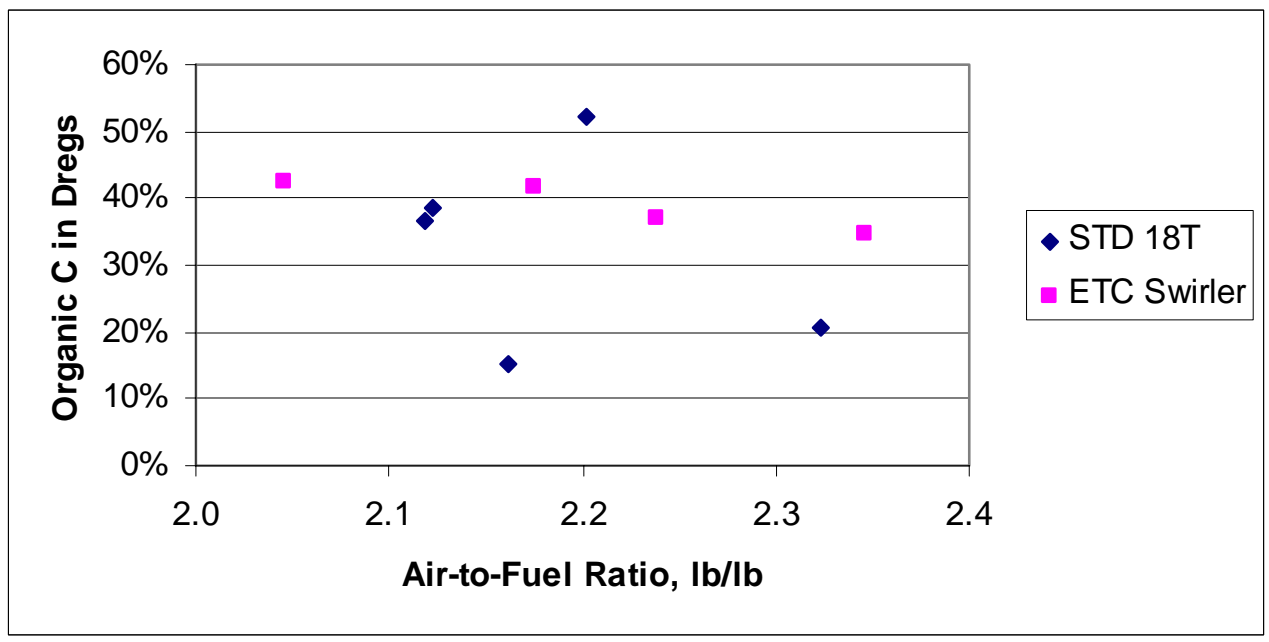

Figure 19. Organic carbon contents in the dregs.

The total amounts of inorganic dregs in green liquor for the two nozzles are shown in Figure 20 and Figure 21. For the new ETC swirler nozzle, the green liquor contained approximately $200 \mathrm{mg} / \mathrm{l}$ of inorganic dregs and the inorganic dregs slightly decreased as the air-to-fuel ratio decreased. For the standard nozzle, the amount of inorganic dregs was slightly less than $200 \mathrm{mg} / \mathrm{l}$ for the three points with the total suspended solids contents of around $400 \mathrm{mg} / \mathrm{l}$. For the point with the different dregs amounts measured at the mill and at the IPST, the dregs content measured at the IPST gives a reasonable ash value $(\sim 200$ $\mathrm{mg} / \mathrm{l})$, whereas the one based on the mill total suspended solids measurements gives an exceedingly high value. Even though in general, a measurement made at the same time in 
the mill for the total suspended solids (dregs) may be expected to give better values, it may be better to use the total suspended solids values measured at the IPST since the ash contents were measured from the IPST samples as well. For the point with the high suspended solids both by the mill and the IPST and the mill measurement, higher inorganic solids content was also found (300 mg/l).

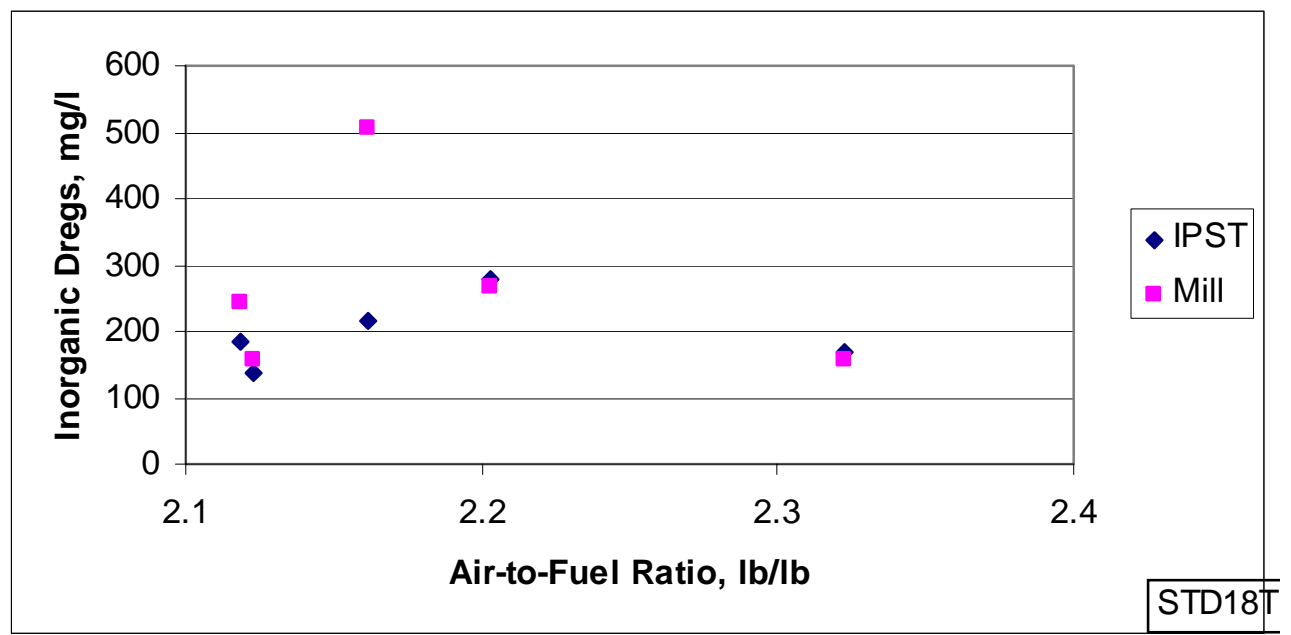

Figure 20. Inorganic dregs (=ash) in green liquor for the standard nozzle. The total amount of dregs is either from the IPST or from the mill measurement.

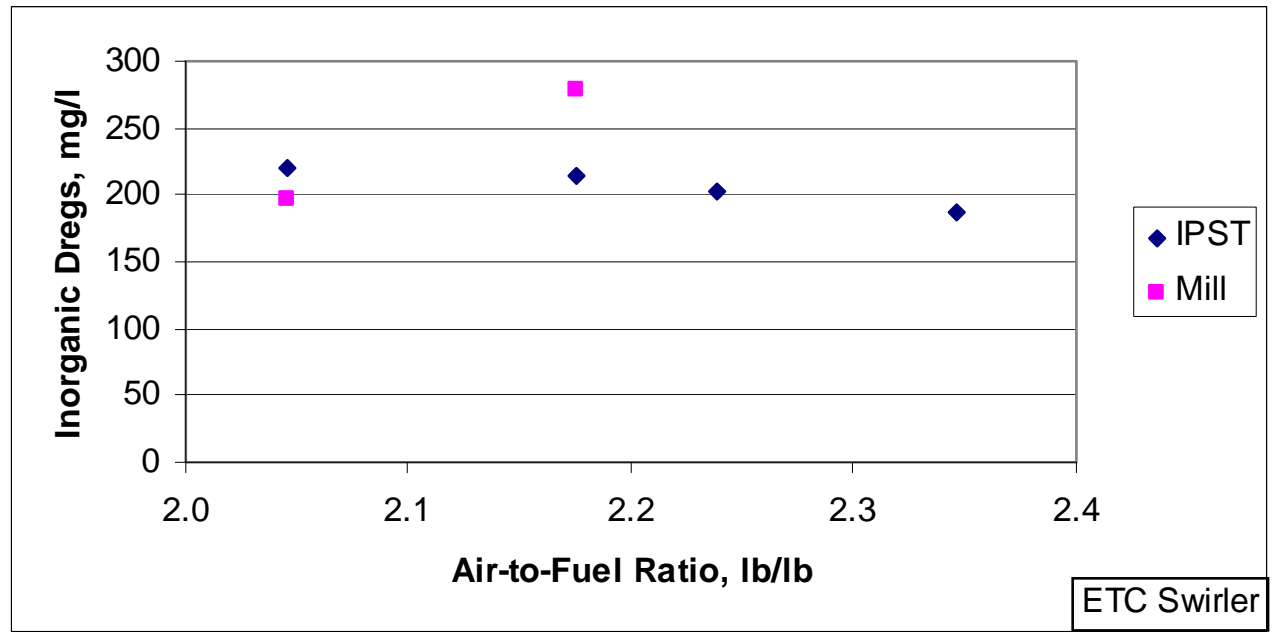

Figure 21. The amount of inorganic dregs (=ash in dregs) for the ETC swirler nozzle. The total amount of dregs is either from the IPST or from the mill measurement.

The organic carbon contents were measured fraction of the incoming black liquor carbon that was found as organic carbon in the dregs is shown in Figure 22 and Figure 23. In all cases, less than $0.4 \%$ of the liquor carbon was found unburnt in green liquor for these two nozzles. For the ETC swirler nozzle, the fraction decreased from $\sim 0.23 \%$ to at an air-tosolids ratio of 2.05 to $0.11 \%$ at an air-to-solids ratio of 2.35 . For the standard nozzle, ignoring the high point at the air-to-solids ratio of 2.2., the fraction of liquor carbon exiting with the dregs decreased from $0.15 \%$ to $0.05 \%$. 


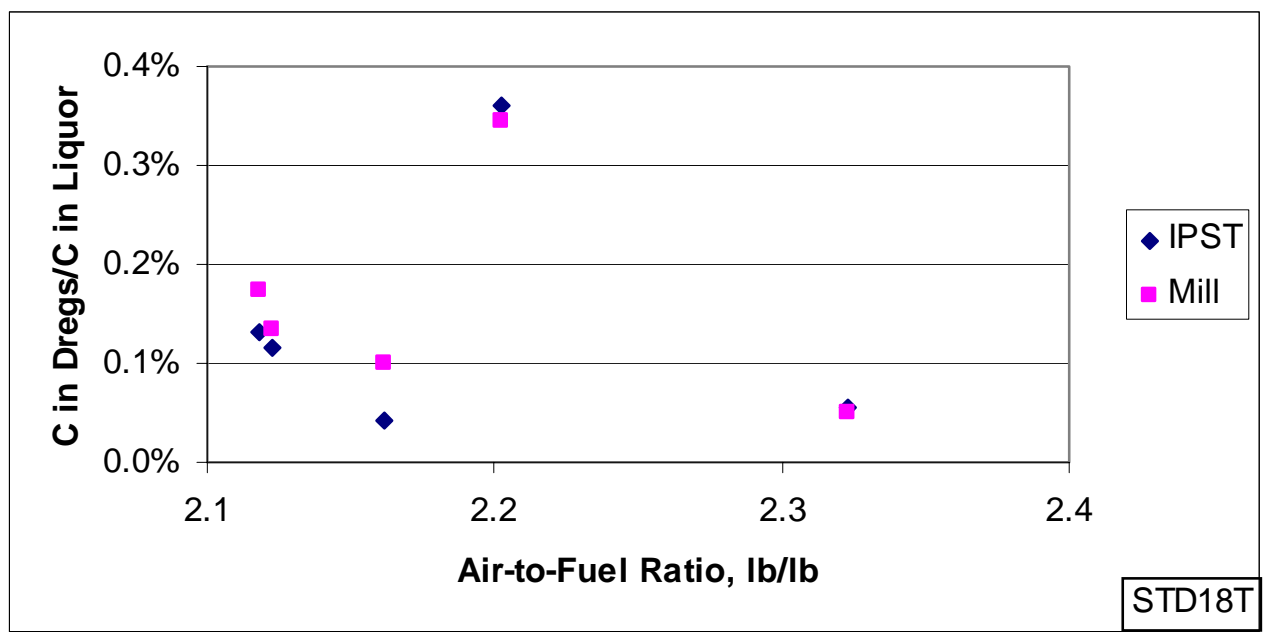

Figure 22. The fraction of incoming liquor carbon that was present as organic carbon in the dregs for the standard nozzle. The total suspended solids content is based on either the mil mill or the IPST measurements.

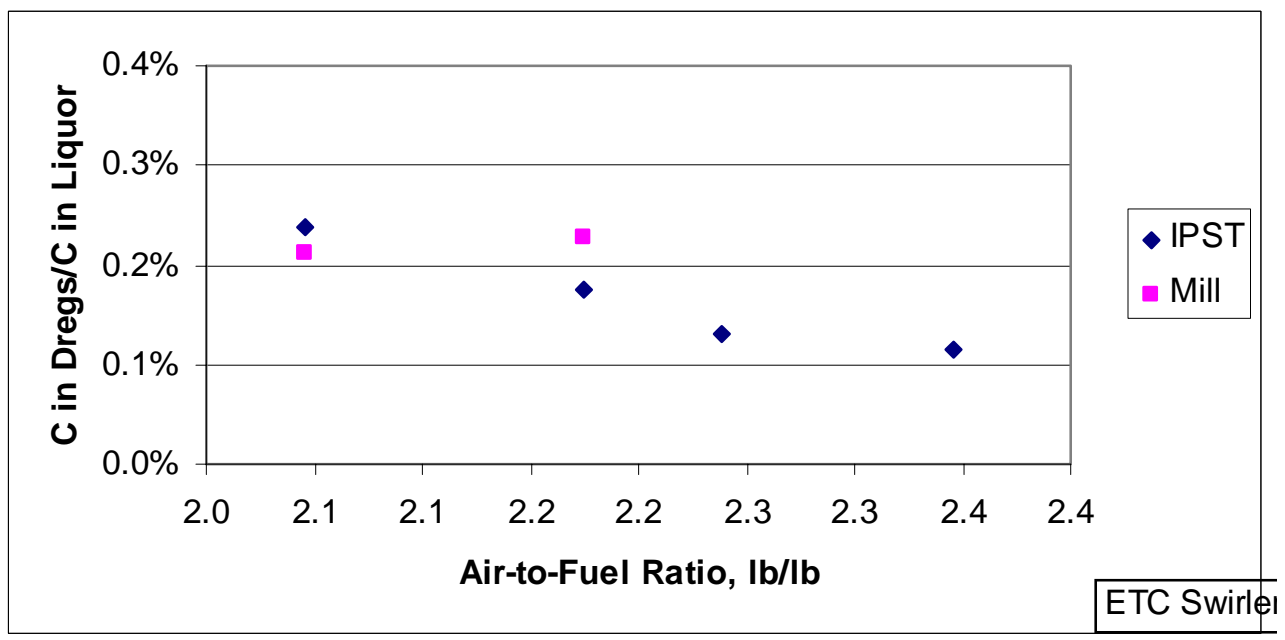

Figure 23. The fraction of incoming liquor carbon that was present as organic carbon in the dregs for the ETC swirler nozzle. The total suspended solids content is based on either the mil mill or the IPST measurements.

Comparisons of the two nozzles are shown in Figure 24 and Figure 25. Both comparisons are based on the amount of total suspended solids (dregs) measured at the IPST. With the exception of the point for the standard nozzle with the highest air-to-solid feed rate, all measurements were made at approximately the same black liquor feed rates $(557,000 \mathrm{lb}$ $\mathrm{DS} / \mathrm{d}+/-23,000 \mathrm{lb} \mathrm{DS} / \mathrm{d})$. The steam rates were lower for the ETC swirler than for the standard nozzle $(3,500 \mathrm{lb} / \mathrm{h}$ vs. 5,400 lb/h). The data for the standard nozzle at an air-tofuel ratio of 2.2, which is circled in the figures, is ignored in the analysis. However, it should be borne in mind that this omission may not be justified.

Figure 24 shows the total suspended solids in g/l and Figure 25 the fraction of liquor carbon that remained unburnt (as organic carbon) in the green liquor. At any given air-tosolids feed ratio, the total suspended solids were slightly lower for the standard nozzle 
than for the ETC swirler nozzle. The fraction of unburnt carbon was clearly lower for the standard nozzle than for the ETC swirler nozzle. However, the steam flow was lower for the ETC swirler nozzle than for the standard nozzle, and it is not possible to claim which nozzle showed better performance. Both can be deemed to have adequate performance. It should be emphasized that the one poor performance point for the standard nozzle is ignored in the analysis. If that is taken into account, the new ETC swirler nozzle gives more solid performance.

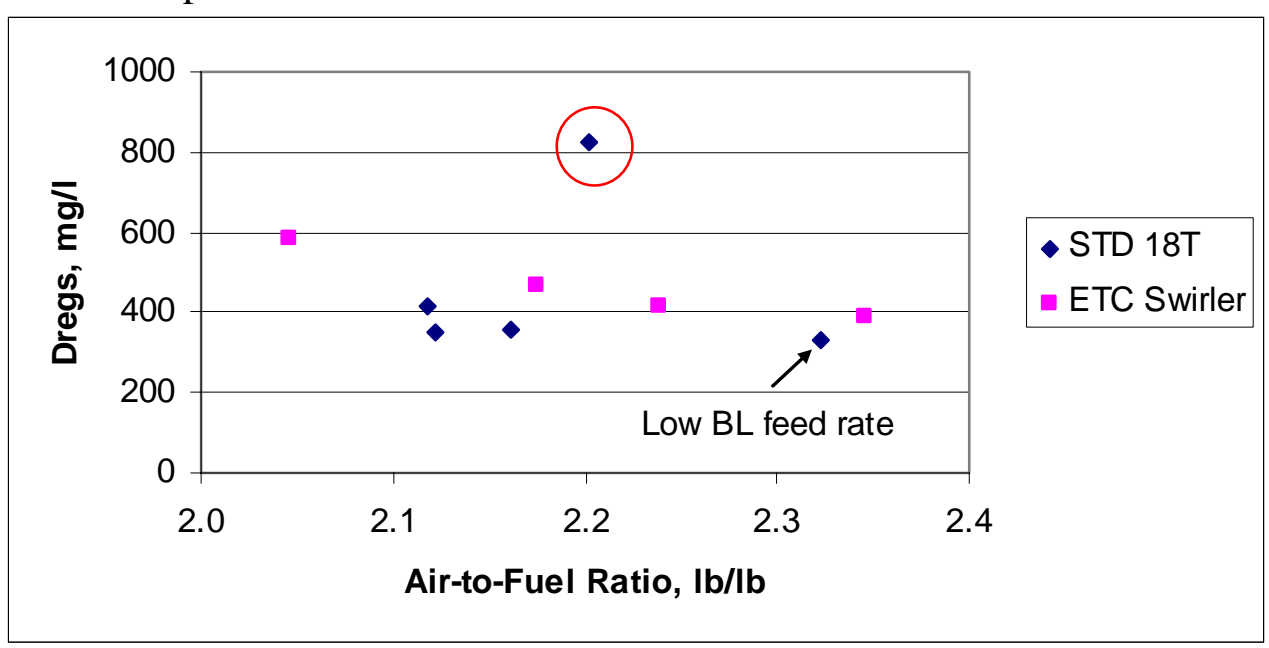

Figure 24. The total amount of suspended solids in green liquor for the standard STD 18T and the new Etc swirler nozzle. The comparison is based on the totals suspended solids measured at the IPST.

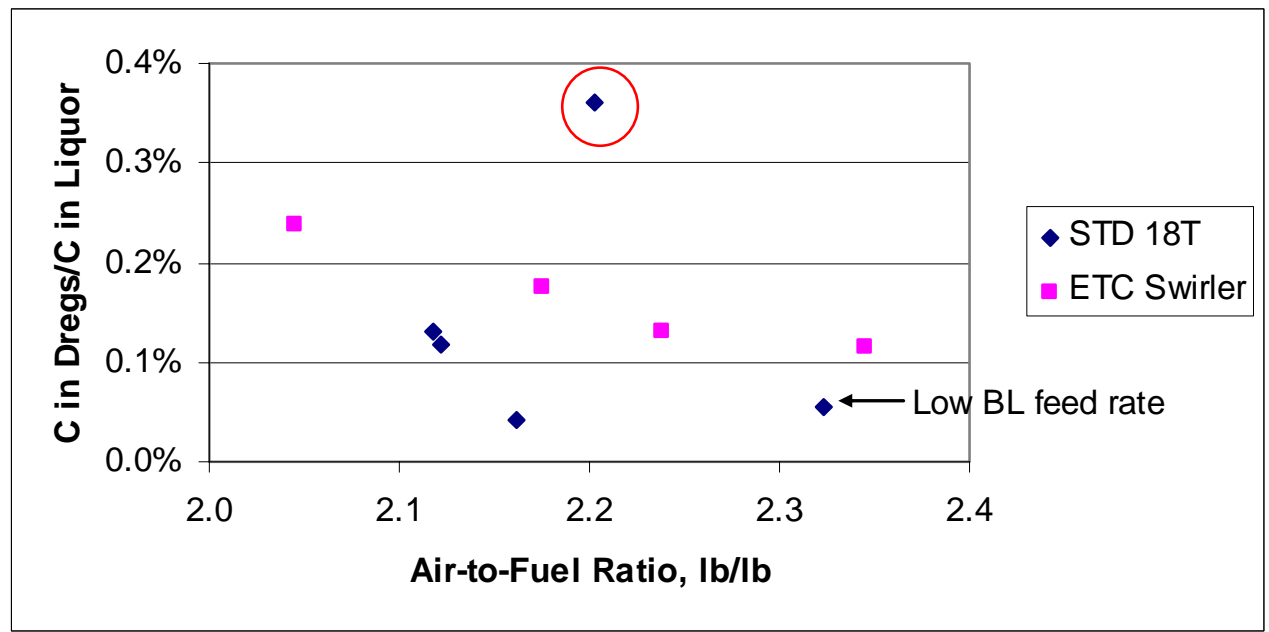

Figure 25. The fraction of liquor carbon exiting as organic carbon (unburnt carbon) with the green liquor. The comparison is based on the totals suspended solids measured at the IPST. 
Appendix \#3

PSL Report on Task 1 


\title{
ATTACHMENT \#1 \\ PSL Task 1 Report
}

Further Development of Black Liquor Gasification Model

\author{
Sub-Program of DOE Project \\ Advancement of High Temperature Black Liquor Gasification \\ Technology
}

DOE Agreement No.: DE-FC26-04NT42259

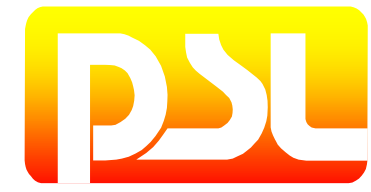

Process Simulations Ltd.

\#206, 2386 East Mall

Vancouver, BC, Canada V6T $1 Z 3$

April, 2006 


\section{CONTENT}

1 Introduction

2 Task description

3 Work done

3.1 Development of black liquor pyrolysis model

3.2 Development of black liquor char gasification/combustion model

3.3 Gas reaction scheme in black liquor gasification modeling

3.4 Water-gas shift reaction in black liquor gasification modeling

3.5 Correlation between model prediction and green liquor quality

3.6 Coupling the gasification model with the CFD code

3.7 Determination of black liquor composition

3.8 References 


\section{INTRODUCTION}

This document reports to Weyerhaeuser Company the work done in Task 1 of the DOE project "Advancement of High Temperature Black Liquor Gasification Technology".

\section{TASK DESCRIPTION}

In the subcontract, Task 1 was proposed as follows.

Task 1: Further development of black liquor gasification model

1-1 Work with the Institute of Paper Science and Technology (IPST) to upgrade our black liquor gasification model based on theirs and other researchers' experimental data for high temperature black liquor gasification, which include swelling characteristics, pyrolysis rate, and kinetics of char gasification;

1-2 Include into the existing CFD code the water shift reaction and hydrocarbon breakdown reactions;

1-3 Correlate gasification model and predictions with green liquor quality;

1-4 Couple the gasification model with PSL's CFD code

\section{WORK DONE}

\subsection{Development of black liquor pyrolysis model}

A new two-reaction pyrolysis model has been developed to describe the evolution process of combustibles when black liquor is heated. In this model, the black liquor undergoes two reactions, which convert the raw black liquor to volatile matter and char. The two reactions are expressed as follows.

Reaction 1

$$
\text { RawBL }=y_{1}(\text { Volatile })+\left(1-y_{1}\right)(\text { Char })
$$

Reaction 2 


$$
\text { RawBL }=y_{2}(\text { Volatile })+\left(1-y_{2}\right)(\text { Char })
$$

Both of the two reactions are temperature dependent; the reaction rates are expressed in Arrhenius format as follows.

$$
\begin{aligned}
& r_{1}=A_{1} \operatorname{Exp}\left(-\frac{E_{1}}{R T_{p}}\right) \\
& r_{2}=A_{2} \operatorname{Exp}\left(-\frac{E_{2}}{R T_{p}}\right)
\end{aligned}
$$

where $\mathrm{R}$ is gas constant; $\mathrm{Tp}$ is liquor droplet temperature.

From the above-defined two-reaction pyrolysis model, the volatile release rate and the liquor mass loss rate can be calculated in the following way.

Volatile releasing rate:

$\frac{d m_{V M}}{d t}=\left[y_{1} A_{1} \operatorname{Exp}\left(-\frac{E_{1}}{R T_{p}}\right)+y_{2} A_{2} \operatorname{Exp}\left(-\frac{E_{2}}{R T_{p}}\right)\right] m_{\text {raw }}$

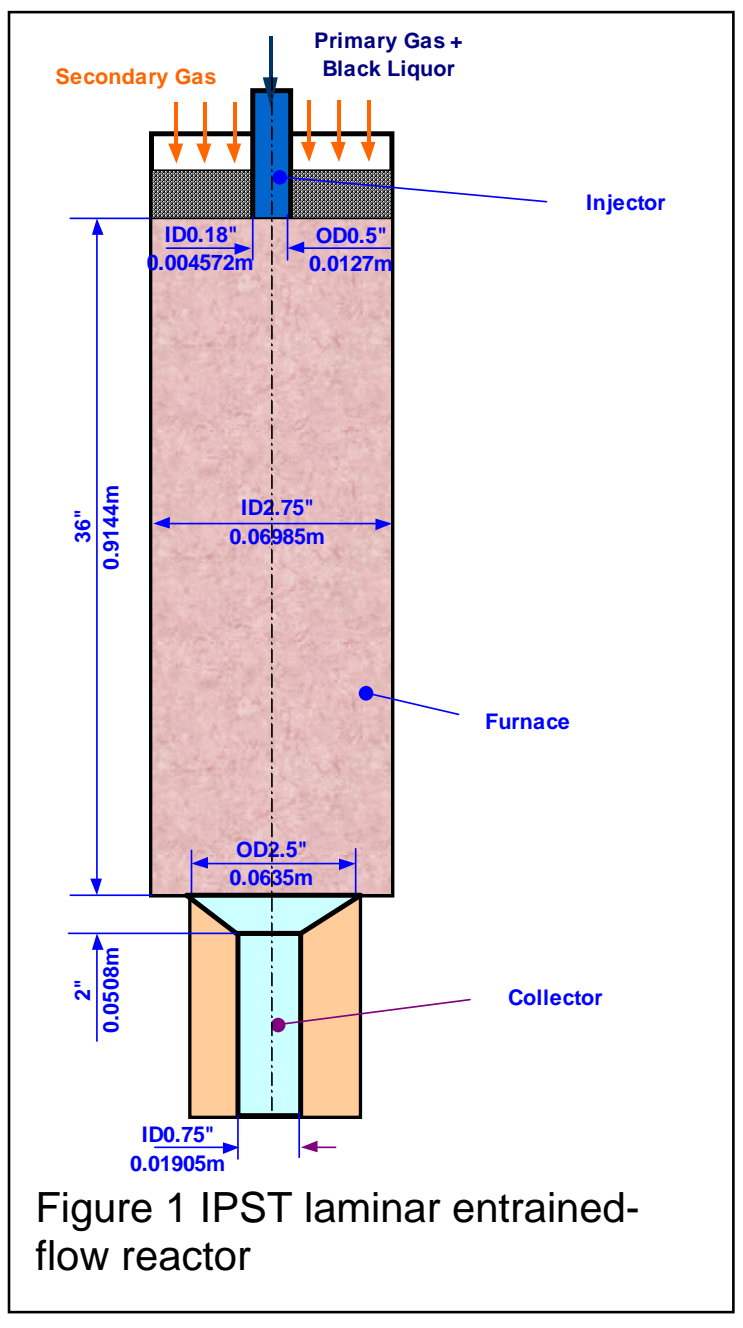

Char yield rate:

$$
\frac{d m_{\text {Char }}}{d t}=\left[\left(1-y_{1}\right) A_{1} \operatorname{Exp}\left(-\frac{E_{1}}{R T_{p}}\right)+\left(1-y_{2}\right) A_{2} \operatorname{Exp}\left(-\frac{E_{2}}{R T_{p}}\right)\right] m_{\text {raw }}
$$

Here, $m_{\text {raw }}$ is unreacted liquor:

$$
\frac{d m_{\text {raw }}}{d t}=\left[A_{1} \operatorname{Exp}\left(-\frac{E_{1}}{R T_{p}}\right)+A_{2} \operatorname{Exp}\left(-\frac{E_{2}}{R T_{p}}\right)\right] m_{\text {raw }}
$$

The coefficients in the reaction rate expression are determined by experimental data of black liquor pyrolysis. The Institute of Paper Science and Technology (IPST) of Georgia Institute of Technology has provided the required experimental data. The pyrolysis experiments were performed in the IPST laminar entrained-flow reactor, which is schematically shown in Figure 1. The dry grounded black liquor particles are fed into the reactor from the top. Helium is 
used as carrier gas, and the reactor is electrically heated to the required temperature. A sampling probe is inserted from the bottom to take the particle samples at different locations. Figure 2 shows the measured char yield (equivalent to weight loss) at different reactor temperatures.

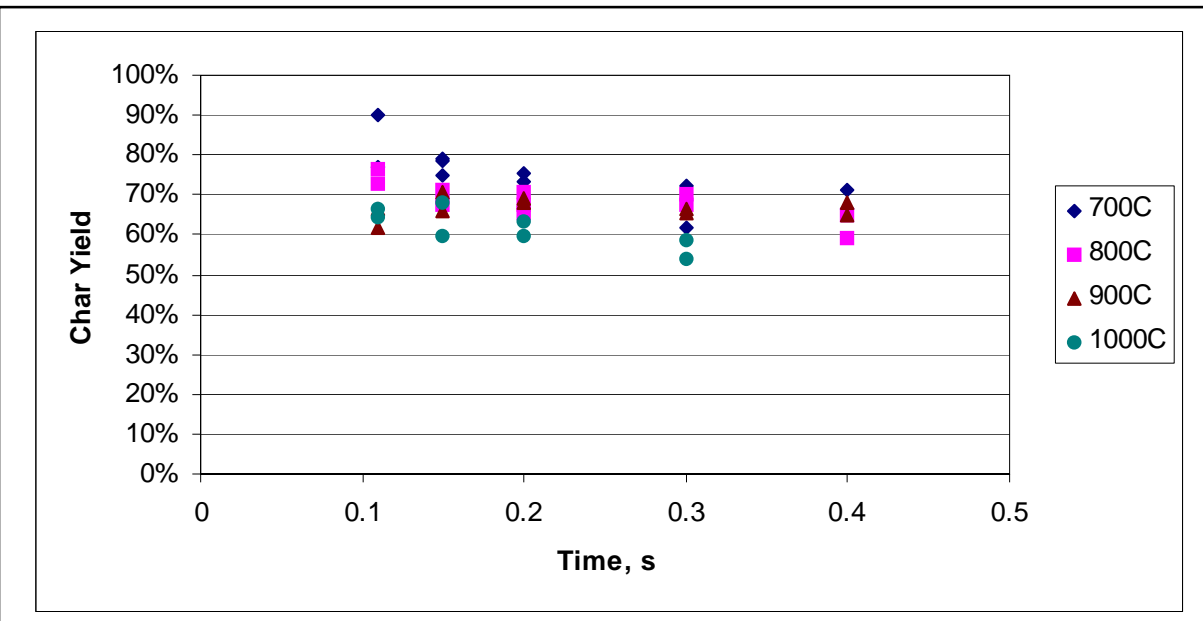

Figure 2 Measured char yield in IPST reactor

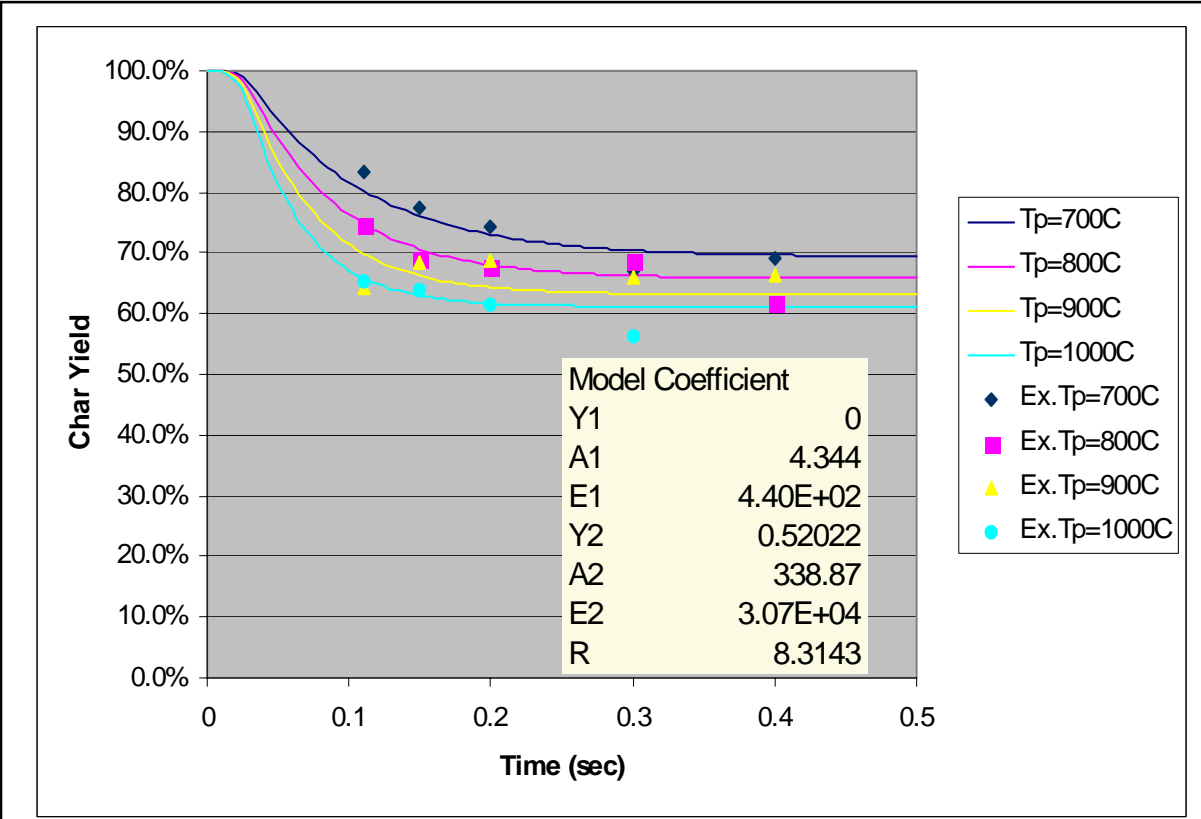

Figure 3 Comparison of model predictions and measurements

PSL has built a CFD model of the IPST reactor to determine the model coefficients and to validate the developed pyrolysis model. The so-determined model coefficients are listed in Table 1. The predicted weight loss in the reactor 
is shown in Figure 3 in comparison with the measurements. As seen, the model prediction fits the measurements reasonably well.

Table 1 Rate coefficients of two-reaction pyrolysis model of black liquor

\begin{tabular}{|l|c|c|}
\hline Coefficients & Reaction 1 & Reaction 2 \\
\hline$Y[-]$ & 0 & 0.52 \\
\hline$A[1 / \mathrm{s}]$ & 4.344 & 338.87 \\
\hline$E[\mathrm{~J} / \mathrm{mol}]$ & 440 & 30700 \\
\hline
\end{tabular}

\subsection{Development of black liquor char gasification/combustion model}

The new black liquor char gasification/combustion model has included the following three types of reactions:

Oxidation:

$$
\mathrm{C}+\mathrm{O}_{2}=\mathrm{CO}_{2}
$$

Gasification:

$$
\begin{aligned}
& \mathrm{C}+\mathrm{CO}_{2}=2 \mathrm{CO} \\
& \mathrm{C}+\mathrm{H}_{2} \mathrm{O}=\mathrm{H}_{2}+\mathrm{CO}
\end{aligned}
$$

Sulfate/carbonate reduction:

$$
\begin{aligned}
& \mathrm{Na}_{2} \mathrm{SO}_{4}+2 \mathrm{C}=\mathrm{Na}_{2} \mathrm{~S}+2 \mathrm{CO}_{2} \\
& \mathrm{Na}_{2} \mathrm{CO}_{3}+2 \mathrm{C}=2 \mathrm{Na}+3 \mathrm{CO}
\end{aligned}
$$

Both film diffusion and chemical kinetic rate control these reactions. The film diffusion rate of a reacting species is calculated from the following formula.

$$
R_{m, i}=k_{g, i} A_{p} C_{i}
$$

Here, $k_{g, i}$ : the film mass transfer coefficient of species $i,[\mathrm{~m} / \mathrm{s}]$;

$$
k_{g, i}=S h_{i} \vartheta_{i} / D_{p}
$$

$S h_{i}$ : Sherwood number,[-];

$\theta i$ : diffusivity of species I, [ $\left.\mathrm{m}^{2} / \mathrm{s}\right]$;

$D_{p}$ : Particle diameter, [m];

$A_{p}$ : particle surface area, $\left[\mathrm{m}^{2}\right]$; and

$C_{i}$ : concentration of species $i$ in bulk gas, $\left[\mathrm{mol} / \mathrm{m}^{3}\right]$ 
IPST has provided the chemical kinetic rates of gasification and reduction reactions from their investigations.

$\mathrm{CO}_{2}$ gasification:

$$
k_{\mathrm{CO}_{2}}=3.1 \times 10^{16} \operatorname{Exp}\left(-\frac{48650}{T_{p}}\right)
$$

$\mathrm{H}_{2} \mathrm{O}$ gasification:

$$
k_{\mathrm{H}_{2} \mathrm{O}}=2.6 \times 10^{10} \operatorname{Exp}\left(-\frac{28000}{T_{p}}\right)\left[\mathrm{H}_{2} \mathrm{O}\right]^{0.3}
$$

Sulfate/carbonate reduction:

$$
k_{\text {red }}=8.532 \times 10^{3} \operatorname{Exp}\left(-\frac{11454}{T_{p}}\right) \quad[1 / \mathrm{s}]
$$

The overall reaction rate of char is then expressed as

$$
-r_{c}=-\frac{d[C]}{d t}=\left(k_{r e d}+k_{\mathrm{CO}_{2}}+k_{\mathrm{H}_{2} \mathrm{O}}\right)[C]
$$

Here, [C]: mass of fixed carbon in char normalized by initial mass of fixed carbon, $[-]$;

[ $\left.\mathrm{H}_{2} \mathrm{O}\right]$ : mass fraction of $\mathrm{H}_{2} \mathrm{O}$ in bulk gas, [-].

Char gasification/combustion normally starts after the liquor devolatilization process finishes. However, char gasification/combustion could overlap with liquor devolatilization when the liquor heating rate is not high enough or when liquor droplets are large. The newly developed black liquor gasification model has accounted for this possible overlap.

\subsection{Gas reaction scheme in black liquor gasification modeling}

W.P. Jones et al [1] have developed a four-step global reaction scheme for the combustion of hydrocarbon. This global reaction scheme includes the following four reactions: 
$\mathrm{C}_{n} \mathrm{H}_{2 n+2}+\frac{n}{2} \mathrm{O}_{2} \rightarrow \mathrm{nCO}+(n+1) \mathrm{H}_{2}$

$\mathrm{C}_{n} \mathrm{H}_{2 n+2}+n \mathrm{H}_{2} \mathrm{O} \rightarrow \mathrm{nCO}+(2 n+1) \mathrm{H}_{2}$

$\mathrm{H}_{2}+\frac{1}{2} \mathrm{O}_{2} \Leftrightarrow \mathrm{H}_{2} \mathrm{O}$

$\mathrm{CO}+\mathrm{H}_{2} \mathrm{O} \Leftrightarrow \mathrm{CO}_{2}+\mathrm{H}_{2}$

Several researchers in the chemical recovery area suggested using this reaction scheme in the black liquor gasification modeling. Using the reaction kinetics determined by W.P. Jones et al, we tested this reaction scheme in the black liquor gasification modeling. As listed in Table 2, the predicted product gas does not contain any hydrocarbon; however, the analysis of the sampled product gas in the New Bern gasifier shows a certain concentration of hydrocarbon.

Table 2 Comparison of two reaction schemes

\begin{tabular}{|c|c|c|c|}
\hline Species (dry, vol\%) & $\begin{array}{l}\text { Without fuel } \\
\text { breakdown }\end{array}$ & $\begin{array}{l}\text { With fuel } \\
\text { breakdown }\end{array}$ & $\begin{array}{l}\text { Typical in } \\
\text { measurements }\end{array}$ \\
\hline $\mathrm{CH}_{4}$ & $0.94 \%$ & $0 \%$ & $0.5 \%$ \\
\hline $\mathrm{CO}$ & $6.68 \%$ & $6.19 \%$ & $6.5 \%$ \\
\hline $\mathrm{H}_{2}$ & $13.05 \%$ & $17.43 \%$ & $11 \%$ \\
\hline $\mathrm{HHV}\left(\mathrm{kJ} / \mathrm{Nm}^{3}\right.$ Dry) & 2576 & 2649 & $2423-3169$ \\
\hline
\end{tabular}

Instead of using this four-step reaction, we have used a reaction scheme with the following four reactions:

$\mathrm{C}_{m} \mathrm{H}_{n}+\left(m+\frac{n}{4}\right) \mathrm{O}_{2} \rightarrow m \mathrm{CO}_{2}+\frac{n}{2} \mathrm{H}_{2} \mathrm{O}$

$\mathrm{CO}+\frac{1}{2} \mathrm{O}_{2} \rightarrow \mathrm{CO}_{2}$

$\mathrm{H}_{2}+\frac{1}{2} \mathrm{O}_{2} \rightarrow \mathrm{H}_{2} \mathrm{O}$

$\mathrm{CO}+\mathrm{H}_{2} \mathrm{O} \Leftrightarrow \mathrm{CO}_{2}+\mathrm{H}_{2}$ 
The first three reactions are controlled by turbulent diffusion, and the water-gas shift reaction is controlled by both turbulent diffusion and chemical kinetics discussed in the coming section. As seen in Table 2, hydrocarbon is predicted in the product gas by using this reaction scheme (water-gas shift reaction was not included in the case listed in Table 2).

\subsection{Water-gas shift reaction in black liquor gasification modeling}

The water-gas shift reaction

$$
\mathrm{CO}+\mathrm{H}_{2} \mathrm{O} \Leftrightarrow \mathrm{H}_{2}+\mathrm{CO}_{2}
$$

is known as being important in the black liquor gasification process. This reaction could have a significant impact on the composition of the product gas and therefore the heating value of the product gas.

Table 3 Impact of water-gas shift reaction on product gas composition

\begin{tabular}{|c|l|l|}
\hline & With WGS reaction & Without WGS reaction \\
\hline $\begin{array}{l}\text { Product gas composition } \\
\text { (vol, wet\%) }\end{array}$ & 9.29 & 8.27 \\
\hline $\mathrm{CO}$ & 0.72 & 0.69 \\
\hline $\mathrm{C}_{\mathrm{m}} \mathrm{H}_{\mathrm{n}}$ & 11.25 & 9.94 \\
\hline $\mathrm{H}_{2}$ & 28.4 & 29.68 \\
\hline $\mathrm{H}_{2} \mathrm{O}$ & 9.51 & 10.6 \\
\hline $\mathrm{CO}_{2}$ & 40.83 & 40.82 \\
\hline $\mathrm{N}_{2}$ & 3680.7 & 3347.3 \\
\hline $\mathrm{HHV}$ of product gas (kJ/Nm ${ }^{3}$ Dry) & 955 & 1050 \\
\hline $\begin{array}{l}\text { Product gas temperature at reactor } \\
\text { exit }\left({ }^{\circ} \mathrm{C}\right)\end{array}$ & 955 & \\
\hline
\end{tabular}

The chemical kinetics of the forward and the backward reactions are adopted from F. Bustamante et al $[2,3]$ and are listed as follows. 
Forward reaction rate:

$$
\begin{gathered}
r_{f}=k_{f} \operatorname{Exp}\left(-\frac{E_{f}}{R T}\right)[\mathrm{CO}]^{0.5}\left[\mathrm{H}_{2} \mathrm{O}\right] \quad\left(\text { mole } / \mathrm{cm}^{3} / \mathrm{s}\right) \\
\text { Here }, k_{f}=7.68 \times 10^{13} \quad\left(\mathrm{~cm}^{3} / \mathrm{mole}\right)^{0.5} \mathrm{~s}^{-1} \\
E_{f}=304.6 \quad(\mathrm{~kJ} / \text { mole }) \\
T=\text { Gas Temperature } \quad(\mathrm{K}) \\
{[\mathrm{CO}]=\text { CO Concentration }\left(\text { mole } / \mathrm{cm}^{3}\right)} \\
{\left[\mathrm{H}_{2} \mathrm{O}\right]=\mathrm{H}_{2} \mathrm{O} \text { Concentration } \quad\left(\text { mole } / \mathrm{cm}^{3}\right)}
\end{gathered}
$$

Backward reaction rate:

$$
\begin{gathered}
r_{r}=k_{r} \operatorname{Exp}\left(-\frac{E_{r}}{R T}\right)\left[\mathrm{CO}_{2}\right]\left[\mathrm{H}_{2}\right]^{0.5} \quad\left(\text { mole } / \mathrm{m}^{3} / \mathrm{s}\right) \\
\text { Here }, k_{r}=3.52 \times 10^{11} \quad\left(\mathrm{~m}^{3} / \text { mole }\right)^{0.5} \mathrm{~s}^{-1} \\
E_{r}=3.27 \times 10^{5} \quad(\mathrm{~J} / \text { mole }) \\
T=\text { Gas Temperature } \quad(\mathrm{K}) \\
{\left[\mathrm{CO}_{2}\right]=\mathrm{CO}_{2} \text { Concentration } \quad\left(\text { mole } / \mathrm{m}^{3}\right)} \\
{\left[\mathrm{H}_{2}\right]=\mathrm{H}_{2} \text { Concentration } \quad\left(\text { mole } / \mathrm{m}^{3}\right)}
\end{gathered}
$$

The impact of water-gas shift reaction on the product gas composition and also the product gas temperature was evaluated by switching on and off this reaction in the gasifier modeling. Table 2 lists the predicted values with and without this reaction. It can be seen that the absence of the water-gas shift reaction results in a higher product gas temperature and a lower product gas heating value.

\subsection{Correlation between model prediction and green liquor quality}

The quality of green liquor is one of the criteria in the evaluations of the gasifier performance. The amount of dregs in queen liquor is the index of quality. Analysis of the dregs reveals that the major content in the dregs is unburned carbon. The developed gasification model will be able to predict the amount of unburned materials in the smelt. According to the description of the model, the carbon conversion rate is controlled by several factors: residence time of the liquor droplets in the reactor, mixing of liquor droplets and gases, and 
temperature. All these factors are dependent on the liquor spray and the aerodynamics in the gasifier. PSL has simulated several cases selected from the test matrix and compared the modeling predictions of unburned carbon with the measured TSS. Details of comparison are given in Task 3 Report.

\subsection{Coupling the gasification model with the CFD code}

After the gasification model was developed, PSL has made huge efforts to couple the model with the CFD code. Firstly the new pyrolysis model was built into the CFD code and validated by modeling the IPST'S LEFR and comparing computed results with measurements. Then the char gasification model was introduced. The upgraded CFD code was tested and validated by switching on and off each char gasification reaction and analyzing the modeling results. In addition to the gasification model, the swelling process and density change during the gasification process was also upgraded in the CFD code. Finally the different gas combustion schemes were tested and the water-gas shift reaction was added into the code. The contribution of the water-gas shift reaction was tested as previously discussed. Further efforts have also been made to improve the convergence of the modeling.

\subsection{Determination of black liquor composition}

Table 4 is a typical TAPPI analysis of black liquor properties, which gives the element contents as well as the contents of a few major components. These data cannot be directly used as the input to the gasification modeling. The detailed black liquor composition is required, which gives the amount and composition of volatile, the amount of fixed carbon, and the amount and composition of smelt. PSL has developed a methodology to determine the black liquor composition.

At first, we assume that sulfur appears as three compounds in the liquor: $\mathrm{Na}_{2} \mathrm{SO}_{4}, \mathrm{Na}_{2} \mathrm{~S}$, and $\mathrm{H}_{2} \mathrm{~S}$. From total sulfur, sulfate and sulfide in the TAPPI analysis, we can calculate the content of $\mathrm{H}_{2} \mathrm{~S}$. 
We also assume that chlorine appears as $\mathrm{NaCl}$, potassium as $\mathrm{K}_{2} \mathrm{CO}_{3}$, and hydroxide as $\mathrm{NaOH}$ only. From the TAPPI analysis, we can determine the contents of $\mathrm{NaCl}, \mathrm{NaOH}, \mathrm{K}_{2} \mathrm{CO}_{3}$, and $\mathrm{Na}_{2} \mathrm{CO}_{3}$. At this point, the composition of inorganic in the smelt is determined.

Then, we need to assume a ratio of the remaining carbon split between fixed carbon and volatile. From this ratio, we can calculate the content of fixed carbon. The remaining carbon, together with the remaining hydrogen, sulfur, nitrogen, and oxygen, forms volatile.

To determine the composition of volatile, we further assume that nitrogen forms $\mathrm{NH}_{3}$ only. Oxygen forms $\mathrm{CO}$ or both $\mathrm{CO}$ and $\mathrm{CO}_{2}$ based on the moles of remaining carbon and oxygen. Once $\mathrm{CO}$ and/or $\mathrm{CO}_{2}$ are determined, any remaining carbon will form $\mathrm{C}_{m} \mathrm{H}_{n}$. Then the remaining hydrogen will form $\mathrm{H}_{2}$. At this point, the composition of black liquor is determined, and all elements are balanced.

Not only have all elements to be balanced; the energy has also to be balanced. TAPPI analysis gives the heating value of liquor, which is measured in a complete combustion atmosphere. If we let all components just determined above to be completely oxidized, the total heat generated has to equal the measured heating value. Based on the determined liquor composition, the following six oxidation reactions are considered in the calculation.

$$
\begin{aligned}
& \mathrm{CO}+0.5 \mathrm{O}_{2}=\mathrm{CO}_{2}+283 \mathrm{~kJ} / \mathrm{mole} \\
& \mathrm{C}_{m} \mathrm{H}_{n}+\left(\mathrm{m}+\frac{\mathrm{n}}{4}\right) \mathrm{O}_{2}=m \mathrm{CO}_{2}+\frac{n}{2} \mathrm{H}_{2} \mathrm{O}+\Delta \mathrm{H}_{\mathrm{C}_{m} \mathrm{H}_{n}} \\
& \mathrm{H}_{2}+0.5 \mathrm{O}_{2}=\mathrm{H}_{2} \mathrm{O}+242 \mathrm{~kJ} / \mathrm{mole} \\
& \mathrm{C}+\mathrm{O}_{2}=\mathrm{CO}_{2}+394 \mathrm{~kJ} / \mathrm{mole} \\
& \mathrm{Na}_{2} \mathrm{~S}+2 \mathrm{O}_{2}=\mathrm{Na}_{2} \mathrm{SO}_{4}+1022 \mathrm{~kJ} / \mathrm{mole} \\
& \mathrm{H}_{2} \mathrm{~S}+\mathrm{Na}_{2} \mathrm{CO}_{3}+2 \mathrm{O}_{2}=\mathrm{Na}_{2} \mathrm{SO}_{4}+\mathrm{H}_{2} \mathrm{O}+\mathrm{CO}_{2}+872 \mathrm{~kJ} / \mathrm{mole}
\end{aligned}
$$

Normally the heat generation from these reactions does not equal the measured heating value. We have two ways to make the energy balanced. One way is to introduce a pyrolysis heat, which is equal to the difference of the 
calculated heat generation and the measured heating value. The other way is to introduce an artificial reaction heat of $\mathrm{C}_{m} \mathrm{H}_{n}$, which is determined from the energy balance calculation. Table 5 is the calculated liquor composition and the pyrolysis heat.

\begin{tabular}{|c|c|c|}
\hline \multicolumn{3}{|c|}{ Table 4 Black liquor analysis } \\
\hline Black liquor solid & $\%$ & $72.6 \%$ \\
\hline C & $\% \mathrm{DS}$ & $35.19 \%$ \\
\hline $\mathrm{H}$ & $\%$ DS & $3.47 \%$ \\
\hline O (by difference) & $\%$ DS & $34.34 \%$ \\
\hline $\mathrm{S}$ & $\% \mathrm{DS}$ & $6.69 \%$ \\
\hline $\mathrm{N}+$ others & $\% \mathrm{DS}$ & $0.09 \%$ \\
\hline $\mathrm{Na}$ & $\% \mathrm{DS}$ & $18.77 \%$ \\
\hline K & $\% \mathrm{DS}$ & $1.28 \%$ \\
\hline $\mathrm{Cl}$ & $\% \mathrm{DS}$ & $0.17 \%$ \\
\hline Total & $\%$ DS & $100.00 \%$ \\
\hline \multirow[t]{2}{*}{ HHV } & Btu/lb & 6082 \\
\hline & $\mathrm{MJ} / \mathrm{kg}$ & 14.15 \\
\hline LHV & $\mathrm{MJ} / \mathbf{k g}$ & 13.44 \\
\hline Sulfate, $\mathrm{SO}_{4}$ & $\% D S$ & $6.19 \%$ \\
\hline Sulfide, $\mathbf{S}$ & \%DS & $3.27 \%$ \\
\hline Carbonate, $\mathrm{CO}_{3}$ & $\% D S$ & $3.48 \%$ \\
\hline Hydroxide, $\mathrm{OH}$ & \%DS & $2.58 \%$ \\
\hline
\end{tabular}

\begin{tabular}{|c|c|c|}
\hline \multicolumn{3}{|c|}{ Table 5 Black liquor composition } \\
\hline CO & $\%$ DS & $34.14 \%$ \\
\hline $\mathrm{C}_{\mathrm{m}} \mathrm{H}_{\mathrm{n}}$ & $\%$ DS & $3.95 \%$ \\
\hline $\mathrm{H}_{2}$ & $\% \mathrm{DS}$ & $2.27 \%$ \\
\hline $\mathrm{H}_{2} \mathrm{~S}$ & $\% \mathrm{DS}$ & $0.97 \%$ \\
\hline $\mathrm{CH}_{3} \mathrm{SH}$ & $\% \mathrm{DS}$ & $0.00 \%$ \\
\hline $\mathrm{NH}_{3}$ & $\% \mathrm{DS}$ & $0.11 \%$ \\
\hline Fixed C & $\% \mathrm{DS}$ & $15.61 \%$ \\
\hline $\mathrm{Na}_{2} \mathrm{~S}$ & $\% \mathrm{DS}$ & $8.64 \%$ \\
\hline $\mathrm{Na}_{2} \mathrm{SO}_{4}$ & $\% \mathrm{DS}$ & $9.92 \%$ \\
\hline $\mathrm{Na}_{2} \mathrm{CO}_{3}$ & $\%$ DS & $15.81 \%$ \\
\hline $\mathrm{K}_{2} \mathrm{CO}_{3}$ & $\%$ DS & $2.24 \%$ \\
\hline $\mathrm{NaCl}$ & $\%$ DS & $0.28 \%$ \\
\hline $\mathrm{NaOH}$ & $\%$ DS & $6.07 \%$ \\
\hline Total & $\%$ DS & $100.0 \%$ \\
\hline \multirow[t]{2}{*}{ Pyrolysis heat } & MJ/kgDS & -1.244 \\
\hline & MJ/kgVM & -3.0010 \\
\hline
\end{tabular}


It has to point out that there are some uncertainties in the determination of black liquor composition. We have introduced several assumptions, which need to be validated by further investigations. Moreover, there may exist oxidation reactions other than the six ones we have considered. These uncertainties could lead to the inaccuracy in the gasification modeling.

\subsection{References}

[1] W.P. Jones and R.P. Lindstedt, Global Reaction Schemes for Hydrocarbon Combustion, Combustion and Flame, 73, 233-249, 1988

[2] F. Bustamante et al, Kinetics of The Homogeneous Reverse Water-Gas Shift Reaction at High Temperature, AIChE Journal, 50 (5), 1028-1041, 2004

[3] Private communication with F. Bustamante on kinetics of the forward watergas shift reaction, 2005 
Appendix \#4

Simulent Report on Comparison with ETC 80cp Syrup Test 


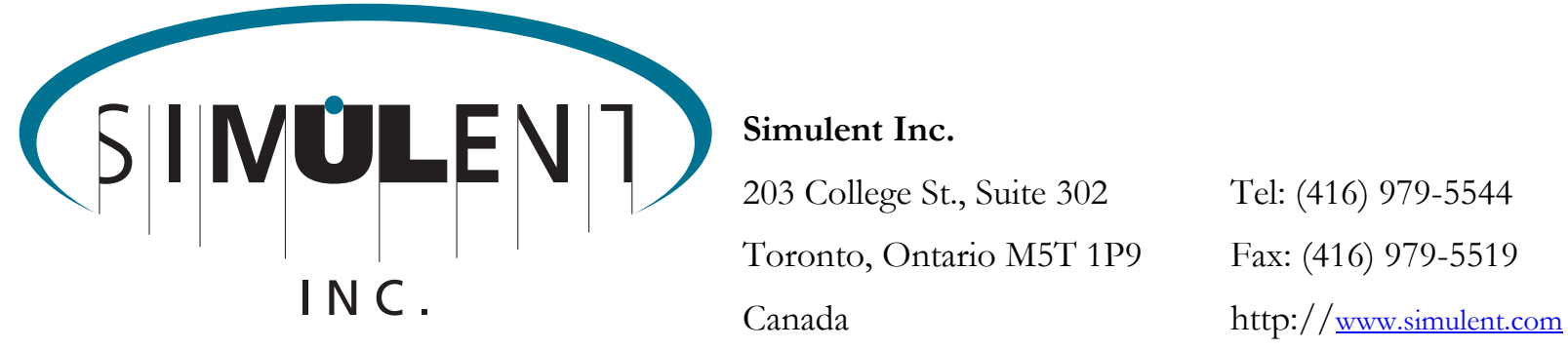

Optimization of Black Liquor Nozzle Design

\author{
Subprogram of DOE Project: \\ Advancement of High Temperature Black Liquor \\ Gasification Technology
}

DOE Agreement No.: DE-FC26-04NT42259

80cP Corn Syrup Experiment (ETC)

Simulent Inc.

203 College St., Suite 302

Toronto, Ontario, M5T 1P9 


\section{INTRODUCTION}

In an earlier report, Simulent's comparison with the Energy Technology Centre (ETC) experimental results with water and air were presented. In February 2006 — during a DOE project review meeting - it was decided that Simulent runs an extra set of simulations to compare ETC's experiment with corn syrup. The following is the report of Simulent's results for the latter along with comparison with ETC's data.

\section{NUMERICAL SIMULATION}

The numerical procedure for modeling the atomization has been described in detail in previous reports. In summary, to simulate the spraying process, the following steps are carried out:

- The flow inside the nozzle is modeled and the initial breakups are simulated ( $2 \mathbf{D}$ model inside the nozzle),

- Using a statistical model, the initial droplet size is calculated at the nozzle exit(atomization model),

- Using the above initial droplet size and a 3D algorithm, spray is modeled outside the nozzle (3D model outside the nozzle).

\section{COMPARISON WITH ETC}

The main purpose of this study was to validate Simulent's numerical model with experimental results. As the ETC data were collected along two perpendicular $\mathbf{r} 1$ and $\mathbf{r} 2$ axis; in this report, droplet size and velocity distributions from the simulation results are compared along the same axis.

Results show that both simulation and experiment provide the same overall droplet size. This is the case where data is averaged over all the available experimental and/or numerical points. Results also show that numerical simulation can quite accurately capture the spray characteristics and that numerical result can predict the same asymmetries observed during the experiment. These asymmetries are the result of nonuniform circumferential water flow rate, and the existence of the spray tilt. However, local averages differ between simulation and experiment. The largest difference occurs near the centre and this value diminishes as we get further from the nozzle axis (Figure $1 \&$ Figure 2). This difference can be explained if we study the velocity distribution graphs (Figure 3 \& Figure 4) where the measured velocity is much higher that the calculated velocity. 
In the numerical 3D model droplet initial velocities are input values based on a mean velocity obtained from the $2 \mathrm{D}$ simulation and this velocity is lower than the maximum air velocity at the core of the orifice. As breakups are a direct result of shear stresses at the gas-liquid interface, relative velocities play an important role in dictating the secondary atomization mechanism. Hence, smaller drop sizes are found at the core during the experiment. 


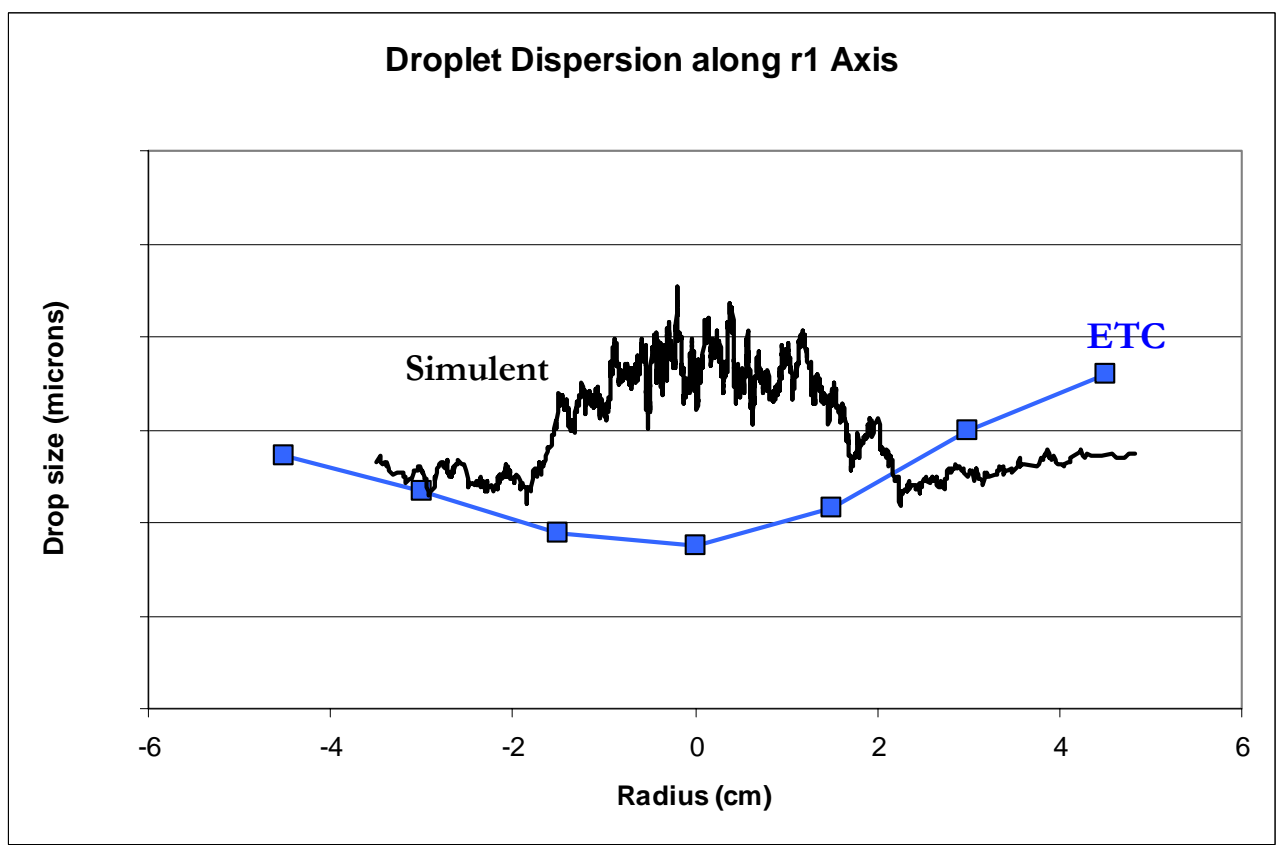

Figure 1. Comparison of droplet dispersion along $\mathbf{r} 1$ between Simulent and ETC results for Test Set 3

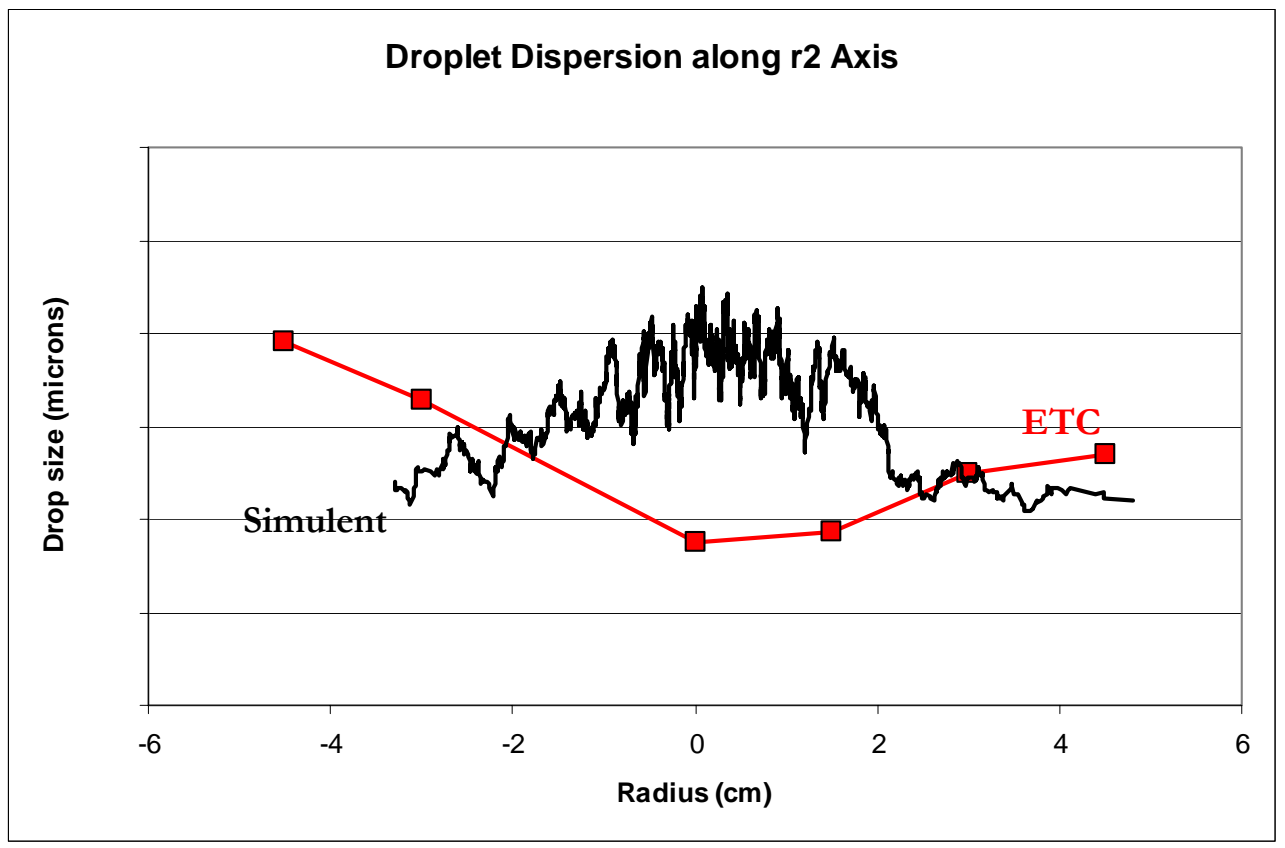

Figure 2. Comparison of droplet dispersion along $\mathbf{r} \mathbf{2}$ between Simulent and ETC results for Test Set 3 


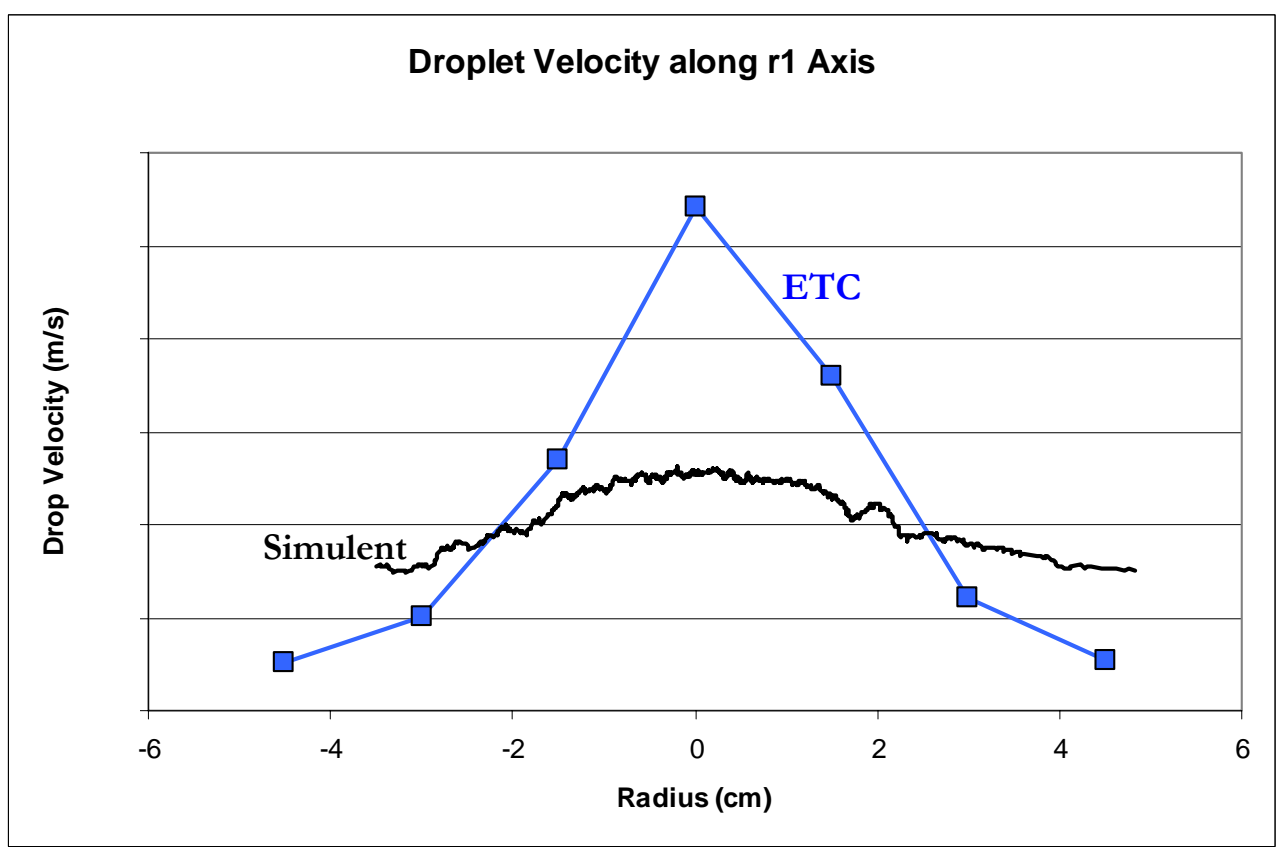

Figure 3. Comparison of droplet Velocities along $\mathbf{r} 1$ between Simulent and ETC results for Test Set 3

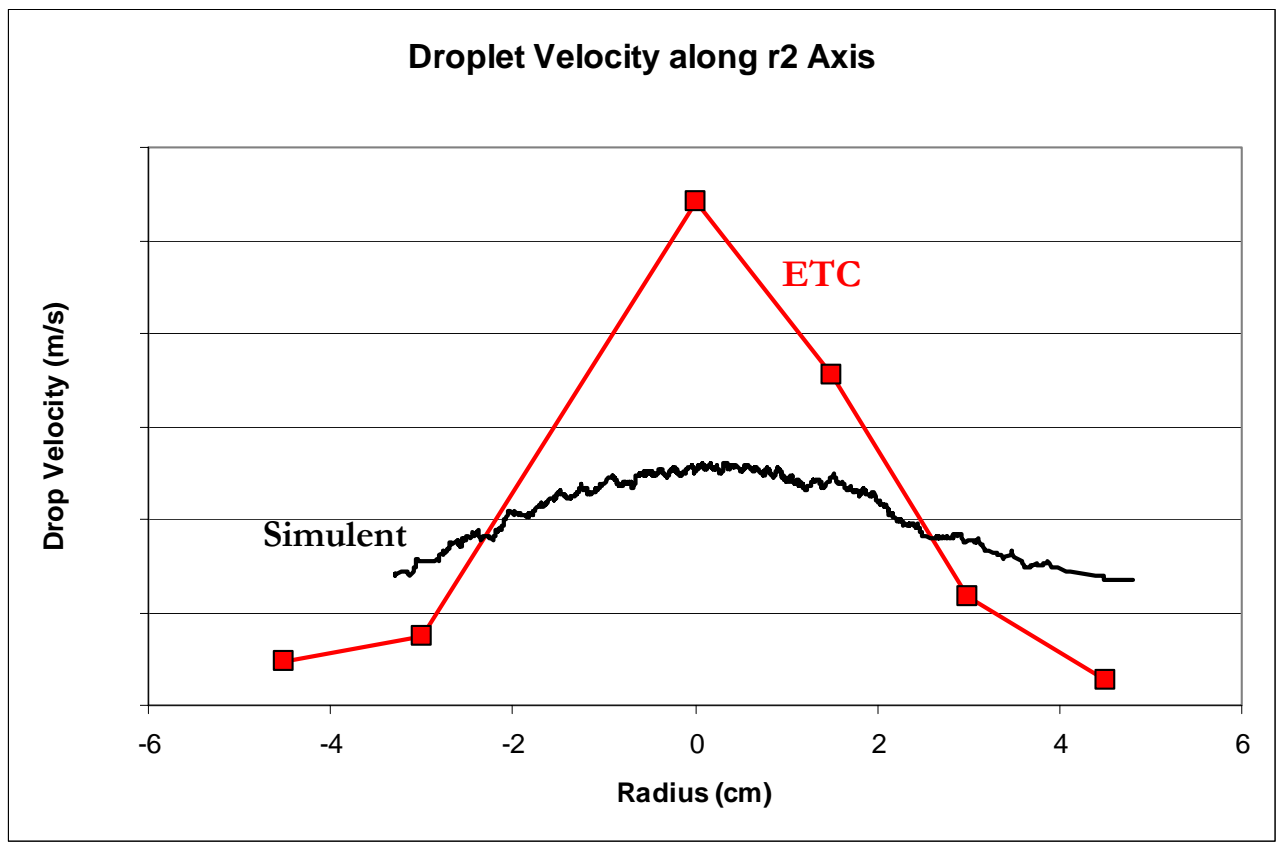

Figure 4. Comparison of droplet Velocities along $\mathbf{r} 2$ between Simulent and ETC results for Test Set 3 


\section{COMPARISON WITH ACTUAL BL CONDITIONS}

ETC's main purpose for using corn syrup was to simulate the Black Liquor atomization. Corn syrup was used as the latter is a very "messy" substance to use for laboratory experiments and is opaque so LASER cannot be used as a measuring device. However, during the experiments corn syrup's viscosity was set to $80 \mathrm{cP}$ which is much lower than $200 \mathrm{cP}$ which is the actual viscosity of Black Liquor used at New Bern.

At Simulent Inc. we have performed two sets of simulations for the flow outside the nozzle. The first one corresponds exactly to the conditions of Test Set 3 (corn syrup; 80cP) and the other simulates corn syrup with $200 \mathrm{cP}$ viscosity. The latter case duplicates the actual conditions used at the Weyerhaeuser plant in New Bern.

Figure 5 and Figure 6 compare Sauter Mean Diameters (SMD) along r1 and r2 axis and Figure 7 and Figure 8 compare the mean axial velocities along the same axis for two different corn syrup viscosities $(80 \mathrm{cP}$ and $200 \mathrm{cP})$.

Comparing results show that droplet size increases dramatically as the viscosity of the liquid is increased. For the present case, the average drop size increases by a factor of about 2.3 times. Moreover, local droplet distributions are different. The nozzle produces a more uniform size distribution when the liquid viscosity is lower and as a result the nozzle behavior can be more predictable.

Comparing mean axial droplet velocities (Figure 7 and Figure 8) show that increasing the viscosity dampens the velocities and as a result the velocity profile for the higher viscosity case is closer to a flat line.

Finally, comparing these to cases proves that a new set of experiment with the actual nozzle condition is needed to ensure that secondary breakups occur as predicted in the numerical model. 


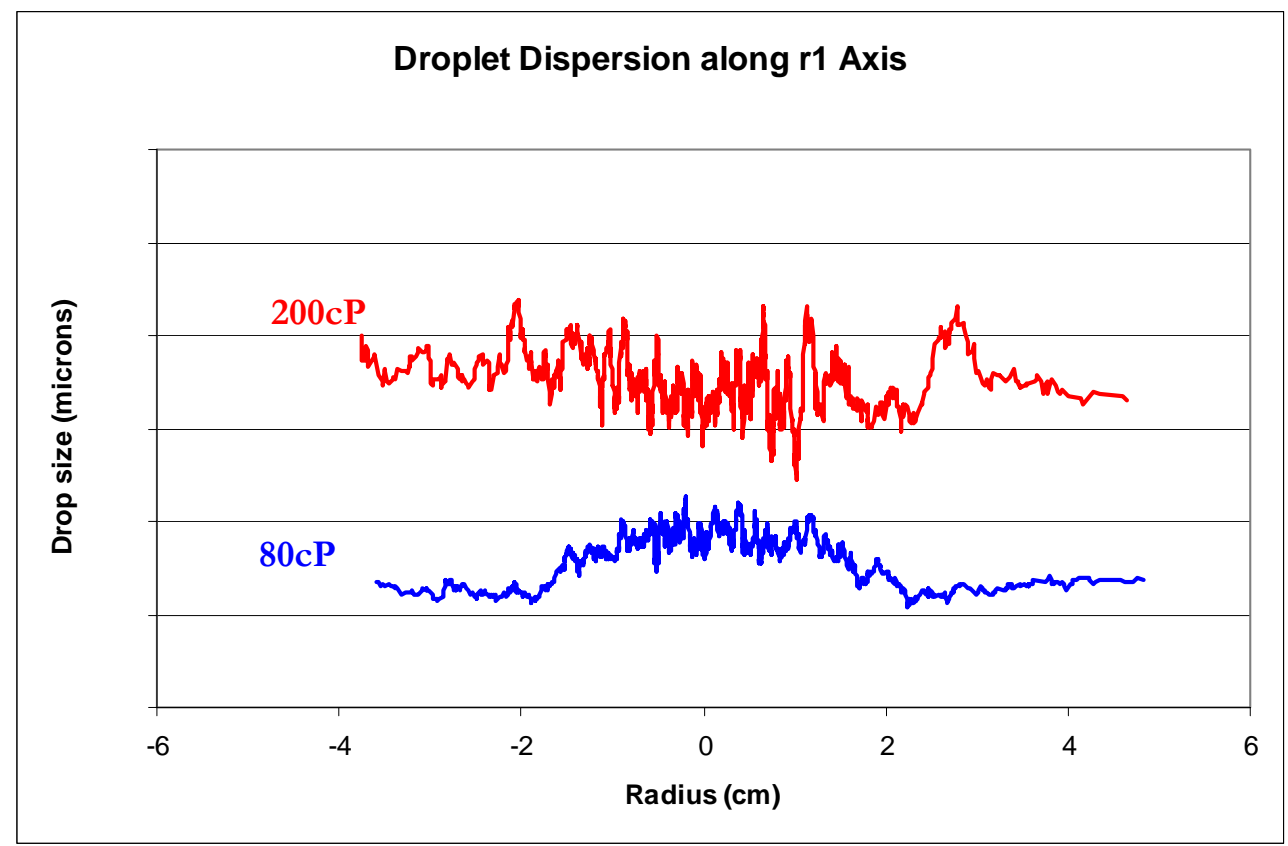

Figure 5. Comparison of droplet dispersion along $\mathbf{r} \mathbf{1}$ for different corn syrup viscosities

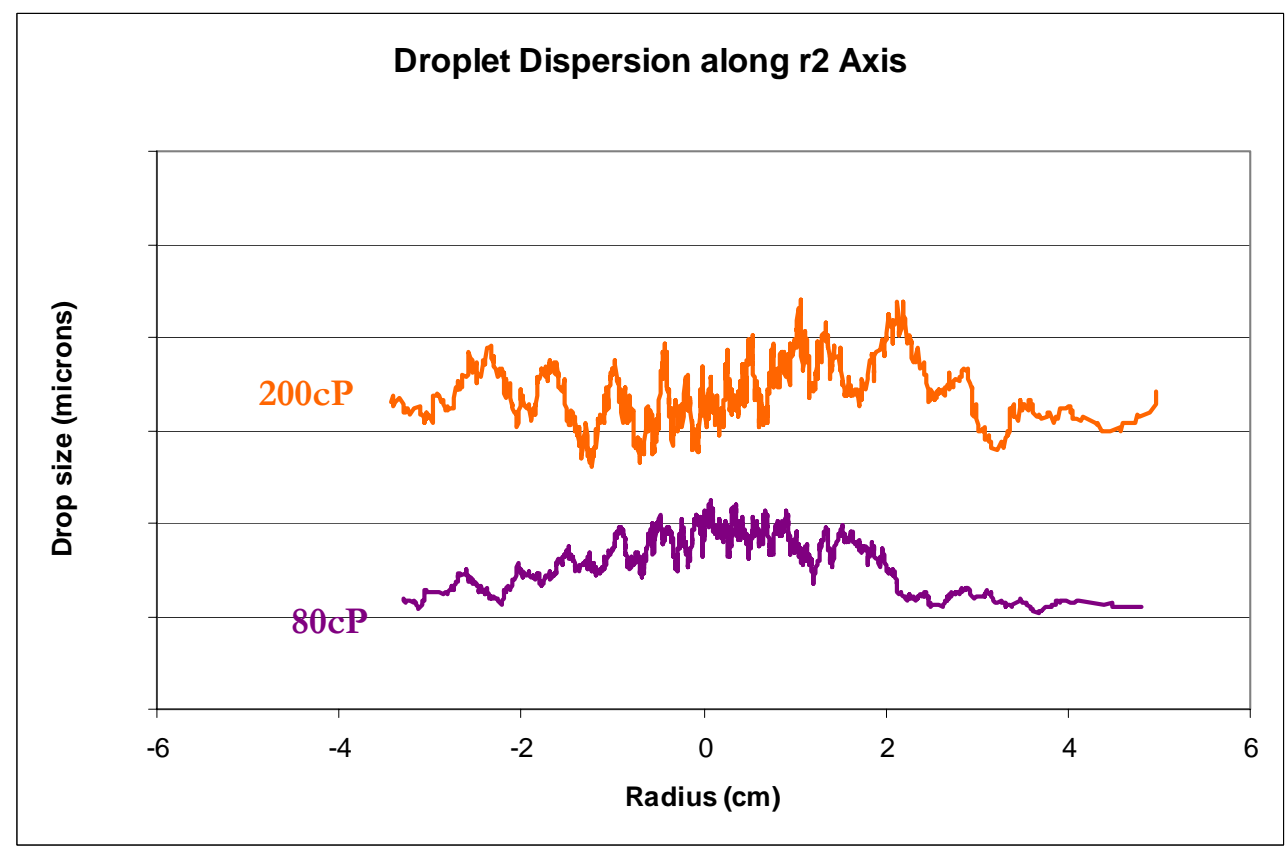

Figure 6. Comparison of droplet dispersion along $\mathbf{r} 2$ for different corn syrup viscosities 


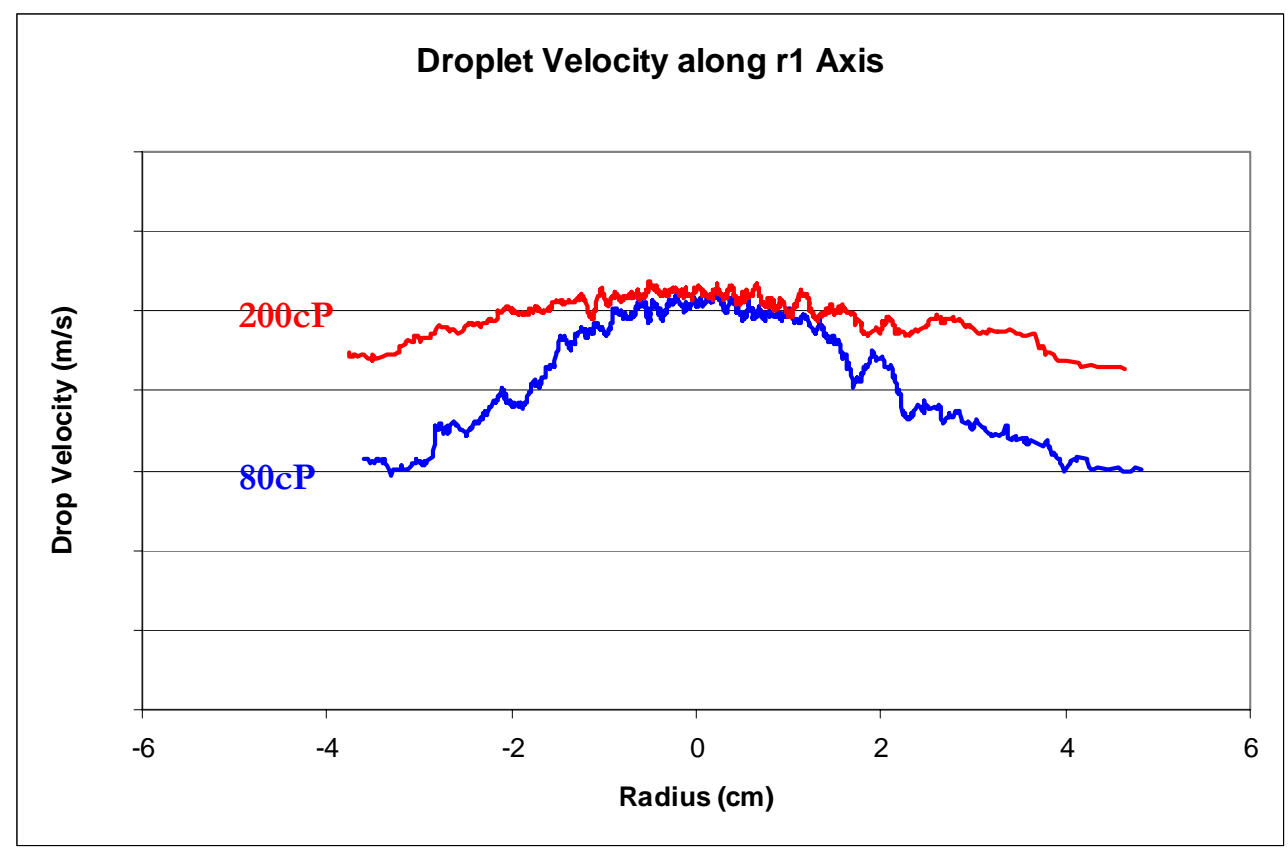

Figure 7. Comparison of droplet velocities along $\mathbf{r} \mathbf{1}$ for different corn syrup viscosities

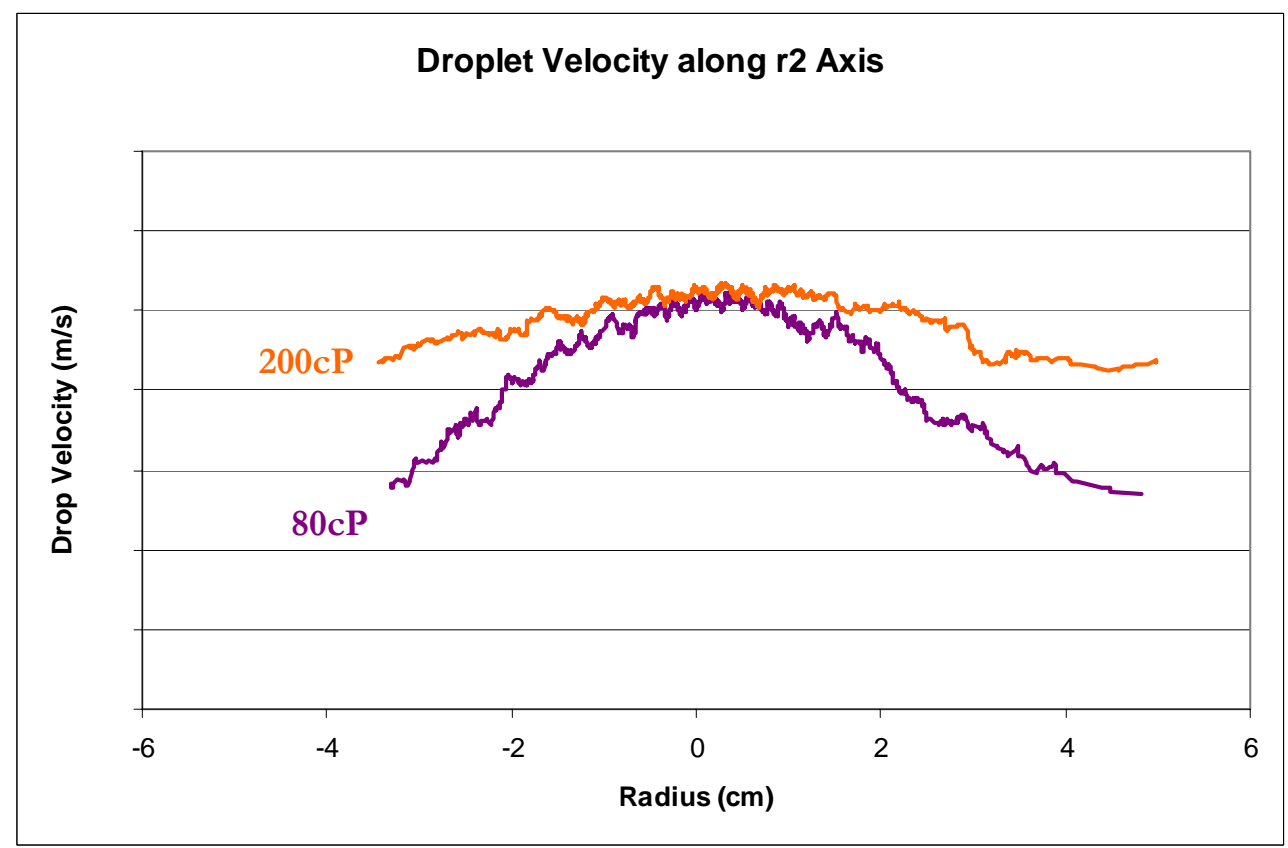

Figure 8. Comparison of droplet velocities along $\mathbf{r} 2$ for different corn syrup viscosities 


\section{CONCLUSION}

Simulent has so far modeled three different experiments.

- $\quad$ Test Set 1 (water; 1cP)

- $\quad$ Test Set $2 \mathrm{a}$ and $2 \mathrm{~b}$ (water; $1 \mathrm{cP}$ )

- $\quad$ Test Set 3 (corn syrup; 80cP)

The results for the first two cases were reported earlier and the third one's results are presented in this report.

All results sustain that Simulent model can accurately predict droplet size distribution and dispersion.

The following is a summary of our findings:

- For Test case 3 (corn syrup; 80cP):

o The overall average size for both simulation and experiment is the same;

o Simulations can capture asymmetries exiting in the actual burner;

o Simulations can accurately model the droplet size distribution and dispersion after two-times the nozzle radius (wings; in the droplet size distribution graphs);

o Droplet size distribution in the simulation is slightly larger than the experiment due to the differences in the actual (experiment) and input (simulation) air velocities near the orifice axis.

- For the actual BL system

o Simulations show that drop size increases as the viscosity increases;

o All available literature sustains this behavior.

\section{Future Work:}

Finally, we suggest that ETC performs an extra set of experiment with corn syrup with 200cP viscosity and compare its results with Simulent data. 